Diogo Destro Barcellos

Estatólitos da lula Doryteuthis plei e suas microestruturas para o estudo da idade e crescimento no litoral norte do Estado de São Paulo, Brasil

Dissertação apresentada ao Instituto Oceanográfico da Universidade de São Paulo, como parte dos requisitos para a obtenção do título de Mestre em Ciências, área de Oceanografia Biológica.

Orientadora: Profa. Dra. Maria de los Angeles Gasalla

São Paulo 
Diogo Destro Barcellos

Estatólitos da lula Doryteuthis plei e suas microestruturas para o estudo da idade e crescimento no litoral norte do Estado de São Paulo, Brasil

Dissertação apresentada ao Instituto Oceanográfico da Universidade de São Paulo, como parte dos requisitos para a obtenção do título de Mestre em Ciências, área de Oceanografia Biológica.

Orientadora: Profa. Dra. Maria de los Angeles Gasalla

São Paulo 
Universidade de São Paulo

Instituto Oceanográfico

\title{
Estatólitos da lula Doryteuthis plei e suas microestruturas para o estudo da idade e crescimento no litoral norte do Estado de São Paulo, Brasil
}

\author{
Versão corrigida \\ Diogo Destro Barcellos
}

Dissertação apresentada ao Instituto Oceanográfico da Universidade de São Paulo, como parte dos requisitos para a obtenção do título de Mestre em Ciências, área de Oceanografia Biológica.

Julgada em 15/05/2014

Profa. Dra. Maria de los Angeles Gasalla

Conceito

Instituição: Instituto Oceanográfico da Universidade de São Paulo (IO-USP)

Prof. Dra. Carmen L.D.B. Rossi-Wongtschowski

Conceito

Instituição: Instituto Oceanográfico da Universidade de São Paulo (IO-USP)

Prof. Dr. Teodoro Vaske Junior

Conceito

Instituição: Universidade Estadual Paulista "Júlio de Mesquita Filho" (UNESP/SÃO VICENTE) 


\section{SUMÁRIO}

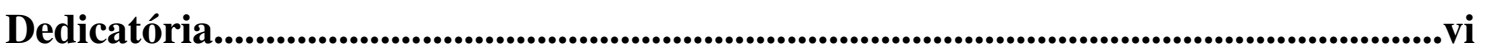

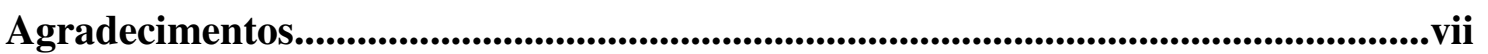

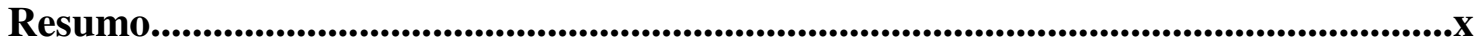

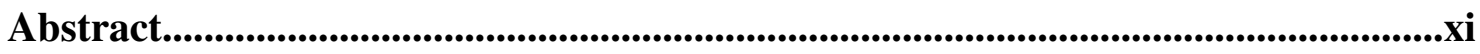

Índice de Figuras.............................................................................................................

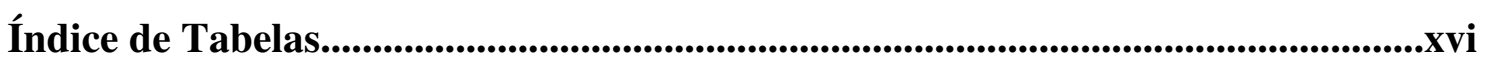

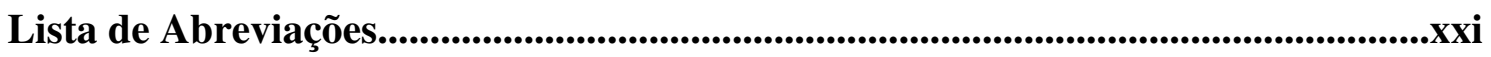

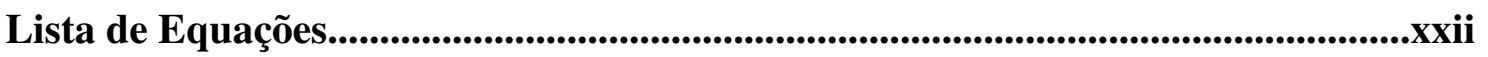

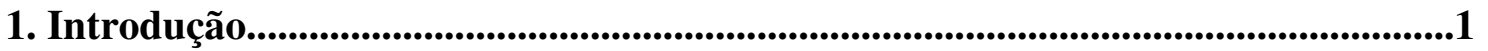

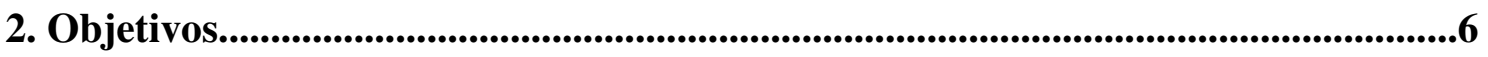

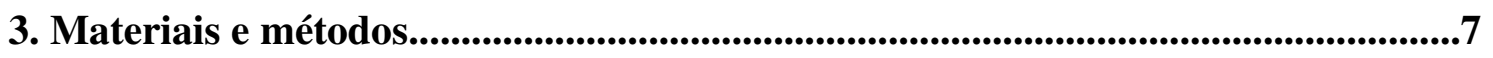

3.1. Área de estudo..........................................................................................

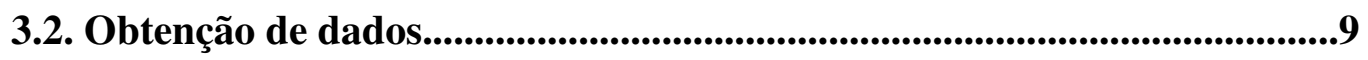

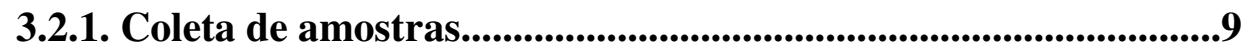

3.2.1.1. Técnicas de captura..........................................................12

3.2.2. Processamento das amostras..................................................13

3.2.2.1. Extração dos estatólitos.............................................15

3.2.2.2. Morfometria dos estatólitos.........................................16

3.2.2.3. Preparo para leitura dos incrementos de

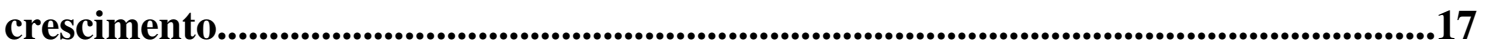

3.2.2.4. Leitura dos incrementos de crescimento.......................19

3.2.3. Análise de dados..........................................................................21 
3.2.3.1. Biologia populacional....................................................21

3.2.3.2. Análise dos estatólitos...............................................21

3.2.3.3. Consistência e precisão entre as leituras........................22

3.2.3.4. Retro-cálculo da idade..................................................23

3.2.3.5. Curva de crescimento.................................................23

3.2.3.6. Longevidade.......................................................................25

3.2.3.7. Taxa de crescimento......................................................25

3.2.3.8. Relação idade e medidas dos estatólitos......................26

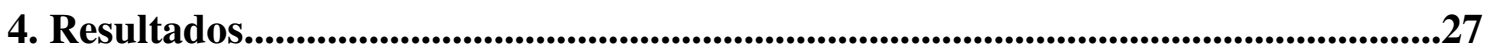

4.1. Descrição das amostras................................................................................27

4.2. Descrição das amostras em estádio de maturação..................................29

4.3. Comprimento de primeira maturação sexual.........................................35

4.4. Relação comprimento-peso................................................................................36

4.5. Características dos estatólitos de $D$. plei..............................................40

4.5.1. Morfologia e morfometria..........................................................40

4.5.2. Diferenciação dos estatólitos de machos e fêmeas........................40

4.5.3. Descrição dos estatólitos por tamanho e estádios de

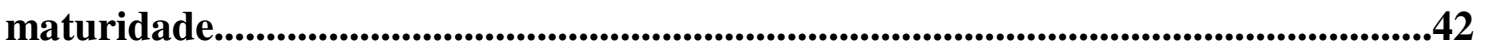

4.5.4. Relação entre o comprimento dos estatólitos com o

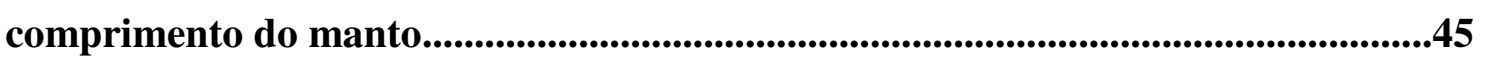

4.5.5. Comparação entre o estatólito de $D$. plei e de $D$.

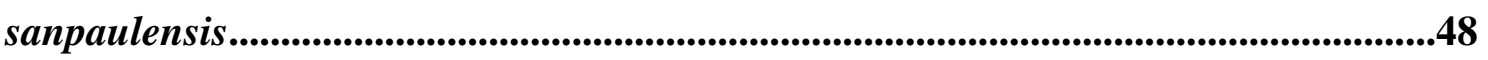

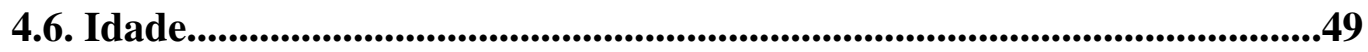


4.6.1. Avaliação da consistência das contagens dos incrementos de crescimento. .49

4.6.2. Retro-cálculo da idade: Frequência de nascimento das paralarvas ao ano................................................................................................................55

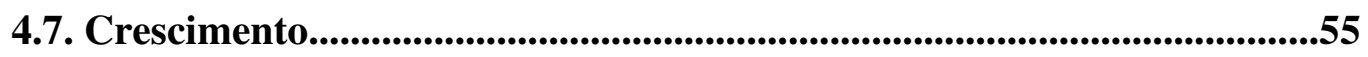

4.7.1. Curva de crescimento: relação idade-comprimento do

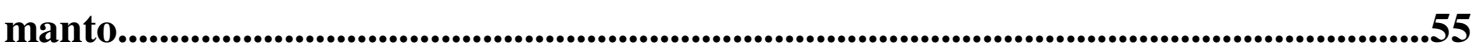

4.7.2. Curva de crescimento por estação do ano......................................61

4.7.3. Longevidade...............................................................................68

4.7.4. Taxa instantânea de crescimento..............................................73

4.7.5. Taxa instantânea de crescimento por estação do ano.................74

4.8. Outras relações com a idade..............................................................76

4.8.1. Idade-comprimento dos estatólitos........................................76

4.8.2. Idade-comprimento dos domos....................................................78

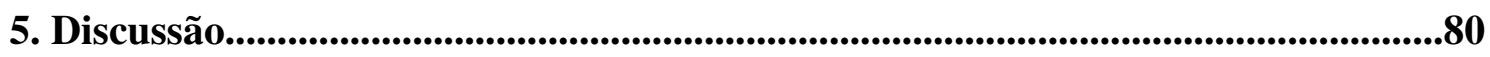

5.1. Um dia, um incremento de crescimento: validação da idade de $D$. plei......................................................................................................................................................................81

5.2. Análise dos incrementos de crescimento..............................................82

5.3. Curva de crescimento........................................................................................84

5.4. Taxa de crescimento....................................................................................................85

5.5. Frequência de nascimento de $D$. plei ao ano...................................................90

5.6. Longevidade e influencias na duração do ciclo de vida...........................91

5.7. Os estatólitos da espécie........................................................................................94

5.8. Relação idade com a morfometria dos estatólitos.........................................96 


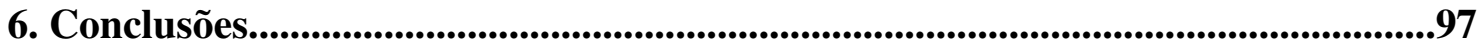

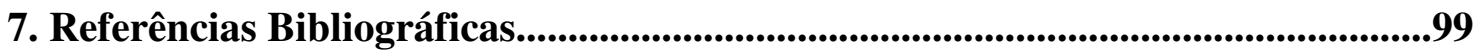

Apêndice 1 - Tabela 32: Leituras de idade de cada um dos exemplares com cálculo do erro médio porcentual e do coeficiente de

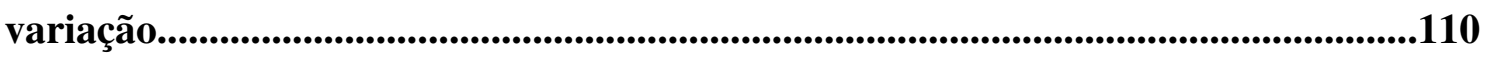


Aos meus pais e avós, por sempre apoiarem as minhas escolhas e me incentivarem na busca e realização dos meus sonhos. 


\section{Agradecimentos}

Não há como se esquecer de agradecer a todas as pessoas especiais que passaram pela minha vida durante a confecção do presente estudo, que contribuíram de alguma maneira para a obtenção deste produto final, o qual tenho muito orgulho em apresentar. Resta-me fazer aqui uma singela homenagem, demonstrando os meus sinceros agradecimentos.

À Profa. Dra. Maria de los Angeles Gasalla pela excelente orientação em todas as etapas deste trabalho, pelas críticas e sugestões valiosas.

Aos meus pais, Rosana e Ronaldo, aos meus avós e ao meu irmão, (Professor) Rodolfo, por todo apoio, conselhos e incentivo que sempre me deram. Todos vocês são os verdadeiros responsáveis pelo passo inicial à minha carreira profissional. Não posso esquecer-me da ajuda silenciosa e alegre da Minie, nossa companheira fiel.

À minha namorada Thioni, por toda ajuda e compreensão com os saídas à campo e coleta de dados e, principalmente, por todo companheirismo, atenção e carinho, durante esta etapa de minha vida.

Aos meus colegas de laboratório (Laboratório de Ecossistemas Pesqueiros LabPesq) Dr. Rodrigo Martins, Ms. Felippe Postuma, Ms. Carolina Araújo e Ms. Melissa Marcon. A ajuda de vocês foi imprescindível para a superação dos obstáculos para a execução do meu trabalho, como: escrita, compreensão, aprimoramento da técnica de leitura dos incrementos dos estatólitos, aprendizado do programa $\mathrm{R}$, triagem de material e todo o conhecimento da lula em estudo. Vocês contribuíram para o meu amadurecimento profissional. Agradeço também pelo clima de cooperação, respeito e amizade que sempre existiu, proporcionando um ambiente adequado às pesquisas.

Ao Tito Conte e ao Dr. Rodrigo Martins pelas valiosas dicas e ensinamentos nos pacotes de ajuste de crescimento (FSA) do software R. Sem a ajuda de vocês eu estaria ainda com as crises de sintaxes do programa não conseguindo os ajustes de crescimento almejados, obrigado pela atenção.

Ao Prof. Dr. Vicente Gomes, pela ajuda e atenção, por me disponibilizar o microscópio, e o laboratório. Agradeço também ao Dr. Artur e a Zezé pela atenção. 
À maravilhosa equipe da embarcação de pesquisas Veliger II, do Instituto Oceanográfico da USP. Este trabalho não seria realizado sem os conhecimentos de pesca e experiência no mar (Oziel); nem mesmo sem a energia, sempre mantida pelas deliciosas comidas, bom humor e sugestões do Daico; e muito menos sem a monstruosa força, amizade e parceria do Adriano.

À equipe da Biblioteca do IOUSP, especial ao bibliotecário Wagner, por seu carisma e atenção, sempre disposto a ajudar a encontrar os artigos e livros que precisei, inclusive aqueles que tive dificuldade em obter.

À Universidade de São Paulo, principalmente ao Instituto Oceanográfico, pelo empenho e qualidade no programa de Graduação e Pós-graduação. À equipe da secretaria de Pós-graduação de Oceanografia Biológica, Silvana, Ana Paula e Letícia, excelentes profissionais que sempre esbanjaram simpatia e eram sempre ágeis na solução de assuntos burocráticos do programa de Pós-graduação. A Comissão de Cultura e Extensão da USP pelo auxílio financeiro (PRCE X-USP N. 12189521-4) possibilitando ida ao CIAC 2012 (Cephalopod International Advisory Council Symposium).

Ao Ms. Richard Schwarz, Ms. Rafael Schroeder, Ms. Mara Bainy e ao Dr. Corey Green, pelos conselhos e métodos na preparação para a leitura dos estatólitos. E ao Ms. Fábio Prior Caltabellotta, pelas valiosas sugestões e dicas de modelos de ajustes de crescimento.

Ao Prof. Dr. Daniel Lemos pelo empréstimo de equipamentos e troca de conhecimentos para a montagem e manutenção de experimentos de crescimento na base de pesquisa de Ubatuba "Clarimundo de Jesus". Não há como deixar de agradecer ao técnico do Prof. Dr. Daniel, o Ricardo Haruo Ota "preto", pela ajuda na manutenção e dicas para a execução dos experimentos.

À equipe do CEBIMar, por me receber em suas instalações em São Sebastião e a ajuda dos técnicos, em especial ao Elso Alves da Silva, que com grande competência e dedicação deram suporte à pesquisa.

Ao Prof. Dr. Álvaro Migoto, pela confiança e hospitalidade no empréstimo do laboratório e equipamentos para a leitura e fotografia dos estatólitos das paralarvas, durante as estadias no CEBIMar. 
À Dra. Ana Moreno, pela atenção e dicas passadas, as quais me ajudaram e muito a extração dos estatólitos das paralarvas, não foi nada fácil!

Ao Dr. Alexander Arkhipkin, pelos valiosos comentários sobre metodologia. Os questionamentos levantados pela minha orientadora, juntamente com a consulta ao especialista (Dr. Alexander) referente ao método utilizado para leitura dos incrementos de crescimento e dados obtidos de idade, fez com que eu reavaliasse todos os estatólitos estudados, refinando as curvas de crescimento da espécie. Além do que foi uma oportunidade incrível conhecer e trocar e-mails com um pesquisador pelo qual tenho grande admiração.

À Profa. Dra. Mônica Ponz Louro, que me proporcionou a oportunidade estagiar pela primeira vez e de dividir todos os seus conhecimentos na área de pesquisa comigo. Me ensinou como um pesquisador deve ser, se portar e conduzir uma pesquisa científica. Obrigado por me introduzir a este mundo fascinante, área pela qual tenho grande satisfação e sonhos a serem conquistados.

À Profa. Dra. Carmen L.D.B. Rossi-Wongtschowski e ao Prof. Dr. Teodoro Vaske Junior pelas críticas, sugestões, ensinamentos e aprimoramento efetuados durante a avaliação deste estudo e adicionados na versão final do trabalho.

Ao CNPq pelo financiamento e auxílio, sem o apoio financeiro da bolsa e a confiança na pesquisa este projeto não seria realizado.

À FAPESP, por financiar o projeto de pesquisa de minha orientadora.

À Equipe Confiance (Brazilian Jiu-Jitsu) por me proporcionar força, equilíbrio, ser minha válvula de escape em muitos momentos difíceis. Agradeço ao Mestre Giba, Professor Rodólfo, Ricardinho, Clay Bergamo, Cícero e Charles, a todos os meus amigos do tatame e a equipe de São José dos Pinhais.

À todos vocês, meu muito obrigado! 


\section{Resumo}

A idade e crescimento da lula Doryteuthis plei da região do litoral norte do Estado de São Paulo é descrita com base em 424 exemplares entre 1,58 a $267 \mathrm{~mm}$ de comprimento de manto (ML). Os estatólitos foram utilizados como ferramenta de análise de idade, bem como foi realizado um estudo ontogenético de sua morfometria e morfologia. Com o objetivo de analisar e aprimorar a curva e a taxa de crescimento de D. plei, o presente estudo deu ênfase aos indivíduos em estágios iniciais do ciclo de vida. O formato dos estatólitos foi descrito e demonstrou semelhança à de outros loliginídeos, porém com características particulares, suficientes para a identificação da espécie. Houve relação entre ML e o comprimento dos estatólitos (SL), obtido pelo modelo de ajuste logarítmico. A idade dos exemplares amostrados foi estimada e com isto foi possível obter a curva de crescimento (relação idade e ML) da população em estudo, a qual foi ajustada pelo modelo logístico. O mesmo modelo de ajuste houve para os machos, porém para as fêmeas e para os juvenis, o melhor modelo foi o Gompertz. A longevidade da espécie no local de estudo foi estimada em aproximadamente oito meses. A taxa de crescimento e suas variações conforme as estações do ano foram estimadas. Foram evidenciados valores sendo em $\mathrm{mm} /$ dia quando em estádio imaturos em relação aos adultos e decrécimo acelerado após atingir $60 \mathrm{~mm}$ ML. Foram observadas diferenças da taxa de crescimento entre os sexos quando os exemplares atingem $150 \mathrm{~mm}$ de ML. Espécimes nascidos no inverno apresentaram maiores taxas de crescimento em relação aos nascidos em outras estações do ano. Através do retrocálculo da idade, foi observado que durante todo o ano ocorrem nascimentos de D. plei, em maior frequência no primeiro semestre. É possível estimar a idade de D. plei tendo apenas as medidas de SL ou comprimento dos domos, sendo que para cada relação, o ajuste obtido foi o logarítmico. Os parâmetros de crescimento apresentados no presente estudo oferecem recursos para estudos de avaliação do estoque pesqueiro e biologia populacional.

Palavras chave: crescimento de cefalópodes, taxa de crescimento, estatólitos, lulas. 


\begin{abstract}
Age and growth of the squid Doryteuthis plei from the northern shelf off São Paulo are described based on 424 specimens from 1.58 to $267 \mathrm{~mm}$ mantle length (ML). Statoliths were used as microstructures for aging, and an ontogenetic study of their morphological and morphometric was performed. The present study aimed to analyze and improve the growth curve and growth rate estimate of individuals of $D$. plei, emphasizing those in early stages of life cycle. The shape of statoliths was described and demonstrated similarity other loliginids, with particular characteristics sufficient to identify the species. There was a relationship between ML and statoliths length (SL) by the logarithmic model. The age of sampled specimens was estimated and it was possible to obtain the growth curve (relationship between age and ML) of the population in study, was better fitted by the logistic model. The same adjustment was found for males, but for females and juveniles, the Gompertz model was best suitable. The longevity of the species from place of study was estimated at approximately eight months. The growth rate and its variations were estimated according to the seasons, which evidenced higher values in $\mathrm{mm}$ /day in immature stage when compared to adults. In addition, individuals after reaching $60 \mathrm{~mm}$ ML accelerated a decrease in growth rate. Differences in growth rate between sexes were found after specimens reach $150 \mathrm{~mm}$ ML. Specimens born in winter had higher growth rates when compared to those born in other seasons. Through retro-calculation of age, it was observed that births of $D$. plei occur throughout the year, but most frequently in the first half. The study enables the age estimate of D. plei having only measures of SL or length of the statolith's domes. Growth parameters obtained provide information useful for stock assessment and population biology.
\end{abstract}

Key words: cephalopods growth, growth rate, statoliths, squids. 


\section{Índice de Figuras}

Figura 1 - Mapa da área de estudo: litoral norte do Estado de São Paulo, entre os municípios de Ubatuba e São Sebastião.

Figura 2 - Mensuração do comprimento de manto (ML) de uma paralarva visualizada em aumento de 2x através de estéreo-microscópio, com 2,32 mm ML (A) e de um macho adulto de Doryteuthis plei, com $277 \mathrm{~mm}$ ML.

Figura 3 - Extração dos estatólitos de paralarvas de lulas, em estéreo-microscópio (A), exemplares juvenis e adultos deD. plei (B).

Figura 4 - Medições realizadas nos estatólitos de D. plei. (A) Face anterior: ângulo domo (ÂD), comprimento do domo (DL). (B) Face posterior:comprimento do estatólito (SL) e ângulo do rostro (ÂR).

Figura 5 - Lâmina em microscópio preparada para leitura (A) e (B) lâmina em microscópio.

Figura 6 - Incrementos de crescimento nos estatólitos de Doryteuthis plei. Uma única imagem não exibe todos os incrementos de crescimento no eixo de leitura. Estatólitos de exemplares adultos (A-E) e de paralarvas (F-G). Aumento na visualização em microscópio: 63x (C), 250x (A, B e C) e 400x (E, F). Como observado na imagem G, a paralarva apresentou 5 dias de vida e $0,18 \mathrm{~mm}$ SL.

Figura 7 - Distribuição do comprimento do manto (ML) em frequência relativa (Fr) dos exemplares da amostra total (A); fêmeas (B); machos (C) e sexo não identificado (D), na qual destaca a frequência significativa de juvenis.

Figura 8 - Distribuição do peso em frequência relativa (Fr) da amostra total (A); fêmeas (B); machos (C) e sexo não identificado (D).

Figura 9 - Distribuição de frequência (Fr) de exemplares por estádios de maturidade.

Figura 10 - Distribuição de frequência (Fr) por estádios de maturidade por sexo.

Figura 11 - Distribuição em frequência (Fr) de comprimento de manto (ML) para os estádios de maturidade II (A) e III (B). 
Figura 12 - Distribuição da frequência (Fr) de comprimento do manto (ML) para fêmeas (A e C) e machos (B e D) para os estádios de maturidade II (A e B) e III (C e D).

Figura 13 - Distribuição de frequência (Fr) por classes de peso, para os estádios de maturidade II (A) e III (B).

Figura 14 - Distribuição da frequência (Fr) por classes de peso para fêmeas (A e C) e machos (B e D) para os estádios de maturidade II (A e B) e III (C e D).

Figura 15 - Comprimento médio de primeira maturação $\left(\mathrm{L}_{50}\right)$ estimado para fêmeas (A) e machos (B).

Figura 16 - Relação entre comprimento do manto (ML) e peso dos exemplares da amostra total (A); Fêmeas (B); Machos (C); Juvenis (D); Estádios de maturidade II (E) e III (F); e por estádios de maturidade II e III por sexo: para fêmeas (G) e (I), e para $\operatorname{machos}(\mathrm{H})$ e $(\mathrm{J})$.

Figura 17 - Crescimento ontogenético dos estatólitos de D. plei, representados de (A) a (P). O primeiro número entre parênteses indica os valores de SL (em mm) e o segundo, o ML individual (em mm), como segue: A $(0,85 ; 25), \mathrm{B}(0,96 ; 35), \mathrm{C}(1,08 ; 45), \mathrm{D}$ (1,16; 50), E (1,25; 57), F (1,32; 82), G (1,46; 85), H (1,49; 109), I (1,51; 111), J (1,56; $123), \mathrm{K}(1,64 ; 139), \mathrm{L}(1,66 ; 166), \mathrm{M}(1,69 ; 157), \mathrm{N}(1,78 ; 221), \mathrm{O}(1,80 ; 194)$ e $\mathrm{P}$ $(1,83 ; 263)$.

Figura 18 - Estatólitos de D. plei em diferentes estádios de maturidade. (A) imaturo, 42 mm ML e 1,04 mm SL; (B) fêmea em maturação com 144 mm ML e 1,6 mm SL; (C) macho maduro com $201 \mathrm{~mm}$ ML e 1,59 mm SL; (D) fêmea desovada com $159 \mathrm{~mm} \mathrm{ML}$ e $1,58 \mathrm{~mm}$ SL.

Figura 19 - Morfometria dos estatólitos de D. plei das categorias: Fêmeas (F); Machos (M); Imaturos (I); Em maturação (II); Maduros (III); e desovados (IV), para as medidas tomadas dos estatólitos: Comprimento dos estatólitos (SL); Comprimento do domo (DL); Ângulo do rostro (ÂR) e ângulo do domo (ÂD).

Figura 20 - Relação entre comprimento de manto (ML) e comprimento do estatólito (SL), para amostra total (A), machos (B), fêmeas (C), imaturos (D), em maturação (E) e maduros (F). Ver Tabela 9 com os ajustes das relações ( $r^{2}$ e AIC). 
Figura 21 - Comparação entre os estatólitos de exemplares de D. plei, comprimento do manto de $82 \mathrm{~mm}$ (A) e D. sanpaulensis, comprimento de manto de $85 \mathrm{~mm}$ (B) de mesmo estádio de maturidade. A aparência azulada do estatólito de D. sanpaulensis é provavelmente devido à propriedade de refração, uma vez que demonstra a transparência em relação aos estatólitos de D. plei.

Figura 22 - Qualidade visual das leituras dos incrementos de crescimento nos estatólitos amostrados, em frequência relativa (Fr), por sexo.

Figura 23 - Qualidade visual das leituras dos incrementos de crescimento nos estatólitos amostrados, em frequência relativa (Fr), por estádios de maturidade.

Figura 24 - Relação linear entre as leituras realizadas dos incrementos dos estatólitos. Ver Tabela 14 os ajustes da relação.

Figura 25 - Frequência relativa (Fr) dos nascimentos de Doryteuthis plei durante os anos de 2010 a 2013.

Figura 26 - Relação entre idade (em dias) e comprimento de manto (ML), com seus respectivos número amostral (n): amostra total (A), ajuste logístico; fêmeas, machos e juvenis (B), ajustados pelos modelos, na sequência, Gompertz, logístico e Gompertz; por estádio de maturidade II (C), ajuste Gompertz; e estádio III (D), ajuste Gompertz; para fêmeas e machos em estádio de maturidade II (E), ajuste na sequência por sexo, Gompertz e Schnute; e por último, para fêmeas e machos em estádio de maturidade III (F), ajuste na sequência por sexo, Gompertz e logarítmico. Ver os parâmetros de ajuste de crescimento nas Tabelas 15 a 17.

Figura 27 - Relação entre idade (dias) e comprimento de manto (ML) dos exemplares de lulas nascidas nas épocas do ano, com seus respectivos ajustes de crescimento: primavera (A), ajuste exponencial; verão (B), ajuste logístico; outono (C), ajuste Gompertz; e inverno (D), ajuste logarítmico. Ver os parâmetros dos modelos de ajuste na Tabela 18.

Figura 28 - Relação entre idade (dias) e comprimento de manto (ML) para fêmeas, machos e juvenis, nascidos por estação do ano e com seus respectivos ajustes de crescimento: primavera (A), ajuste von Bertalanffy para as fêmeas e exponencial para os machos; verão (B), ajuste Gompertz para ambos os sexos e Schnute para juvenis; 
outono (C), ajuste Gompertz e exponencial, para fêmeas e machos, e ajuste logarítmico para os juvenis; e inverno (D), ajuste linear para ambos os sexos. Ver os parâmetros dos modelos de ajuste nas Tabelas 19 a 22.

Figura 29 - Taxa instantânea de crescimento (G) estimada para a amostra total (A) e por $\operatorname{sexo}(B)$.

Figura 30 - Taxa instantânea de crescimento (G) para os estádios de maturidade I, II e III.

Figura 31 - Taxa instantânea de crescimento (G) para fêmeas (F) e machos $(\mathrm{M})$, em estádios de maturidade II (A) e III (B).

Figura 32 - Taxa instantânea de crescimento (G) em mm/dia por comprimento do manto (ML) para indivíduos nascidos por estação do ano (A) e para fêmeas e machos (B), onde as legendas para fêmeas, as siglas representadas são: primavera (FP), verão (FV), outono (FO) e inverno (FI); e para os machos: MP (primavera), MV (verão), MO (outono) e MI (inverno).

Figura 33 - Taxa instantânea de crescimento (G) em mm/dia por comprimento do manto (ML) para juvenis, fêmeas e machos,nascidos nas quatro estações do ano, onde: primavera (A), verão (B), outono (C) e inverno (D).

Figura 34- Relação entre idade e comprimento do estatólito (SL) para: Amostra total (A), ajuste exponencial; Fêmeas e machos (B), ajuste logarítmico; e juvenis (B), ajuste exponencial. Ver na Tabela 28 os parâmetros do ajuste obtido.

Figura 35 - Relação entre idade e comprimento dos domos do estatólito (DL) para: amostra total (A), ajuste logarítmico; Fêmeas e machos (B), ajuste logarítmico; e juvenis (B), ajuste linear. Ver na Tabela 29 os parâmetros do ajuste obtido. 


\section{Índice de Tabelas}

Tabela 1 - Descrição das amostras. Data da coleta dos exemplares, número de indivíduos por evento amostral (n), áreas de capturas (local), métodos de coleta de dados (arte de pesca), e procedência dos dados.

Tabela 2 - Escala de classificação dos estádios de maturidade sexual adaptada de Juanicó-Rivero (1979) e Perez et al. (2002).

Tabela 3 - Valores médios de comprimento do manto e peso, por estádios de maturidade dos todos exemplares, onde: número de exemplares amostrados (n), média (Md), desvio padrão (Dp), intervalo de comprimento de manto (ML) e peso (g, em gramas). O número de exemplares (n) amostrados para o cálculo da média, desvio padrão e do intervalo de peso para os juvenis em estádio de maturidade I foi de 58 exemplares.

Tabela 4 - Valores médios de comprimento do manto e peso, de fêmeas por estádios de maturidade (II - IV), onde: número de exemplares (n), média (Md), desvio padrão (Dp), intervalo de comprimento de manto (ML) e peso (g, em gramas).

Tabela 5 - Valores médios de comprimento do manto e peso, de machos por estádios de maturidade (II - IV), onde: número de exemplares (n), média (Md), desvio padrão (Dp), intervalo de comprimento de manto (ML) e peso ( $\mathrm{g}$, em gramas).

Tabela 6 - Comprimento médio de primeira maturação $\left(\mathrm{L}_{50}\right)$, em mm, estimados para fêmeas (F) e machos (M), com seus respectivos valores de $a$ e $b$ da função: $p=1 /(1+$ $\exp (-a+b * \mathrm{ML}))$.

Tabela 7 - Modelos de ajuste testados (linear, potencial, logarítmico e exponencial) para a relação entre comprimento do manto (ML, mm) e peso $(\mathrm{g})$, com os valores de $a$ e $b$ das equações testadas, número de exemplares amostrados (n) $r^{2}$ e AIC para o total, para fêmeas (F), machos (M), juvenis, e por estádio de maturidade (II e III).

Tabela 8 - Comparação morfométrica dos estatólitos entre os valores: comprimento dos estatólitos (SL), comprimento do domo (DL), ângulo do rostro (ÂR) e do domo (ÂD) para a amostra total, por sexo e estádios de maturidade. 
Tabela 9 - Relação entre os valores de ML e SL para a amostra total, por sexo e estádios de maturidade, com os valores de $r^{2}$ e AIC para os modelos testados: linear, logarítmico, potencial e exponencial.

Tabela 10 - Análise dos incrementos depositados nos estatólitos, onde: Identificação do exemplar amostrado (n); Leituras dos anéis de crescimento realizadas em cada estatólito; Média entre as leituras (Média); Desvio padrão (DP); Erro médio porcentual (EMP); e coeficiente de variação (CV).

Tabela 11 - Categorias visuais de qualidade das leituras dos estatólitos com o número amostral (n), erro médio porcentual (EMP), coeficiente de variação (CV) (ambos em $\%)$.

Tabela 12 - Análise da confiabilidade das leituras realizadas para fêmeas e machos com o número de exemplares utilizados para análise por sexo (n), erro médio porcentual (EMP), coeficiente de variação $(\mathrm{CV})$.

Tabela 13 - Análise da confiabilidade das leituras para todos os estádios de maturidade (I - IV) com o número de exemplares utilizados para análise por sexo (n), erro médio porcentual (EMP), coeficiente de variação (CV).

Tabela 14 - Relações das leituras dos incrementos de crescimento com os respectivos números de exemplares testados para cada relação (n), equação da regressão linear, coeficiente de correlação da equação $r^{2}$, valores de $p$ do teste $\mathrm{t}$ para amostras dependentes e valores de $p$ do teste Wilcoxon.

Tabela 15 - Modelos de crescimento obtidos para as relações: total, por sexo e para juvenis, com seus respectivos: número amostral (n), parâmetros do modelo testados: valores de $L$ infinito $\left(L_{\text {inf }}\right)$, taxa de crescimento $(K)$, valor de $t_{0}\left(t_{0}\right)$, valor de $a$ e $b$ da equação $(a, b)$, coeficiente de determinação da equação $\left(r^{2}\right)$, índice Akaike (AIC) e pesos de Akaike (AICw).

Tabela 16 - Modelos de crescimento obtidos para os exemplares em maturação (II) e maduras (III), com seus respectivos: número amostral (n), parâmetros do modelo testados: valores de $L$ infinito $\left(L_{\text {inf }}\right.$ ), taxa de crescimento $(K)$, valor de $t_{0}\left(t_{0}\right)$, valor de $a \mathrm{e}$ $b$ da equação $(a, b)$, coeficiente de determinação da equação $\left(r^{2}\right)$, índice Akaike (AIC) e pesos de Akaike (AICw). 
Tabela 17 - Modelos de crescimento testados para os exemplares de fêmeas (F) e machos (M) em estádio de maturação II e III, com seus respectivos número amostral (n), parâmetros do modelo testados: valores de $L$ infinito $\left(L_{i n f}\right)$, taxa de crescimento $(K)$, valor de $t O(t O)$, valor de $a$ e $b(a, b)$, coeficiente de determinação da equação $\left(r^{2}\right)$, índice Akaike (AIC) e peso de AIC (AICw).

Tabela 18- Modelos de crescimento obtidos para lulas nascidas na primavera, verão, outono e inverno, com seus respectivos número amostral (n), parâmetros dos modelos testados: valores de $L$ infinito $\left(L_{i n f}\right)$, taxa de crescimento $(K)$, valor de $t_{0}\left(t_{0}\right)$, valor de $a$ e $b(a, b)$, coeficiente de determinação da equação $\left(r^{2}\right)$, índice Akaike (AIC) e peso de $\mathrm{AIC}(\mathrm{AICw})$.

Tabela 19 - Modelos de crescimento obtidos para fêmeas e machos nascidos na primavera com seus respectivos número amostral (n), parâmetros dos modelos testados: valores de $L$ infinito $\left(L_{i n f}\right)$, taxa de crescimento $(K)$, valor de $t_{0}\left(t_{0}\right)$, valor de $a$ e $b(a, b)$, coeficiente de determinação da equação $\left(r^{2}\right)$, índice Akaike (AIC) e peso de AIC $(\mathrm{AICw})$.

Tabela 20- Modelos de crescimento obtidos para fêmeas, machos e juvenis nascidos no verão com seus respectivos número amostral (n), parâmetros dos modelos testados: valores de $L$ infinito $\left(L_{i n f}\right)$, taxa de crescimento $(K)$, valor de $t_{0}\left(t_{0}\right)$, valor de $a$ e $b(a, b)$, coeficiente de determinação da equação $\left(r^{2}\right)$, índice Akaike (AIC) e peso de AIC $(\mathrm{AICw})$.

Tabela 21 - Modelos de crescimento obtidos para fêmeas, machos e juvenis nascidos no outono com seus respectivos número amostral (n), parâmetros dos modelos testados: valores de $L$ infinito $\left(L_{i n f}\right)$, taxa de crescimento $(K)$, valor de $t_{0}\left(t_{0}\right)$, valor de $a$ e $b(a, b)$, coeficiente de determinação da equação $\left(r^{2}\right)$, índice Akaike (AIC) e peso de AIC (AICw).

Tabela 22- Modelos de crescimento obtidos para fêmeas e machos nascidos no inverno com seus respectivos número amostral (n), parâmetros dos modelos testados: valores de $L$ infinito $\left(L_{i n f}\right)$, taxa de crescimento $(K)$, valor de $t_{0}\left(t_{0}\right)$, valor de $a$ e $b(a, b)$, coeficiente de determinação da equação $\left(r^{2}\right)$, índice Akaike (AIC) e peso de AIC (AICw). 
Tabela 23 - Idade média (em dias) dos exemplares por classes de tamanho (ML, mm) com o número de exemplares (n), desvio padrão da média da idade (DP), e valores mínimos (Mínimo) e máximos (Máximo) das idades por classe de tamanho.

Tabela 24 - Média do peso (g, gramas) e média de incrementos nos estatólitos (em dias) por classe de comprimento de manto (ML, mm) para fêmeas e machos.

Tabela 25 - Comparação das médias de idade obtida por classe de comprimento de manto (ML) em relação a trabalhos prévios para $D$. plei.

Tabela 26- Comparação das médias de idade obtida por classe de comprimento de manto (ML) de fêmeas e machos, obtida no presente estudo com estudos prévios de Doryteuthis plei e Loligo vulgaris.

Tabela 27 - Intervalo dos valores mínimo e máximo das idades por estádio de maturidade e por sexo.

Tabela 28 - Relação entre idade de D. plei com o comprimento dos estatólitos (SL) para a amostra total, fêmeas, machos e juvenis, com seus respectivos número amostral (n), parâmetros dos modelos ajustados: valor de $a$ e $b(a, b)$, coeficiente de determinação da equação $\left(r^{2}\right)$, índice Akaike (AIC) e peso de AIC (AICw).

Tabela 29 - Relação entre idade de D. plei com o comprimento dos domos (DL) para a amostra total, fêmeas, machos e juvenis, com seus respectivos número amostral (n), parâmetros dos modelos ajustados: valor de $a$ e $b(a, b)$, coeficiente de determinação da equação $\left(r^{2}\right)$, índice Akaike (AIC) e peso de AIC (AICw).

Tabela 30 - Comparação da variação de comprimento de manto (ML) e número amostral (n) de D. plei obtido no presente estudo em relação a outros trabalhos.

Tabela 31 - Comparação da relação comprimento de manto-peso do presente estudo com estudos prévios. Os ajustes e os valores do coeficiente de correlação $\left(r^{2}\right)$ do presente estudo podem ser comparados por sexo em relação a estudos prévios de $D$. plei.

Tabela 32 - Análise dos incrementos depositados nos estatólitos, onde: identificação do exemplar amostrado (n); leituras dos anéis de crescimento realizadas em cada estatólito, sendo que ocorreram com repetição entre três e cinco vezes; média entre as leituras 
(Média); desvio padrão (DP); erro médio porcentual (EMP); e coeficiente de variação $(\mathrm{CV})$. 


\section{Lista de abreviações}

$\mathrm{A}_{0,95}$ : Longevidade

AC: Água Costeira

ACAS: Água Central do Atlântico Sul

AT: Água Tropical

ÂD: ângulo do domo dorsal em graus $\left(^{\circ}\right)$;

AIC: índice Akaike;

AICw: peso de Akaike;

ÂR: ângulo do rostro em graus $\left(^{\circ}\right)$;

AS: área do estatólito em milímetros quadrados $\left(\mathrm{mm}^{2}\right)$;

CV: coeficiente de variação;

DL: comprimento do domo em milímetros (mm);

DP: desvio padrão;

EMP: erro médio porcentual;

Fr: frequência relativa (\%);

G: taxa instantânea de crescimento (mm/d-1);

$\mathrm{L}_{50}$ : comprimento médio de maturação;

L: comprimento médio das lulas capturadas igual ou superior a L';

$\mathrm{L}^{\prime}=$ comprimento do menor indivíduo da amostra;

$L_{\text {inf: }}$ comprimento assintótico da espécie;

Md: média;

ML: comprimento do manto em milímetros (mm);

n: número de exemplares

SL: comprimento do estatólito em milímetros (mm);

$k$ : taxa de crescimento, em mm/dia;

$\mathrm{P}$ : peso em gramas

$r^{2}$ : coeficiente de determinação da equação; 


\section{Lista de equações}

$\mathrm{y}=1 /\left(1+\exp \left(-a+b^{*} \mathrm{x}\right)\right)(1)$, comprimento médio de maturação ( $\left.\mathrm{L}_{50}\right)$, onde $\mathrm{x}$ correspondeu aos valores de ML (mm) e y aos valores de $p$-value. O valor de $\mathrm{L}_{50}$ é obtido através da divisão do valor $a$ da função pelo valor de $b\left(\mathrm{~L}_{50}=a / b\right)$;

$$
\begin{aligned}
& \mathrm{y}=a+b^{* x} \\
& \mathrm{y}=a^{*} \mathrm{e}^{b^{* \mathrm{x}}} \\
& \mathrm{y}=a+b^{*} \log (3) \\
& \mathrm{y}=a^{*} \mathrm{x}^{b}
\end{aligned}
$$

Modelo linear;

Modelo exponencial;

Modelo logarítmico;

Modelo potencial, onde para estimativa da relação peso-comprimento de manto: os valores de x correspondem aos valores de ML (mm) e y aos valores do peso (g, gramas); relação ML-SL, o x correspondeu aos valores de ML $(\mathrm{mm})$ e y aos valores do SL (mm); relação idade-ML, x correspondeu aos valores de idade (dias) e y aos valores do ML (mm); relação idade-SL, o x correspondeu aos valores de idade (em dias) e y aos valores do SL (mm); e para relação idade-DL, x correspondeu aos valores de idade (em dias) e y aos valores do DL (mm)

$\mathrm{EMP}=1 / \mathrm{N} * \sum_{\mathrm{j}=1}^{\mathrm{N}} * 1 / \mathrm{R} * \sum_{\mathrm{i}=1}^{\mathrm{R}}\left|\mathrm{X}_{\mathrm{ij}}-\overline{\mathrm{X}}_{\mathrm{j}}\right| / \overline{\mathrm{X}}_{\mathrm{j}} * 100 \quad$ (6) $\quad$ Erro Médio Percentual (EMP), onde $\mathrm{N}=$ número de indivíduos; $\mathrm{j}=\mathrm{j}^{\text {ésimo }}$ indivíduo; $\mathrm{R}=$ número de leituras; $\mathrm{X}_{\mathrm{ij}}=\mathrm{i}^{\text {esima }}$ leitura do $\mathrm{j}^{\text {ésimo }}$ lula; $\overline{\mathrm{X}}_{\mathrm{j}}=$ média da leitura do jésimo ${ }^{\text {indivíduo; }}$

$\mathrm{CV}=\mathrm{s} / \overline{\mathrm{X}}_{\mathrm{j}} * 100$

Coeficiente de Variabilidade (CV), onde $\mathrm{s}=$ desvio padrão, $\overline{\mathrm{X}}_{\mathrm{j}}=$ média da leitura do jésimo indivíduo;

$\mathrm{y}=L_{i n f} * e^{-a^{*} \exp \left(-b^{*} x\right)}$

$\mathrm{y}=L_{\text {inf }} / 1+e^{(-k(\mathrm{x}-t 0))}$

Modelo Gompertz;

$\mathrm{y}=L_{\text {inf }}\left[1-e^{-k(\mathrm{x}-t)}\right]$

Modelo logistico;

Modelo von Bertalanffy;

$\mathrm{y}=\left[\mathrm{m}_{1}{ }^{b}+\left(\left(\mathrm{m}_{2}{ }^{b}-\mathrm{m}_{1}{ }^{b} / 1-e^{-a(\mathrm{x} 2-\mathrm{x} 1)}\right) * 1-e^{-a(\mathrm{x}-\mathrm{x} 1)}\right)\right]^{1 / b}$

(11) Modelo Schnute, onde y é a medida (em mm) de um indivíduo na idade $\mathrm{x}$, onde $\mathrm{x}$ é a idade (em dias), $\mathrm{m}_{1}$ e $\mathrm{m}_{2}$ são os comprimentos de manto extremos (ML mínimo e máximo) nas idades $\mathrm{x}_{1} \mathrm{e}$ $\mathrm{x}_{2}$, sendo que $\mathrm{x}_{1}$ e $\mathrm{x}_{2}$ são as idades extremas (idade mínima e máxima), $a$ é o parâmetro de taxa de crescimento em ML (mm) ( dia $\left.^{-1}\right), b$ é o parâmetro de curvatura nos modelos de crescimento, sendo que $a$ e $b$ são parâmetros estimados na regressão não linear. Os valores devem respeitar as condições: $a$ e $b \neq 0, \mathrm{~m}_{2}>\mathrm{m}_{1}, \mathrm{x}_{2}>\mathrm{x}>\mathrm{x}_{1}$;

$L_{\text {inf }}=\left[e^{a^{*} \times 2} * \mathrm{~m}_{2}^{b}-e^{a^{*} \times 1} * \mathrm{~m}_{1}{ }^{b} / e^{a * \times 2}-e^{a^{*} \times 1}\right]^{1 / b}$

Linfinito,

comprimento

máximo estimado pelo modelo de ajuste da relação;

$t 0=\mathrm{x}_{1}+\mathrm{x}_{2}-1 / a * \ln \left[e^{a^{*} \times 2} * \mathrm{~m}_{2}{ }^{b}-e^{a^{*} \times 1} * \mathrm{~m}_{1}{ }^{b} / \mathrm{m}_{2}{ }^{b}-\mathrm{m}_{1}{ }^{b}\right]$

(13) $t$ zero, comprimento mínimo estimado pelo modelo de ajuste da relação; 
$\operatorname{AICw}(\operatorname{Mil} x,\{\mathrm{Mj}\})=\mathrm{e}^{-1 / 2(\operatorname{AICj}-\operatorname{AICmin})} / \sum_{\mathrm{i}}^{\mathrm{j}} \mathrm{e}^{-1 / 2(\operatorname{AICj}-\operatorname{AICmin})}$

(14) Akaike (AICw), onde

$\{\mathrm{Mj}\}$ são os j modelos testados e $\mathrm{AIC}_{\text {min }}$ é o AIC do modelo com menor AIC. Os pesos de Akaike variam entre 0 e 1 ;

$\mathrm{A}_{0,95}=(2,996 / k)+\mathrm{t}_{0} \quad$ (15) longevidade $\left(\mathrm{A}_{0,95}\right)$, onde $\mathrm{t}_{0}$ é a idade teórica de comprimento zero $(1,99)$ e $k$ é o coeficiente de crescimento estimado pelo melhor ajuste na curva de crescimento $(0,03)$;

$\mathrm{G}=\left(\ln _{2}-\ln \mathrm{W}_{1} / \mathrm{T}_{2}-\mathrm{T}_{1}\right) * 100 \quad$ (16) Taxa instantânea de crescimento $(\mathrm{G})$, onde $\mathrm{G}$ é a taxa em mm/ $\left.\mathrm{d}^{-1}\right), \mathrm{W}_{1}$ e $\mathrm{W}_{2}$ são os comprimentos de manto no início e no final do intervalo de tempo $\mathrm{T}_{1}$ e $\mathrm{T}_{2}$. $\mathrm{O}$ intervalo de tempo utilizado no estudo foi de 30 dias. Sendo assim, $\mathrm{T}_{1}-\mathrm{T}_{2}=30$ dias. 


\section{INTRODUÇÃO}

As populações de lulas constituem importantes elos nas relações ecológicas dos ecossistemas marinhos, fazendo parte da dieta de animais de topo de cadeia como cetáceos, aves marinhas e peixes pelágicos (AMARATUNGA, 1983; GASALLA et al., 2010). São predadores ágeis, rápidos e ativos, predam crustáceos, poliquetas, peixes e ocasionalmente outros cefalópodes. Além disso, ocupam nichos ecológicos como carnívoros, competindo com os peixes, também compartilhando muitas características convergentes, como tamanho, habitat, ecologia, anatomia e comportamento (RUPPERT et al., 2005). Possuem também importância como presas e são recursos valiosos para pesca artesanal e industrial (GASALLA et al., 2005; GASALLA et al., 2010; RODHOUSE \& BOYLE, 2010). Em geral, os loliginídeos possuem vida curta, com ciclo de vida próximo de um ano e com uma única desova seguida de morte (semelparidade) (RODHOUSE \& BOYLE, 2010), porém há lulas com maiores longevidades.

O conhecimento da composição etária e das taxas de crescimento populacional são essenciais para o estudo da dinâmica de populações de lulas, estrutura dos estoques explotados pela pesca, e monitoramento do desempenho pesqueiro (BOYLE \& RODHOUSE, 2005; SIFNER, 2008). Para tal, a técnica de análise dos estatólitos provou ser uma ferramenta adequada para a estimativa de crescimento de cefalópodes (HURLEY et al., 1979; KRISTENSEN, 1980; LIPINSKI, 1986; JACKSON, 1994; AGUIAR, 2002; VILLANUEVA et al.,2003; CERIOLA \& MILONE, 2007).

Os estatólitos dos cefalópodes são estruturas calcáreas, compostas primariamente de carbonato de cálcio em forma de cristais de aragonita e material orgânico (predominantemente proteínas) em menor proporção. Eles se localizam na superfície anterior dos estatocistos, que por sua vez estão localizados no lado ventral do crânio (RADTKE, 1983; BETTENCOURT \& GUERRA, 2000). Os estatólitos se movem no interior das cavidades (estatocisto) e estimulam as células ciliadas salientes para o interior das paredes do estatocisto. As células ciliadas são orientadas em vários planos, de maneira que o número e posição dos receptores excitados pelo movimento possam transmitir informação precisa ao cérebro sobre o movimento do animal em três dimensões (linear, angular e gravitacional) (STEPHENS \& YOUNG, 1978; ARKHIPKIN \& BIZIKOV, 2000). 
Dessa forma, os estatólitos são resultado da deposição de uma estrutura mineral de uma criatura viva (alimento ingerido), como também do ambiente. Este processo de mineralização em um ambiente biológico é chamado de biomineralização (BETTENCOURT \& GUERRA, 2000). Os cristais se depositam em uma matriz protéica, acumulando-se a partir do núcleo para a borda do estatólito em forma de incrementos (anéis de crescimento) (RADTKE, 1983; JACKSON, 1994).

Durante a embriogênese, os estatólitos são formados e persistem até ao fim da pós-eclosão, possuindo a função de "black boxes" ou "caixas pretas", pois gravam informações sobre a vida dos cefalópodes (ARKHIPKIN, 2005). Os estatólitos além de serem os órgãos de equilíbrio e orientação espacial dos cefalópodes, fornecem informações sobre idade e crescimento, os quais podem ser estimados através da identificação e interpretação de incrementos neles depositados, após preparo adequado, como polimento e colagem dos mesmos em lâminas de vidro, e visualização em microscopia (VILLANUEVA et al., 2003; BOYLE \& RODHOUSE, 2005; PEREZ et al., 2006). Além disso, estatólitos são um dos poucos vestígios de registro de fósseis de cefalópodes, e seus restos mortais podem servir como um recurso para inferir hipóteses sobre o estilo de vida de espécies extintas (ARKHIPKIN, 2005).

Historicamente, têm sido estabelecidas empiricamente correlações positivas entre medidas morfométricas de estatólitos, e ocomprimento do manto e a massa corporal de várias espécies de lulas. Estas correlações, combinadas com valores taxonômicos da morfologia do estatólito, são de utilidade para estimar o tamanho e massa de lulas que servem de alimento para seus predadores (BRUNETTI \& IVANOVIC, 1991). Assim, em estudos de ecologia trófica, os estatólitos são encontrados em conteúdos estomacais de espécies predadoras de peixes e mesmo de cefalópodes (CLARKE \& FITCH, 1975; CLARKE, 1978; VEGA et al., 2001), e são utilizados para fins de identificação das presas.

Os estatólitos variam em morfologia, morfometria, e coloração entre as diferentes espécies (CLARKE, 1978; JACKSON, 1994). São compostos por quatro porções: domo dorsal, domo lateral, rostro e asa. A asa apresenta coloração opaca em relação às outras porções do estatólito, as quais são parcialmente translúcidas (CLARKE, 1978; JACKSON, 1994). A descrição morfológica dos estatólitos permite a identificação de espécies. Em adição, a morfometria dos estatólitos pode ser utilizada 
para a identificação e comparação de subpopulações (VEGA et al., 2001; SCHWARZ \&PEREZ, 2007). Isso destaca a utilização dos estatólitos como uma ferramenta de identificação taxonômica (CLARKE, 1978; BRUNETTI \& IVANOVIC, 1991; FLORES \& GARLAND, 2002).

O estatólito cresce de forma sincrônica com o animal e incremental (THOMAS \& MOLTSCHANIWSKYJ, 1999). Através da inserção de tetraciclina ou marcadores radioativos como estrôncio na alimentação de lulas em cativeiro e um tempo de confinamento conhecido, foi concluído que os incrementos de crescimento são depositados diariamente. Linhas escuras são separadas por espaços brancos, sendo que os dois juntos formam os incrementos de crescimento, em área curvada do domo do estatólito (HURLEY et al., 1979; HURLEY et al., 1985; DAWE et al., 1985; LIPINSKI, 1986; JACKSON, 1990b; NAKAMURA et al., 1991; LIPINSKI et al., 1998; JACKSON \& FORSYTHE, 2002; DURHOLTZ et al., 2002; BOYLE \& RODHOUSE 2005; AGUIAR et al., 2012).

Até o início da década de 60, não era conhecida técnica de leitura de incrementos depositados nas estruturas rígidas, para estudar a idade de cefalópodes (CERIOLA \& MILONE, 2007). Nessa época eram feitas apenas estimativas de idade com métodos indiretos (PACKARD, 1972). O primeiro autor a noticiar marcas periódicas nos estatólitos foi Young, entre 1960 e 1965, o qual estudou o estatocisto de Octopus vulgaris Cuvier, 1797 (CERIOLA \& MILONE, 2007). Clarke (1966) reconheceu os incrementos de crescimento e a partir disto, estatólitos de muitas espécies de cefalópodes foram descritos (CERIOLA \& MILONE, 2007). Sendo assim, um método semelhante ao aplicado às estruturas internas em peixes (otólitos e vértebras) passou a ser utilizado para validação e determinação da idade em cefalópodes (HERMOSILLA et al., 2010).

Há diversas referências sobre o assunto estimativa de idade através de interpretação de anéis de crescimento depositados nos estatólitos, como exemplo: Lipinski (1986); Jackson (1990a); Arkhipkin (1996b); Zakaria (2000); Villanueva et al. (2003); Sakai et al. (2004); Arkhipkin (2005); Aguiar (2006); Perez et al. (2006); Ceriola \& Milone (2007); González et al. (2010); Hermosilla et al. (2010); Schwarz \& Perez (2010); Aguiar et al. (2012); Schwarz \& Perez (2013). Nestes estudos foram 
testados diferentes ajustes de crescimento para descrever o crescimento da espécie em estudo.

Nesse sentido, tanto a massa do corpo quanto as medidas de comprimento de manto são comumente utilizadas, e comparadas com a idade da espécie estudada (FORSYTHE \& VAN HEUKELEM, 1987). Inicialmente, a curva de crescimento (relação estabelecida entre massa do corpo do cefalópode com a idade ou entre comprimento do manto e a idade) era modelada pela equação e curva de crescimento de von Bertalanffy, provavelmente devido ao amplo uso da mesma para peixes.

Apesar de algumas melhorias na sua aplicação em cefalópodes, muitos autores acreditam que ela não se ajusta bem aos dados observados, como apontados por Forsythe \& Van Heukelem (1987) e Day \& Taylor (1997), já que há discrepâncias no comportamento da curva de crescimento apresentada por von Bertalanffy e a do crescimento observado nos cefalópodes (principalmente para indivíduos juvenis). Desde então, outros modelos de ajuste têm sido utilizados para melhor descrever o comportamento da curva de crescimento. Uma das premissas do presente estudo é testar diferentes modelos de crescimento, os quais ainda não foram testados para Doryteuthis plei e definir qual o melhor ajuste a curva e crescimento para a espécie.

Outro ponto a destacar são os padrões diferenciados de crescimento entre machos e fêmeas, frequentemente encontrados para a maioria dos cefalópodes. Após o nascimento, a curva de crescimento para ambos os sexos se comporta de maneira exponencial, porém após a maturação sexual, quando se espera que os efeitos de maturação das gônadas demandem maior gasto energético, de fato, o comportamento é diferente entre os sexos. Durante a maturação sexual, ocorre uma diminuição da taxa de crescimento (FORSYTHE \& VAN HEUKELEM, 1987). De modo geral, o início da maturação sexual nas fêmeas é marcado pelo fim do crescimento exponencial e início do logarítmico (comportamento da curva de crescimento) (BOYLE \& RODHOUSE, 2005). Sendo assim, para o comportamento característico dos cefalópodes, a curva de von Bertalanffy não se aplica.

Em Loligo vulgaris Lamark, 1798, Loligo forbesii Steenstrup, Doryteuthis (Amerigo) pealeii (Lesueur, 1821), D. (Amerigo) opalescens (Berry, 1911), Sepioteuthis lessoniana Ferussac in Lesson, 1831, Alloteuthis subulata (Lamarck, 1798), e muitos outros Loliginídeos, os machos crescem mais rapidamente do que as fêmeas. Já para as 
espécies: Alloteuthis media (Linnaeus, 1758), Sepioteuthis sepioedea (Blainville, 1823), Lolliguncula brevis, Todarodes sagittatus (Lamarck, 1798), T. pacificus (Steenstrup, 1880), Todaropsis eblanae (Ball, 1841), Illex illecebrosus (Lesueur), Ommastrephes caroli Furtado, 1887, entre outras, os machos crescem mais vagarosamente em relação às fêmeas (FORSYTHE \& VAN HEUKELEM, 1987; ZUEV \& NESIS, 2003; BOYLE \& RODHOUSE, 2005).

Estudos prévios de estimativa e validação do padrão de crescimento (JACKSON \& FORSYTHE, 2002, AGUIAR 2002; PEREZ et al, 2006) confirmaram que o depósito de incrementos de crescimento, nos estatólitos de Doryteuthis plei, são diários (AGUIAR, 2002; JACKSON \& FORSYTHE, 2002, AGUIAR et al., 2012). Porém, em nenhum dos estudos foi dada ênfase na análise do crescimento nos estágios iniciais de vida. Sendo assim, as abordagens supracitadas levantaram questões importantes para a realização de novos estudos.

Mesmo que o padrão de crescimento de $D$. plei de pequeno porte não seja completamente conhecido, devido à baixa representação amostral em coletas de campo (FORSYTHE \& VAN HEUKELEM, 1987), se espera obter um crescimento similar aos demais lolíginídeos, com comportamento de modelo de crescimento exponencial nas idades iniciais de vida.

Em virtude da escassez de dados sobre a dinâmica da população, biologia, e crescimento (comportamento da curva de crescimento) dos exemplares juvenis de $D$. plei, existe ainda uma lacuna-chave na curva de crescimento da espécie, a qual até o momento é desconhecida. Este estudo pretende completar essa lacuna, procedendo à estimativa da taxa de crescimento, e demonstração da curva de crescimento mais consistente para a espécie, bem como possibilitando outros tipos de análise relacionados ao seu crescimento.

Tendo como premissa que fatores bióticos e abióticos, destacando como um dos principais a temperatura, tem influencia na taxa de crescimento, espera-se que as paralarvas de D. plei eclodidas nas temporadas de primavera e verão, apresentem taxa de crescimento mais acelerado do que as paralarvas eclodidas no outono e inverno. Acredita-se também que o crescimento das lulas é variável entre as estações do ano, entre os sexos e entre os estádios de maturidade. 


\section{OBJETIVOS}

O objetivo geral do presente estudo foi analisar e estimar a curva de crescimento de indivíduos da espécie $D$. plei, com ênfase nos estágios iniciais do ciclo de vida, por meio da interpretação dos incrementos de crescimento depositados nos estatólitos. Paralelamente ao objetivo geral, o presente trabalho almeja:

a) Descrever os estatólitos morfologicamente e morfométricamente;

b) Relacionar a quantidade de incrementos dos estatólitos com o comprimento do manto (curva de crescimento) dos exemplares, bem como com o comprimento dos domos dos estatólitos;

c) Estimar a data de aniversário dos exemplares amostrados e a longevidade da espécie;

d) Estimar a taxa de crescimento para a espécie, por sexo, e por estádio de maturidade;

e) Avaliar possíveis diferenças na taxa de crescimento entre organismos eclodidos em diferentes épocas do ano. 


\section{MATERIAIS E MÉTODOS}

O presente estudo está inserido nos projetos "A lula (Cephalopoda: Loliginidae) como recurso da pesca no litoral norte do estado de São Paulo: dinâmica populacional, oceanografia pesqueira e a dimensão humana associada" (BIOTA/FAPESP $\mathrm{n}^{\circ}$ 10/50183-6), financiada pela Fundação de Amparo à Pesquisa do Estado de São Paulo, e "Dinâmica populacional, oceanografia pesqueira, e a dimensão humana associada à pesca da lula (Cephalopoda: Loliginidae) em ilhas do litoral norte de São Paulo" (CNPq $\mathrm{n}^{\circ}$ 562044/2010-8), financiado pelo Conselho Nacional de desenvolvimento científico e tecnológico. Este estudo contribuirá para uma melhor compreensão da estrutura populacional da lula Doryteuthis plei, bem como aplicação do protocolo de preparação, leitura e interpretação dos incrementos de crescimento depositados nos estatólitos, estimativa da taxa de crescimento, e descrição desta estrutura de estudo.

\section{1. Área de estudo}

Amostras de exemplares da lula D. plei foram obtidas no litoral norte do Estado de São Paulo, especificamente na plataforma continental adjacente às regiões marinhas dos municípios de Ubatuba ( $\left.23^{\circ} 45^{\prime} \mathrm{S} ; 4^{\circ} 06^{\prime} \mathrm{W}\right)$ e São Sebastião $\left(23^{\circ}\right.$ 96'S; $\left.45^{\circ} 51^{\prime} \mathrm{W}\right)$ (Figura 1), regiões estas de importância para a pesca artesanal e industrial, onde ocorrem pescarias de peixes como corvinas, sardinhas, cações e camarões (ROSSIWONGTSCHOWSKI et al., 2008) e de pescarias direcionadas à captura de lulas com zangarelhos (garatéia sem isca) (POSTUMA \& GASALLA, 2010) e de arrastos camaroeiros (RODRIGUES, 2007).

Estão presentes na área de estudo, três massas de água predominantes: a Água Central do Atlântico Sul (ACAS), caracterizada pela baixa temperatura (menor do que $20^{\circ} \mathrm{C}$ ) e alta salinidade (maior do que 36,4), rica em nutrientes, estimulando a produtividade pelágica na zona fótica; a Água Tropical (AT) com alta temperatura (maior do que $20^{\circ} \mathrm{C}$ ) e salinidade superior a 36,4 ppt e Água Costeira (AC), com alta temperatura (acima de $24^{\circ} \mathrm{C}$ ) (MIRANDA, 1982; CASTRO-FILHO, 1987).

Silva et al. (2004) estudaram a circulação e a distribuição de temperatura, salinidade, e densidade da água na região costeira adjacente à ilha de São Sebastião e observaram que a ACAS presente em camadas mais profundas da plataforma continental, penetra no canal de São Sebastião pela entrada sul durante a primavera e 
verão. Constataram também a massa de água AT nas camadas sobrejacentes à termoclina. No outono e inverno, a massa de água AT não foi presente no canal, porém fracos sinais da ACAS foram encontrados no outono, contudo, ausentes no inverno quando predominam características termohalinas da AC (SILVA et al., 2004).

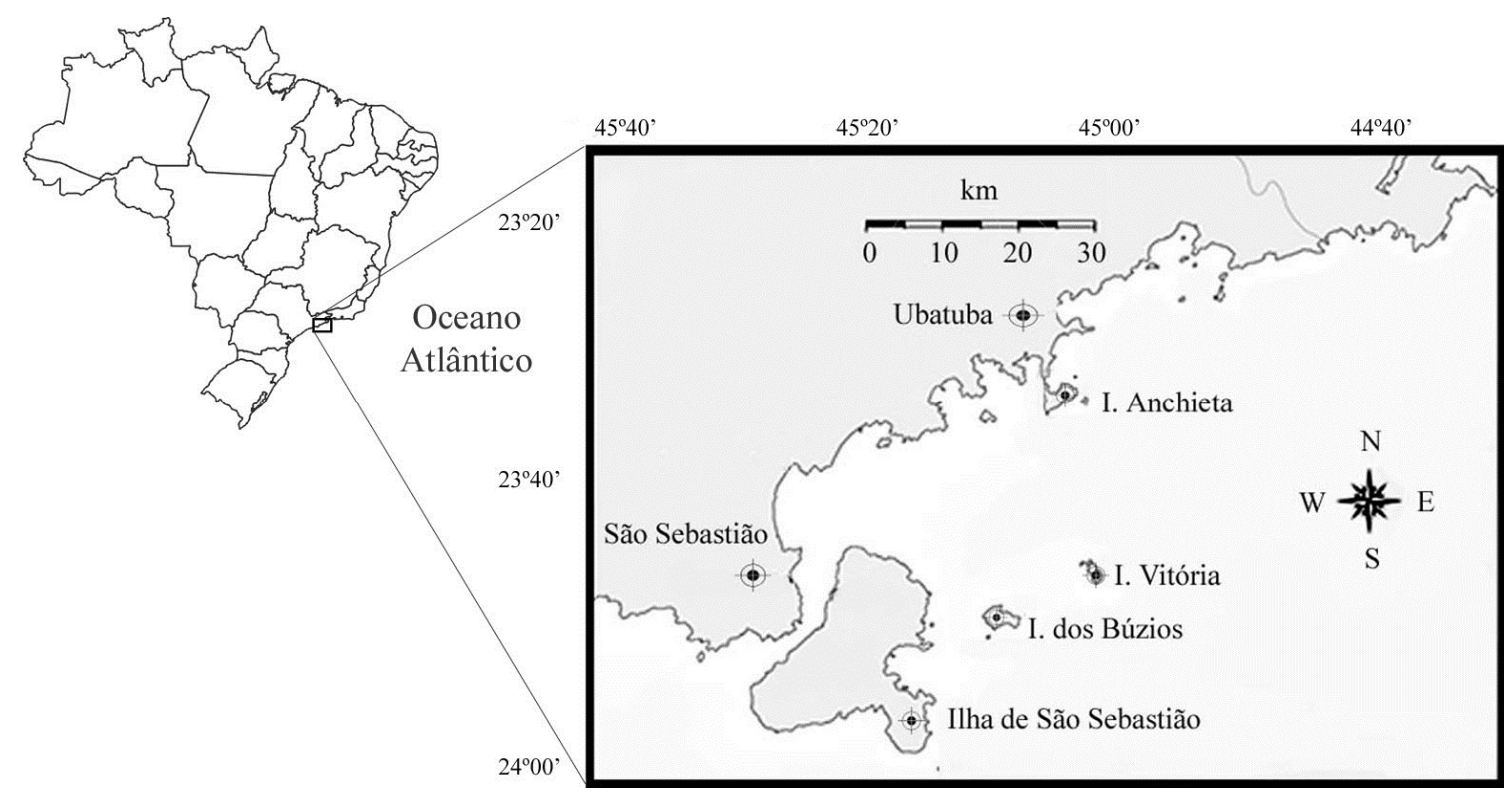

Figura 1 - Mapa da área de estudo: litoral norte do Estado de São Paulo, entre os municípios de Ubatuba e São Sebastião.

Já na plataforma continental de Ubatuba, no verão, em profundidades inferiores a 20 metros, a massa de água predominante é a AC que se mistura com a AT. Na camada superficial predomina a ACAS, cuja mistura vertical com a AC é somente observada nas proximidades da costa (CASTRO FILHO et al., 1987). No inverno a ACAS não avança muito sobre a plataforma continental, porém na camada superficial, há intrusão significativa da AT e pela AC. Há uma interação entre AC e ACAS apenas na zona frontal que delimita a região de ocorrência dessas massas de água. Assim, considera-se para a região costeira de Ubatuba, a partir dos padrões de distribuição e interação entre as massas de águas; como também as condições meteorológicas de regiões vizinhas, um modelo de circulação de águas controlado pelo vento e ação da Corrente do Brasil (CASTRO FILHO et al., 1987).

Esta corrente gera vórtices com características frontais no verão e inverno. Os vórtices ocorrentes apresentam em extensões horizontais em profundidades de 25 e $50 \mathrm{~m}$ na estrutura térmica e halina, promovendo a troca de massas de água entre a costa e o talude, o que contribui para o enriquecimento das águas da plataforma continental com 
movimentos ascendentes que ocorrem no núcleo da troca (CASTRO FILHO et al., 1987).

Ao sul da Ilha Anchieta, no canal formado entre a Ilha e o Ilhote, há correntes fortes vindas ao leste do Ilhote, local onde ocorrem variações de marés. Devido à constante correnteza leste, o local é rico em vida marinha. A temperatura da água varia entre $20^{\circ} \mathrm{C}$ e $28^{\circ} \mathrm{C}$ (PIRES-VANIN, 2008).

De acordo com Barcellos \& Furtado (1999), o assoalho marinho no entorno de Ilhabela é caracterizado pela variabilidade granulométrica de sedimentos principalmente na porção norte, onde há proteção da Ilha de São Sebastião e de ilhas menores, atenuando assim a incidência direta de ondas provenientes de sul e sudoeste, associadas às passagens de frentes frias. Esta proteção possibilita a deposição de sedimentos argilosos. A região sul de São Sebastião, como não há a proteção de ilhas, a incidência de ondas é direta, estando esta área suscetível a movimentações efetivas junto ao fundo, havendo assim maior presença de areia no fundo (BARCELLOS \& FURTADO, 1999).

\subsection{Obtenção de dados}

\subsubsection{Coleta de amostras}

Entre setembro de 2011 e março de 2013, exemplares de D. plei foram capturados mediante as campanhas de investigação do projeto BIOTA/FAPESP $\mathrm{n}^{\circ}$ 10/50183-6, com a utilização do barco de pesquisa "Veliger II" do Instituto Oceanográfico da Universidade de São Paulo. Foram obtidos exemplares complementares, provenientes de desembarques pesqueiros junto à Cooperativa de Pesca de São Sebastião (COOPERPESCASS). A Tabela 1 descreve as amostras, incluindo a data de captura, o número amostral de exemplares por captura, local da pesca, e o método e procedência da coleta de dados. Para a coleta dos exemplares estudados, foi submetida autorização do SISBIO (IBAMA). 
Tabela 1 - Descrição das amostras. Data da coleta dos exemplares, número de indivíduos por evento amostral (n), áreas de capturas (local), métodos de coleta de dados (arte de pesca), e procedência dos dados.

\begin{tabular}{|c|c|c|c|c|}
\hline Data & $\mathbf{n}$ & Local & Arte de pesca & Procedência \\
\hline 30/09/2011 & 6 & $\begin{array}{c}\text { São Sebastião: canal Ilha Bela à Praia } \\
\text { Enseada }\end{array}$ & $\begin{array}{l}\text { arrasto de } \\
\text { camarão }\end{array}$ & $\begin{array}{c}\text { pesca } \\
\text { comercial }\end{array}$ \\
\hline 13/10/2011 & 19 & Ubatuba: Ilhote sul da Ilha Anchieta & $\begin{array}{l}\text { passaguá e } \\
\text { zangarelho }\end{array}$ & pesca científica \\
\hline 28/10/2011 & 2 & $\begin{array}{l}\text { São Sebastião: Entre praia da Fome e do } \\
\text { Poço }\end{array}$ & $\begin{array}{l}\text { arrasto de } \\
\text { camarão }\end{array}$ & $\begin{array}{c}\text { pesca } \\
\text { comercial }\end{array}$ \\
\hline 30/10/2011 & 8 & $\begin{array}{l}\text { São Sebastião: Entre praia da Fome e do } \\
\text { Poço }\end{array}$ & $\begin{array}{l}\text { arrasto de } \\
\text { camarão }\end{array}$ & $\begin{array}{l}\text { pesca } \\
\text { comercial }\end{array}$ \\
\hline 07/11/2011 & 6 & São Sebastião: praia Jabaquara & $\begin{array}{l}\text { arrasto de } \\
\text { camarão }\end{array}$ & $\begin{array}{l}\text { pesca } \\
\text { comercial }\end{array}$ \\
\hline $14 / 11 / 2011$ & 27 & São Sebastião: praia Massaguaçu & $\begin{array}{l}\text { arrasto de } \\
\text { camarão }\end{array}$ & $\begin{array}{l}\text { pesca } \\
\text { comercial }\end{array}$ \\
\hline 17/11/2011 & 19 & São Sebastião: praia do Poço à Ilha Vitória & zangarelho & pescacomercial \\
\hline 19/11/2011 & 5 & São Sebastião: praia do Poço à Ilha Vitória & zangarelho & $\begin{array}{c}\text { pesca } \\
\text { comercial }\end{array}$ \\
\hline 21/11/2011 & 52 & Ubatuba: praia Camburi & $\begin{array}{c}\text { passaguá, } \\
\text { zangarelho e } \\
\text { cerco } \\
\text { flutuante }\end{array}$ & pesca científica \\
\hline 24/11/2011 & 5 & São Sebastião: praia Jabaquara & zangarelho & $\begin{array}{c}\text { pesca } \\
\text { comercial }\end{array}$ \\
\hline 06/12/2011 & 11 & São Sebastião: praia do Poço & zangarelho & $\begin{array}{c}\text { pesca } \\
\text { comercial }\end{array}$ \\
\hline $17 / 12 / 2011$ & 2 & São Sebastião: praia Jabaquara & zangarelho & $\begin{array}{c}\text { pesca } \\
\text { comercial }\end{array}$ \\
\hline 21/12/2011 & 10 & São Sebastião: praia do Bonete & zangarelho & $\begin{array}{c}\text { pesca } \\
\text { comercial }\end{array}$ \\
\hline 05/01/2012 & 15 & São Sebastião: praia do Bonete & zangarelho & $\begin{array}{c}\text { pesca } \\
\text { comercial }\end{array}$ \\
\hline 07/01/2012 & 9 & São Sebastião: praia do Massaguaçu & zangarelho & $\begin{array}{c}\text { pesca } \\
\text { comercial }\end{array}$ \\
\hline 23/01/2012 & 5 & São Sebastião: praia do Jabaquara & zangarelho & $\begin{array}{c}\text { pesca } \\
\text { comercial }\end{array}$ \\
\hline 08/02/2012 & 1 & São Sebastião: praia do Jabaquara & zangarelho & pesca científica \\
\hline 09/02/2012 & 1 & São Sebastião: praia do Bonete & zangarelho & pesca científica \\
\hline 09/02/2012 & 4 & São Sebastião: praia Barequeçaba & zangarelho & pesca científica \\
\hline $11 / 02 / 2012$ & 9 & São Sebastião: Ponta Pacuíba & zangarelho & pesca científica \\
\hline $13 / 02 / 2012$ & 14 & São Sebastião: praia do Cabelo Gordo & zangarelho & pesca científica \\
\hline $15 / 02 / 2012$ & 9 & São Sebastião: praia Barequeçaba & zangarelho & pesca científica \\
\hline $14 / 03 / 2012$ & 2 & Ubatuba: praia Enseada & $\begin{array}{l}\text { cerco } \\
\text { flutuante }\end{array}$ & pesca científica \\
\hline $18 / 03 / 2012$ & 3 & Ubatuba: praia Enseada & $\begin{array}{l}\text { cerco } \\
\text { flutuante }\end{array}$ & pesca científica \\
\hline 20/03/2012 & 1 & Ubatuba: praia Enseada & $\begin{array}{l}\text { cerco } \\
\text { flutuante }\end{array}$ & pesca científica \\
\hline $21 / 03 / 2012$ & 3 & Ubatuba: praia Enseada & $\begin{array}{l}\text { cerco } \\
\text { flutuante }\end{array}$ & pesca científica \\
\hline
\end{tabular}


Continuação Tabela 1.

\begin{tabular}{|c|c|c|c|c|}
\hline Data & n & Local & Arte de pesca & Procedência \\
\hline 04/04/2012 & 7 & São Sebastião: praia do Poço & zangarelho & $\begin{array}{c}\text { pesca } \\
\text { comercial }\end{array}$ \\
\hline 20/04/2012 & 16 & São Sebastião: praia da Toca & zangarelho & $\begin{array}{c}\text { pesca } \\
\text { comercial }\end{array}$ \\
\hline 19/06/2012 & 1 & São Sebastião: praia Massaguaçu & $\begin{array}{l}\text { arrasto de } \\
\text { camarão }\end{array}$ & $\begin{array}{c}\text { pesca } \\
\text { comercial }\end{array}$ \\
\hline 29/06/2012 & 1 & São Sebastião: praia Massaguaçu & $\begin{array}{l}\text { arrasto de } \\
\text { camarão }\end{array}$ & $\begin{array}{c}\text { pesca } \\
\text { comercial }\end{array}$ \\
\hline 04/07/2012 & 67 & Ubatuba: Ponta Grossa & $\begin{array}{l}\text { arrasto de } \\
\text { camarão }\end{array}$ & pesca científica \\
\hline 05/07/2012 & 11 & Ubatuba: Ponta Grossa & $\begin{array}{l}\text { arrasto de } \\
\text { camarão }\end{array}$ & pesca científica \\
\hline 06/07/2012 & 8 & Ubatuba: Ponta Grossa & $\begin{array}{l}\text { arrasto de } \\
\text { camarão }\end{array}$ & pesca científica \\
\hline 07/07/2012 & 3 & Ubatuba: Ponta Grossa & $\begin{array}{l}\text { arrasto de } \\
\text { camarão }\end{array}$ & pesca científica \\
\hline 08/07/2012 & 1 & Ubatuba: Ponta Grossa & $\begin{array}{l}\text { arrasto de } \\
\text { camarão }\end{array}$ & pesca científica \\
\hline 10/07/2012 & 2 & Ubatuba: Ponta Grossa & $\begin{array}{l}\text { arrasto de } \\
\text { camarão }\end{array}$ & pesca científica \\
\hline $13 / 07 / 2012$ & 10 & Ubatuba: Ponta Grossa & $\begin{array}{l}\text { arrasto de } \\
\text { camarão }\end{array}$ & pesca científica \\
\hline 01/03/2013 & 12 & São Sebastião: praia Barequeçaba & passaguá & pesca científica \\
\hline 02/03/2013 & 6 & São Sebastião: praia Barequeçaba & passaguá & pesca científica \\
\hline 03/03/2013 & 8 & São Sebastião: praia Barequeçaba & passaguá & pesca científica \\
\hline 04/03/2013 & 16 & São Sebastião: praia Barequeçaba & passaguá & pesca científica \\
\hline 05/03/2013 & 12 & São Sebastião: praia Barequeçaba & passaguá & pesca científica \\
\hline 06/03/2013 & 20 & São Sebastião: praia Barequeçaba & passaguá & pesca científica \\
\hline 07/03/2013 & 9 & São Sebastião: praia Barequeçaba & passaguá & pesca científica \\
\hline 08/03/2013 & 8 & São Sebastião: praia Barequeçaba & passaguá & pesca científica \\
\hline
\end{tabular}

No total, foram capturadas 466 lulas, porém foram utilizados apenas 424 estatólitos para o estudo de idade e crescimento. As lulas amostradas e não consideradas para o estudo de idade e crescimento apresentaram estatólitos ilegíveis para leitura de idade, bem como os valores (mensurações como ex: peso, ML e idade) se comportavam como outliers ou valor atípico nas relações testadas. 


\subsubsection{Técnicas de captura}

Com relação à pesca científica, os exemplares de Doryteuthis plei foram obtidos em profundidades entre 3 e 30 metros, com as seguintes técnicas de captura: zangarelho, atração luminosa e captura com passaguá. A pesca comercial incluiu arrasto de portas (arrasto de camarão), e cerco flutuante. Os procedimentos são brevemente descritos a seguir.

Zangarelho: é um equipamento de chumbo, com formato cilíndrico e afunilado na extremidade inferior, onde é colocado um conjunto de anzóis. O corpo do zangarelho é revestido de linha de costura, que pode ser branca, amarela, rosa ou verde. $\mathrm{Na}$ extremidade superior do zangarelho há um anel soldado na estrutura, no qual a linha de nylon é amarrada. Para pescar lulas, basta o pescador lançar o zangarelho em água e deixar que ganhe profundidade, fazendo com que o aparelho se movimente suavemente na coluna de água, simulando assim uma isca viva e estimulando que as lula tentem capturar esta "falsa presa".

Atração luminosa: foi realizada com luminárias equipadas com luzes fluorescentes, direcionadas para a lâmina d'água. Animais da comunidade pelágica são atraídos e se concentram ao redor da atração luminosa durante o período noturno (MARTINS \& PEREZ, 2006). A atração luminosa consistiu em dois braços luminosos com lâmpadas fluorescentes de 60 watts, sendo alimentadas por uma bateria. As lulas são atraídas pela fonte luminosa ou então por presa que também foram atraídas. A captura se deu através de um passaguá com uma rede de malha de $10 \mathrm{~mm}$.

A captura das paralarvas se deu através de coleta manual ou com passaguá (rede de malha de $10 \mathrm{~mm}$ ), de desovas, previamente identificadas de Doryteuthis plei. O tanque de incubação e manutenção das desovas e das paralarvas é descrito adiante.

Cerco flutuante: é um método de pesca artesanal (BLANK et al., 2009), introduzido inicialmente no município de Ilha bela, litoral norte do Estado de São Paulo, em 1920 por imigrantes japoneses (MUSSOLINI, 1980). Constituído estruturalmente de rede de pesca circular, é ancorado no fundo do mar próximo a um costão rochoso. A rede é sustentada (esticada do fundo à superfície) por flutuadores. É constituída pela casa (rodo que é o local de armazenamento da pesca) e espia (caminho). A espia é um pano de rede retangular que vai se prender ao costão rochoso e tem a função de impedir 
a passagem dos cardumes, pois os direciona para a entrada do rodo, onde ficam confinados (BLANK et al., 2009). Para o funcionamento adequado, o cerco deve ser instalado em locais abrigados e não suposto a condições adversas marítimas e climatológicas (MUSSOLINI, 1980).

Arrasto de portas: uma das técnicas mais comuns tanto em comunidades caiçaras (pesca artesanal) como para a pesca em larga escala, utilizando barcos de grandes dimensões (pesca industrial). Pesca de pouca seletividade, captura peixes e crustáceos, muita praticada em toda a costa brasileira. As redes são confeccionadas com poliamida (nylon mole) com malhas de $25 \mathrm{~mm}$ e fio $\mathrm{n}^{\circ} 12$ e tamanho aproximado de 9 a 12 metros Possuem forma cônica e a extremidade que retêm os animais capturados é conhecida como ensacador (MALHEIROS, 2008).

Para a preservação dos exemplares capturados, as lulas foram acondicionadas em saco plástico, com etiquetas de identificação e mantidas congeladas até serem processadas no Laboratório de Ecossistemas Pesqueiros (LabPesq) do Instituto Oceanográfico da Universidade de São Paulo.

\subsubsection{Processamento das amostras}

A identificação dos exemplares se baseou em literatura especializada, principalmente em Roper et al. (1984), Toll (1998), Jereb \& Roper (2010). Os dados biométricos de cada indivíduo foram mensurados, peso ( $\mathrm{P}$, em gramas), e comprimento de manto (ML, em milímetros). A Figura 2 exibe a mensuração do ML de uma paralarva, com uso do software AxioVision@( (versão 4.8) e de um exemplar adulto. O peso foi obtido através da pesagem do exemplar em balança analítica. O comprimento do manto foi tomado através de um ictiômetro, onde o exemplar em estudo foi colocado sobre o instrumento de medição com o dorso direcionado para cima. 

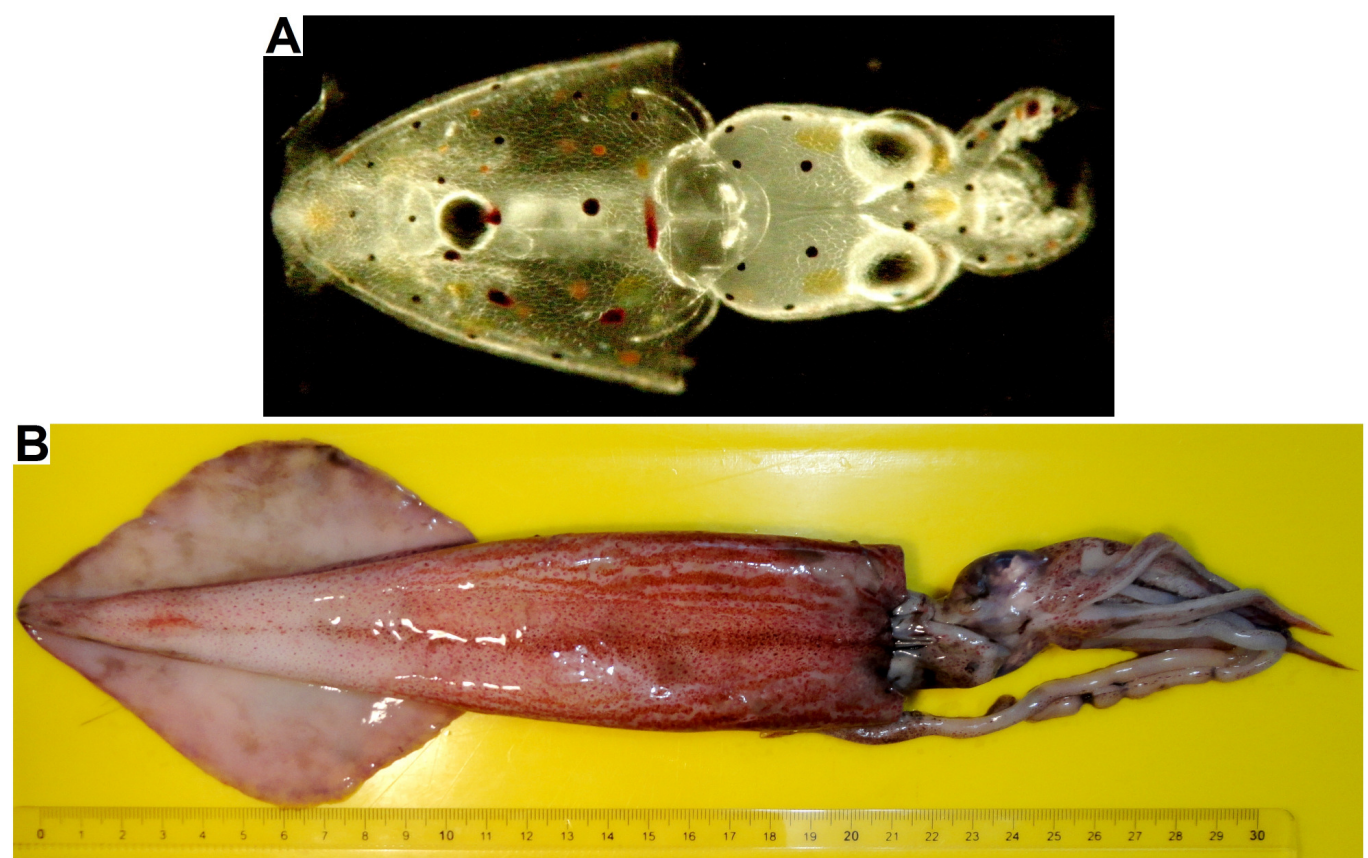

Figura 2 - Mensuração do comprimento de manto (ML) de uma paralarva visualizada em aumento de $2 \mathrm{x}$ através de estéreo-microscópio, com 2,32 $\mathrm{mm}$ ML (A) e de um macho adulto de Doryteuthis plei, com $277 \mathrm{~mm}$ ML.

Com o uso de tesoura cirúrgica, foi realizado um corte longitudinal ventral com exposição da cavidade do manto e da massa visceral, efetuando-se a dissecção do manto. O sexo foi identificado através de características morfológicas e identificação visual das gônadas. O estádio de maturidade foi identificado através de uma análise das características macroscópicas (cor, textura, estruturas, tamanho) do aparelho reprodutivo. O estádio de maturidade sexual foi considerado de acordo com a escala proposta por Juanicó-Rivero (1979), modificado por Perez et al. (2002) e adaptado ao presente estudo: I - imaturos ou juvenis; II - em maturação; III - maduros; IV Desovados, descrição na Tabela 2. Indivíduos onde não foi possível identificar o sexo foram considerados em estádio de maturação I. 
Tabela 2 - Escala de classificação dos estádios de maturidade sexual adaptada de JuanicóRivero (1979) e Perez et al. (2002).

\begin{tabular}{|c|c|c|}
\hline Estádios & Machos & Fêmeas \\
\hline Imaturo ou juvenis (I) & \multicolumn{2}{|c|}{ Órgãos reprodutivos não diferenciados. } \\
\hline Em maturação (II) & 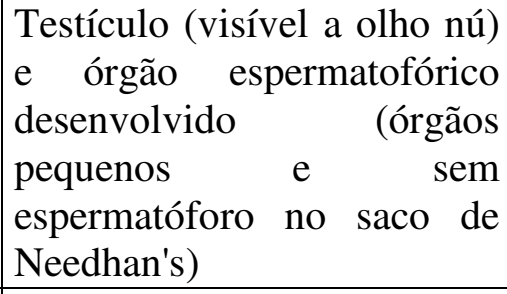 & $\begin{array}{l}\text { Glândulas nidamentais, ovário } \\
\text { pequeno e filamentoso. Oviduto } \\
\text { sem ovos }\end{array}$ \\
\hline Maduros (III) & $\begin{array}{l}\text { Testículo e órgãos } \\
\text { espermatofórico alargado. } \\
\text { Saco espermatofórico com } \\
\text { muitos espermatóforos } \\
\text { desenvolvidos }\end{array}$ & $\begin{array}{l}\text { Ovidutos e glândulas acessórias } \\
\text { alargadas. Ovário e oviduto } \\
\text { cheio de óvulos. Glândulas } \\
\text { nidamentais rígidas. Óvulo com } \\
\text { cor de âmbar, semitransparentes }\end{array}$ \\
\hline Desovados (IV) & $\begin{array}{l}\text { Testículos e órgãos } \\
\text { espermatofóricos } \\
\text { de exaustão. Sinais } \\
\text { Needhan's vazio }\end{array}$ & $\begin{array}{l}\text { Glândulas acessórias com sinais } \\
\text { de exaustão. Ovidutos com } \\
\text { poucos ovócitos ou vazio }\end{array}$ \\
\hline
\end{tabular}

\subsubsection{Extração dos estatólitos}

Os estatólitos foram extraídos através de uma incisão na parte posterior ventral da cartilagem cefálica. Foram retirados com o auxílio de pinça, secos em papel toalha para remoção do gel aderente dos estatocistos e armazenados em álcool 70\% em eppendorfs (capacidade de $2 \mathrm{ml}$ ) identificados com etiquetas para análise posterior.

Para a extração dos estatólitos das paralarvas, estas, ainda vivas foram capturadas do tanque de manutenção de paralarvas (tanque circular com 2 metros de diâmetro e 1 metro de profundidade, sistema aberto de circulação de água direta do mar e com duas pedras porosas de aeração) com pipeta de vidro de $1 \mathrm{~mL}$ e depositadas em um becker de $10 \mathrm{~mL}$ com água do mar. As paralarvas foram anestesiadas com solução de cloreto de magnésio (foi misturado $50 \%$ da solução em água salgada).

Uma paralarva por vez, devidamente anestesiada, foi depositada com o uso de pipeta em lâmina de microscopia escavada e visualizada em lupa acoplada em sistema de análise de imagem. Através do uso da lupa, o comprimento de manto foi obtido. $\mathrm{O}$ peso das paralarvas (indivíduos entre 1,58 a 2,5 mm, amostragem das datas de março de 2013) não foi realizado, pois não havia equipamento disponível para este procedimento. 
Os estatólitos foram extraídos com o auxílio de agulhas e pinças entomológicas e foram colados em lâminas de microscopia com esmalte de unha incolor (Risqué®). Estatólitos de paralarvas e de lulas juvenis são de difícil extração devido ao pequeno tamanho $(<0,5 \mathrm{~mm})$ (ARKHIPKIN \& SHCHERBICH, 2012). Para a leitura dos incrementos de crescimento, foi preciso fazer o polimento da porção convexa do estatólito (previamente colado em lâmina de microscopia). A Figura 3 expõe a extração dos estatólitos de paralarvas e de lulas juvenis e adultas.

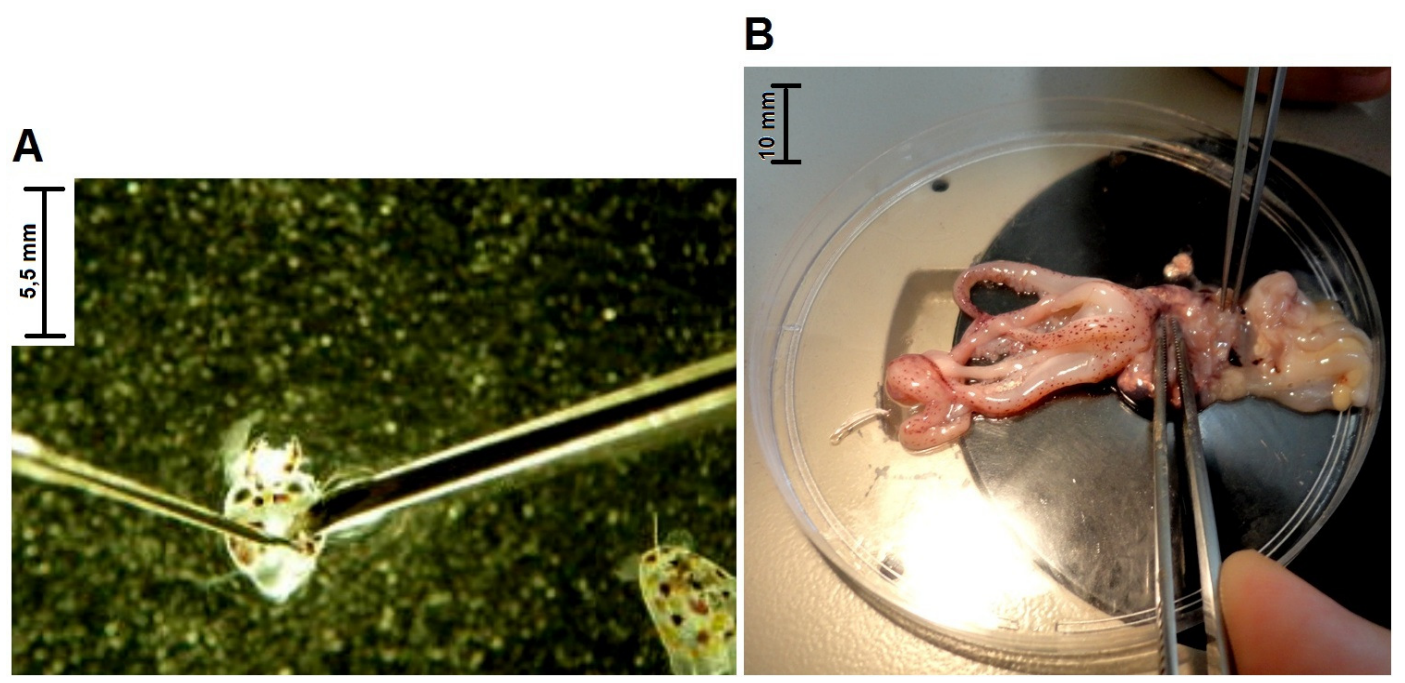

Figura 3 - Extração dos estatólitos de paralarvas de lulas, em estéreo-microscópio (A), exemplares juvenis e adultos de D. plei (B).

\subsubsection{Morfometria dos estatólitos}

Com o uso de estéreo-microscópio, aumento de 3,2 - 6,3x, e câmera digital acoplada (AxioCamERc 5s) interligada a sistema de computador, foi feita uma análise morfológica e morfométrica em uma parcela do total de estatólitos extraídos (em 390 indivíduos capturados entre setembro de 2011 e fevereiro de 2012). Medidas de comprimento do estatólito (SL, em mm), comprimento do domo (DL, em mm) foram tomadas no maior eixo de cada estrutura, seguindo os padrões de Clarke (1978). Outras medidas foram incluídas como: (1) ângulo do rostro (ÂR, em graus); (2) ângulo do domo dorsal (ÂD, em graus); e (3) área do estatólito (AS, em $\mathrm{mm}^{2}$ ). As medições foram executadas através de análise de imagens digitalizadas, com a utilização de software AxioVision@ (versão 4.8). 
Para a descrição das partes estruturais dos estatólitos, foi considerada a nomenclatura proposta por Clarke (1978). A morfologia dos estatólitos de D. plei é apresentada na Figura 4, juntamente com as medições realizadas na estrutura.

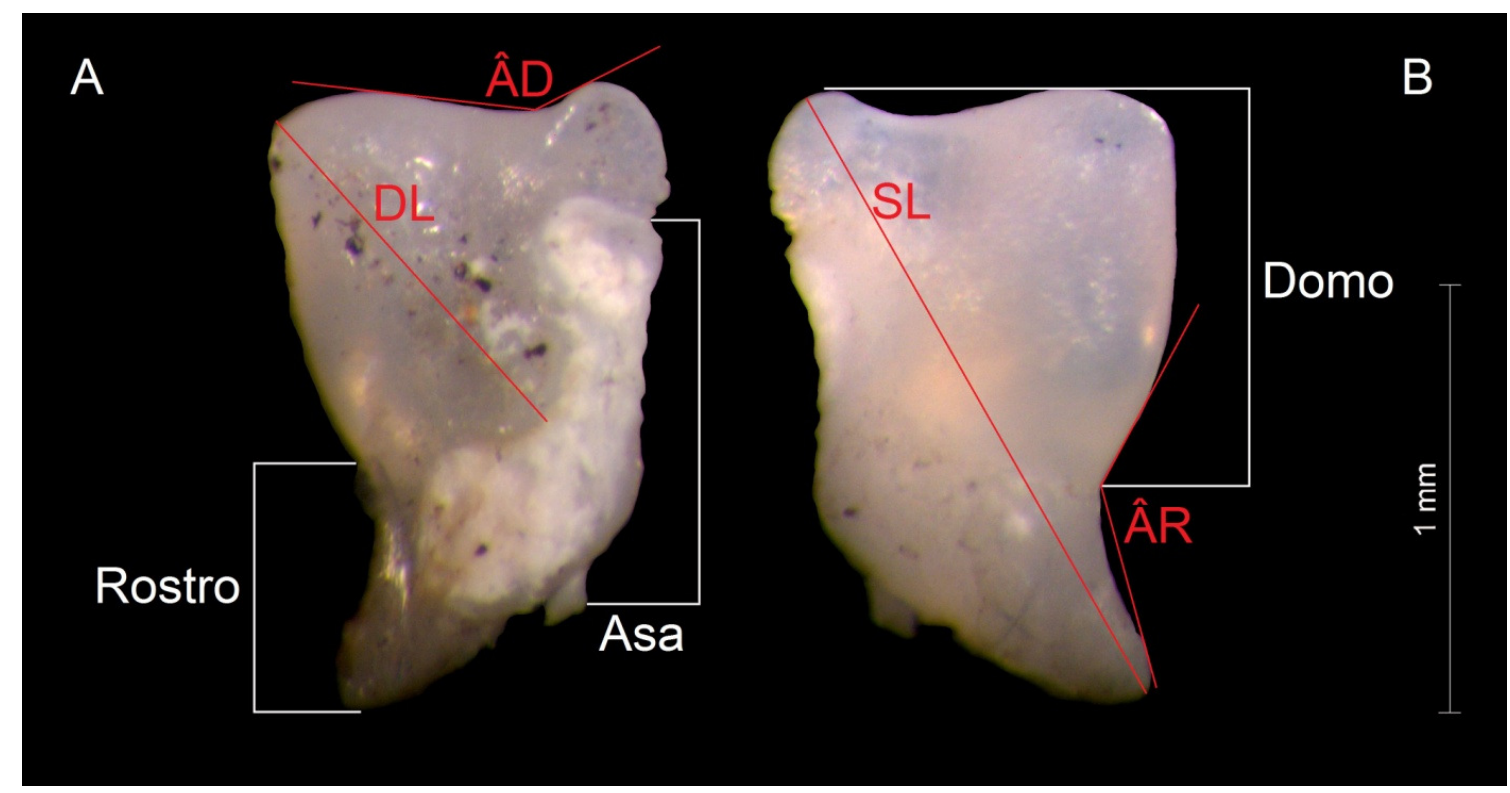

Figura 4 - Medições realizadas nos estatólitos de D. plei. (A) Face anterior: ângulo domo (ÂD), comprimento do domo (DL). (B) Face posterior:comprimento do estatólito (SL) e ângulo do rostro (ÂR).

Como um componente adicional de descrição dos estatólitos de D. plei, foi comparado a morfologia dos estatólitos da espécie estudada com o de D. sanpaulensis (descritos apenas morfologicamente).

\subsubsection{Preparo para leitura dos incrementos de crescimento}

Para a leitura dos anéis de crescimento, os estatólitos foram preparados segundo Ceriola \& Milone (2007), com a montagem de lâminas (preparo de lixar, polir e colagem em lâmina de microscopia) e contagem dos incrementos em microscópio óptico. Apenas um estatólito foi selecionado de cada indivíduo. Padronizou-se o uso do estatólito direito para a contagem dos incrementos de crescimento e análise morfométrica.

Foi realizado polimento manual dos estatólitos a serem estudados. Estes foram mantidos firmemente com pinça de ponta fina e lixados com "lixas de água" de 1200 (3M Imperial Film Micro Finishing) e filme de lapidação (12, 9 e 5 mm; 3M Imperial 
Lapping Film) com intervalos para umedecer as lixas com água fria, até que o núcleo e o limite da borda do domo dorsal fossem visualizados em microscópio.

Após o polimento, uma gota de esmalte de unha incolor (Risqué®) foi depositada em uma das bordas da lâmina devidamente etiquetada, e o estatólito na posição convexa foi posicionado sobre a gota de verniz. Durante 24 horas, a lâmina ficou exposta à temperatura ambiente para secagem da resina. Após secagem, as lâminas foram lixadas e polidas com as mesmas lixas de água e filme de lapidação citados anteriormente, na sequência. A Figura 5 ilustra as lâminas com os estatólitos colados (Figura 5A), e as lâminas já preparadas para leitura, no microscópio (Figura $5 B)$.

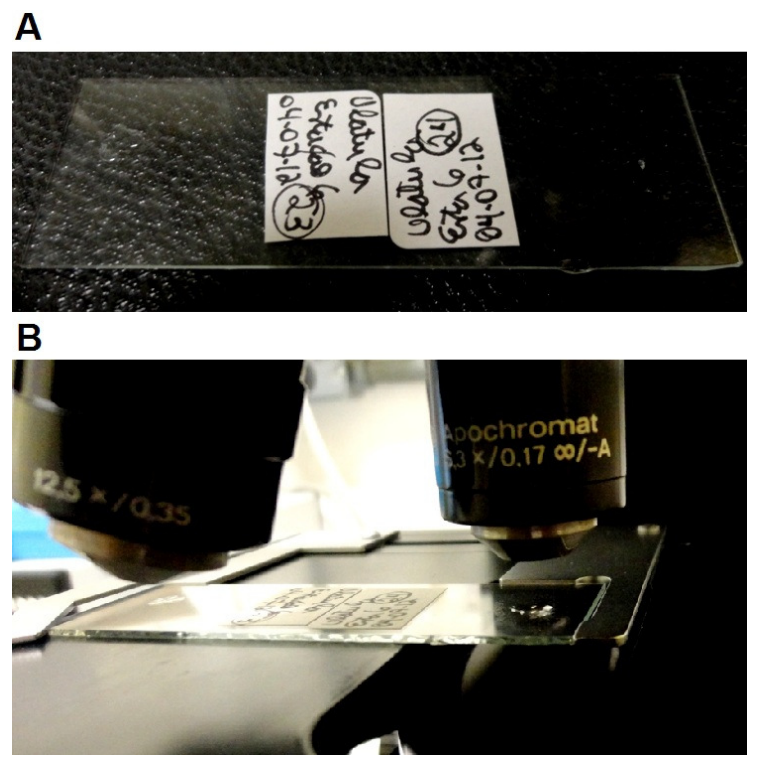

Figura 5 - Lâmina de microscópio preparada para leitura (A) e (B) lâmina em microscópio. 


\subsubsection{Leitura dos incrementos de crescimento}

Os incrementos de crescimento foram contados ao longo do eixo de crescimento, o qual foi estabelecido após a identificação do check de anel nascimento (núcleo, anél de eclosão, um anel mais evidente do que os outros na região nuclear dos estatólitos) até a margem extrema do domo (demonstrado na Figura 6D). Foi considerada como marca de crescimento por dia, cada deposição (uma banda clara e uma escura). Os incrementos de crescimento foram contados através de visualização direta em microscópio de luz (com objetiva de aumento entre 400x e 1000x) (Figura 6). Foram criadas categorias referentes a qualidade da visualização dos incrementos de crescimento: ruim, regular, boa e muito boa. Para auxílio da contagem dos anéis de crescimento, foi utilizado um contador manual. Foram realizadas de 3 a 5 contagens consecutivas, de forma consecutiva pelo mesmo observador. 
A

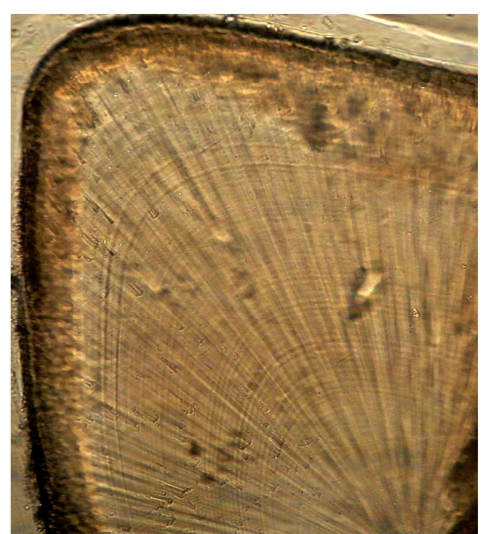

D

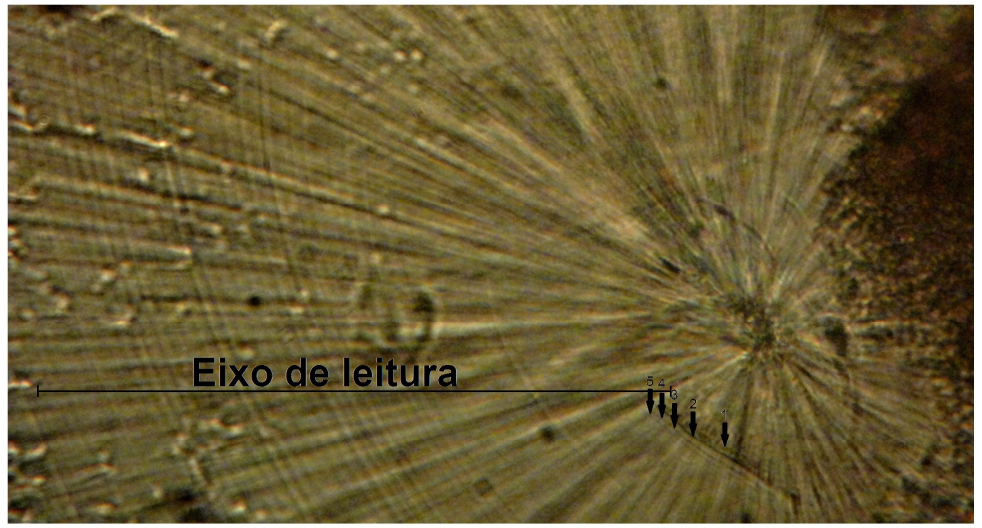

F
C
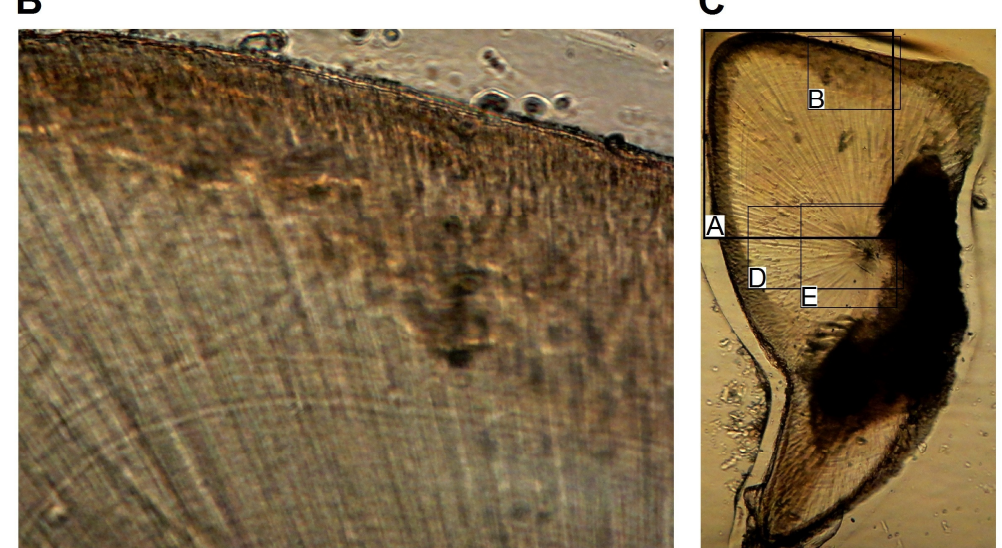

E
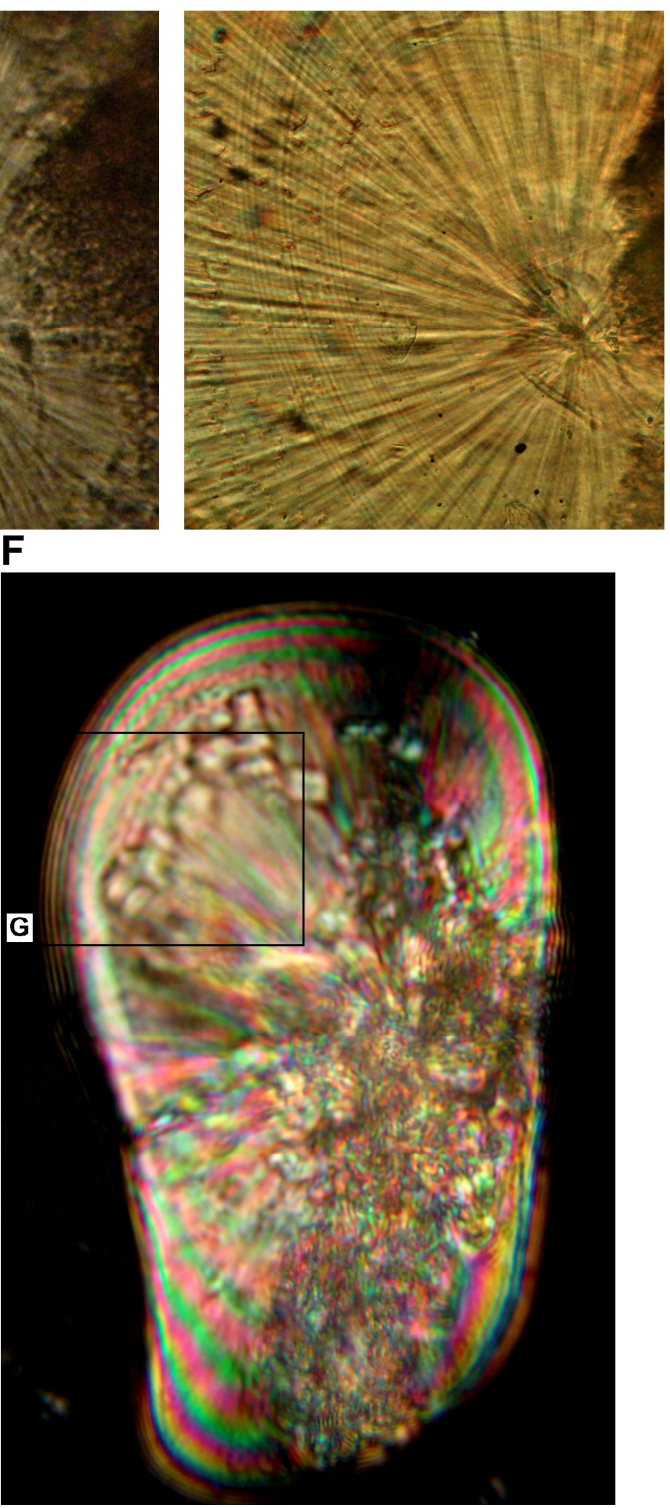

E

\section{G}

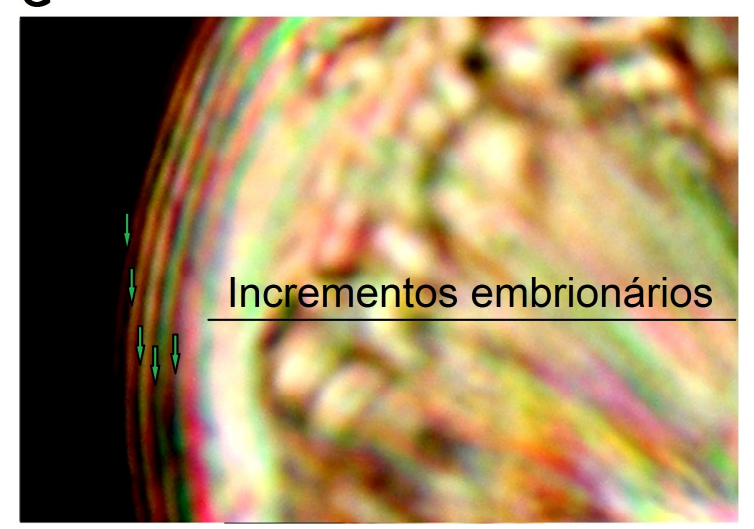




\subsubsection{Análise de dados}

\subsubsection{Biologia populacional}

Primeiramente foi feita uma descrição e análise, como: a média, variação e desvio padrão dos valores de ML, peso e por estádio de maturidade foram calculadas para o total da amostra, por sexo e para juvenis, bem como por estádios de maturidade. Sendo assim, a porcentagem (\%) de cada análise foram exibidos graficamente.

$\mathrm{O}$ comprimento médio de maturação $\left(\mathrm{L}_{50}\right)$, que corresponde àquele com o qual $50 \%$ dos indivíduos se encontram maduros, foi calculado por sexo, utilizando o modelo sigmóide:

$$
\mathrm{y}=1 /(1+\exp (-a+b * \mathrm{x}))
$$

onde $\mathrm{x}$ correspondeu aos valores de $\mathrm{ML}(\mathrm{mm})$ e y aos valores do $p$-value. $\mathrm{O}$ valor de $\mathrm{L}_{50}$ é obtido através da divisão do valor $a$ da função pelo valor de $b\left(\mathrm{~L}_{50}=a / b\right)$.

A relação comprimento do manto (ML) x peso (em gramas) foi testada com os modelos: linear (2), exponencial (3), logarítmico (4) e potencial (5), através das equações:

$$
\begin{aligned}
& \mathrm{y}=a+b^{*} \mathrm{x} \\
& \mathrm{y}=a^{*} \mathrm{e}^{b^{*} \mathrm{x}} \\
& \mathrm{y}=a+b^{*} \log (\mathrm{x}) \\
& \mathrm{y}=a^{*} \mathrm{x}^{b}
\end{aligned}
$$

onde $\mathrm{x}$ corresponde aos valores de $\mathrm{ML}(\mathrm{mm})$ e y aos valores do peso ( $\mathrm{g}$, gramas). $\mathrm{O}$ melhor ajuste foi selecionado de acordo com os mais altos valores de $r^{2}$ (coeficiente de correlação) e menores valores de AIC (Critério de Informação Akaike) (AKAIKE, 1973). Esta análise foi realizada utilizando o software R@ (R Development Core Team, 2012).

\subsubsection{Análise dos estatólitos}

Parte do número total dos estatólitos obtidos foi descrita morfologicamente e morfométricamente. A distribuição das medidas extraídas dos estatólitos e ML foram testadas utilizando o teste Shapiro-Wilk, o qual indicou que os dados eram não paramétricos $(p<0,05)$. Satisfeita esta condição, o teste Kruskal-Wallis foi aplicado para verificar se havia diferenças entre as medidas tomadas dos estatólitos direito e esquerdo e padronizar o estudo. Como não houve diferenças significativas entre os estatólitos direito e esquerdo (Kruskal-Wallis $p=1$ ), as análises posteriores foram realizadas com os valores dos estatólitos direitos. 
Para detectar diferenças possíveis entre os sexos, o teste Kruskal-Wallis foi aplicado para os dados dos estatólitos de machos e fêmeas. A relação entre SL e ML de machos e fêmeas e em relação aos estádios de maturidade foram testados com ANCOVA (teste de homogeneidade), onde ML foi a variável dependente, sexo (ou maturidade) o fator categórico, e SL preditor (Zar, 1996). Antes da análise, os dados foram log-transformados e realizados com o software Statistica@ (versão 10).

A relação entre ML e SL foi testada com os modelos matemáticos: linear (2), exponencial (3), logarítmico (4) e potencial (5), onde x correspondeu aos valores de ML $(\mathrm{mm})$ e y aos valores do SL (mm). Seguindo o critério de escolha adotado, o melhor ajuste foi selecionado de acordo com os mais altos valores de $r^{2}$ e menores de AIC. Esta análise foi realizada utilizando o software R@ (R Development Core Team, 2012).

\subsubsection{Consistência e precisão entre as leituras}

A consistência e precisão entre as leituras foram analisadas através de duas aproximações: índice estatístico Erro Médio Percentual (EMP), proposto por (BEAMISH \& FOURNIER, 1981), através da equação:

$$
\mathrm{EMP}=1 / \mathrm{N} * \sum_{\mathrm{j}=1}^{\mathrm{N}} * 1 / \mathrm{R} * \sum_{\mathrm{i}=1}^{\mathrm{R}}\left|\mathrm{X}_{\mathrm{ij}}-\overline{\mathrm{X}}_{\mathrm{j}}\right| / \overline{\mathrm{X}}_{\mathrm{j}} * 100
$$

e pelo Coeficiente de Variabilidade (CV) (Zar, 1996), utilizando a equação:

$$
\mathrm{CV}=\mathrm{s} / \overline{\mathrm{X}}_{\mathrm{j}} * 100
$$

onde: $\mathrm{N}=$ número de indivíduos; $\mathrm{j}=\mathrm{j}^{\text {ésimo }}$ indivíduo; $\mathrm{R}=$ número de leituras; $\mathrm{X}_{\mathrm{ij}}=$

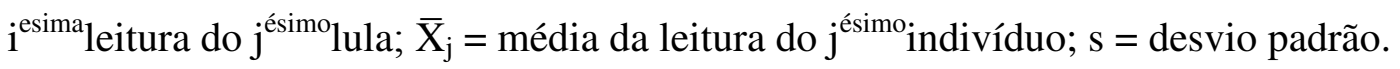

A porcentagem das categorias referente à qualidade da visualização dos incrementos de crescimento (ruim, regular, boa e muito boa) de toda a amostra, por sexo e para os indivíduos de ambos os estádios de maturidade foram relacionadas com os valores obtidos de EMP (6) e CV (7).

As leituras dos incrementos de crescimento (da leitura 1 até a 5) foram plotadas em dois a dois (ex: leitura 1 vs. leitura 2) em regressão linear para verificar a coincidência entre as contagens. Verificada a variação de consistência da leitura 1 e 5 em relação as demais leituras, para o cálculo de EMP e CV foram utilizados apenas os valores obtidos nas leituras 2, 3 e 4. Para o cálculo da idade dos indivíduos analisados, foram desconsideradas as leituras de idade 1 e 5 pelo motivo destas terem apresentado maiores valores de EMP e CV em relação a todas as leituras realizadas. Foram considerados os valores médios das leituras 2,3 e 4, pois de acordo com a análise da 
regressão linear entre as leituras, os valores de $r^{2}$ foram um dos mais elevados, houve mais coincidência entre os pontos na relação e os valores de EMP foram mais confiáveis (os mais baixos), em relação as leituras desconsideradas.

Foi testada a normalidade dos dados das leituras dos incrementos de crescimento através do teste de Shapiro-Wilk, o qual indicou que os dados eram paramétricos, possibilitando a aplicação do teste $t$ para amostras dependentes, quando diferenças significativas são consideradas quando $p<0,05$ (Zar, 1996). Sendo assim, as contagens realizadas de maneira consecutiva e independente foram comparadas duas a duas através de regressões lineares (2), análise dos valores obtidos de $r^{2}$ e aplicação do teste $t$ para amostras dependentes para verificar diferenças entre as estimações de idade. Para testar a concordância entre as leituras, foi aplicado o teste Wilcox, com auxílio do software R().

\subsubsection{Retro-cálculo da idade}

Assim como nos trabalhos de Perez et al. (2006) e Aguiar (2006), as datas de nascimento foram estimadas através do retro-cálculo da idade, obtido através do número de incrementos de cada exemplar e da data de captura (data de morte). Um gráfico de freqüência relativa (\%) de nascimento por mês e ao ano foi elaborado. Também com os dados obtidos pelo retro-cálculo de idade, curvas de crescimento e taxas de crescimento foram plotadas para as quatro estações climáticas do ano (primavera= outubro a dezembro; verão = janeiro a março; outono = abril a junho; inverno = julho a setembro). Através das curvas de crescimento por época do ano, foi possível comparar as diferentes taxas de crescimento instantânea (G) das lulas.

\subsubsection{Curva de crescimento}

Para estimar os parâmetros da curva de crescimento da espécie na região de estudo, a relação entre os dias de vida da lula com comprimento de manto (ML), foram testados a partir de modelos matemáticos (linear (2), exponencial (3), logarítmico (4) e potencial (5), onde x correspondeu aos valores de idade (dias) e y aos valores do ML ( $\mathrm{mm}$ ), bem como os modelos de crescimento:

$$
\begin{array}{ll}
\text { Gompertz (8): } & \mathrm{y}=L_{\text {inf }} * e^{-a^{*} \exp \left(-b^{*} x\right)} \\
\text { Logístico (9): } & \mathrm{y}=L_{\text {inf }} / 1+e^{(-k(\mathrm{x}-t 0))} \\
\text { von Bertalanffy (10): } & \mathrm{y}=L_{\text {inf }}\left[1-e^{-k(\mathrm{x}-t 0)}\right]
\end{array}
$$


e Schnute (11):

$$
\mathrm{y}=\left[\mathrm{m}_{1}^{b}+\left(\left(\mathrm{m}_{2}^{b}-\mathrm{m}_{1}^{b} / 1-e^{-a(\mathrm{x} 2-\mathrm{x} 1)}\right) * 1-e^{-a(\mathrm{x}-\mathrm{x} 1)}\right)\right]^{1 / b}
$$

onde y é a medida (em mm) de um indivíduo na idade $\mathrm{x}$, onde $\mathrm{x}$ é a idade (em dias), $\mathrm{m}_{1}$ e $\mathrm{m}_{2}$ são os comprimentos de manto extremos (ML mínimo e máximo) nas idades $\mathrm{x}_{1} \mathrm{e}$ $\mathrm{x}_{2}$, sendo que $\mathrm{x}_{1}$ e $\mathrm{x}_{2}$ são as idades extremas (idade mínima e máxima), $a$ é o parâmetro de taxa de crescimento em ML (mm) $\left(\right.$ dia $\left.^{-1}\right), b$ é o parâmetro de curvatura nos modelos de crescimento, sendo que $a$ e $b$ são parâmetros estimados na regressão não linear. Os valores devem respeitar as condições: $a$ e $b \neq 0, \mathrm{~m}_{2}>\mathrm{m}_{1}, \mathrm{x}_{2}>\mathrm{x}>\mathrm{x}_{1}$.

Estas equações foram testadas utilizando o software R@ (R Development Core Team, 2012), com valores iniciais de $\mathrm{m}_{1}$ e $\mathrm{m}_{2}, a$ e $b$, e o modelo fornecendo os valores estimados finais destes quatro parâmetros após uma série de interações. Os valores estimados de $\mathrm{m}_{1}$ e $\mathrm{m}_{2}$, $a$ e $b$ foram transformados nos parâmetros de crescimento dos modelos tradicionais, sendo que $a=k$ (VAZ, 2001). Para o cálculo de $L_{\text {inf }}$ (12) foi utilizada a equação: $\quad L_{\text {inf }}=\left[e^{a^{*} \times 2} * \mathrm{~m}_{2}{ }^{b}-e^{a^{*} \mathrm{x} 1} * \mathrm{~m}_{1}{ }^{b} / e^{a^{*} \mathrm{x} 2}-e^{a^{*} \times 1}\right]^{1 / b}$ e para $t 0(13)$ a equação: $t 0=\mathrm{x}_{1}+\mathrm{x}_{2}-1 / a * \ln \left[e^{a^{* * 2} *} \mathrm{~m}_{2}^{b}-e^{a^{*} \times 1} * \mathrm{~m}_{1}{ }^{b} / \mathrm{m}_{2}{ }^{b}-\mathrm{m}_{1}{ }^{b}\right]$

Para o teste dos modelos von Bertalanffy e Schnute, foi utilizado o pacote FSA do software R@ (OGLE, 2012; R Development Core Team, 2012).

Tendo em vista que o modelo com o menor AIC é aquele que melhor descreve a variabilidade dos dados (AKAIKE, 1973), sendo assim foram estimados os pesos de Akaike (AICw) segundo a fórmula proposta por Arkhipkin \& Roa-Ureta (2005) para escolha do melhor ajuste da curva de crescimento:

$$
\operatorname{AICw}(\operatorname{Mil},\{\mathrm{Mj}\})=\mathrm{e}^{-1 / 2(\operatorname{AICj}-\mathrm{AICmin})} / \sum_{\mathrm{i}}^{\mathrm{j}} \mathrm{e}^{-1 / 2(\operatorname{AICj}-\mathrm{AICmin})}
$$

onde $\{\mathrm{Mj}\}$ são os j modelos testados e $\mathrm{AIC}_{\min }$ é o $\mathrm{AIC}$ do modelo com menor AIC. Os pesos de Akaike variam entre 0 e 1 . Como critério de escolha, são interpretados como o peso da evidência, o modelo testado que mais se aproximar de 1, dentre os outros modelos candidatos (ARKHIPKIN \& ROA-URETA, 2005).

Sendo assim, o melhor ajuste foi escolhido a partir do maior valor de AICw (14) dos modelos testados. Foram construídas curvas de crescimento para as relações: todos os exemplares da amostra, por sexo (fêmeas e machos), juvenis (lulas em estádio de maturidade I), para lulas em maturação e maduras (II e III) e por sexo para os estádios de maturidade II e III. Para algumas das relações proposta (das quais os valores de $r^{2} \mathrm{e}$ AIC não foram demonstrados nas Tabelas dos testes dos modelos matemáticos) não foi possível ajustar todos os modelos matemáticos devido ao comportamento dos dados. 
Sendo assim, os valores de $k, L_{\text {inf }}$ e $t_{0}$ foram subestimados pelo modelo, porém os valores AIC e $r^{2}$ não foram possíveis de serem estimados, por este motivo não há valores nos espaços das Tabelas 15 a 22.

\subsubsection{Longevidade}

A longevidade foi estimada através das médias das idades dos exemplares desovantes (em estágio de maturidade III e IV) para fêmeas e machos separadamente (ZALESKI, 2010). Para comparação, a longevidade proposta pela equação de Taylor (1958) também foi calculada: $\mathrm{A}_{0,95}=(2,996 / k)+\mathrm{t}_{0}$

(SPARRE \& VENEMA, 1997) onde $\mathrm{t}_{0}$ é a idade teórica no comprimento zero $(1,99)$ e $k$ é o coeficiente de crescimento estimado pelo melhor ajuste da curva de crescimento $(0,03)$. Os valores médios da idade por intervalos de comprimento do manto (ML, mm) constam nas Tabelas 23 a 27.

\subsubsection{Taxa de crescimento}

A taxa instantânea de crescimento $(\mathrm{G})$ foi estimada através da equação proposta por Forsythe \& VanHeukelem (1987):

$$
\mathrm{G}=\left(\ln \mathrm{W}_{2}-\ln \mathrm{W}_{1} / \mathrm{T}_{2}-\mathrm{T}_{1}\right) * 100
$$

onde $\mathrm{G}$ é a taxa em $\left.\mathrm{mm} / \mathrm{d}^{-1}\right), \mathrm{W}_{1}$ e $\mathrm{W}_{2}$ são os comprimentos de manto no início e no final do intervalo de tempo $\mathrm{T}_{1}$ e $\mathrm{T}_{2}$. $\mathrm{O}$ intervalo de tempo utilizado foi de 30 dias. Sendo assim, $\mathrm{T}_{1}-\mathrm{T}_{2}=30$ dias. Para $\mathrm{W}_{1}$ foram usados os valores em intervalo de ML de $10 \mathrm{em}$ $10 \mathrm{~mm}$, de indivíduos com valores de ML na data de morte. Com a equação do modelo de crescimento ajustado para a relação ML vs. idade, os valores de $\mathrm{W}_{2}$ foram estimados para cada intervalo de comprimento de ML com a subtração de 30 dias na idade de cada intervalo. Os intervalos estabelecidos por sexo foram determinados de acordo com os valores de máximo e mínimo de ML encontrados na amostragem das fêmeas e machos. Do mesmo modo, os valores de $\mathrm{G}$ foram estimados para lulas em estádio de maturidade I, II e III, como também para fêmeas e machos em estádio II e III. 


\subsubsection{Relação idade e medidas dos estatólitos}

A relação entre SL e idade, como também DL vs. idade foram testadas com os modelos matemáticos: linear (2), exponencial (3), logarítmico (4) e exponencial (5), onde x correspondeu aos valores de idade (em dias) e y aos valores do SL (mm) (para o teste da relação idade-SL), e para a relação idade-DL, x correspondeu aos valores de idade (em dias) e y aos valores do DL (mm).

Foram utilizados os mesmos critérios de escolha do melhor modelo de ajuste, seguindo o padrão de escolha da curva de crescimento da espécie (do maior valor de $\mathrm{AICw}$ e quando houve empate entre os valores, o maior valor de $r^{2}$ foi considerado). Esta análise foi realizada utilizando o software R@ (R Development Core Team, 2012). 


\section{RESULTADOS}

\subsection{Descrição das amostras}

Um total de 424 estatólitos, sendo destes 162 (38,21\%) de indivíduos fêmeas, $137(32,31 \%)$ machos e $125(29,48 \%)$ sem sexo identificado foram amostrados no presente estudo. Os exemplares apresentaram um comprimento de manto médio de $80,30 \mathrm{~mm}$, variando entre 1,58 a $267 \mathrm{~mm}$ ML. A média do ML das fêmeas foi de 122,94 mm e variação de 32 a 210 mm, enquanto que a média de ML dos machos foi de 91,62 mm ML, variando em comprimento de 30 a $267 \mathrm{~mm}$. Os exemplares sem sexo identificado, a média de ML foi de 12,62 mm com amplitude de 1,58 a $71 \mathrm{~mm}$.

As distribuições de frequência do comprimento do manto dos exemplares (total, por sexo e indivíduos sem sexo identificado) são apresentadas em \% na Figura 7. Indivíduos entre 1,58 e $9 \mathrm{~mm}$, e 30 e $59 \mathrm{~mm}$ de ML foram mais representativos na amostragem, com freqüência de ocorrência próxima a $20 \%$ e $17 \%$, destacando também, com frequiência próxima a 8\% lulas com ML entre 140 e 179 mm (Figura 7, A). Dos indivíduos entre 30 e $59 \mathrm{~mm}$ de $\mathrm{ML}$, houve predominância de machos em relação às fêmeas (Figura 7, B-C).

Nos intervalos de comprimento do manto entre 110 a $179 \mathrm{~mm}$, a frequência de fêmeas foi maior do que a de machos. Tendo foco no estudo de indivíduos de pequeno porte, vale destacar (Figura 7A) a presença em maior freqüência de indivíduos entre 0 e 100 mm ML em relação aos outros intervalos de ML, mostra adequação do objetivo principal do presente trabalho.

Exemplares com sexo não identificado (125 juvenis) foram mais freqüentes nos espectros entre $1,58 \mathrm{~mm}$ a $9 \mathrm{~mm}$, porém também foram presentes nas amostras entre as classes de ML entre 30 a 59 mm (Figura 7D). 

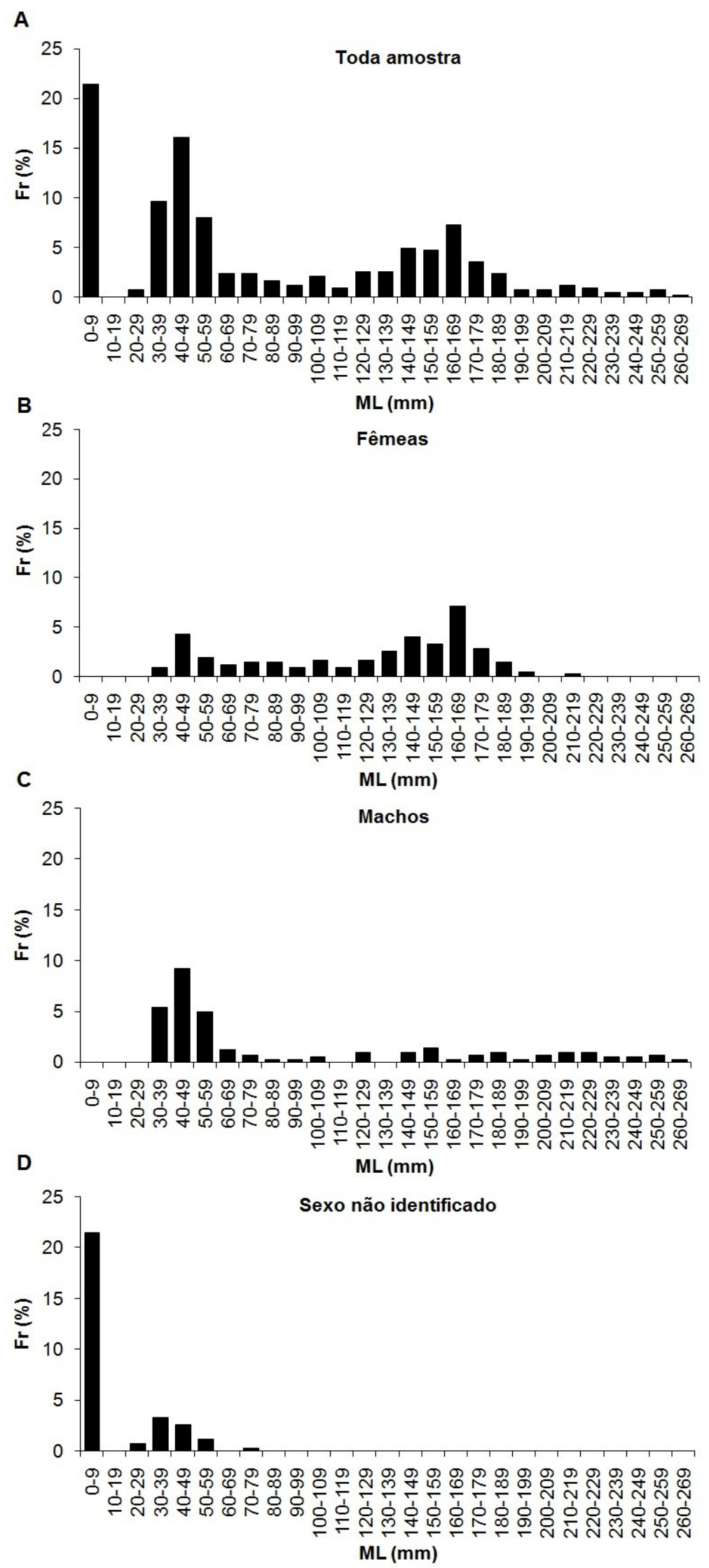

Figura 7 - Distribuição do comprimento do manto (ML) em frequência relativa (Fr) dos exemplares da amostra total (A); fêmeas (B); machos (C) e sexo não identificado (D), na qual destaca a frequência significativa de juvenis. 
O peso médio dos indivíduos em estudo foi de 38,21 g, variando de 1,49 a 167,7 g. As fêmeas pesaram entre 2,32 a 117,26 g, em média de 49,33 g, e os machos, 33,68 g, com variação de 1,9 a 167,7 g (Figura 8A-D). Foi observado que houve em maiores valores em porcentagem de indivíduos machos em relação às fêmeas no espectro de peso entre 0 e $9 \mathrm{~g}$ (Figura 8B-C), enquanto que nos outros estratos de peso as fêmeas foram predominantes. O peso dos indivíduos cujo sexo não foi identificado variou entre 1,49 a 11,33 g, tendo média de 3,67 g (Figura 8D).

A

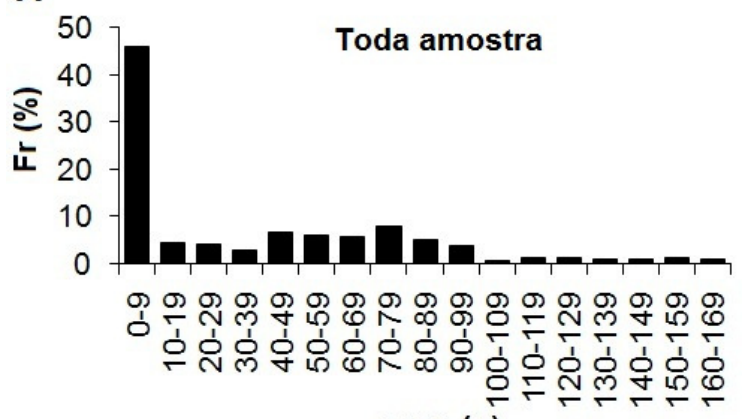

peso $(g)$

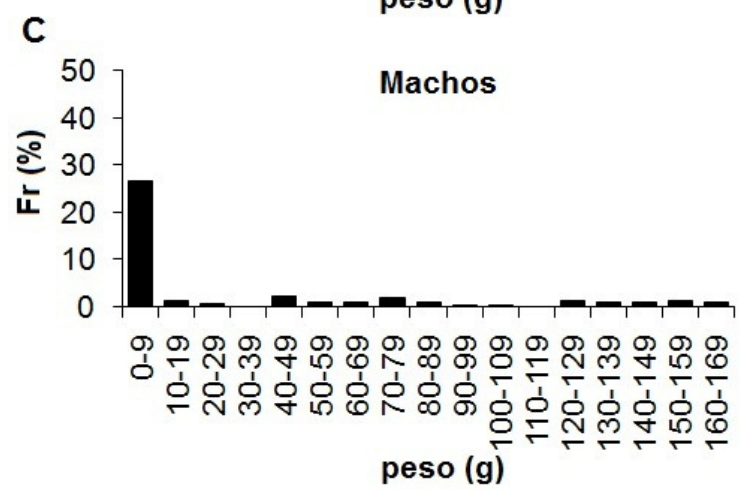

B

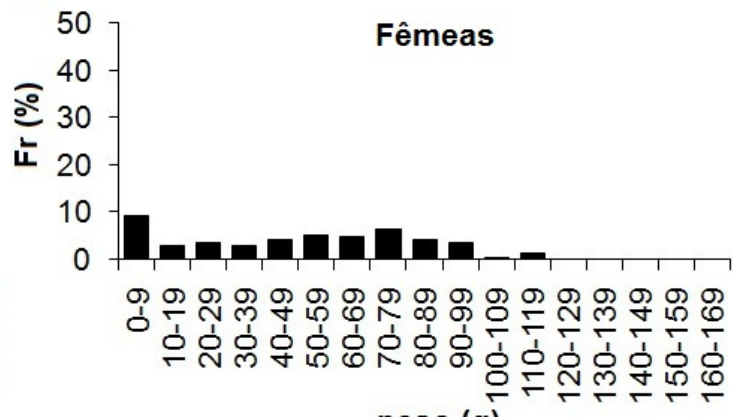

peso $(g)$

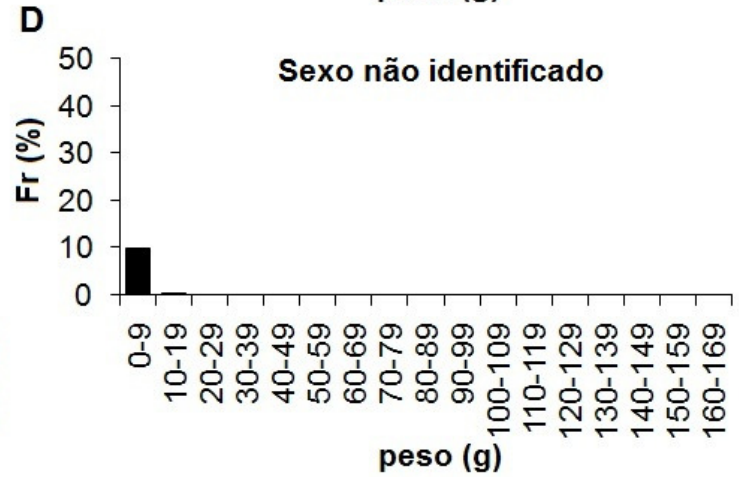

Figura 8 - Distribuição do peso em frequência relativa (Fr) da amostra total (A); fêmeas (B); machos (C) e sexo não identificado (D).

\subsection{Descrição das amostras em estádio de maturação}

O valor médio, desvio padrão, intervalo de variação e número total são apresentados para as medidas de comprimento de manto (ML) e peso por estádios de maturação (Tabela 3 a 5). 
Tabela 3 - Valores médios de comprimento do manto e peso, por estádios de maturidade dos todos exemplares, onde: número de exemplares amostrados $(\mathrm{n})$, média $(\mathrm{Md})$, desvio padrão (Dp), intervalo de comprimento de manto (ML) e peso (g, em gramas). O número de exemplares (n) amostrados para o cálculo da média, desvio padrão e do intervalo de peso para os juvenis em estádio de maturidade I foi de 58 exemplares.

Total

\begin{tabular}{|c|c|cc|cc|}
\hline \multirow{2}{*}{ Maturação } & \multirow{2}{*}{$\mathbf{n}$} & \multicolumn{2}{|c|}{ ML (mm) } & \multicolumn{2}{c|}{ Peso (g) } \\
& & Md \pm Dp & Intervalo & Md \pm Dp & Intervalo \\
\hline I & 125 & $12,62 \pm 17,99$ & $1,58-71$ & $3,55 \pm 1,86$ & $1,49-11,33$ \\
II & 166 & $67,69 \pm 39,69$ & $30-176$ & $16,09 \pm 21,79$ & $1,90-94,83$ \\
III & 130 & $159,91 \pm 42,09$ & $66-267$ & $75,04 \pm 35,74$ & $12,25-167,70$ \\
IV & 3 & $148 \pm 14,18$ & $132-159$ & $59,10 \pm 7,42$ & $50,81-65,11$ \\
\hline
\end{tabular}

Exemplares em estádio de maturidade II foram predominantes $(39,15 \%)$, enquanto os estádios III e I apresentaram valores próximos (30,66\% e 29,48\%, respectivamente) e com menor representação na amostragem o estádio IV $(0,80 \%)$ (Figura 9).

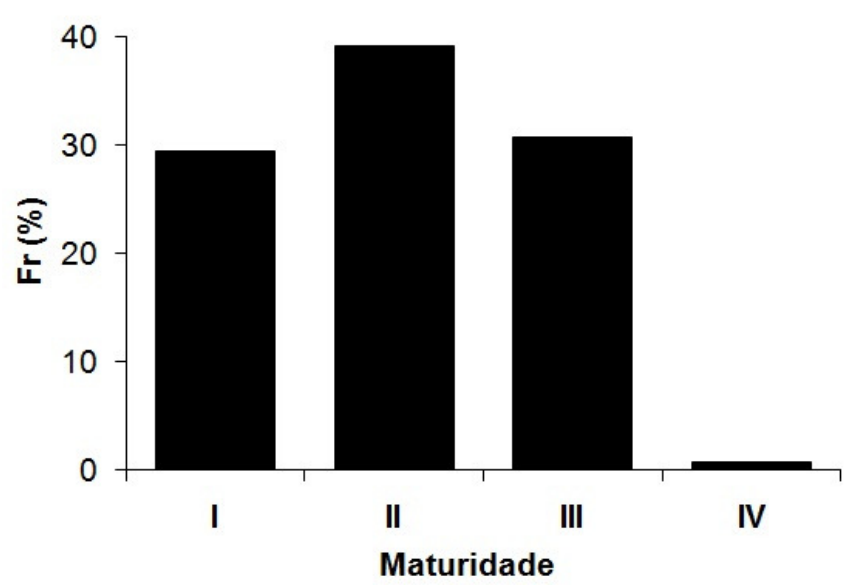

Figura 9 - Distribuição de frequência (Fr) de exemplares por estádios de maturidade.

As Tabelas 4 e 5 apresentam os valores médios de ML e peso de estádio de maturação por sexo, sendo a Tabela 4 referente aos valores das fêmeas e a Tabela 5 para machos. O estádio de maturidade II foi melhor representado pelos machos, com 103 lulas (Tabela 5) e 63 fêmeas (Tabela 4). A distribuição das freqüências (\%) os estádios de maturidade por sexo é representado na Figura 10. 
Tabela 4 - Valores médios de comprimento do manto e peso, de fêmeas por estádios de maturidade (II - IV), onde: número de exemplares (n), média (Md), desvio padrão (Dp), intervalo de comprimento de manto (ML) e peso (g, em gramas).

\section{Fêmeas}

\begin{tabular}{|c|c|cc|cc|}
\hline \multirow{2}{*}{ Maturação } & \multirow{2}{*}{$\mathbf{n}$} & \multicolumn{2}{|c|}{ ML (mm) } & \multicolumn{2}{c|}{ Peso (g) } \\
& & Md \pm Dp & Intervalo & Md \pm Dp & Intervalo \\
\hline II & 63 & $86,43 \pm 46,99$ & $32-176$ & $26,32 \pm 27,29$ & $2,32-94,83$ \\
III & 97 & $146,19 \pm 32,24$ & $66-210$ & $64,12 \pm 25,38$ & $12,25-117,26$ \\
IV & 2 & $145,50 \pm 19,10$ & $132-159$ & $56,10 \pm 7,49$ & $50,81-61,40$ \\
\hline
\end{tabular}

Tabela 5 - Valores médios de comprimento do manto e peso, de machos por estádios de maturidade (II - IV), onde: número de exemplares (n), média (Md), desvio padrão (Dp), intervalo de comprimento de manto (ML) e peso (g, em gramas).

\begin{tabular}{|c|c|cc|cc|}
\multicolumn{9}{|c|}{ Machos } \\
\multirow{2}{*}{ Maturação } & \multirow{2}{*}{$\mathbf{n}$} & \multicolumn{2}{|c|}{ ML (mm) } & \multicolumn{2}{c|}{ Peso (g) } \\
& & Md \pm Dp & Intervalo & Md \pm Dp & Intervalo \\
\hline II & 103 & $56,23 \pm 25,38$ & $30-160$ & $9,84 \pm 15,53$ & $1,90-80,42$ \\
III & 33 & $200,21 \pm 42,17$ & $69-267$ & $107,11 \pm 42,37$ & $15,14-167,70$ \\
IV & 1 & 153 & 153 & 65,11 & 65,11 \\
\hline
\end{tabular}

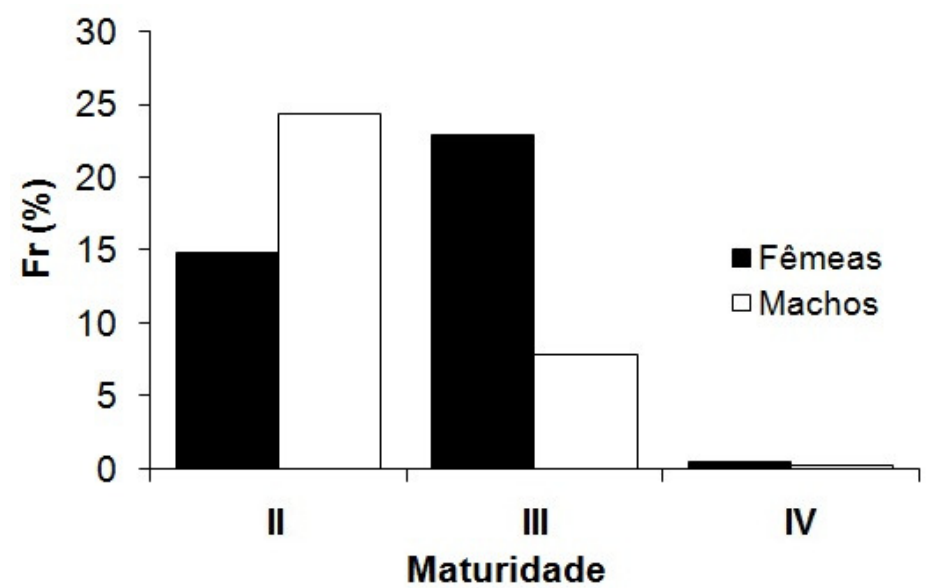

Figura 10 - Distribuição de frequência (Fr) por estádios de maturidade por sexo.

Foram construídos gráficos de frequência relativa (\%) referente ao espectro de comprimento de manto (ML) das lulas para os estádios de maturidade II e III (Figuras 11A e B). A frequência relativa (\%) para exemplares em estádio I já foi descrita anteriormente e apresentada na Figura 7D. Foram mais freqüentes lulas entre 30 e 59 mm de ML no estádio de maturidade II (Fig. 11A) e lulas entre 140 e 189 no estádio III (Fig. 11B). 


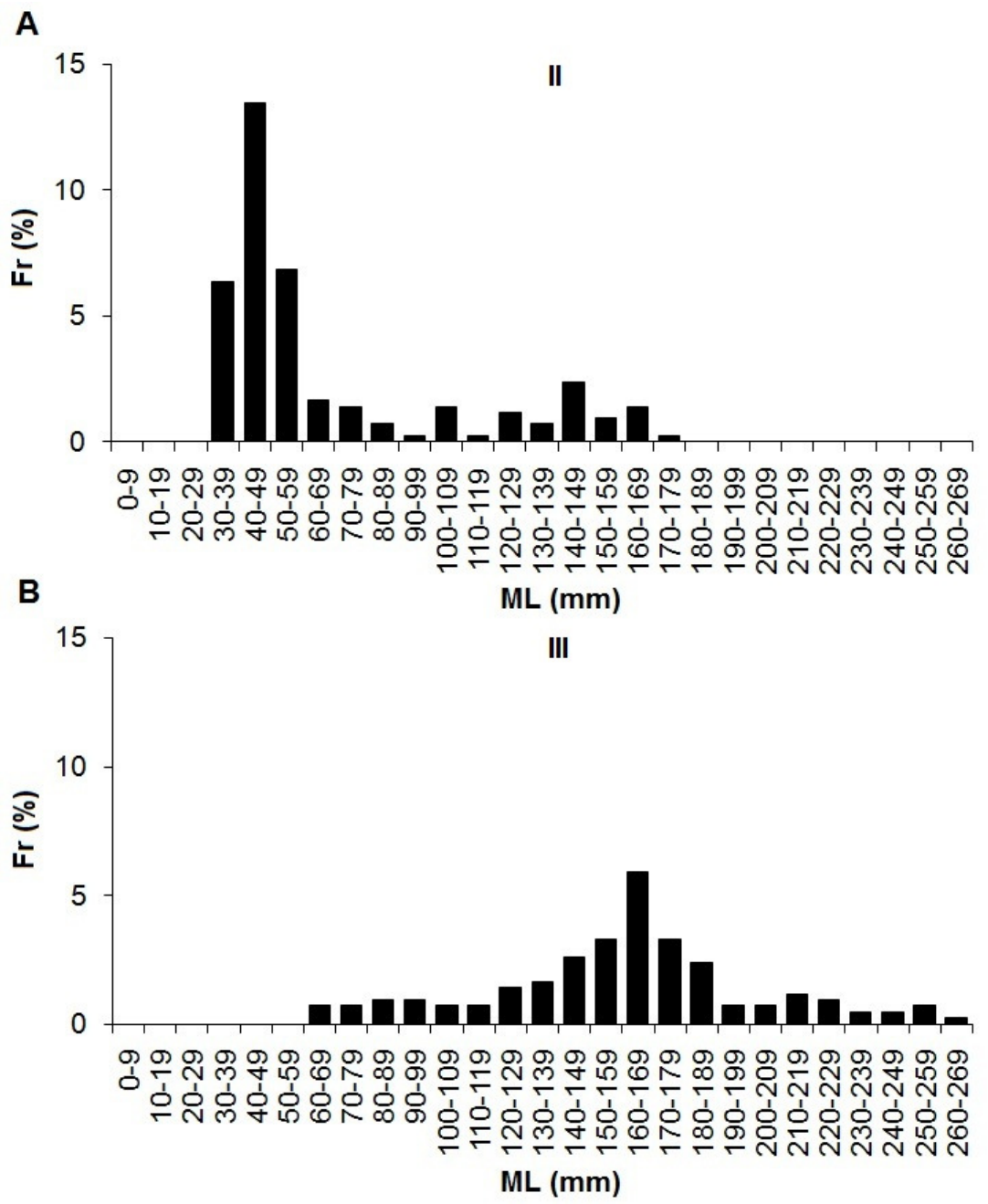

Figura 11 - Distribuição em frequência (Fr) de comprimento de manto (ML) para os estádios de maturidade II (A) e III (B).

Lulas em estádio de maturidade IV foram pouco frequentes na amostra (apenas três lulas, sendo duas fêmeas que variaram em ML 132 e 159 mm, e um macho, com $153 \mathrm{~mm}$ ML), não chegando a $1 \%$ nos espectros de comprimento de 130 a $139 \mathrm{~mm}$ e 150 a 159 mm de ML. Do intervalo de ML de 30 a 59 mm do estádio de maturidade II, a presença dos machos foi mais frequente (entre 5 e 9\%); já para o estádio III, no intervalo entre 140 e $189 \mathrm{~mm}$ de ML, as fêmeas foram mais freqüentes (Fig. 12A-D). 
A

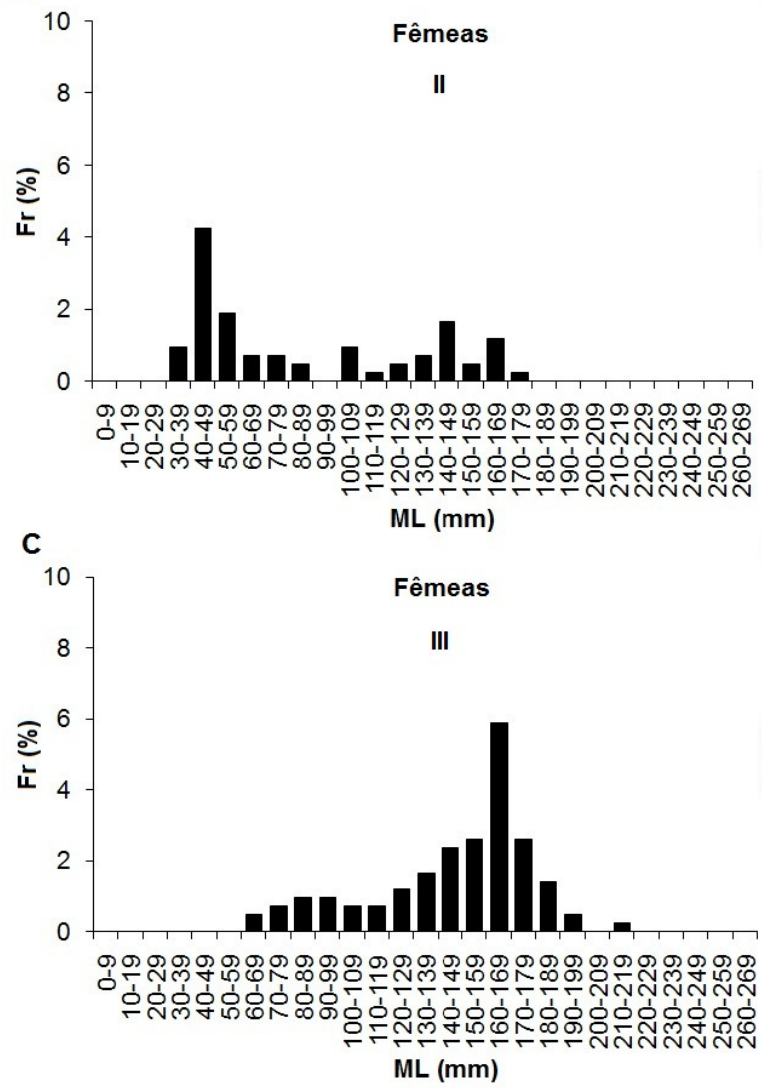

B

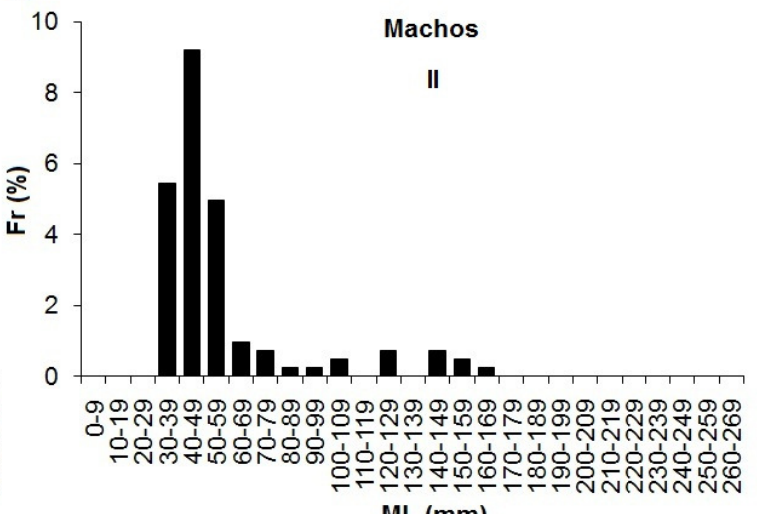

ML (mm)

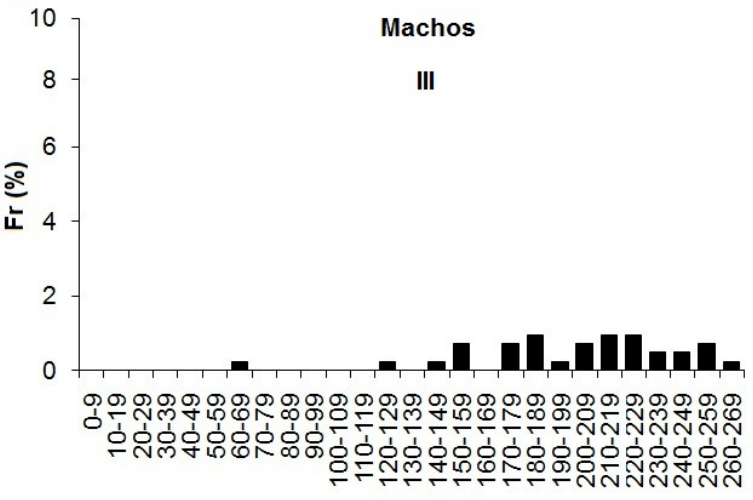

$M L(m m)$

Figura 12 - Distribuição da frequência (Fr) de comprimento do manto (ML) para fêmeas (A e C) e machos (B e D) para os estádios de maturidade II (A e B) e III (C e D).

A mesma análise gráfica feita em relação aos estádios de maturidade (II e III) foi conduzida para o peso (g) dos exemplares (Figura 13). O peso predominante (\%) das lulas em estádio de maturidade II foi de até 9 gramas (Figura 13A). Já para as lulas em estádio II foi entre 70 e 99 gramas (Figura 13B) quando que as fêmeas foram mais freqüentes (próximo a 3\%) neste estrato de peso (Figura 14C-D). O peso das lulas em estádio IV variou entre 50,81 e 65,11 gramas, sendo a média do peso das fêmeas de $56,10 \mathrm{~g}$ enquanto que o peso dos machos foi $65,11 \mathrm{~g}$. 

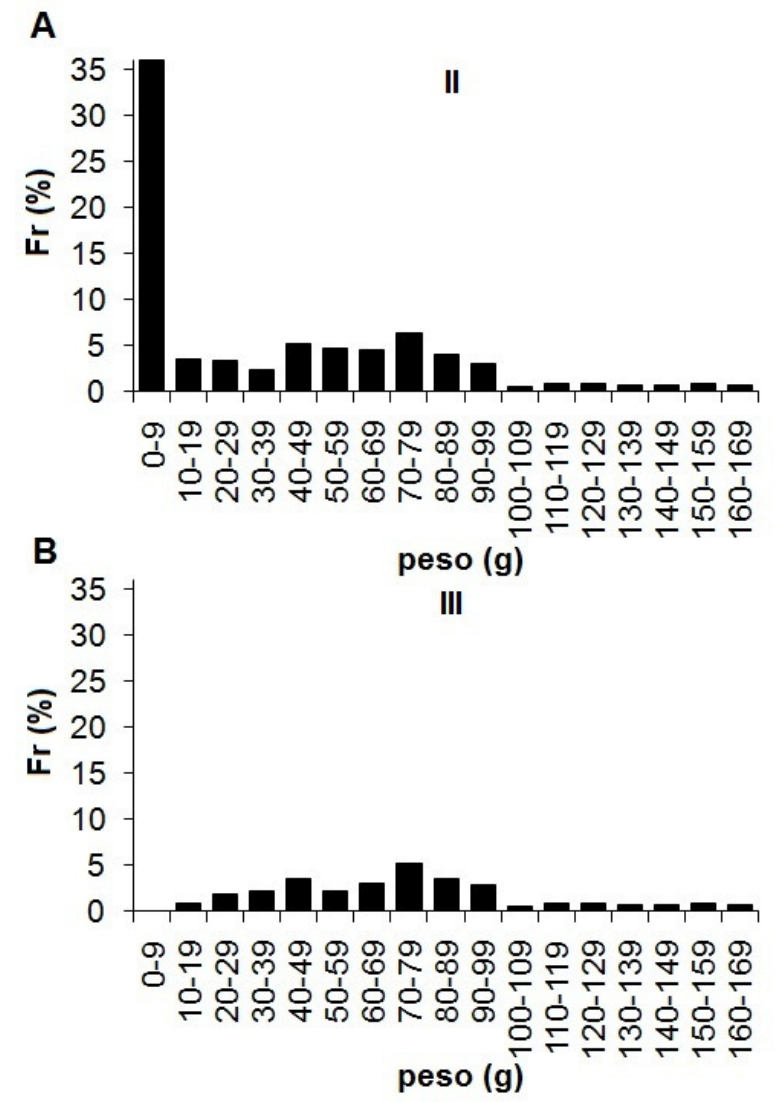

Figura 13 - Distribuição de frequência (Fr) por classes de peso, para os estádios de maturidade II (A) e III (B).
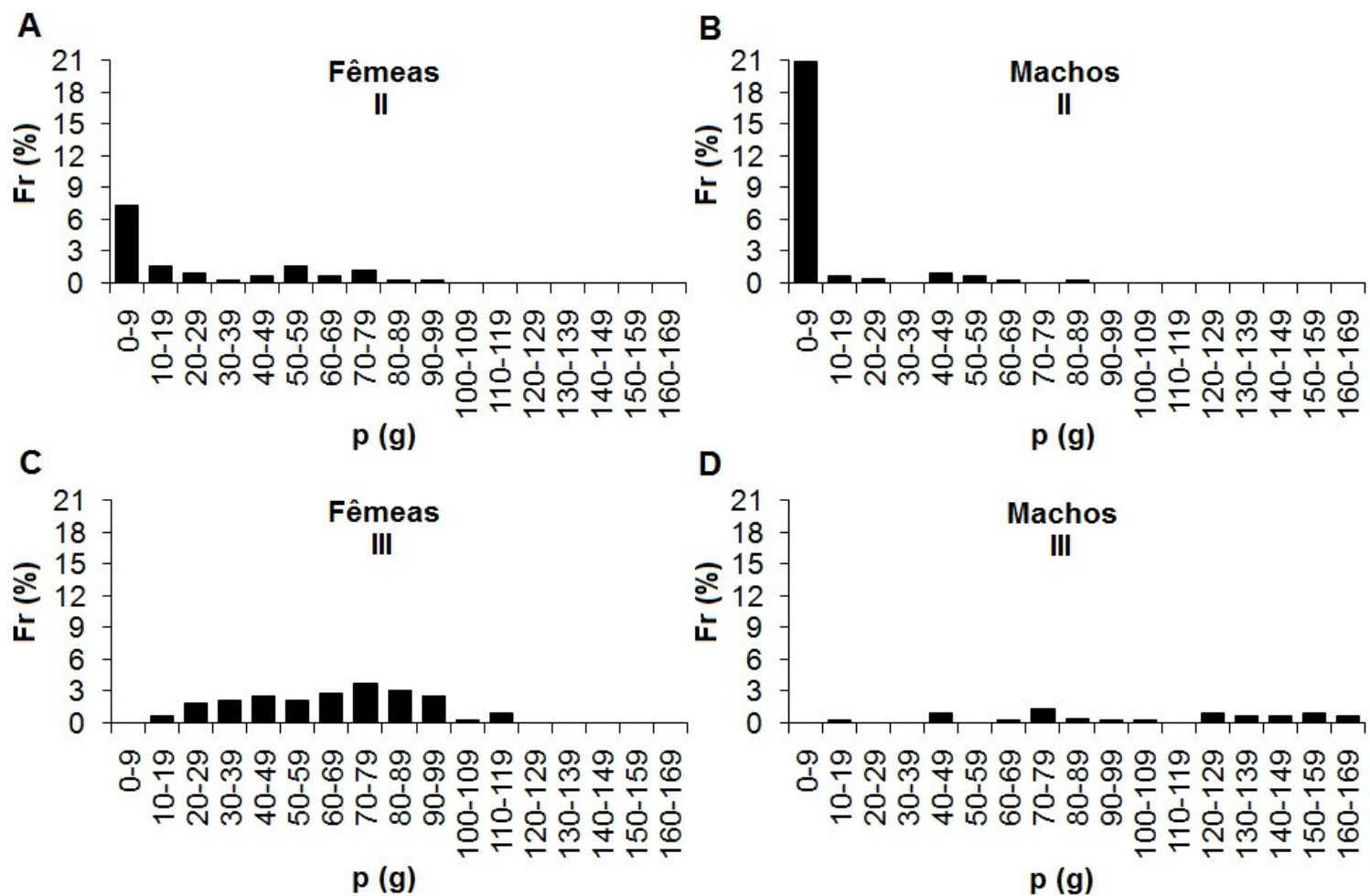

Figura 14 - Distribuição da frequência (Fr) por classes de peso para fêmeas (A e C) e machos (B e D) para os estádios de maturidade II (A e B) e III (C e D). 


\subsection{Comprimento de primeira maturação sexual}

O comprimento do manto (ML) em que ao menos $50 \%$ das fêmeas e machos, estavam aptos para reprodução $\left(\mathrm{L}_{50}\right)$ foi estimado em 146,25 mm para as fêmeas e 198,97 mm para machos (Tabela 6 e Figura 15). Dos exemplares em estádio de maturação III, a fêmea com menor comprimento do manto apresentou $152 \mathrm{~mm}$ ML e o macho, 200,7 mm ML (ver intervalo de ML por estágio de maturidade, Tabela 27).

A variação entre os valores obtidos de $\mathrm{L}_{50}$ por estudos prévios, como os de Perez et al. (2002), Martins \& Perez (2007), Rodrigues (2007), Postuma (2010) e Postuma \& Gasalla (2014), juntamente com os estimados no presente estudo foram de 97-146,25 mm ML, com média em 132,1 mm ML para as fêmeas e para os machos, 146,8-215 mm ML, com média em 188,4 mm ML.

Tabela 6 - Comprimento médio de primeira maturação $\left(\mathrm{L}_{50}\right)$, em mm, estimados para fêmeas (F) e machos (M), com seus respectivos valores de $a$ e $b$ da função: $p=1 /(1+\exp (-a+b *$ $\mathrm{ML})$ ).

\begin{tabular}{|c|c|c|c|}
\hline Sexo & $\boldsymbol{a}$ & $\boldsymbol{b}$ & $\mathbf{L}_{\mathbf{5 0}}(\boldsymbol{a} / \boldsymbol{b})$ \\
\hline Fêmeas & $-8,2194$ & $-0,0562$ & 146,25 \\
Machos & $-8,4163$ & $-0,0423$ & 198,97 \\
\hline
\end{tabular}
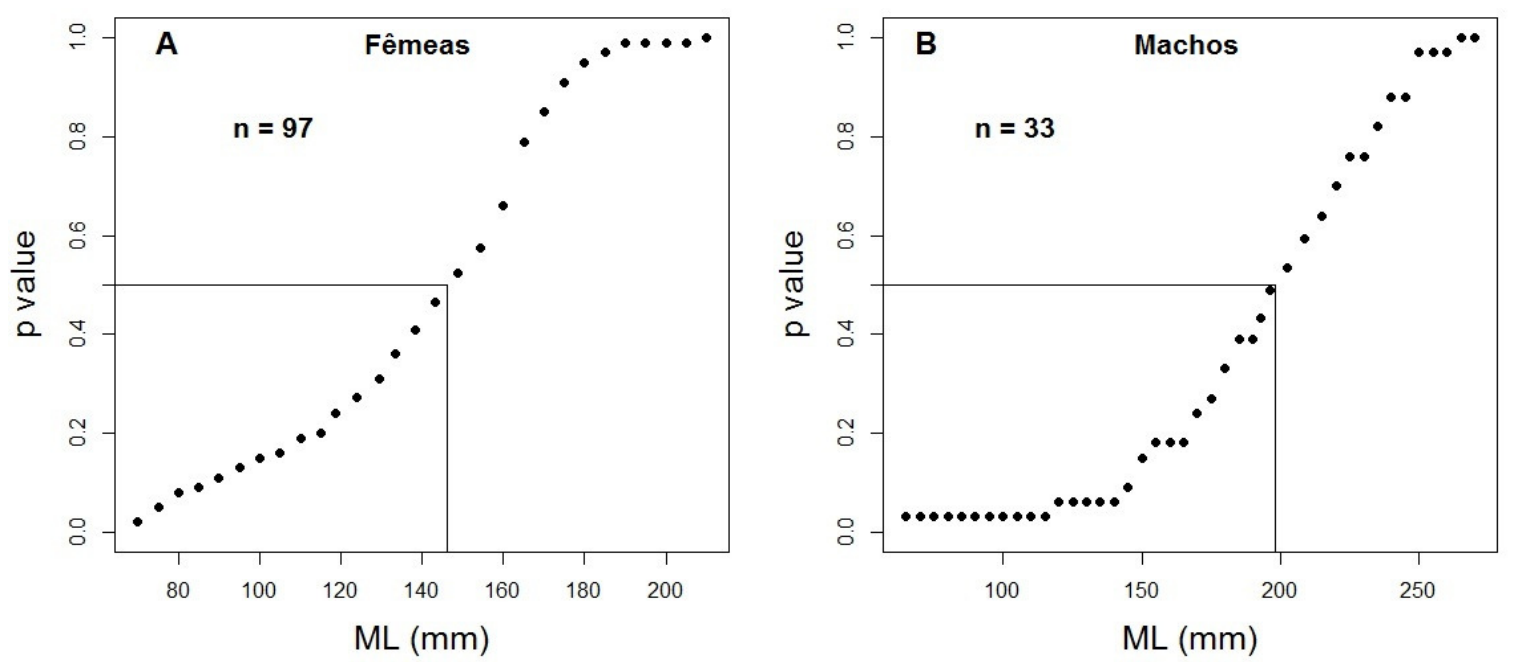

Figura 15 - Comprimento médio de primeira maturação $\left(L_{50}\right)$ estimado para fêmeas $(A)$ e machos (B). 


\subsection{Relação comprimento-peso}

O melhor ajuste da relação entre $\mathrm{ML}(\mathrm{mm})$ e peso $(\mathrm{g})$, para todas as relações utilizadas (total, por sexo, juvenis, por estádio de maturidade e por sexo em estádio de maturidade) foi melhor ajustada pelo modelo potencial, de acordo com os maiores valores de $r^{2}$ e menores valores de AIC. A Tabela 7 exibe os modelos de ajuste utilizados na relação, com valores dos parâmetros da equação $(a ; b)$, número de exemplares na amostra (n) $r^{2}$ e AIC. O coeficiente de determinação $\left(r^{2}\right)$ variou entre 0,86 (indivíduos juvenis), 0,98 para fêmeas e machos e 0,98 para amostra total. Tal relação mostrou que há relação de ganho em peso conforme ocorre o crescimento da lula, podendo destacar maior ganho (em maior taxa) quanto maior for o comprimento de manto (ML) da lula (Figura 16). 
Tabela 7 - Modelos de ajuste testados (linear, potencial, logarítmico e exponencial) para a relação entre comprimento do manto (ML, mm) e peso (g), com os valores de $a$ e $b$ das equações testadas, número de exemplares amostrados (n) $r^{2}$ e AIC para o total, para fêmeas (F), machos (M), juvenis, e por estádio de maturidade (II e III).

\begin{tabular}{|c|c|c|c|c|c|}
\hline \multicolumn{6}{|c|}{ Total } \\
\hline Modelo & $\mathbf{n}$ & \begin{tabular}{l|l|}
$a$ \\
\end{tabular} & $b$ & $r^{2}$ & AIC \\
\hline linear & & 0,636 & $-26,54$ & 0,94 & 2481,462 \\
\hline potencial & 232 & 0,001 & 2,13 & 0,98 & 2272,424 \\
\hline logarítmico & 353 & 56,740 & $-212,60$ & 0,83 & 2825,538 \\
\hline exponencial & & 1,818 & 0,02 & 0,92 & 2272,424 \\
\hline \multicolumn{6}{|c|}{ Fêmeas } \\
\hline Modelo & $\mathbf{n}$ & $a$ & $\boldsymbol{b}$ & $r^{2}$ & AIC \\
\hline linear & & 0,631 & $-28,29$ & 0,92 & 1182,045 \\
\hline potencial & 162 & 0,001 & 2,11 & 0,98 & 1123,373 \\
\hline logarítmico & 102 & 57,540 & $-221,40$ & 0,83 & 1293,359 \\
\hline exponencial & & 2,252 & 0,02 & 0,92 & 1123,373 \\
\hline \multicolumn{6}{|c|}{ Machos } \\
\hline Modelo & $\mathbf{n}$ & a & $b$ & $r^{2}$ & AIC \\
\hline linear & & 0,671 & $-27,85$ & 0,95 & 1046,832 \\
\hline potencial & 137 & 0,001 & 2,08 & 0,98 & 920,397 \\
\hline logarítmico & 151 & 65,650 & $-246,50$ & 0,85 & 1198,618 \\
\hline exponencial & & 1,947 & 0,02 & 0,94 & 920,397 \\
\hline \multicolumn{6}{|c|}{ Juvenis } \\
\hline Modelo & $\mathbf{n}$ & $a$ & $b$ & $r^{2}$ & AIC \\
\hline linear & & 0,173 & $-3,53$ & 0,84 & 81,947 \\
\hline potencial & 34 & 0,004 & 1,76 & 0,85 & 65,394 \\
\hline logarítmico & 34 & 6,983 & $-22,16$ & 0,75 & 96,340 \\
\hline exponencial & & 0,586 & 0,04 & 0,86 & 65,394 \\
\hline
\end{tabular}


Continuação Tabela 7

\begin{tabular}{|c|c|c|c|c|c|}
\hline \multicolumn{6}{|c|}{ Maturidade II } \\
\hline Modelo & $\mathbf{n}$ & $a$ & $b$ & $r^{2}$ & AIC \\
\hline inear & \multirow{4}{*}{166} & 0,531 & $-19,85$ & 0,94 & 1042,184 \\
\hline potencial & & 0,001 & 2,13 & 0,98 & 924,817 \\
\hline logarítmico & & 41,220 & $-152,10$ & 0,85 & 1184,764 \\
\hline cial & & 1,403 & 0,04 & 0,93 & 924,817 \\
\hline \multicolumn{6}{|c|}{ Maturidade III } \\
\hline & $\mathbf{n}$ & $a$ & $\boldsymbol{b}$ & $r^{2}$ & AIC \\
\hline inear & \multirow{4}{*}{130} & 0,803 & $-53,49$ & 0,90 & 1009,564 \\
\hline potencial & & 0,008 & 1,77 & 0,93 & 982,298 \\
\hline logarítmico & & 109,100 & $-474,60$ & 0,80 & 1092,910 \\
\hline expo & & 9,212 & 0,01 & 0,90 & 982,298 \\
\hline \multicolumn{6}{|c|}{ Maturidade II F } \\
\hline & $\mathbf{n}$ & $a$ & $\boldsymbol{b}$ & $r^{2}$ & AIC \\
\hline linear & \multirow{4}{*}{63} & 0,562 & $-22,25$ & 0,94 & 426,439 \\
\hline potencial & & 0,001 & 2,14 & 0,97 & 400,053 \\
\hline logarítmico & & 46,390 & $-173,70$ & 0,87 & \\
\hline vo & & 1,580 & 0,02 & 0,95 & 400,053 \\
\hline \multicolumn{6}{|c|}{ Maturidade II M } \\
\hline & $\mathbf{n}$ & $a$ & $\boldsymbol{b}$ & $r^{2}$ & AIC \\
\hline linear & \multirow{4}{*}{103} & 0,476 & $-16,95$ & 0,92 & 585,692 \\
\hline potencial & & 0,001 & 2,11 & 0,92 & 459,238 \\
\hline logarítmico & & 33,750 & $-123,10$ & 0,80 & 682,157 \\
\hline & & 1,299 & 0,03 & 0,89 & 459,238 \\
\hline \multicolumn{6}{|c|}{ Maturidade III F } \\
\hline & $\mathbf{n}$ & $a$ & $b$ & $r^{2}$ & AIC \\
\hline linear & \multirow{4}{*}{97} & 0,729 & $-42,44$ & 0,86 & 718,794 \\
\hline potencia & & 0,007 & 1,80 & 0,90 & 700,116 \\
\hline logar & & 87,360 & $-368,70$ & 0,80 & 752,119 \\
\hline & & 6,916 & 0,01 & 0,91 & 700,116 \\
\hline \multicolumn{6}{|c|}{ Maturidade III M } \\
\hline Model & & $a$ & $b$ & $r^{2}$ & AIC \\
\hline linear & \multirow{4}{*}{33} & 0,945 & $-82,10$ & 0,88 & 274,593 \\
\hline & & 0,003 & 1,97 & 0,94 & 269,408 \\
\hline logarítmico & & 143,900 & $-651,70$ & 0,78 & 295,963 \\
\hline exponencial & & 8,571 & 0,01 & 0,93 & 269,408 \\
\hline
\end{tabular}


A

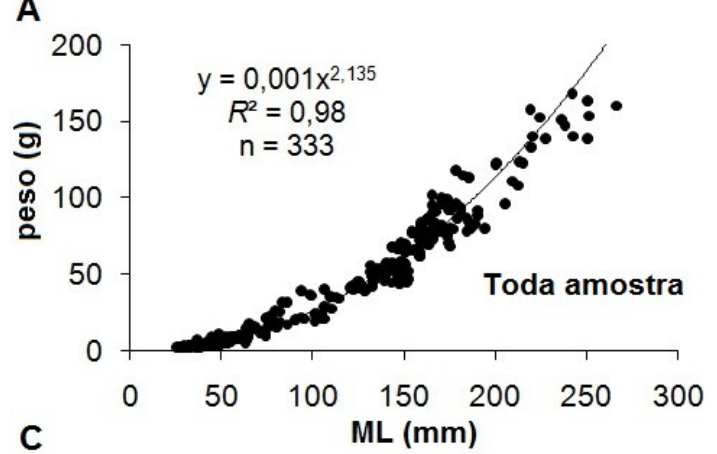

C

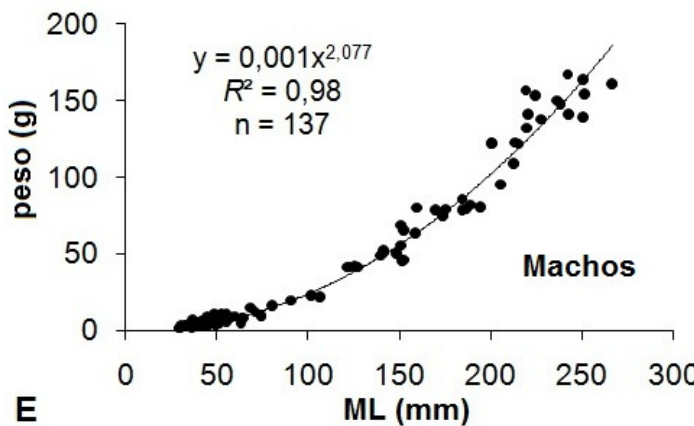

E

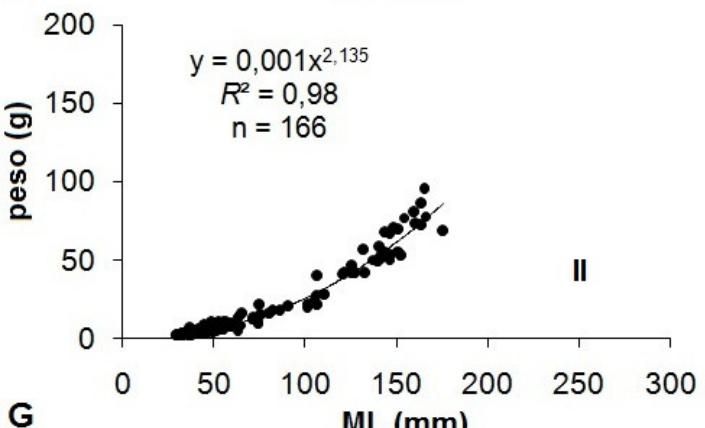

G
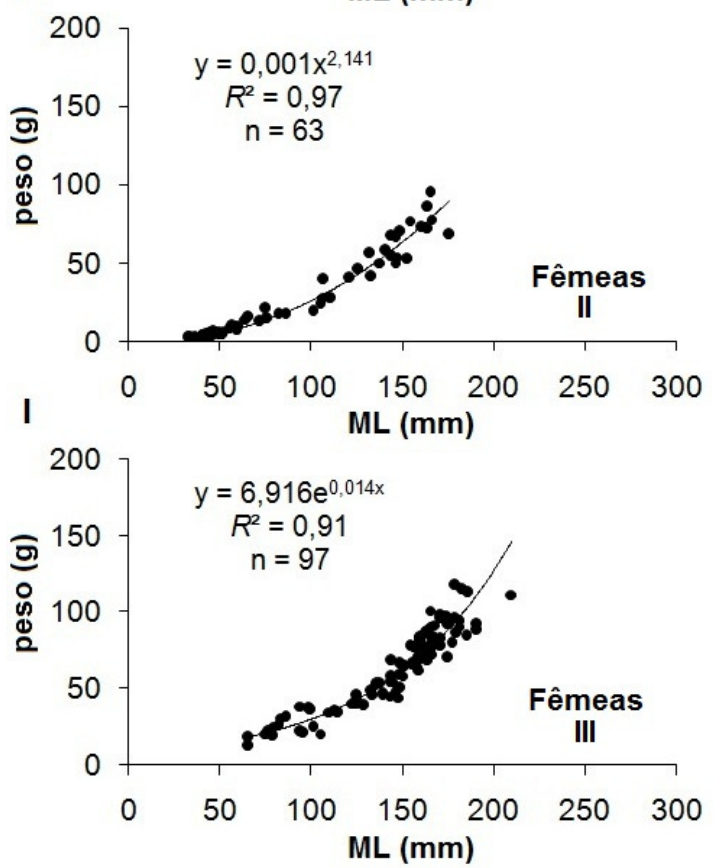

B
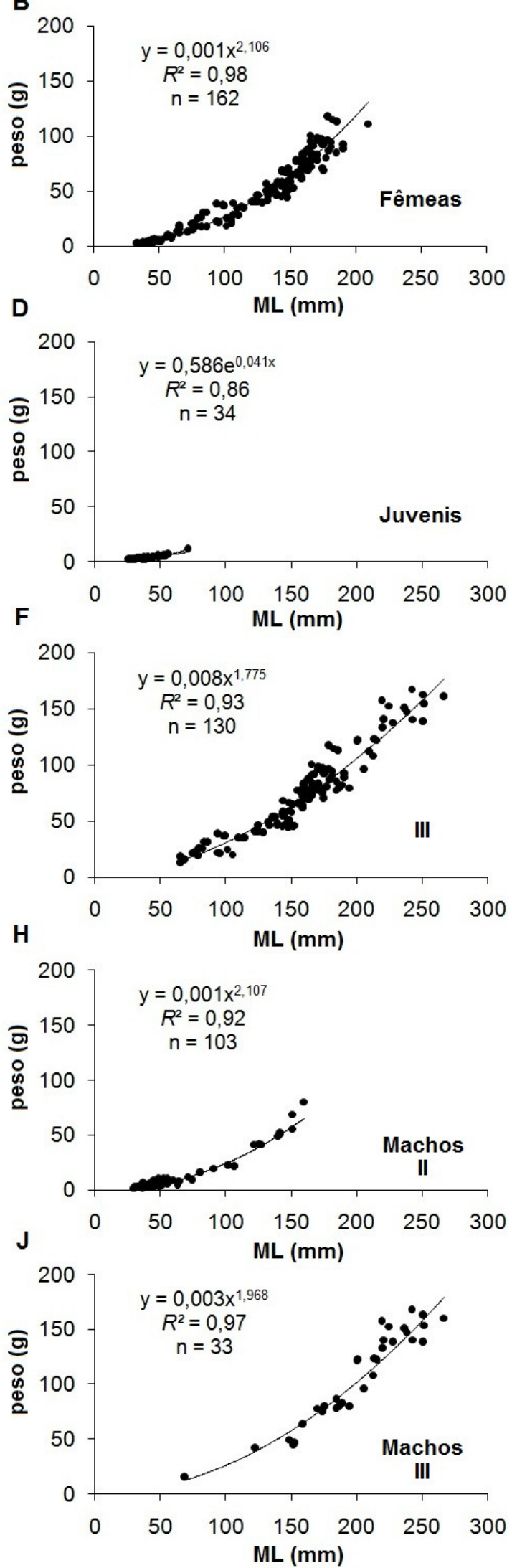

Figura 16 - Relação entre comprimento do manto (ML) e peso dos exemplares da amostra total (A); Fêmeas (B); Machos (C); Juvenis (D); Estádios de maturidade II (E) e III (F); e por estádios de maturidade II e III por sexo: para fêmeas $(\mathrm{G})$ e (I), e para machos (H) e (J). 


\subsection{Características dos estatólitos de $D$. plei}

\subsubsection{Morfologia e morfometria}

Para a descrição da morfologia e morfometria dos estatólitos das lulas estudadas, foram utilizados estatólitos de 390 lulas, 223 eram fêmeas, 140 machos e 27 juvenis, com média de comprimento de manto de 112,06 mm e amplitude entre 25 e $291 \mathrm{~mm}$ ML. A média de ML para fêmeas e machos foi de 126,71 mm e os juvenis apresentaram média de tamanho de 44,48 mm ML.

Os estatólitos apresentaram coloração esbranquiçada. Com uma fina superfície acidentada, compreendendo em média $28,51 \%$ da área do estatólito, a asa apresentou, em geral, coloração mais esbranquiçada em relação às outras porções da estrutura. Os domos e o rostro se caracterizaram por serem translúcidos, principalmente quando submersos em água, em comparação com a porção da asa. A maior parte dos estatólitos é constituída pelas porções do domo lateral e dorsal e pelo rostro, ocupando 71,49\% em área (Figura 4). O rostro é estreito medialmente e se estende até a extremidade da asa, que tem uma ponta relativamente acentuada (Figura 4). O rostro tende a se tornar afunilado conforme o crescimento (Figura 17).

A média de comprimento dos estatólitos foi de $1,35 \mathrm{~mm}$, variando entre 0,8 a 1,83 mm SL (Tabela 8). A média do ângulo do domo dorsal (ÂD) foi de $161,87^{\circ}$, variando de 123,14 a $179,81^{\circ}$. Não entanto, a média de ÂD de juvenis foi próxima de $180^{\circ}$. A média do ângulo do rostro (ÂR) foi de $140,51^{\circ}$ (amplitude: 114,63 a 166,64º ). A Tabela 8 e a Figura 19 exibem outros resultados obtidos sobre as medidas extraídas dos estatólitos.

\subsubsection{Diferenciação dos estatólitos de machos e fêmeas}

Não houve diferenças visuais marcantes sobre a morfologia e a morfométricas entre estatólitos de fêmeas e machos (teste Kruskal-Wallis $p=1$; ANCOVA $p=0,83$ ). 


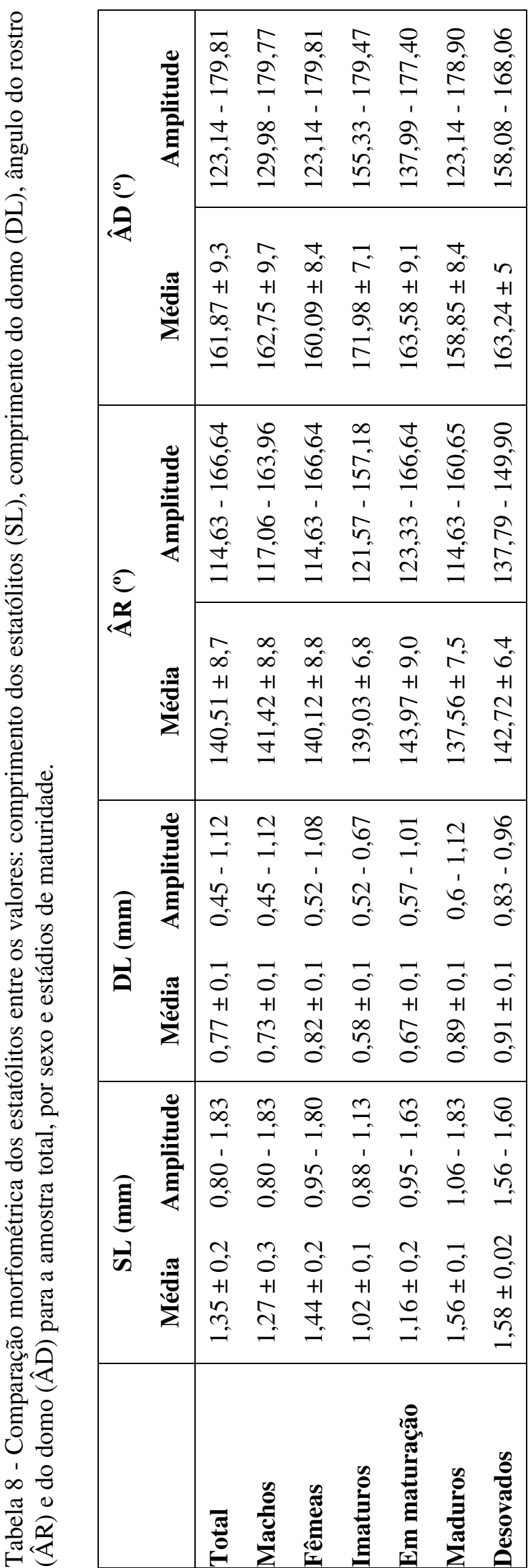




\subsubsection{Descrição dos estatólitos por tamanho e estádios de maturidade}

Foi observada tendência de afunilamento nas extremidades do rostro e dos domos conforme o crescimento de D. plei. A Figura 17 apresenta as principais mudanças em estatólitos entre 0,85-1,83 mm SL em relação ao tamanho da lula (25-263 $\mathrm{mm}$ ML).

Indivíduos entre 25-100 mm ML apresentaram estátolitos com média de 1,18 mm SL, domos arredondados e ângulo do domo próximo a $180^{\circ}$, o ângulo do rostro variou entre $121^{\circ}$ a $166^{\circ}$ (Figura 17A-G). Lulas entre 101-200 mm ML apresentaram expansão das áreas do domo, rostro e asa, apresentando variação do ÂD de $123^{\circ}$ à $179^{\circ}$, e SL entre 1,34-1,80 mm (Figura 17H-M e O). Em indivíduos maiores do que $200 \mathrm{~mm}$ ML, a média de SL foi de 1,45 $\mathrm{mm}$ e, em geral, os estátolitos apresentaram proeminência no domo dorsal e lateral (Figura $17 \mathrm{~N}$ e P).

Os estatólitos de exemplares de D. plei imaturos (Figura 18A) são caracterizados por possuírem tamanho em média de 1,02 mm (variando entre 0,88-1,13 mm) (Tabela 8). Alguns estatólitos de imaturos apresentaram uma pequena mancha azul escura na região do domo (Fig. 18A). O rostro possui formato cônico e os domos são arredondados. O ângulo do rostro é mais acentuado em juvenis $\left(139,03^{\circ}\right)$, formando uma borda (Tabela 8; Fig. 18). 


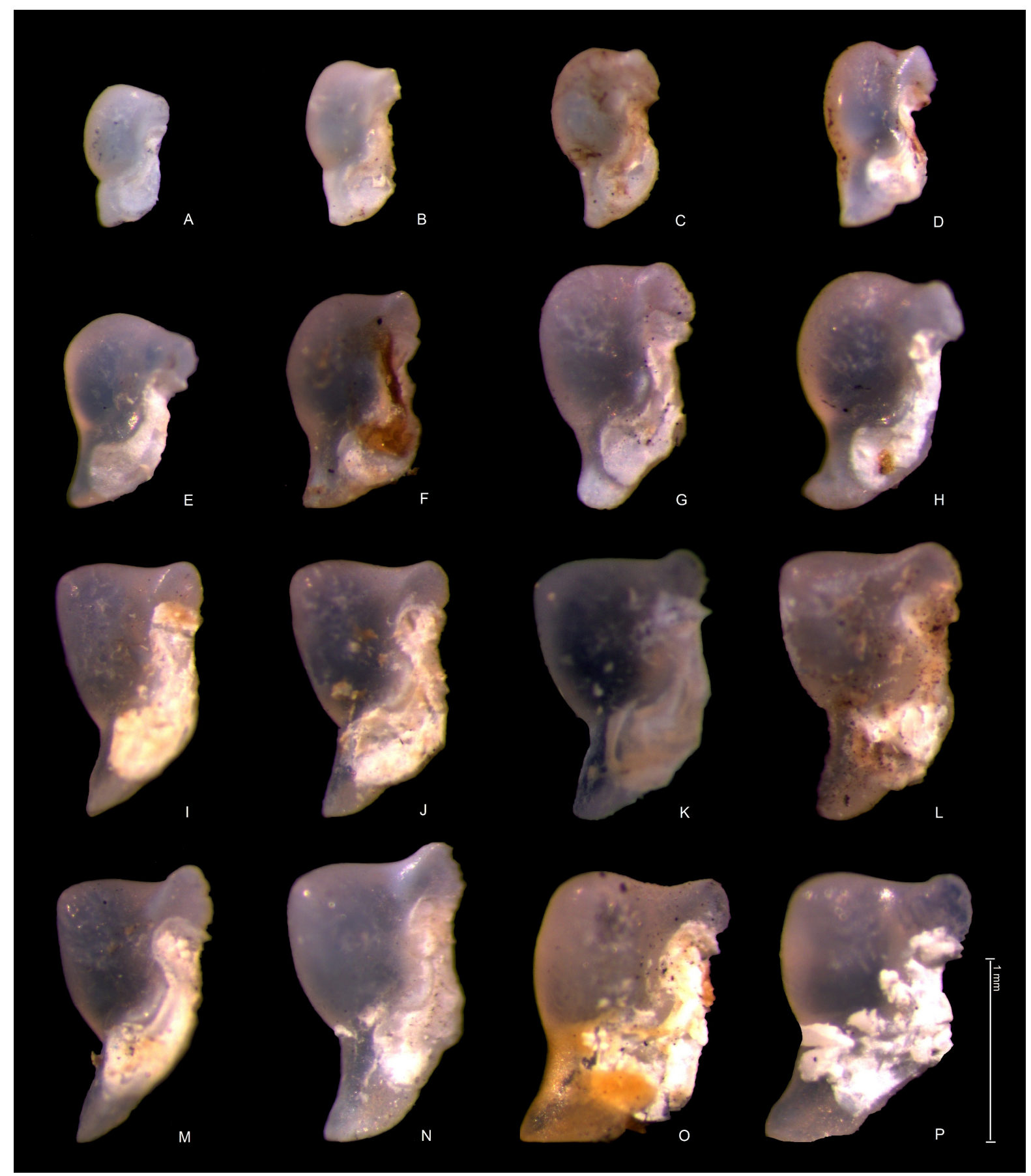

Figura 17 - Crescimento ontogenético dos estatólitos de D. plei, representados de (A) a (P). O primeiro número entre parênteses indica os valores de SL (em $\mathrm{mm}$ ) e o segundo, o ML individual (em mm), como segue: A $(0,85 ; 25)$, B $(0,96 ; 35), C(1,08 ; 45), \mathrm{D}(1,16 ; 50), \mathrm{E}(1,25$; $57)$, F (1,32; 82), G (1,46; 85), H (1,49; 109), I (1,51; 111), J (1,56; 123), K (1,64; 139), L $(1,66 ; 166), \mathrm{M}(1,69 ; 157), \mathrm{N}(1,78 ; 221), \mathrm{O}(1,80 ; 194)$ e $\mathrm{P}(1,83 ; 263)$. 


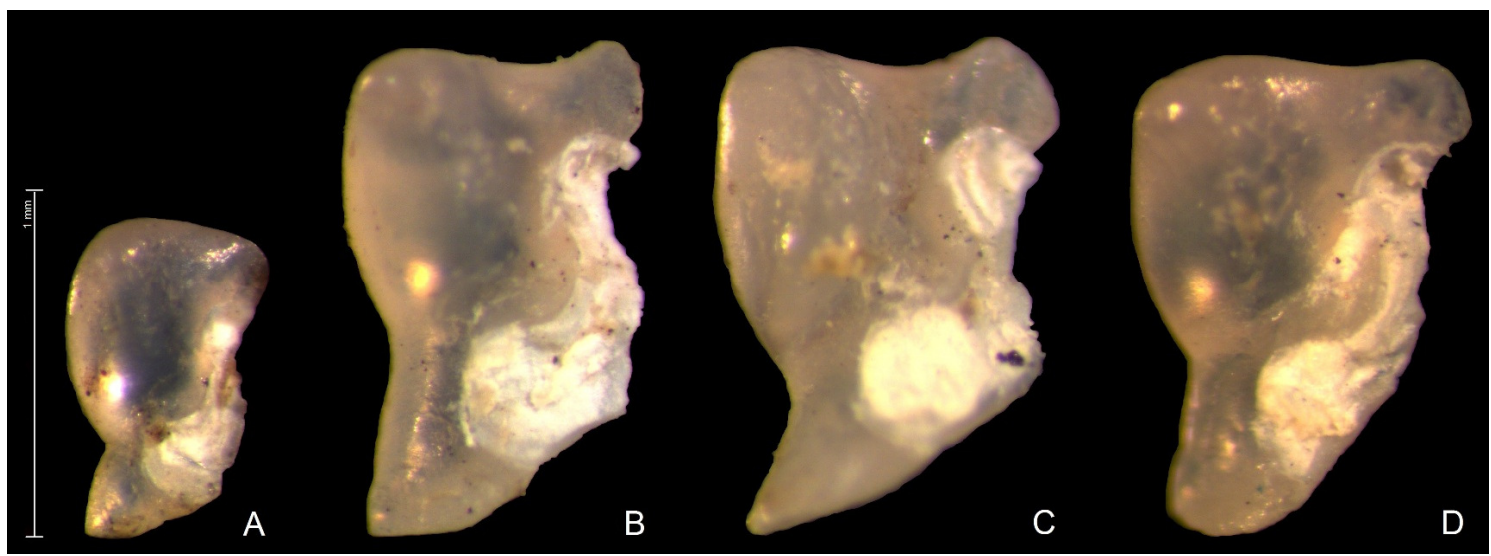

Figura 18 - Estatólitos de D. plei em diferentes estádios de maturidade. (A) imaturo, $42 \mathrm{~mm}$ ML e 1,04 mm SL; (B) fêmea em maturação com $144 \mathrm{~mm}$ ML e 1,6 mm SL; (C) macho maduro com $201 \mathrm{~mm}$ ML e 1,59 mm SL; (D) fêmea desovada com $159 \mathrm{~mm}$ ML e 1,58 mm SL.
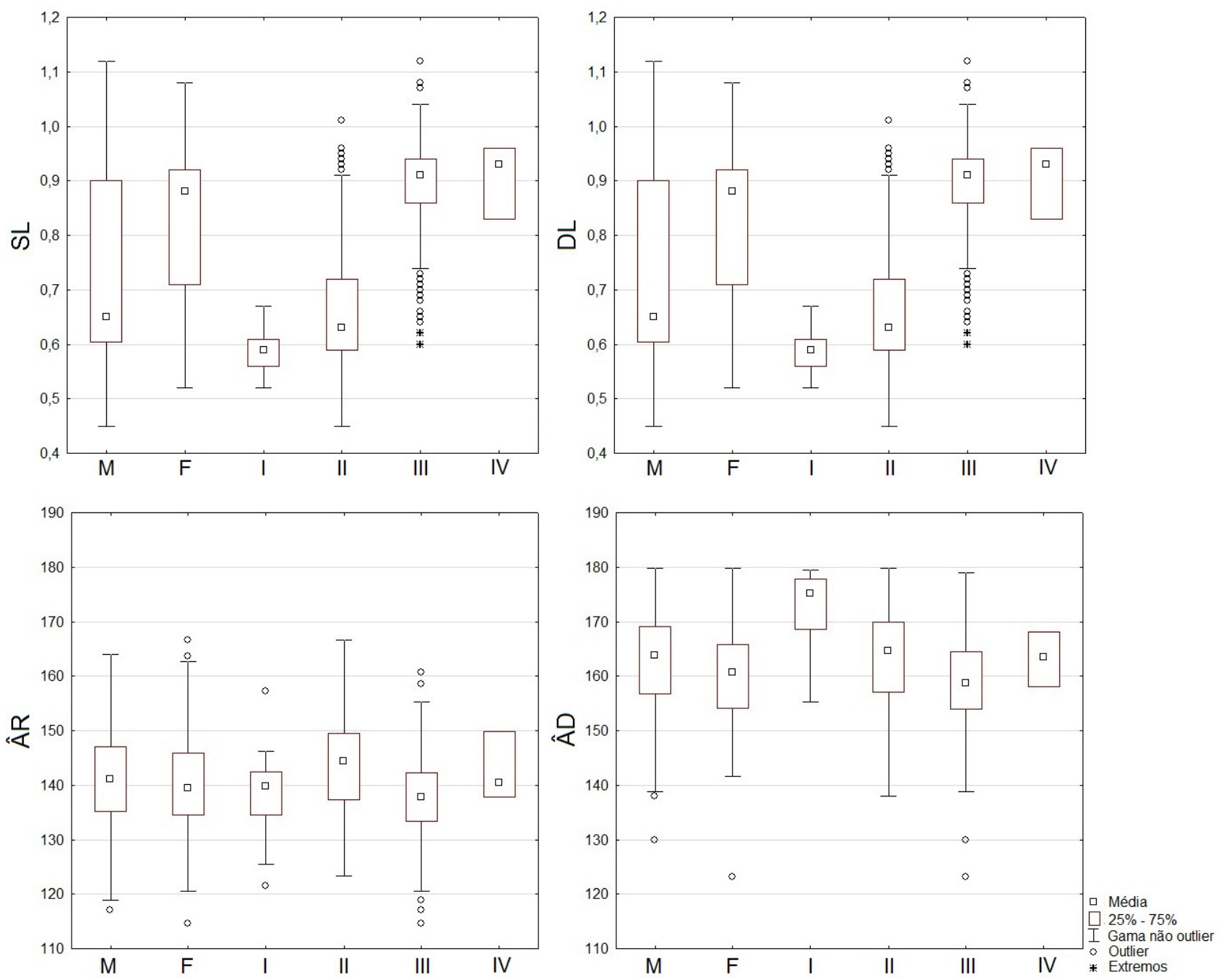

Figura 19 - Morfometria dos estatólitos de D. plei das categorias: Fêmeas (F); Machos (M); Imaturos (I); Em maturação (II); Maduros (III); e desovados (IV), para as medidas tomadas dos estatólitos: Comprimento dos estatólitos (SL); Comprimento do domo (DL); Ângulo do rostro (ÂR) e ângulo do domo (ÂD). 
Lulas em maturação (Figura 18B) apresentaram estatólitos com SL em média de 1,16 mm (variando entre 0,8-1,63 mm) (Tabela 8; Figura 19). O rostro foi caracterizado por possuir extremidade arredondada. A região de união entre o rostro e o domo lateral teve tendência em ser arredondado, assim como a junção entre o domo dorsal e lateral (média do ângulo de $143,97^{\circ}$ e $163,58^{\circ}$ para o rostro e domo dorsal, respectivamente), que forma uma ponta afiada na extremidade.

Indivíduos em estádio de maturação maduros apresentaram estatólitos maiores do que os estatólitos de outros estádios (Figura 18C), com média de comprimento de 1,56 mm SL (com variação de 1,06-1,83 mm) (Tabela 8; Figura 19). O domo dorsal foi caracterizado por um ângulo visivelmente inferior ao ângulo praticamente imperceptível de indivíduos juvenis, e a variação do comprimento do domo variou entre 0,6 e 1,12 mm DL (Tabela 8). Não foi encontrada diferença morfológica e morfométrica entre estatólitos de indivíduos maduros e desovados (Fig. 18D). Houve diferença significativa entre SL em relação a ML apenas entre indivíduos maduros com lulas imaturas (ANCOVA $p<0,0000001)$.

\subsubsection{Relação entre o comprimento dos estatólitos com o} comprimento do manto

A função logarítmica forneceu o melhor ajuste para a maioria das relações (para o total da amostra; fêmeas; machos e indivíduos maduros), com melhores valores de $r^{2} \mathrm{e}$ AIC. A Tabela 9 apresenta os valores dos ajustes testados nos modelos propostos para toda a amostra, por sexo e por estádio de maturidade. Indivíduos em estádio de maturidade imaturos, os modelos potencial e exponencial proveram o melhor ajuste, porém os parâmetros foram próximos aos apresentados ao logarítmico. O ajuste exponencial foi o melhor ajuste para lulas imaturas. Para indivíduos maduros, todos os modelos apresentaram mesmo valor de $r^{2}$, porém o menor valor de AIC foi demonstrado para o modelo da função potencial. A Figura 20 exibe a relação SL e ML com o melhor ajuste dos modelos testados, seus respectivos modelos de equação para: toda amostra, por sexo e por estádios de maturidade. 


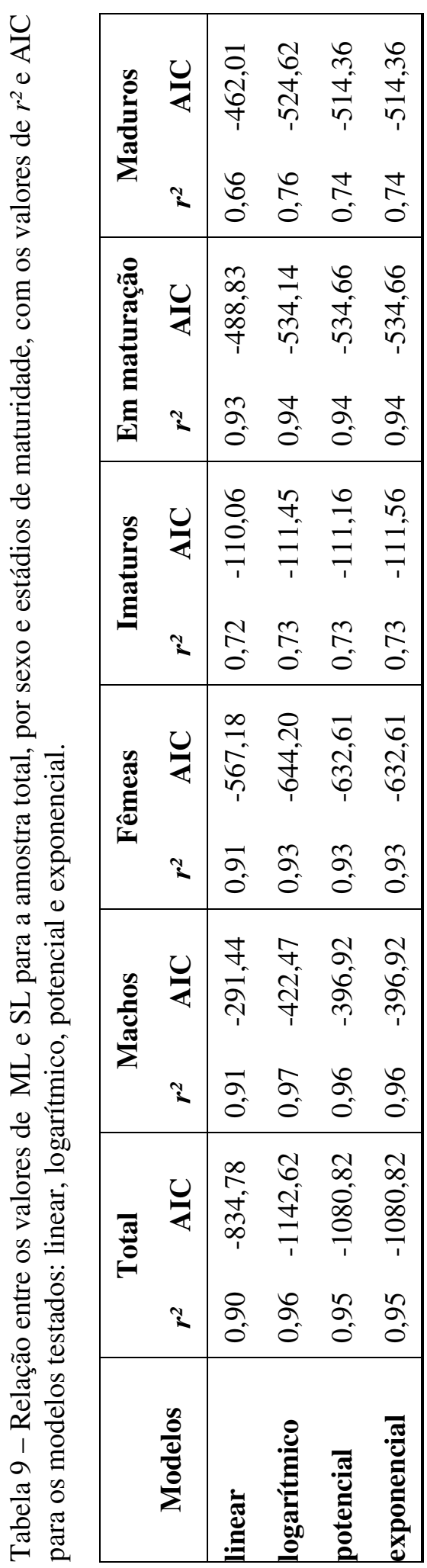



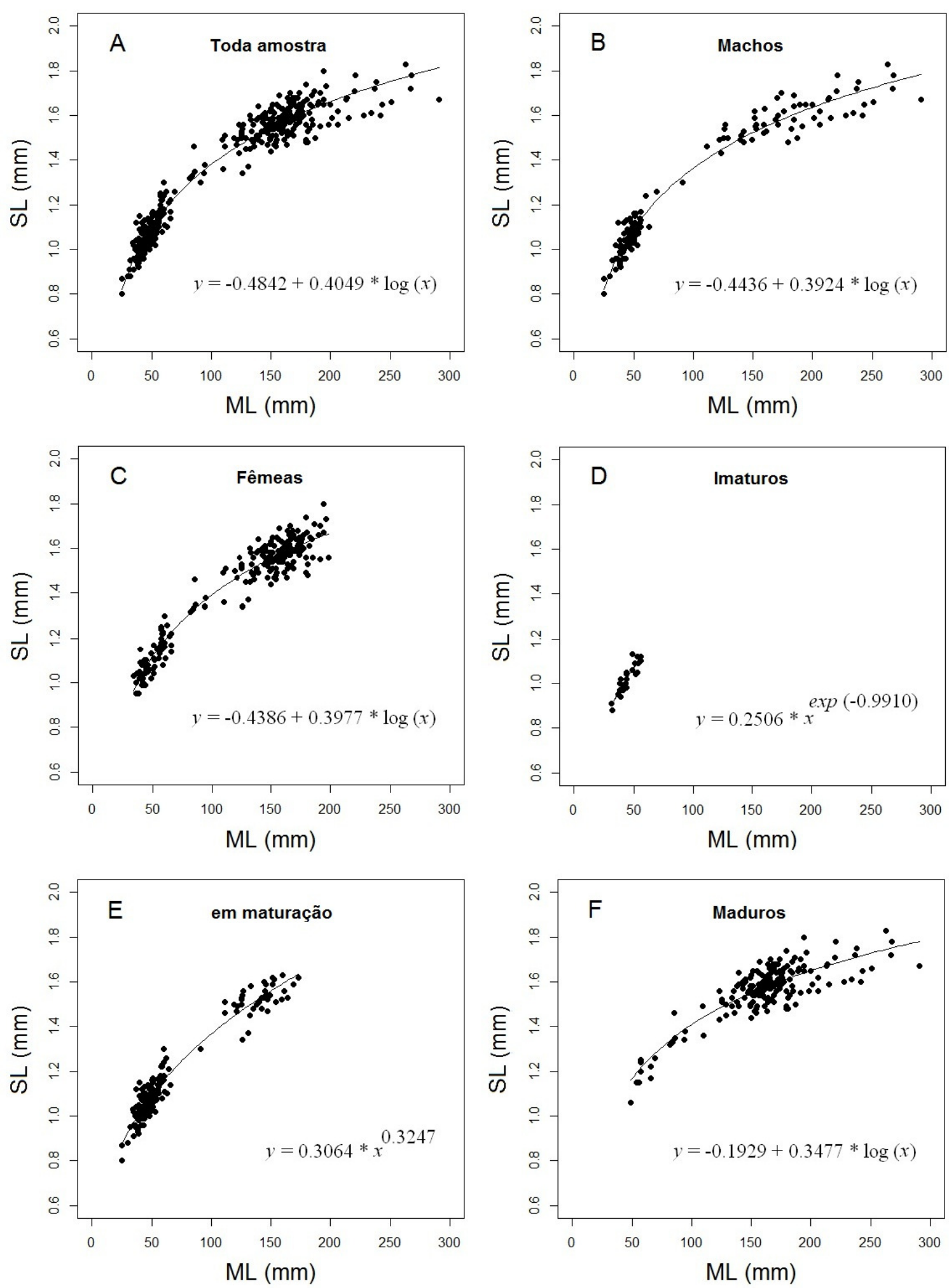

Figura 20 - Relação entre comprimento de manto (ML) e comprimento do estatólito (SL), para amostra total (A), machos (B), fêmeas (C), imaturos (D), em maturação (E) e maduros (F). Ver Tabela 9 com os ajustes das relações $\left(r^{2}\right.$ e AIC). 
No entanto, pode-se notar que a função potencial apresentou ajustes próximos ao modelo de ajuste adotado (Tabela 9). Sendo assim, considerando que a função potencial exibe na equação o coeficiente de alometria, o qual pode ser comparado com o coeficiente de outras lulas, a equação do modelo potencial é aqui disponível para toda amostra $\left(y=0,3323 * x^{0,3054}\right)$; fêmeas $\left(y=0,3499 * x^{0,2971}\right)$; machos $(y=0,3407 *$ $\left.x^{0,2963}\right)$; imaturos $\left(y=0,2506 * x^{0,3712}\right)$ e lulas maduras $\left(y=0,4851 * x^{0,2312}\right)$.

\subsubsection{Comparação entre o estatólito de $D$. plei e de $D$. sanpaulensis}

As diferenças mais marcante entre os estatólitos de D. plei e D. sanpaulensis foram o formato da extremidade do rostro, tamanho e ângulo do rostro e formato menos arredondado do domo dorsal de D. plei (Figura 21). O rostro de D. plei é maior do que o de $D$. sanpaulensis, e tende a se afilar na extremidade. O ÂR é mais acentuado em $D$. plei $\left(140,51^{\circ}\right)$ enquanto que para $D$. sanpaulensis (próximo a $180^{\circ}$ ) se assemelha aos estatólitos de indivíduos imaturos de D. plei. O domo lateral de D. plei apresenta formato oval, diferentemente de D. sanpaulensis, o qual é mais arredondado.

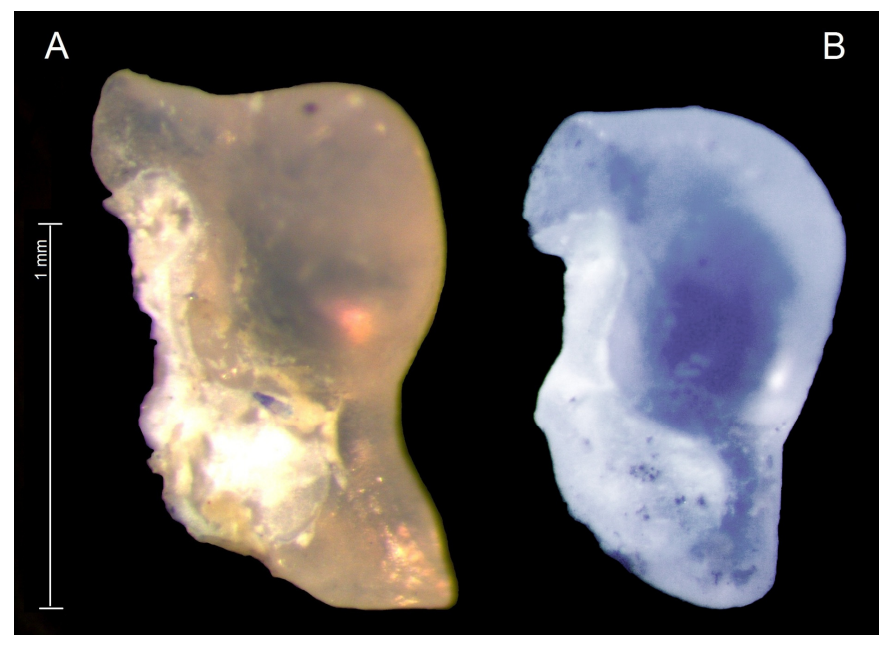

Figura 21 - Comparação entre os estatólitos de exemplares de D. plei, comprimento do manto de $82 \mathrm{~mm}$ (A) e D. sanpaulensis, comprimento de manto de $85 \mathrm{~mm}$ (B) de mesmo estádio de maturidade. A aparência azulada do estatólito de D. sanpaulensis é provavelmente devido à propriedade de refração, uma vez que demonstra a transparência em relação aos estatólitos de $D$. plei. 


\subsection{Idade}

\subsubsection{Avaliação da consistência das contagens dos incrementos de} crescimento

Para obter a média da idade de cada indivíduo a porcentagem de erro médio (EMP) entre as contagens dos incrementos de crescimento consideradas (leituras 2, $3 \mathrm{e}$ 4) foi calculada, onde a média de EMP foi de 3,72\%, considerada baixa e a precisão entre as contagens foi alta, em variabilidade entre as leituras de 4,85\% (CV). A Tabela 31 localizada no Apêndice 1, disponibiliza os dados brutos das leituras e o cálculo de EMP e CV. Sendo assim a consistência entre as contagens foi satisfatória. O valor de EMP seria de 4,90\% caso fossem utilizadas todas as leituras (leitura de 1 a 5) efetuadas no estudo. A Tabela 10 exibe uma síntese da Tabela 31 (em Apêndice 1).

Das 424 lâminas preparadas para as leituras dos incrementos de crescimentos presentes nos estatólitos, 13,39\% foram consideradas de qualidade de visualização ruim, $12,26 \%$ regular, $60,38 \%$ boa e $12,98 \%$ muito boa, apresentados na Tabela 11 , onde os valores mais baixos de EMP e do coeficiente de variação (CV) são os da categoria de qualidade de leitura muito boa.

As lâminas classificadas como de qualidade visual ruim tiveram os maiores valores em \% de erro entre as leituras dos incrementos de crescimento (EMP) e menor precisão entre as leituras (CV). 
Tabela 10 - Análise dos incrementos depositados nos estatólitos, onde: Identificação do exemplar amostrado (n); Leituras dos anéis de crescimento realizadas em cada estatólito; Média entre as leituras (Média); Desvio padrão (DP); Erro médio porcentual (EMP); e coeficiente de variação $(\mathrm{CV})$.

\begin{tabular}{|c|c|c|c|c|c|c|c|c|c|}
\hline \multirow{2}{*}{ n } & \multicolumn{5}{|c|}{ Leituras } & \multirow{2}{*}{ Média } & \multirow{2}{*}{ DP } & \multirow{2}{*}{ EMP } & \multirow{2}{*}{ CV } \\
\hline & 1 & 2 & 3 & 4 & 5 & & & & \\
\hline 161 & 241 & 238 & 240 & 243 & \multirow{13}{*}{206} & 240,33 & 2,52 & 0,74 & 1,05 \\
\hline 162 & 284 & 291 & 288 & 293 & & 290,67 & 2,52 & 0,61 & 0,87 \\
\hline 163 & 317 & 286 & 293 & 308 & & 295,67 & 11,24 & 2,78 & 3,80 \\
\hline 164 & 340 & 345 & 346 & 345 & & 345,33 & 0,58 & 0,13 & 0,17 \\
\hline 165 & 230 & 192 & 209 & 201 & & 200,67 & 8,50 & 2,88 & 4,24 \\
\hline 166 & 365 & 351 & 368 & 346 & & 355 & 11,53 & 2,44 & 3,25 \\
\hline 167 & 254 & 270 & 267 & 272 & & 269,67 & 2,52 & 0,66 & 0,93 \\
\hline 168 & 244 & 289 & 294 & 286 & & 289,67 & 4,04 & 1 & 1,40 \\
\hline 169 & 187 & 192 & 192 & & & 192 & 0 & 0 & 0 \\
\hline 170 & 230 & 232 & 224 & & & 228 & 5,66 & 1,75 & 2,48 \\
\hline 171 & 260 & 250 & 244 & 248 & & 247,33 & 3,06 & 0,90 & 1,24 \\
\hline 172 & 246 & 231 & 236 & 236 & & 234,33 & 2,89 & 0,95 & 1,23 \\
\hline 173 & 191 & 199 & 202 & 202 & & 201 & 1,73 & 0,66 & 0,86 \\
\hline 174 & 228 & 235 & 253 & 239 & \multirow[t]{6}{*}{223} & 242,33 & 9,45 & 2,93 & 3,90 \\
\hline 175 & 203 & 190 & 204 & 210 & & 201,33 & 10,26 & 3,75 & 5,10 \\
\hline 176 & 211 & 207 & 13 & 216 & & & 4,58 & 1,57 & 2,16 \\
\hline 177 & 230 & 210 & 194 & 202 & & 202 & 8 & 2,64 & 3,96 \\
\hline 178 & 245 & 208 & 190 & & & 199 & 12,73 & 4,52 & 6,40 \\
\hline 179 & 189 & 163 & 177 & & & 170 & 9,90 & 4,12 & 5,82 \\
\hline 180 & 206 & 196 & 206 & 235 & \multirow[t]{20}{*}{241} & 212,33 & 20,26 & 7,12 & 9,54 \\
\hline 181 & 301 & 277 & 278 & & & 277,50 & 0,71 & 0,18 & 0,25 \\
\hline 182 & 255 & 263 & 227 & 250 & & 246,67 & 18,23 & 5,32 & 7,39 \\
\hline 183 & 249 & 226 & 234 & 232 & & 230,67 & 4,16 & 1,35 & 1,80 \\
\hline 184 & 289 & 259 & 268 & & & 263,50 & 6,36 & 1,71 & 2,42 \\
\hline 185 & 264 & 249 & 261 & & & 255 & 8,49 & 2,35 & 3,33 \\
\hline 186 & 226 & 225 & 226 & & & 225,50 & 0,71 & 0,22 & 0,31 \\
\hline 187 & 255 & 230 & 236 & & & 233 & 4,24 & 1,29 & 1,82 \\
\hline 188 & 222 & 241 & 253 & & & 247 & 8,49 & 2,43 & 3,44 \\
\hline 189 & 285 & 218 & 234 & & & 226 & 11,31 & 3,54 & 5,01 \\
\hline 190 & 260 & 289 & 277 & & & & 8,49 & 2,12 & 3 \\
\hline 191 & 247 & 244 & 250 & & & 247 & 4,24 & 1,21 & 1,72 \\
\hline 192 & 310 & 253 & 273 & & & 263 & 14,14 & 3,80 & 5,38 \\
\hline 193 & 319 & 317 & 319 & 321 & & & & 0,42 & 0,63 \\
\hline 194 & 317 & 319 & 320 & 319 & & 319,33 & 0,58 & 0,14 & 0,18 \\
\hline 195 & 338 & 290 & 309 & 325 & & 308 & 17,52 & 3,90 & 5,69 \\
\hline 196 & 347 & 344 & 346 & 348 & & 346 & 2 & 0,39 & 0,58 \\
\hline 197 & 277 & 299 & 286 & 288 & & 291 & 7 & 1,83 & 2,41 \\
\hline 198 & 263 & 268 & 270 & 270 & & 269,33 & 1,15 & 0,33 & 0,43 \\
\hline 199 & 344 & 309 & 321 & 313 & & 314,33 & 6,11 & 1,41 & 1,94 \\
\hline & & & & & & & Média & 1,95 & 2,72 \\
\hline
\end{tabular}


Tabela 11 - Categorias visuais de qualidade das leituras dos estatólitos com o número amostral (n), erro médio porcentual (EMP), coeficiente de variação (CV) (ambos em \%).

\begin{tabular}{|c|r|c|c|}
\hline Qualidade leitura & \multicolumn{1}{|c|}{ n } & EMP (\%) & CV (\%) \\
\hline Ruim & 61 & 4,13 & 4,93 \\
Regular & 52 & 3,53 & 4,89 \\
Boa & 256 & 3,91 & 5,11 \\
Muito Boa & 55 & 2,58 & 3,51 \\
\hline
\end{tabular}

A qualidade de leitura boa foi presente em maior frequência (entre 58,64 a $59,12 \%$ ) em relação às outras categorias (ruim, regular e muito boa), para fêmeas e machos (Figura 22). Todas as outras categorias ficaram abaixo dos $20 \%$, não havendo destaque. Também presente em destaque a mesma categoria de qualidade da visualização e leitura dos incrementos de crescimento dos estatólitos, para todos os estádios de maturidade, variando em \% entre 57,83 a 66,66\% (Figura 22). Novamente todas as outras categorias ficaram abaixo dos $20 \%$, salvo a categoria regular do estádio de maturidade IV.

O erro médio entre as leituras dos incrementos de crescimento (EMP) a precisão entre as leituras (CV), quando comparado entre os sexos (Tabela 12), não exibiram diferenças (EMP entre 2,34 e 2,44\% e CV entre 2,93 e 2,96\%).

Tabela 12 - Análise da confiabilidade das leituras realizadas para fêmeas e machos com o número de exemplares utilizados para análise por sexo (n), erro médio porcentual (EMP), coeficiente de variação $(\mathrm{CV})$.

\begin{tabular}{|c|c|c|c|}
\hline Sexo & n & EMP (\%) & CV (\%) \\
\hline Fêmeas & 162 & 2,34 & 2,93 \\
Machos & 137 & 2,44 & 2,86 \\
\hline
\end{tabular}

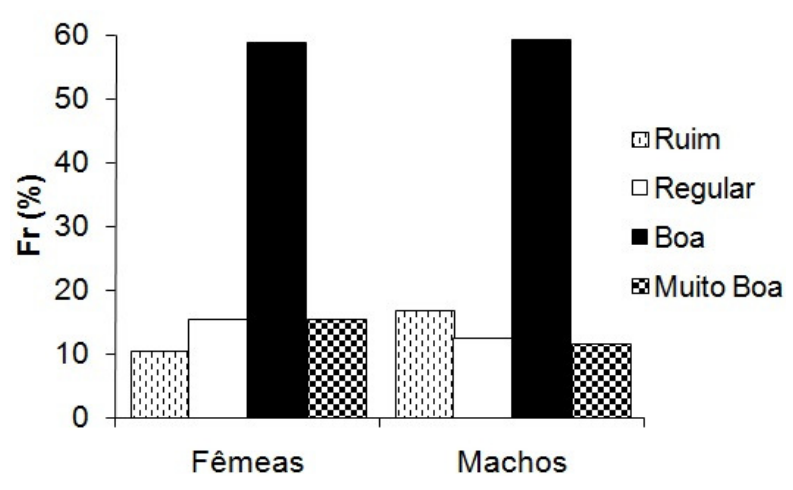

Figura 22 - Qualidade visual das leituras dos incrementos de crescimento nos estatólitos amostrados, em frequência relativa (Fr), por sexo. 
Quando os valores de EMP e CV foram comparados por estádio de maturidade, constatou-se que os indivíduos em estádio de maturidade II e III tiveram melhor qualidade de leitura (valores de EMP entre 1,99 e 2,37\% e CV entre 2,74 e 3,01\%). Já os exemplares em estádio IV e I apresentaram valores EMP mais elevado em relação aos outros estádios de maturidade (14,80 e 3,85\%) e CV de 5,02\% (lulas em estádio I) e 41,27\% para lulas IV (Tabela 13; Figura 23).

Tabela 13 - Análise da confiabilidade das leituras para todos os estádios de maturidade (I - IV) com o número de exemplares utilizados para análise por sexo (n), erro médio porcentual (EMP), coeficiente de variação $(\mathrm{CV})$.

\begin{tabular}{|c|c|c|c|}
\hline Maturidade & N & EMP (\%) & CV (\%) \\
\hline I & 125 & 3,85 & 5,02 \\
II & 166 & 2,37 & 3,01 \\
III & 130 & 1,99 & 2,74 \\
IV & 3 & 14,8 & 1,27 \\
\hline
\end{tabular}

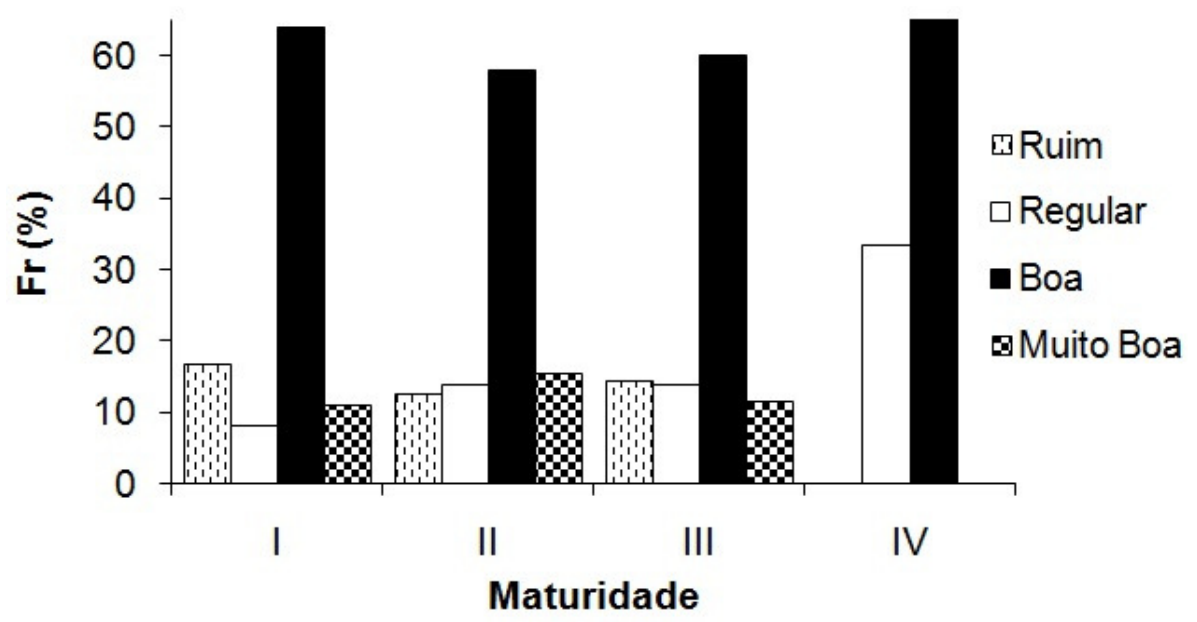

Figura 23 - Qualidade visual das leituras dos incrementos de crescimento nos estatólitos amostrados, em frequência relativa (Fr), por estádios de maturidade.

Apesar de terem sido consideradas apenas as leituras 2, 3 e 4, a Tabela 14 exibe os valores de $r^{2}$ das regressões lineares estabelecidas entre os incrementos encontrados entre todas as leituras dos estatólitos realizadas no estudo (Figura 24), possibilitando desta maneira, comparar os parâmetros da relação obtidos em todas as leituras realizadas.

Os valores de $r^{2}$ variaram entre 0,51 (leitura 2 vs 5) e 0,99 (leitura 2 vs. 3, 1 vs. 4, 2 vs. 4 e 3 vs. 4), demonstrando que houve boa coincidência entre os pontos entre as 
diferentes leituras. $\mathrm{O}$ teste $t$ para amostras dependentes apresentou diferença significativa $(p<0,05)$ entre as leituras 1 vs. 2,2 vs. 3,1 vs. 4 e 2 vs. 4 (Tabela 14).

Tabela 14 - Relações das leituras dos incrementos de crescimento com os respectivos números de exemplares testados para cada relação (n), equação da regressão linear, coeficiente de correlação da equação $r^{2}$, valores de $p$ do teste t para amostras dependentes e valores de $p$ do teste Wilcoxon.

\begin{tabular}{|c|c|c|c|c|c|}
\hline Leituras & $\mathbf{n}$ & Regressão linear & $r^{2}$ & $\begin{array}{c}\text { Teste } t \\
p\end{array}$ & $\begin{array}{c}\text { Wilcoxon } \\
p\end{array}$ \\
\hline 1 vs 2 & & $y=0,963 x+4,328$ & 0,97 & 0,04037 & 0,19320 \\
\hline 2 vs 3 & 424 & $y=1,004 x+1,689$ & 0,99 & 0,00001 & 0 \\
\hline 1 vs 3 & & $y=0,980 x+3,993$ & 0,98 & 0,29501 & 0,01207 \\
\hline 1 vs 4 & & $y=0,994 x+2,727$ & 0,99 & 0,03202 & 0,00044 \\
\hline 2 vs 4 & 262 & $y=1,008 x+1,283$ & 0,99 & 0,00014 & 0 \\
\hline 3 vs 4 & & $y=0,999 x+0,310$ & 0,99 & 0,71046 & 0,10253 \\
\hline 1 vs 5 & & $y=0,738 x+52,030$ & 0,66 & 0,68474 & 0,61209 \\
\hline 2 vs 5 & & $y=0,497 x+102,600$ & 0,51 & 0,80063 & 1 \\
\hline 3 vs 5 & 8 & $y=0,586 x+83,430$ & 0,67 & 0,68520 & 0,83364 \\
\hline 4 vs 5 & & $y=0,803 x+37,740$ & 0,91 & 0,39131 & 0,67442 \\
\hline
\end{tabular}

Como observado na Tabela 14, maiores valores de $p$ teste $t$ foram obtidos para a leitura 3 vs. 4 e para as leituras que foram feitas até cinco vezes, ou seja, a qualidade entre as leituras aumentou conforme a contagem se aproximou da quinta leitura, porém a replicação dos dados demonstrados pelos valores de $r^{2}$ para todos os dados das leituras relacionados com a leitura 5 foram os mais baixos. Isto se deve a pouca quantidade de leitura 5. De acordo com os resultados apresentados pelo teste Wilcox $(0<p<1)$ houve uma boa acurácia entre as leituras. Quando comparadas as leituras: 2 vs. 3, 1 vs. 3, 1 vs. 4 e 2 vs. 4 apresentaram valores de $p<0,5$. 
A

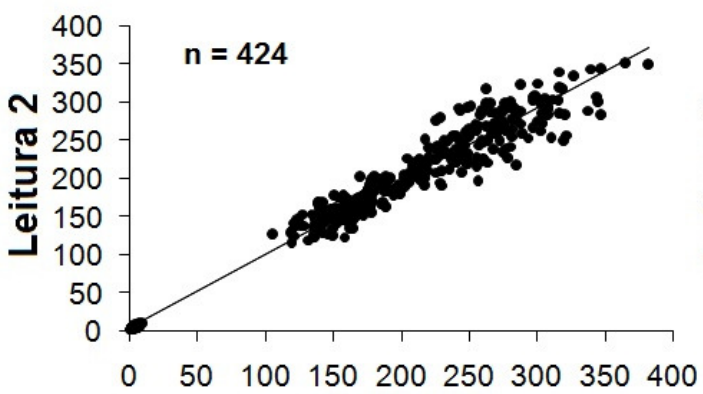

C

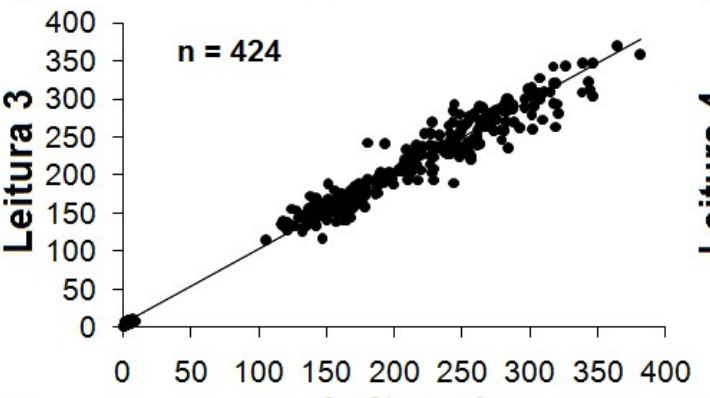

E

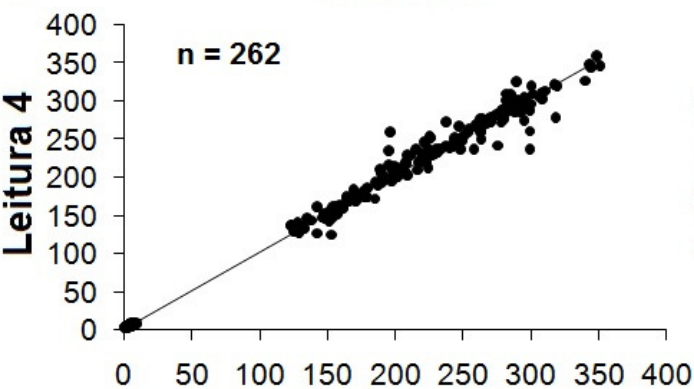

G

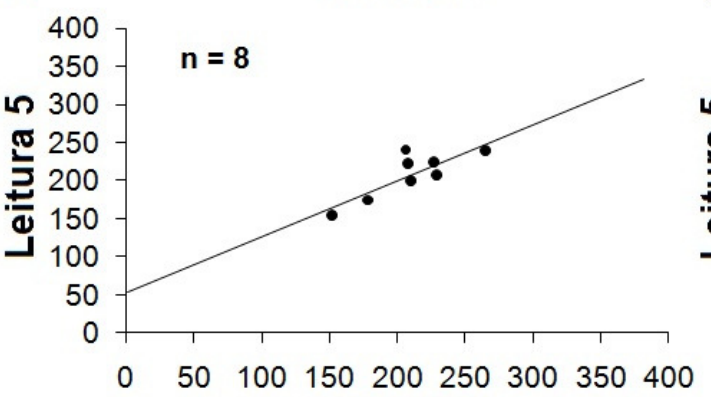

I

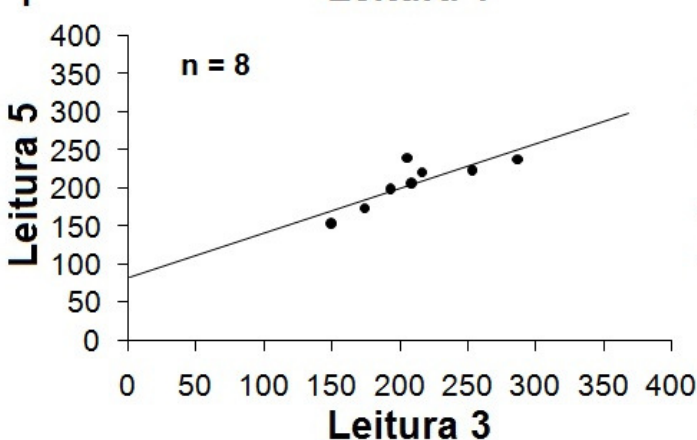

B

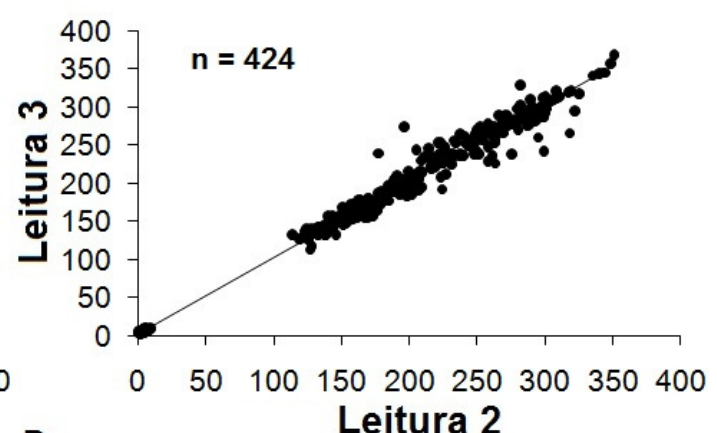

D

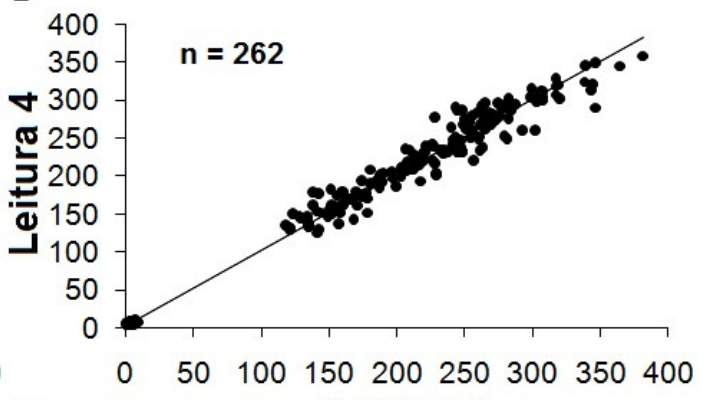

$\mathbf{F}$

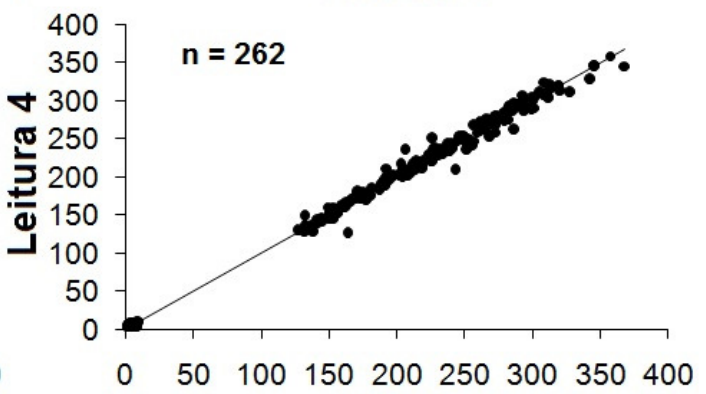

H
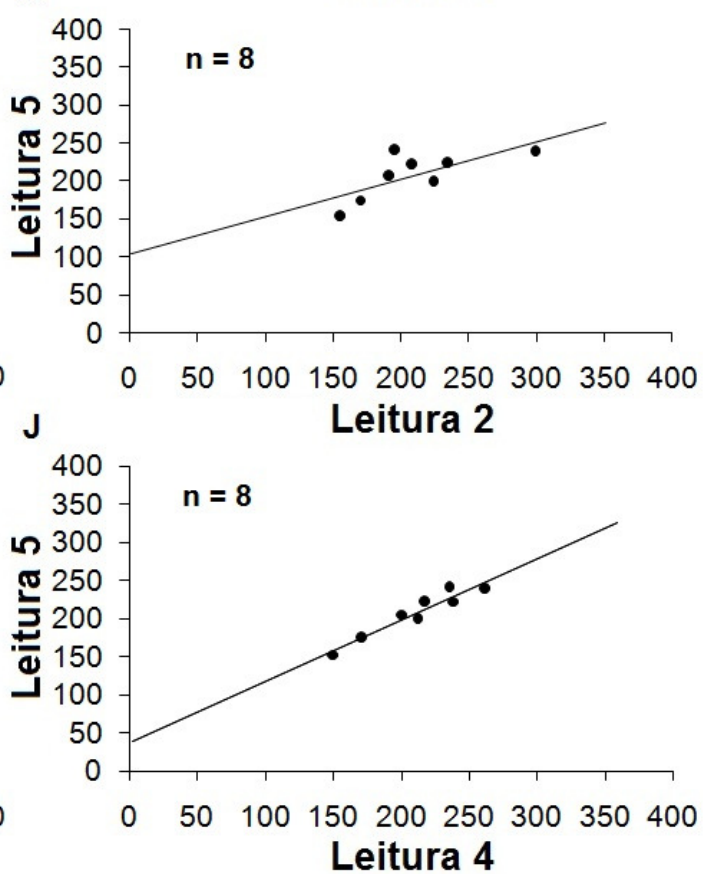

Figura 24 - Relação linear entre as leituras realizadas dos incrementos dos estatólitos. Ver Tabela 14 os ajustes da relação. 
4.6.2. Retro-cálculo da idade: Frequência de nascimento das paralarvas ao ano

Através do retro-cálculo da idade dos exemplares, observou-se que durante um ano (2011), de acordo com os exemplares amostrados, ocorreram maiores frequências de nascimento de Doryteuthis plei durante os meses de maio e junho (13\%). De acordo com a Figura 25, estima-se que a eclosão das paralarvas ocorreu durante todo o ano, porém em menor frequência no segundo semestre. Os meses finais do ano de 2010 e 2011 confirmam esta afirmação. A época do ano em que ocorreram as maiores porcentagens de eclosão foi no verão $(55,66 \%)$, seguido de outono $(31,60 \%)$. Os períodos de inverno e primavera tiveram as menores porcentagens de eclosão $(8,25$ e $4,48 \%)$.

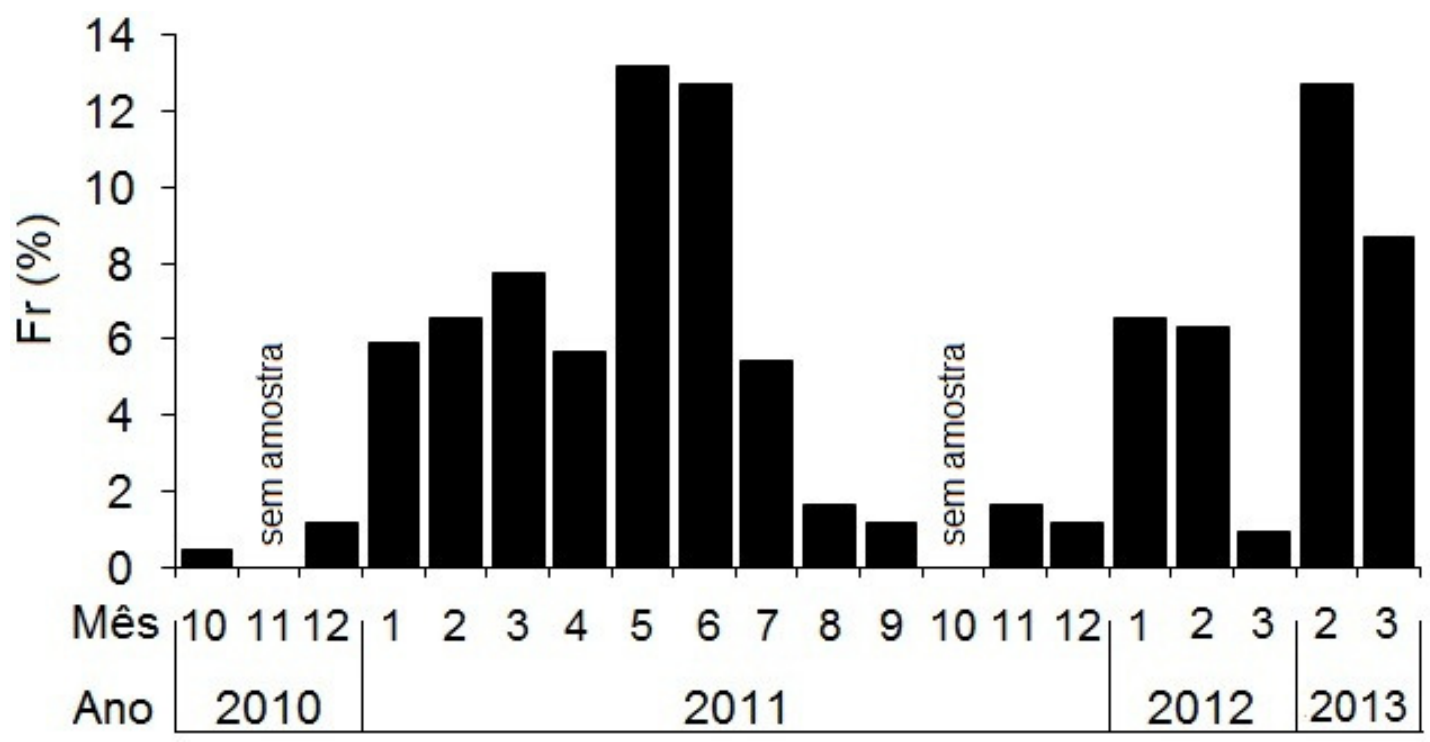

Figura 25 - Frequência relativa (Fr) dos nascimentos de Doryteuthis plei durante os anos de 2010 a 2013.

\subsection{Crescimento}

\subsubsection{Curva de crescimento: relação idade-comprimento do manto}

De acordo com os modelos de crescimento testados para cada grupo analisado (toda amostra, por sexo e por estádio de maturidade), os valores computados por AICw que mais se aproximaram de 1 serviram de critério para escolha do modelo de ajuste de crescimento. 
Sendo assim, a curva de crescimento de Doryteuthis plei pode ser melhor representada através de ajustes sigmóides, onde o melhor ajuste da relação entre idade (dias) vs. ML (mm) para toda amostra (para a espécie na região em estudo), foi estabelecido pelo modelo logístico $\left(r^{2}=0,84\right)$. Sendo assim, os parâmetros de crescimento obtidos por este ajuste oferecem recursos para estudos de avaliação de estoque pesqueiro de D. plei da região de estudo.

Quando analisando o crescimento por sexo e para indivíduos sem a identificação do sexo, o ajuste das curvas de crescimento de fêmeas e machos foram obtidos, pelos modelos de Gompertz e logístico $\left(r^{2}=0,74\right.$ e $\left.r^{2}=0,76\right)$ e para juvenis, pelo modelo Gompertz $\left(r^{2}=0,96\right.$, o maior valor obtido de todas as relações) (Tabela 15, Figura 26).

O modelo Gompertz foi o que melhor se ajustou para a relação estabelecida entre os estádios de maturidade II e II (Tabela 16, Figura 26), exibindo valores de $r^{2}$ entre de 0,75 e 0,19. Já para a análise efetuada com as lulas em estádio de maturidade II e III, por sexo (fêmeas e machos), o ajuste obtido para as fêmeas foi o modelo Gompertz $\left(r^{2}\right.$ entre 0,80 e 0,31$)$ e para os machos II, Schnute $\left(r^{2}=0,70\right)$ e machos III, ajuste logarítmico $\left(r^{2}=0,17\right.$, o menor valor de todos os modelos ajustados $)$.

Os parâmetros de crescimento dos modelos $\left(L_{i n f}, t_{0}, k\right)$, valores $a$ e $b$ da equação, bem como o $r^{2}$, AIC e AICw de todas as relações testadas, estão disponíveis na Tabela 15 para o total, fêmeas, machos e juvenis; Tabela 16, estádio de maturidade II e III; e finalmente, por sexo (fêmeas e machos) em estádio de maturidade II e III, Tabela 17. A Figura 26 exibe a curva de crescimento de cada grupo analisado com seus respectivos ajustes.

O $L_{\text {inf }}$ das fêmeas e machos em estádio III foi de $168 \mathrm{~mm}$ ML e $238 \mathrm{~mm}$ ML (Figura 26, Tabela 17). Quando comparados estes valores com o comprimento médio de maturação $\left(\mathrm{L}_{50}\right)$ obtido para fêmeas (146 mm ML) e para machos (198,97 mm ML), observa-se maior proximidade entre valores obtidos para as fêmeas do que para os machos. Com os valores estimados de $\mathrm{L}_{50}$ por sexo, estima-se que quando as fêmeas completam 251 dias de vida e os machos quando 290 dias atinjam em média a maturação (estádio III), ou seja, se tornam aptos para a reprodução. Sendo assim, o $L_{\text {inf }}$ estimado possui relação com o $\mathrm{L}_{50}$ proposto. 
Tabela 15 - Modelos de crescimento obtidos para as relações: total, por sexo e para juvenis, com seus respectivos: número amostral (n), parâmetros do modelo testados: valores de $L$ infinito ( $L$ inf), taxa de crescimento $(k)$, valor de $t_{0}\left(t_{0}\right)$, valor de $a$ e $b$ da equação $(a, b)$, coeficiente de determinação da equação $\left(r^{2}\right)$, índice Akaike (AIC) e pesos de Akaike (AICw).

\begin{tabular}{|c|c|c|c|c|c|c|c|c|c|}
\hline \multicolumn{2}{|c|}{ Modelo de crescimento } & $L_{\text {inf }}$ & $\boldsymbol{k}$ & $t_{0}$ & \multirow{2}{*}{$\frac{a}{0,59}$} & \multirow{2}{*}{$\begin{array}{c}\boldsymbol{b} \\
-19,55\end{array}$} & \multirow{2}{*}{$\frac{\boldsymbol{r}^{2}}{0,74}$} & \multirow{2}{*}{$\frac{\text { AIC }}{4220,490}$} & \multirow{2}{*}{$\begin{array}{c}\text { AICw } \\
0\end{array}$} \\
\hline \multirow{8}{*}{$\begin{array}{c}\text { Total } \\
n=424\end{array}$} & linear & & & & & & & & \\
\hline & potencial & & & & 0,01 & 0,59 & 0,94 & 4104,487 & 0 \\
\hline & exponencial & & & & 2,65 & 0,02 & 0,93 & 4104,487 & 0 \\
\hline & logarítmico & & & & 30,88 & $-59,85$ & 0,48 & 4508,696 & 0 \\
\hline & von Bertalanffy & $-69,28$ & $-1,67$ & 0,06 & & & 0,79 & 4132,312 & 0 \\
\hline & logístico & 181,90 & 0,03 & 1,99 & & & 0,84 & 4003,122 & 1 \\
\hline & Gompertz & 0,02 & 0,02 & 0,24 & & & 0,84 & 4021,691 & $<0,001$ \\
\hline & Schnute & 34,72 & $-1,67$ & $-6,21$ & & & 0,79 & 4132,312 & 0 \\
\hline \multirow{8}{*}{$\begin{array}{c}\text { Fêmeas } \\
n=162\end{array}$} & linear & & & & 0,92 & 95,64 & 0,71 & 3248,997 & $<0,001$ \\
\hline & potencial & & & & 0,01 & 1,80 & 0,78 & 3277,793 & 0 \\
\hline & exponencial & & & & 9,73 & 0,01 & 0,76 & 3277,793 & 0 \\
\hline & logarítmico & & & & 198,20 & $-954,20$ & 0,72 & 3242,296 & $<0,001$ \\
\hline & von Bertalanffy & 349,61 & 1,43 & 0,33 & & & 0,72 & 3238,276 & $<0,001$ \\
\hline & logístico & 102,77 & 0,22 & $-0,11$ & & & & & 0 \\
\hline & Gompertz & 210,67 & 0,02 & 10,67 & & & 0,74 & 3213,459 & 1 \\
\hline & Schnute & & 1,43 & $-210,21$ & & & 0,72 & 3239,728 & $<0,001$ \\
\hline \multirow{8}{*}{$\begin{array}{c}\text { Machos } \\
n=137\end{array}$} & linear & & & & 1,13 & $-129,40$ & 0,72 & 1381,381 & $<0,001$ \\
\hline & potencial & & & & 0,01 & 2,15 & 0,75 & 1387,947 & $<0,001$ \\
\hline & exponencial & & & & 8,01 & 0,01 & 0,76 & 1387,947 & $<0,001$ \\
\hline & logarítmico & & & & 228,20 & -1105 & 0,70 & 1394,085 & $<0,001$ \\
\hline & von Bertalanffy & 150,91 & 0,11 & $-0,25$ & & & & & 0 \\
\hline & logístico & 236 & 0,03 & 17 & & & 0,76 & 1365,757 & 0,953 \\
\hline & Gompertz & 301,53 & 0,01 & 13,20 & & & 0,75 & 1371,821 & 0,046 \\
\hline & Schnute & 293,18 & $-0,24$ & $-113,51$ & & & 0,72 & 1383,901 & $<0,001$ \\
\hline \multirow{8}{*}{$\begin{array}{l}\text { Juvenis } \\
n=125\end{array}$} & linear & & & & 0,25 & 0,64 & 0,95 & 704,849 & 0 \\
\hline & potencial & & & & 0,53 & 0,84 & 0,98 & 694,072 & $<0,001$ \\
\hline & exponencial & & & & 1,90 & 0,02 & 0,99 & 694,072 & $<0,001$ \\
\hline & logarítmico & & & & 11,14 & $-16,12$ & 0,91 & 774,717 & 0 \\
\hline & von Bertalanffy & 64,76 & 0,15 & $-0,59$ & & & & & 0 \\
\hline & logístico & 45,87 & 0,07 & $-0,20$ & & & & & 0 \\
\hline & Gompertz & 66,67 & 0,01 & 0,70 & & & 0,96 & 663,649 & 0,718 \\
\hline & Schnute & 564,01 & $-4,55$ & 1,71 & & & 0,96 & 665,518 & 0,282 \\
\hline
\end{tabular}


Tabela 16 - Modelos de crescimento obtidos para os exemplares em maturação (II) e maduras (III), com seus respectivos: número amostral (n), parâmetros do modelo testados: valores de $L$ infinito ( $L$ inf), taxa de crescimento $(k)$, valor de $t_{0}\left(t_{0}\right)$, valor de $a$ e $b$ da equação $(a, b)$, coeficiente de determinação da equação $\left(r^{2}\right)$, índice Akaike (AIC) e pesos de Akaike (AICw).

\begin{tabular}{|c|c|c|c|c|c|c|c|c|c|}
\hline \multicolumn{2}{|c|}{ Modelo de crescimento } & $L_{\text {inf }}$ & $\boldsymbol{k}$ & $t_{0}$ & $a$ & $\boldsymbol{b}$ & $r^{2}$ & AIC & $\mathrm{AICw}$ \\
\hline \multirow{8}{*}{$\begin{array}{c}\text { II } \\
\mathrm{n}=166\end{array}$} & linear & & & & 0,79 & $-79,41$ & 0,73 & 1479,571 & 0,001 \\
\hline & potencial & & & & 0,01 & 1,88 & 0,71 & 1470,002 & 0,155 \\
\hline & exponencial & & & & 9,65 & 0,01 & 0,74 & 1470,002 & 0,155 \\
\hline & logarítmico & & & & 151,30 & $-718,90$ & 0,69 & 1504,446 & $<0,001$ \\
\hline & von Bertalanffy & $-103,07$ & $-1,57$ & 0,20 & & & 0,74 & 1474,602 & 0,016 \\
\hline & logístico & 76,36 & 0,15 & $-0,17$ & & & & & 0 \\
\hline & Gompertz & 173 & 0,01 & 23 & & & 0,75 & 1467,104 & 0,658 \\
\hline & Schnute & 259,52 & $-1,57$ & $-27,34$ & & & 0,74 & 1474,602 & 0,016 \\
\hline \multirow{8}{*}{$\begin{array}{c}\text { III } \\
\mathrm{n}=\mathbf{1 3 0}\end{array}$} & linear & & & & 0,44 & 45,97 & 0,17 & 1322,273 & 0,065 \\
\hline & potencial & & & & 1,11 & 0,89 & 0,22 & 1321,685 & 0,087 \\
\hline & exponencial & & & & 64,05 & 0,01 & 0,20 & 1321,685 & 0,087 \\
\hline & logarítmico & & & & 114,70 & $-477,40$ & 0,18 & 1320,364 & 0,169 \\
\hline & von Bertalanffy & 190,49 & 5,24 & 0,34 & & & 0,19 & 1320,071 & 0,195 \\
\hline & logístico & 159,91 & 1,47 & $-0,66$ & & & & & 0 \\
\hline & Gompertz & 180,40 & 0,02 & 33,33 & & & 0,19 & 1320,016 & 0,201 \\
\hline & Schnute & 190,49 & 5,25 & 0,34 & & & 0,19 & 1320,071 & 0,195 \\
\hline
\end{tabular}


Tabela 17 - Modelos de crescimento testados para os exemplares de fêmeas (F) e machos (M) em estádio de maturação II e III, com seus respectivos número amostral (n), parâmetros do modelo testados: valores de $L$ infinito $\left(L_{\text {inf }}\right)$, taxa de crescimento $(k)$, valor de $t O(t O)$, valor de $a$ e $b(a, b)$, coeficiente de determinação da equação $\left(r^{2}\right)$, índice Akaike (AIC) e peso de AIC $(\mathrm{AICw})$.

\begin{tabular}{|c|c|c|c|c|c|c|c|c|c|}
\hline \multicolumn{2}{|c|}{ Modelo de crescimento } & $L_{\text {inf }}$ & $\boldsymbol{k}$ & $t_{0}$ & \multirow{2}{*}{$\frac{\boldsymbol{A}}{0,89}$} & \multirow{2}{*}{$\begin{array}{c}\boldsymbol{b} \\
-93,97\end{array}$} & \multirow{2}{*}{\begin{tabular}{|c|}
$\boldsymbol{r}^{2}$ \\
0,77
\end{tabular}} & \multirow{2}{*}{$\frac{\text { AIC }}{576,568}$} & \multirow{2}{*}{$\frac{\mathbf{A I C w}}{0,026}$} \\
\hline \multirow{8}{*}{$\begin{array}{c}\text { II F } \\
n=63\end{array}$} & linear & & & & & & & & \\
\hline & potencial & & & & 0,01 & 1,93 & 0,77 & 582,066 & 0,002 \\
\hline & exponencial & & & & 9,13 & 0,01 & 0,77 & 582,066 & 0,002 \\
\hline & logarítmico & & & & 183,70 & $-886,20$ & 0,77 & 577,771 & 0,014 \\
\hline & von Bertalanffy & 464,03 & 0,88 & 0,32 & & & 0,77 & 577,606 & 0,015 \\
\hline & logístico & 97,96 & 0,13 & $-0,27$ & & & & & 0 \\
\hline & Gompertz & 166 & 0,02 & 17 & & & 0,80 & 569,382 & 0,927 \\
\hline & Schnute & 446,16 & 0,88 & 0,31 & & & 0,77 & 577,607 & 0,015 \\
\hline \multirow{8}{*}{$\begin{array}{c}\text { II M } \\
n=\mathbf{1 0 3}\end{array}$} & linear & & & & 0,64 & $-55,84$ & 0,63 & 889,903 & $<0,001$ \\
\hline & potencial & & & & 0,02 & 1,53 & 0,59 & 876,097 & 0,043 \\
\hline & exponencial & & & & 11,59 & 0,01 & 0,64 & 876,097 & 0,043 \\
\hline & logarítmico & & & & 113,80 & $-528,80$ & 0,56 & 907,064 & $<0,001$ \\
\hline & von Bertalanffy & 63,85 & 0,25 & $-0,28$ & & & & & 0 \\
\hline & logístico & 63,35 & 0,25 & $-0,27$ & & & & & 0 \\
\hline & Gompertz & 63,85 & 0,25 & $-0,28$ & & & & & 0 \\
\hline & Schnute & 160,50 & $-4,56$ & 35 & & & 0,70 & 869,977 & 0,914 \\
\hline \multirow{8}{*}{$\begin{array}{l}\text { III F } \\
n=97\end{array}$} & linear & & & & 0,42 & 36,01 & 0,28 & 922,641 & 0,079 \\
\hline & potencial & & & & 0,89 & 0,91 & 0,32 & 921,935 & 0,112 \\
\hline & exponencial & & & & 56,70 & 0,01 & 0,30 & 921,935 & 0,112 \\
\hline & logarítmico & & & & 109,10 & -460 & 0,29 & 920,092 & 0,281 \\
\hline & von Bertalanffy & 146,98 & 1,24 & $-0,70$ & & & & & 0 \\
\hline & logístico & 146,98 & 1,24 & $-0,70$ & & & & & 0 \\
\hline & Gompertz & 168 & 0,02 & 65,33 & & & 0,31 & 919,308 & 0,416 \\
\hline & Schnute & 146,98 & 1,24 & $-0,70$ & & & & & 0 \\
\hline \multirow{8}{*}{$\begin{array}{l}\text { III M } \\
n=33\end{array}$} & linear & & & & 0,44 & 84,18 & 0,16 & 339,689 & 0,198 \\
\hline & potencial & & & & 3,86 & 0,70 & 0,15 & 339,582 & 0,208 \\
\hline & exponencial & & & & 98,58 & 0,01 & 0,15 & 339,582 & 0,208 \\
\hline & logarítmico & & & & 120,60 & $-470,50$ & 0,17 & 339,476 & 0,220 \\
\hline & von Bertalanffy & 259,99 & 2,96 & 0,21 & & & 0,17 & 341,561 & 0,078 \\
\hline & logístico & 201,15 & 2,46 & $-1,48$ & & & & & 0 \\
\hline & Gompertz & 259,50 & 0,01 & 4,02 & & & 0,17 & 341,318 & 0,087 \\
\hline & Schnute & 201,15 & 2,46 & $-1,48$ & & & & & 0 \\
\hline
\end{tabular}



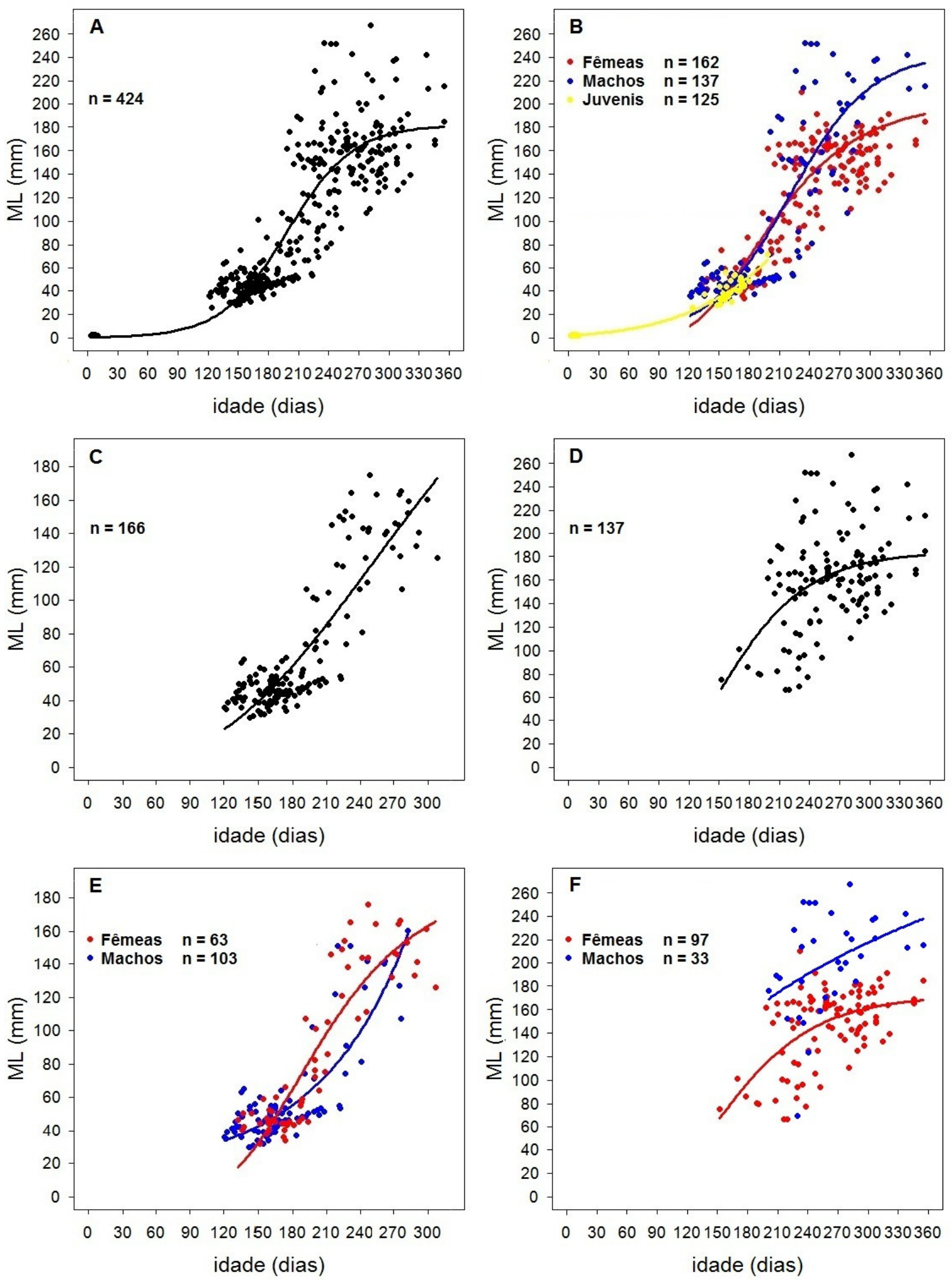

Figura 26 - Relação entre idade (em dias) e comprimento de manto (ML), com seus respectivos número amostral (n): amostra total (A), ajuste logístico; fêmeas, machos e juvenis (B), ajustados pelos modelos, na sequência, Gompertz, logístico e Gompertz; por estádio de maturidade II (C), ajuste Gompertz; e estádio III (D), ajuste Gompertz; para fêmeas e machos em estádio de maturidade II (E), ajuste na sequência por sexo, Gompertz e Schnute; e por último, para fêmeas e machos em estádio de maturidade III (F), ajuste na sequência por sexo, Gompertz e logarítmico. Ver os parâmetros de ajuste de crescimento nas Tabelas 15 a 17. 


\subsubsection{Curva de crescimento por estação do ano}

Também através do retro-cálculo de idade foram testados os modelos de crescimento com os dados de (idade e ML) das lulas por época do ano (primavera, verão, outono e inverno). Sendo assim, a curva de crescimento de lulas nascidas na primavera foi ajustada pelo modelo exponencial. Apesar de o modelo potencial ter apresentado mesmo valor de $\mathrm{AICw}$ o $r^{2}$ do modelo potencial apresentou valor mais significativo. O modelo Logístico foi o que melhor se ajustou para lulas nascidas no verão. Já para lulas do outono, o modelo Gompertz. O melhor ajuste para lulas nascidas no inverno foi estabelecido pelo modelo logarítmico (Tabela 18 e Figura 27). 
Tabela 18- Modelos de crescimento obtidos para lulas nascidas na primavera, verão, outono e inverno, com seus respectivos número amostral (n), parâmetros dos modelos testados: valores de $L$ infinito $\left(L_{i n f}\right)$, taxa de crescimento $(k)$, valor de $t_{0}\left(t_{0}\right)$, valor de $a$ e $b(a, b)$, coeficiente de determinação da equação $\left(r^{2}\right)$, índice Akaike (AIC) e peso de AIC (AICw).

\begin{tabular}{|c|c|c|c|c|c|c|c|c|c|}
\hline \multicolumn{2}{|c|}{ Modelo de crescimento } & $L_{\text {inf }}$ & $k$ & $t_{0}$ & $\boldsymbol{A}$ & \multirow{2}{*}{$\frac{\boldsymbol{b}}{-44,680}$} & \multirow{2}{*}{\begin{tabular}{|c|}
$\boldsymbol{r}^{2}$ \\
0,83
\end{tabular}} & \multirow{2}{*}{$\frac{\text { AIC }}{176,386}$} & $\mathrm{AICw}$ \\
\hline \multirow{8}{*}{ 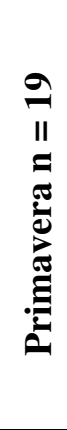 } & linear & & & & 0,642 & & & & 0,088 \\
\hline & potencial & & & & 0,061 & 1,350 & 0,78 & 173,902 & 0,304 \\
\hline & exponencial & & & & 21,470 & 0,006 & 0,81 & 173,902 & 0,304 \\
\hline & logarítmico & & & & 136,700 & $-633,400$ & 0,77 & 182,511 & 0,004 \\
\hline & von Bertalanffy & 158,44 & 0,17 & $-0,62$ & & & & & 0 \\
\hline & logístico & 160,83 & 0,14 & $-0,56$ & & & & & 0 \\
\hline & Gompertz & 160,83 & 0,14 & $-0,56$ & & & & & 0 \\
\hline & Schnute & 186,65 & $-2,16$ & 19,39 & & & 0,87 & 173,918 & 0,301 \\
\hline \multirow{8}{*}{ 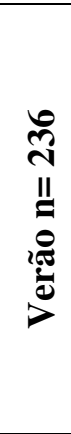 } & linear & & & & 0,552 & $-11,040$ & 0,81 & 2291,917 & 0 \\
\hline & potencial & & & & 0,390 & 1,005 & 0,96 & 2188,286 & 0 \\
\hline & exponencial & & & & 2,242 & 0,016 & 0,96 & 2188,286 & 0 \\
\hline & logarítmico & & & & 29,740 & $-52,100$ & 0,60 & 2468,280 & 0 \\
\hline & von Bertalanffy & 45,45 & $-1,99$ & 0,03 & & & 0,87 & 2208,916 & 0 \\
\hline & logístico & 187,50 & 0,03 & 2,05 & & & 0,90 & 2139,024 & 0,970 \\
\hline & Gompertz & 211,15 & 0,02 & 2,06 & & & 0,90 & 2145,958 & 0,030 \\
\hline & Schnute & 222,20 & $-1,99$ & 1,25 & & & 0,87 & 2208,916 & 0 \\
\hline \multirow{8}{*}{ 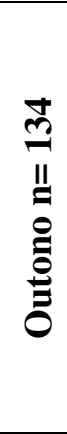 } & linear & & & & 0,977 & $-107,100$ & 0,68 & 1323,742 & $<0,001$ \\
\hline & potencial & & & & 0,003 & 1,941 & 0,77 & 1336,440 & $<0,001$ \\
\hline & exponencial & & & & 8,359 & 0,010 & 0,75 & 1336,440 & $<0,001$ \\
\hline & logarítmico & & & & 208 & -1007 & 0,69 & 1317,845 & 0,004 \\
\hline & von Bertalanffy & 259,90 & 2,38 & 0,35 & & & 0,70 & 1317,527 & 0,005 \\
\hline & logístico & 98,43 & 0,33 & $-0,19$ & & & & & 0 \\
\hline & Gompertz & 184,60 & 0,02 & 4,17 & & & 0,72 & 1306,861 & 0,986 \\
\hline & Schnute & 259,86 & 2,38 & 34,50 & & & 0,70 & 1317,527 & 0,005 \\
\hline \multirow{8}{*}{ 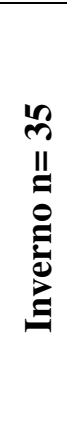 } & linear & & & & 0,991 & $-84,91$ & 0,69 & 348,582 & 0,225 \\
\hline & potencial & & & & 0,001 & 2,054 & 0,82 & 350,261 & 0,097 \\
\hline & exponencial & & & & 11,160 & 0,010 & 0,79 & 350,261 & 0,097 \\
\hline & logarítmico & & & & 188,100 & -876 & 0,69 & 348,308 & 0,259 \\
\hline & von Bertalanffy & 397,65 & 1,28 & 0,27 & & & 0,69 & 350,353 & 0,093 \\
\hline & logístico & 139,80 & 0,48 & $-0,45$ & & & & & 0 \\
\hline & Gompertz & 23,61 & 0,01 & 10,20 & & & 0,69 & 349,603 & 0,135 \\
\hline & Schnute & 164,93 & 1,28 & 39,42 & & & 0,69 & 350,353 & 0,093 \\
\hline
\end{tabular}



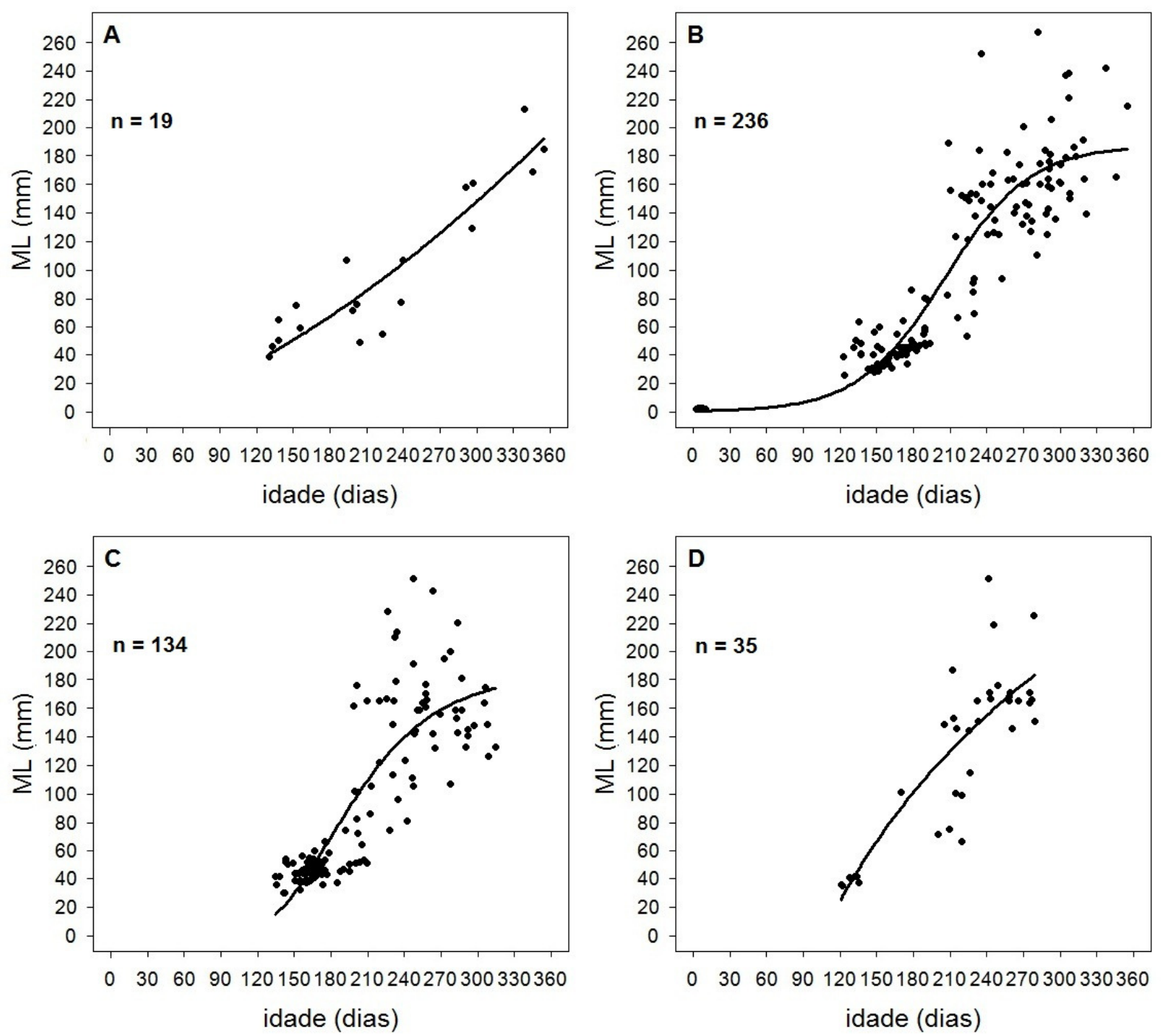

Figura 27 - Relação entre idade (dias) e comprimento de manto (ML) dos exemplares de lulas nascidas nas épocas do ano, com seus respectivos ajustes de crescimento: primavera (A), ajuste exponencial; verão (B), ajuste logístico; outono (C), ajuste Gompertz; e inverno (D), ajuste logarítmico. Ver os parâmetros dos modelos de ajuste na Tabela 18.

Quando analisado por sexo, para as fêmeas nascidas na primavera, o melhor ajuste foi estabelecido pelo von Bertalanffy e para machos, o exponencial (Tabela 19, Figura 28A). O ajuste Gompertz foi à melhor escolha para fêmeas e machos nascidos no verão, onde os juvenis tiveram o modelo de crescimento Schnute que melhor se relacionou (Tabela 20, Figura 28B). 
Para as lulas nascidas no outono, o modelo Gompertz foi ajustado para as fêmeas e exponencial para os machos (Tabela 21, Figura 28C). O melhor ajuste de crescimento estabelecido para os juvenis nascidos no outono foi o modelo logarítmico. Os modelos von Bertalanffy, Logístico, Gompertz e Schnute, não foram possíveis de serem ajustados, talvez devido ao baixo número amostral de lulas (16 indivíduos). Já o modelo de crescimento linear foi ajustado para ambos os sexos das lulas nascidas no inverno (Tabela 22, Figura 28D).

Tabela 19 - Modelos de crescimento obtidos para fêmeas e machos nascidos na primavera com seus respectivos número amostral (n), parâmetros dos modelos testados: valores de $L$ infinito $(L$ inf), taxa de crescimento $(k)$, valor de $t_{0}\left(t_{0}\right)$, valor de $a$ e $b(a, b)$, coeficiente de determinação da equação $\left(r^{2}\right)$, índice Akaike (AIC) e peso de AIC (AICw).

\begin{tabular}{|c|c|c|c|c|c|c|c|c|c|c|}
\hline \multicolumn{3}{|c|}{ Modelo de crescimento } & $L_{\text {inf }}$ & $\boldsymbol{k}$ & to & $a$ & $b$ & $r^{2}$ & AIC & AICw \\
\hline \multirow{16}{*}{ 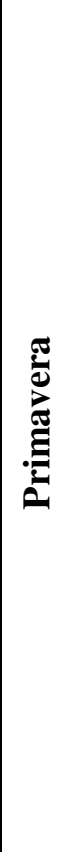 } & \multirow{8}{*}{$\begin{array}{c}\text { Fêmeas } \\
n=13\end{array}$} & linear & & & & 0,586 & $-29,180$ & 0,90 & 113,140 & 0 \\
\hline & & potencial & & & & 0,090 & 1,290 & 0,89 & 112,757 & 0 \\
\hline & & exponencial & & & & 25,510 & 0,010 & 0,88 & 113,757 & 0 \\
\hline & & logarítmico & & & & 129 & -590 & 0,87 & 116,307 & 0 \\
\hline & & von Bertalanffy & 137,40 & 0,29 & 39 & & & 0,99 & 36,899 & 1 \\
\hline & & logistico & 186,48 & 0,15 & $-0,71$ & & & & & 0 \\
\hline & & Gompertz & 57,16 & 0 & 3,33 & & & 0,90 & 114,664 & 0 \\
\hline & & Schnute & 145,86 & 0,29 & $-5,44$ & & & 0,99 & 36,899 & 0 \\
\hline & \multirow{8}{*}{$\begin{array}{c}\text { Machos } \\
\mathrm{n}=5\end{array}$} & linear & & & & 0,754 & $-71,830$ & 0,76 & 54,687 & 0,092 \\
\hline & & potencial & & & & 0,054 & 1,350 & 0,63 & 51,557 & 0,439 \\
\hline & & exponencial & & & & 16,550 & 0,010 & 0,75 & 51,557 & 0,439 \\
\hline & & logarítmico & & & & 148 & -696 & 0,63 & 56,881 & 0,031 \\
\hline & & von Bertalanffy & 224,07 & 0,29 & $-0,97$ & & & & & 0 \\
\hline & & logistico & 224,07 & 0,29 & $-0,95$ & & & & & 0 \\
\hline & & Gompertz & 224,07 & 0,29 & $-0,95$ & & & & & 0 \\
\hline & & Schnute & 224,07 & 0,29 & $-0,97$ & & & & & 0 \\
\hline
\end{tabular}


Tabela 20- Modelos de crescimento obtidos para fêmeas, machos e juvenis nascidos no verão com seus respectivos número amostral (n), parâmetros dos modelos testados: valores de $L$ infinito $\left(L_{i n f}\right)$, taxa de crescimento $(k)$, valor de $t_{0}\left(t_{0}\right)$, valor de $a$ e $b(a, b)$, coeficiente de determinação da equação $\left(r^{2}\right)$, índice Akaike (AIC) e peso de AIC (AICw).

\begin{tabular}{|c|c|c|c|c|c|c|c|c|c|c|}
\hline \multicolumn{3}{|c|}{ Modelo de crescimento } & $L_{\text {inf }}$ & $k$ & to & $a$ & $b$ & $r^{2}$ & AIC & $\mathrm{AICw}$ \\
\hline \multirow{24}{*}{ 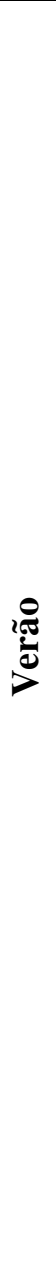 } & \multirow{8}{*}{$\begin{array}{c}\text { Fêmeas } \\
n=70\end{array}$} & linear & & & & 0,810 & $-75,890$ & 0,72 & 655,590 & $<0,001$ \\
\hline & & potencial & & & & 0,001 & 2,080 & 0,76 & 661,821 & $<0,001$ \\
\hline & & exponencial & & & & 13,140 & 0,010 & 0,71 & 661,821 & $<0,001$ \\
\hline & & logarítmico & & & & 192 & -932 & 0,75 & 647,192 & 0,004 \\
\hline & & von Bertalanffy & 135,75 & 0,34 & $-0,44$ & & & & & 0 \\
\hline & & logistico & 131,79 & 0,25 & $-0,34$ & & & & & 0 \\
\hline & & Gompertz & 168,40 & 0,03 & 12,66 & & & 0,79 & 636,133 & 0,984 \\
\hline & & Schnute & 214,76 & 3,23 & 51,65 & & & 0,77 & 644,972 & 0,012 \\
\hline & \multirow{8}{*}{$\begin{array}{c}\text { Machos } \\
\text { n= 59 }\end{array}$} & linear & & & & 1,106 & -126 & 0,79 & 588,506 & 0,140 \\
\hline & & potencial & & & & 0,001 & 2,090 & 0,79 & 592,223 & 0,022 \\
\hline & & exponencial & & & & 8,546 & 0,010 & 0,80 & 592,223 & 0,022 \\
\hline & & logarítmico & & & & 232 & -1124 & 0,76 & 594,676 & 0,006 \\
\hline & & von Bertalanffy & 295,20 & $-1,31$ & 0,31 & & & 0,78 & 591,287 & 0,035 \\
\hline & & logistico & 116,36 & 0,17 & $-0,20$ & & & & & 0 \\
\hline & & Gompertz & 30,37 & 0,01 & 1,24 & & & 0,80 & 585,173 & 0,740 \\
\hline & & Schnute & 184,20 & $-0,13$ & 11,71 & & & 0,78 & 591,287 & 0,035 \\
\hline & \multirow{8}{*}{$\begin{array}{c}\text { Juvenis } \\
\mathrm{n}=107\end{array}$} & linear & & & & 0,215 & 0,920 & 0,98 & 385,343 & 0 \\
\hline & & potencial & & & & 0,577 & 0,790 & 0,96 & 402,473 & 0 \\
\hline & & exponencial & & & & 1,906 & 0,020 & 0,99 & 402,473 & 0 \\
\hline & & logarítmico & & & & 9,270 & $-13,030$ & 0,94 & 536,908 & 0 \\
\hline & & von Bertalanffy & 54,29 & 0,16 & $-0,57$ & & & & & 0 \\
\hline & & logistico & 215,93 & $-0,01$ & $-0,18$ & & & & & 0 \\
\hline & & Gompertz & 215,93 & $-0,01$ & $-0,18$ & & & & & 0 \\
\hline & & Schnute & 175,93 & $-4,60$ & 5,08 & & & 0,99 & 279,965 & 1 \\
\hline
\end{tabular}


Tabela 21 - Modelos de crescimento obtidos para fêmeas, machos e juvenis nascidos no outono com seus respectivos número amostral (n), parâmetros dos modelos testados: valores de $L$ infinito $\left(L_{i n f}\right)$, taxa de crescimento $(k)$, valor de $t_{0}\left(t_{0}\right)$, valor de $a$ e $b(a, b)$, coeficiente de determinação da equação $\left(r^{2}\right)$, índice Akaike (AIC) e peso de AIC (AICw).

\begin{tabular}{|c|c|c|c|c|c|c|c|c|c|c|}
\hline \multicolumn{3}{|c|}{ Modelo de crescimento } & $L_{\text {inf }}$ & $k$ & to & $a$ & $b$ & $r^{2}$ & AIC & $\mathrm{AICw}$ \\
\hline \multirow{24}{*}{$\begin{array}{l}\stackrel{0}{0} \\
\stackrel{\Xi}{\Xi}\end{array}$} & \multirow{8}{*}{$\begin{array}{c}\text { Fêmeas } \\
\mathrm{n}=\mathbf{5 7}\end{array}$} & linear & & & & 0,793 & $-65,650$ & 0,60 & 564,173 & $<0,001$ \\
\hline & & potencial & & & & 0,002 & 2 & 0,71 & 567,836 & $<0,001$ \\
\hline & & exponencial & & & & 13,560 & 0,010 & 0,66 & 567,836 & $<0,001$ \\
\hline & & logarítmico & & & & 180 & -858 & 0,64 & 557,882 & 0,008 \\
\hline & & von Bertalanffy & 124,30 & 0,25 & $-0,41$ & & & & & 0 \\
\hline & & logistico & 119,86 & 0,35 & $-0,34$ & & & & & 0 \\
\hline & & Gompertz & 162,90 & 0,03 & 11,78 & & & 0,71 & 548,416 & 0,915 \\
\hline & & Schnute & 180,43 & 4,92 & 9,50 & & & 0,68 & 553,369 & 0,077 \\
\hline & \multirow{8}{*}{$\begin{array}{c}\text { Machos } \\
n=61\end{array}$} & linear & & & & 1,224 & -152 & 0,68 & 611,707 & 0,088 \\
\hline & & potencial & & & & 0 & 2,530 & 0,75 & 616,291 & 0,009 \\
\hline & & exponencial & & & & 5,778 & 0,010 & 0,76 & 609,543 & 0,260 \\
\hline & & logarítmico & & & & 241 & -1179 & 0,66 & 609,543 & 0,260 \\
\hline & & von Bertalanffy & 100,32 & $-2,25$ & 0,27 & & & 0,69 & 611,282 & 0,109 \\
\hline & & logistico & 89,17 & 0,52 & $-0,23$ & & & & & 0 \\
\hline & & Gompertz & 43,56 & 0,01 & 9,91 & & & 0,70 & 610,462 & 0,164 \\
\hline & & Schnute & 129,33 & $-2,26$ & 46,24 & & & 0,69 & 611,282 & 0,109 \\
\hline & \multirow{8}{*}{$\begin{array}{c}\text { Juvenis } \\
n=16\end{array}$} & linear & & & & 0,390 & $-18,220$ & 0,25 & 109,051 & 0,248 \\
\hline & & potencial & & & & 0,012 & 1,610 & 0,30 & 109,138 & 0,237 \\
\hline & & exponencial & & & & 8,935 & 0,010 & 0,29 & 109,138 & 0,237 \\
\hline & & logarítmico & & & & 63,46 & -278 & 0,26 & 108,822 & 0,278 \\
\hline & & von Bertalanffy & & & & & & & & 0 \\
\hline & & logistico & & & & & & & & 0 \\
\hline & & Gompertz & & & & & & & & 0 \\
\hline & & Schnute & & & & & & & & 0 \\
\hline
\end{tabular}


Tabela 22- Modelos de crescimento obtidos para fêmeas e machos nascidos no inverno com seus respectivos número amostral (n), parâmetros dos modelos testados: valores de $L$ infinito $\left(L_{\text {inf }}\right)$, taxa de crescimento $(k)$, valor de $t_{0}\left(t_{0}\right)$, valor de $a$ e $b(a, b)$, coeficiente de determinação da equação $\left(r^{2}\right)$, índice Akaike (AIC) e peso de AIC (AICw).

\begin{tabular}{|c|c|c|c|c|c|c|c|c|c|c|}
\hline \multicolumn{3}{|c|}{ Modelo de crescimento } & $L_{\text {inf }}$ & $\boldsymbol{k}$ & to & $a$ & $b$ & $r^{2}$ & AIC & AICw \\
\hline \multirow{16}{*}{ 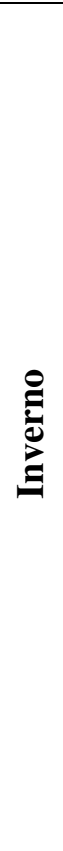 } & \multirow{8}{*}{$\begin{array}{c}\text { Fêmeas } \\
\mathbf{n}=22\end{array}$} & linear & & & & 0,803 & -50 & $\overline{0,46}$ & 208,742 & 0,197 \\
\hline & & potencial & & & & 0,044 & 1,470 & 0,41 & 208,764 & 0,195 \\
\hline & & exponencial & & & & 29,410 & 0,010 & 0,42 & 208,764 & 0,195 \\
\hline & & logarítmico & & & & 184 & -863 & 0,46 & 208,917 & 0,180 \\
\hline & & von Bertalanffy & 567,20 & 0,69 & 0,23 & & & 0,46 & 210,597 & 0,078 \\
\hline & & logistico & 145,54 & 0,83 & $-1,36$ & & & & & 0 \\
\hline & & Gompertz & 277,70 & 0,01 & 5,18 & & & 0,46 & 210,585 & 0,078 \\
\hline & & Schnute & 99,23 & 0,69 & 52,47 & & & 0,46 & 210,597 & 0,078 \\
\hline & \multirow{8}{*}{$\begin{array}{c}\text { Machos } \\
\mathrm{n}=12\end{array}$} & linear & & & & 1,376 & -138 & 0,87 & 121,464 & 0,246 \\
\hline & & potencial & & & & 0,001 & 2,240 & 0,93 & 122,223 & 0,168 \\
\hline & & exponencial & & & & 7,052 & 0,010 & 0,92 & 122,223 & 0,168 \\
\hline & & logarítmico & & & & 245,7 & -1154 & 0,85 & 122,717 & 0,131 \\
\hline & & von Bertalanffy & 804,69 & $-0,54$ & 0,26 & & & 0,86 & 123,773 & 0,077 \\
\hline & & logistico & 231,62 & 0,15 & $-0,47$ & & & & & 0 \\
\hline & & Gompertz & 392,04 & 0,01 & 9,61 & & & 0,87 & 122,707 & 0,132 \\
\hline & & Schnute & 107,63 & $-0,54$ & 12,66 & & & 0,86 & 123,773 & 0,077 \\
\hline
\end{tabular}



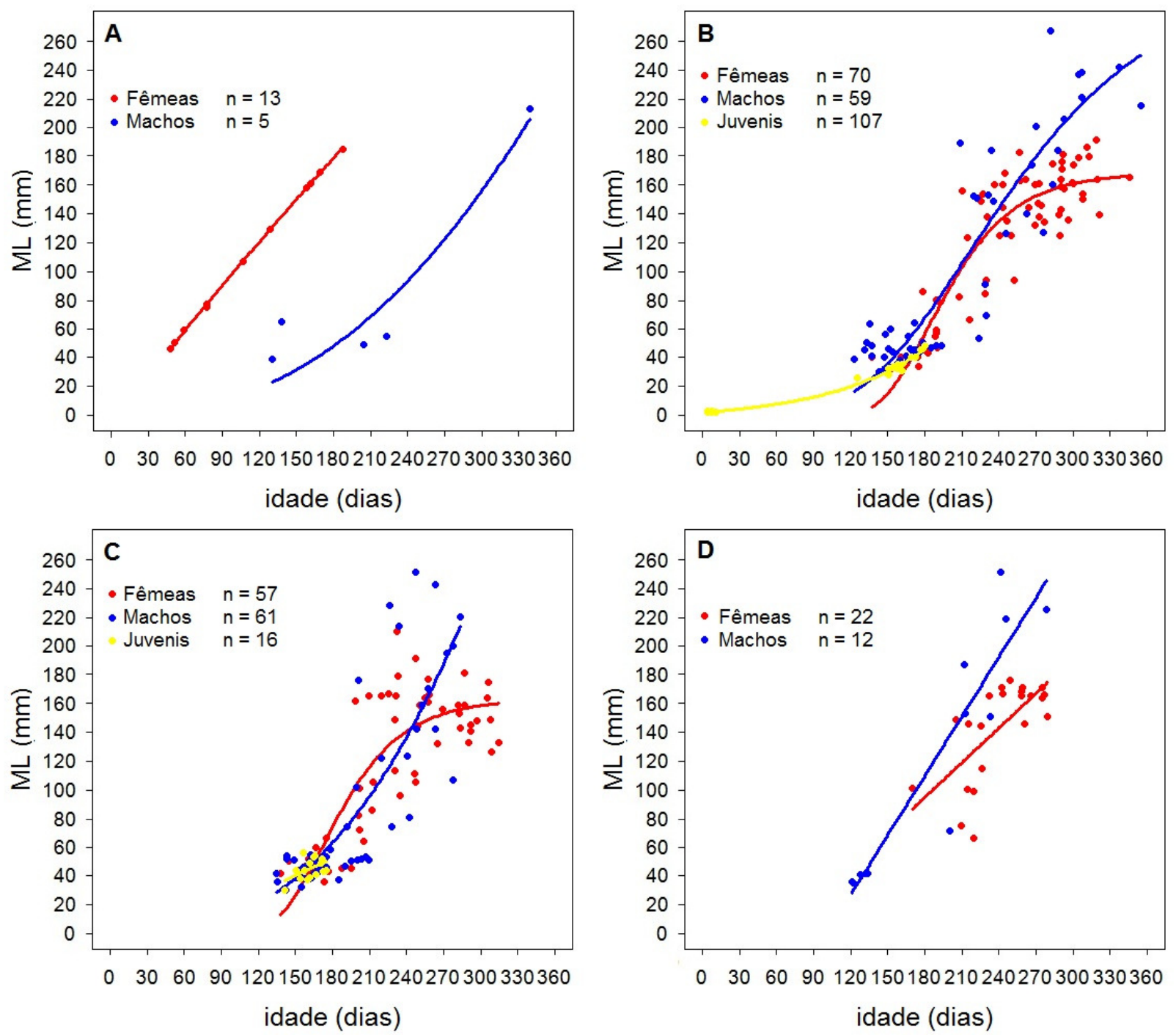

Figura 28 - Relação entre idade (dias) e comprimento de manto (ML) para fêmeas, machos e juvenis, nascidos por estação do ano e com seus respectivos ajustes de crescimento: primavera (A), ajuste von Bertalanffy para as fêmeas e exponencial para os machos; verão (B), ajuste Gompertz para ambos os sexos e Schnute para juvenis; outono (C), ajuste Gompertz e exponencial, para fêmeas e machos, e ajuste logarítmico para os juvenis; e inverno (D), ajuste linear para ambos os sexos. Ver os parâmetros dos modelos de ajuste nas Tabelas 19 a 22.

\subsubsection{Longevidade}

A longevidade de Doryteuthis plei, foi estimada pela equação de Taylor (1958) em 102 dias (três meses e doze dias), porém não é o que os dados obtidos no estudos confirmam, pois foram encontrados lulas com até 355 dias (onze meses e 25 dias) na amostra. A longevidade estimada para fêmeas e machos também foram subestimadas pela equação de Taylor (1958). A estimativa para fêmeas foi de 160 dias (cinco meses e dez dias) e para machos, 117 dias (três meses e vinte e sete dias). Em contrapartida, a estimativa de longevidade através da média de idade dos indivíduos desovantes 
(estádios III e IV) quando analisados por sexo, revelou que de 99 exemplares fêmeas, com intervalo de idade entre 152 e 255 dias, a média de idade foi de 262 dias. Dos 34 exemplares dos machos desovantes (estádios III e IV), com intervalo de idade entre 201 e 212 a 355 dias, a média de idade foi de 261 dias. Sedo assim, esta estimativa se aproxima da idade máxima obtida na amostra. A longevidade obtida para a espécie da região em estudada é de oito meses e sete dias, igual para fêmeas e machos.

A Tabela 23 exibe os valores médios de idade obtida através das leituras dos incrementos de crescimento nos estatólitos em classes de tamanho, e a Tabela 27 os intervalos e médias de idade por estágio de maturidade.

Tabela 23 - Idade média (em dias) dos exemplares por classes de tamanho (ML, mm) com o número de exemplares (n), desvio padrão da média da idade (DP), e valores mínimos (Mínimo) e máximos (Máximo) das idades por classe de tamanho.

\begin{tabular}{|c|c|c|c|c|c|}
\hline $\mathbf{n}$ & ML (mm) & Média idade & DP & Mínimo & Máximo \\
\hline 91 & 0 a 9 & 5 & 1 & 3 & 10 \\
3 & 20 a 29 & 141 & 15 & 124 & 151 \\
41 & 30 a 39 & 153 & 13 & 121 & 185 \\
68 & 40 a 49 & 165 & 17 & 128 & 205 \\
34 & 50 a 59 & 172 & 24 & 133 & 223 \\
10 & 60 a 69 & 181 & 35 & 136 & 229 \\
10 & 70 a 79 & 201 & 23 & 152 & 238 \\
7 & 80 a 89 & 208 & 22 & 178 & 242 \\
5 & 90 a 99 & 233 & 12 & 220 & 252 \\
9 & 100 a 109 & 217 & 33 & 170 & 278 \\
4 & 110 a 119 & 246 & 25 & 226 & 281 \\
11 & 120 a 129 & 255 & 32 & 215 & 309 \\
11 & 130 a 139 & 279 & 27 & 230 & 322 \\
21 & 140 a 149 & 259 & 29 & 205 & 308 \\
20 & 150 a 159 & 258 & 34 & 210 & 308 \\
31 & 160 a 169 & 266 & 36 & 199 & 346 \\
15 & 170 a 179 & 268 & 30 & 201 & 306 \\
10 & 180 a 189 & 276 & 47 & 209 & 355 \\
3 & 190 a 199 & 279 & 37 & 247 & 319 \\
3 & 200 a 209 & 280 & 12 & 270 & 293 \\
5 & 210 a 219 & 281 & 60 & 232 & 355 \\
4 & 220 a 229 & 274 & 34 & 226 & 307 \\
2 & 230 a 239 & 305 & 2 & 304 & 307 \\
2 & 240 a 249 & 300 & 53 & 263 & 337 \\
3 & 250 a 259 & 241 & 6 & 235 & 247 \\
1 & 260 a 269 & 282 & 0 & 282 & 282 \\
\hline
\end{tabular}


As lulas fêmeas apresentam peso equivalente ao dos machos até atingirem comprimento de manto próximo a $59 \mathrm{~mm}$. A partir deste ML, os machos continuam com mesmo ritmo de ganho em peso, porém as fêmeas dobram de massa corpórea quando atingem comprimento de manto entre as classes de 60 a $69 \mathrm{~mm}$ em relação o espectro de comprimento anterior (Tabela 24). Em geral, a média da idade das lulas fêmeas e machos variaram em até 185 dias, destacando o intervalo de ML 160 a 169 mm e 67 dias de variação (intervalo de ML entre 180 a 189 mm) (Tabela 24).

Tabela 24 - Média do peso (g, gramas) e média de incrementos nos estatólitos (em dias) por classe de comprimento de manto (ML, mm) para fêmeas e machos.

\begin{tabular}{|c|c|c|c|c|}
\hline \multirow{2}{*}{ ML (mm) } & \multicolumn{2}{|c|}{ Média de peso (g) } & \multicolumn{2}{|c|}{ Média incrementos estatólitos } \\
\hline & Fêmeas & Machos & Fêmeas & Machos \\
\hline 30 a 39 & 2,7 & 3,0 & 165 & 150 \\
\hline 40 a 49 & 4,3 & 4,7 & 167 & 163 \\
\hline 50 a 59 & 6,9 & 6,7 & 166 & 176 \\
\hline 60 a 69 & 13,9 & 8,9 & 196 & 165 \\
\hline 70 a 79 & 18,2 & 10,2 & 199 & 207 \\
\hline 80 a 89 & 24,7 & 15,5 & 203 & 242 \\
\hline 90 a 99 & 29,6 & 20,0 & 234 & 229 \\
\hline 100 a 109 & 27,4 & 21,8 & 211 & 238 \\
\hline 110 a 119 & 33,0 & sem dados & 246 & sem dados \\
\hline 120 a 129 & 41,9 & 41,6 & 260 & 245 \\
\hline 130 a 139 & 49,5 & sem dados & 279 & sem dados \\
\hline 140 a 149 & 56,9 & 50,4 & 260 & 252 \\
\hline 150 a 159 & 66,4 & 57,4 & 271 & 228 \\
\hline 160 a 169 & 80,0 & 120,5 & 265 & 80 \\
\hline 170 a 179 & 89,1 & 77,5 & 274 & 241 \\
\hline 180 a 189 & 97,1 & 81,5 & 302 & 235 \\
\hline 190 a 199 & 90,2 & 79,8 & 283 & 272 \\
\hline 200 a 209 & sem dados & 113,0 & sem dados & 280 \\
\hline 210 a 219 & 111,35 & 127,6 & 232 & 293 \\
\hline 220 a 229 & sem dados & 141,1 & sem dados & 274 \\
\hline 230 a 239 & sem dados & 148,8 & sem dados & 305 \\
\hline 240 a 249 & sem dados & 154,2 & sem dados & 300 \\
\hline 250 a 259 & sem dados & 151,9 & sem dados & 152 \\
\hline 260 a 269 & sem dados & 160,6 & sem dados & 282 \\
\hline
\end{tabular}

As médias de idade para classes de comprimento de manto obtidos no presente estudo foram em geral mais elevadas do que as obtidas em outros trabalhos. A Tabela 
25 compara as diferença entre as médias de idade encontrada para Doryteuthis plei por diferentes estudos e evidencia que o presente estudo abrange classes de ML em que não foram contempladas em outros estudos (intervalo de 0 a $79 \mathrm{~mm}$ e de 240 a $269 \mathrm{~mm}$ ).

Tabela 25 - Comparação das médias de idade obtida por classe de comprimento de manto (ML) em relação a trabalhos prévios para $D$. plei.

\begin{tabular}{|c|c|c|c|}
\hline \multirow{2}{*}{$\begin{array}{c}\text { ML } \\
(\mathbf{m m})\end{array}$} & \multicolumn{3}{|c|}{$\begin{array}{l}\text { Idade média por classe de } \\
\text { tamanho }\end{array}$} \\
\hline & $\begin{array}{c}\text { Presente } \\
\text { estudo }\end{array}$ & $\begin{array}{c}\text { Perez et al. } \\
(2006)\end{array}$ & $\begin{array}{c}\text { Jackson \& } \\
\text { Forsythe } \\
(\mathbf{2 0 0 2}) \\
\end{array}$ \\
\hline $0-9$ & 5 & - & - \\
\hline $20-29$ & 141 & - & - \\
\hline $30-39$ & 153 & - & - \\
\hline $40-49$ & 165 & - & - \\
\hline $50-59$ & 172 & - & - \\
\hline $60-69$ & 181 & - & - \\
\hline $70-79$ & 201 & - & - \\
\hline $80-89$ & 208 & 174,7 & 83,1 \\
\hline $90-99$ & 233 & 179,2 & 92,1 \\
\hline $100-109$ & 217 & 187 & 100,2 \\
\hline $110-119$ & 246 & 219,3 & 107,5 \\
\hline $120-129$ & 255 & 217,3 & 114,1 \\
\hline $130-139$ & 279 & 227,6 & 120,2 \\
\hline $140-149$ & 259 & 228,5 & 125,9 \\
\hline $150-159$ & 258 & 235,1 & 131,1 \\
\hline $160-169$ & 266 & 243,7 & 136,1 \\
\hline $170-179$ & 268 & 253,3 & 140,7 \\
\hline $180-189$ & 276 & 246,4 & 145 \\
\hline $190-199$ & 279 & 280,5 & 149,2 \\
\hline $200-209$ & 280 & 263,3 & 153,1 \\
\hline $210-219$ & 281 & 254,3 & 156,8 \\
\hline $220-229$ & 274 & 259,7 & 160,4 \\
\hline $230-239$ & 305 & 277,5 & 163,8 \\
\hline $240-249$ & 300 & - & - \\
\hline $250-259$ & 241 & - & - \\
\hline $260-269$ & 282 & - & - \\
\hline
\end{tabular}

Quando a média das idades obtidas no presente estudo é comparada com a média das idades de fêmeas e machos de outros estudos de Doryteuhis plei e de Loligo vulgaris, é observado que as médias obtidas para as classes de ML por sexo para lulas com $100 \mathrm{~mm}$ foram superiores aos outros estudos, quando comparado com os valores 
obtidos para os comprimentos de manto de 150 e $200 \mathrm{~mm}$, as médias foram equivalentes (Tabela 26).

Tabela 26- Comparação das médias de idade obtida por classe de comprimento de manto (ML) de fêmeas e machos, obtida no presente estudo com estudos prévios de Doryteuthis plei e Loligo vulgaris.

\begin{tabular}{|c|c|c|c|c|c|c|}
\hline \multirow{4}{*}{$\begin{array}{l}\text { ML classes } \\
\quad(\mathbf{m m})\end{array}$} & \multicolumn{6}{|c|}{ Idade média por classe de tamanho } \\
\hline & \multicolumn{4}{|c|}{ Doryteuthis plei } & \multirow{2}{*}{\multicolumn{2}{|c|}{$\begin{array}{l}\text { Loligo vulgaris } \\
\text { Arkhipkin (1995) }\end{array}$}} \\
\hline & \multicolumn{2}{|c|}{ Presente estudo } & \multicolumn{2}{|c|}{ Aguiar (2002) } & & \\
\hline & Fêmeas & Machos & Fêmeas & Machos & Fêmeas & Machos \\
\hline 100 & 220 & 229 & 170 & 184 & 180 & 170 \\
\hline 150 & 263 & 235 & 206 & 224 & 230 & 220 \\
\hline 200 & 266 & 278 & 310 & 280 & 280 & 250 \\
\hline
\end{tabular}

Analisando as médias de idade por estádio de maturidade, lulas no estádio I apresentaram variação de idade entre 2,7 a 198,5 dias, porém, exemplares com idade a partir de 120 dias (machos) de idade foram identificados em estádio II e 132,7 dias (fêmeas). Sendo assim, os machos entram em maturação antes do que as fêmeas, porém as fêmeas ficam maduras (estádio III) antes do que os machos, com idade a partir de 152 dias, enquanto que os machos, com 201 dias. As fêmeas 100\% desovadas (maturidade IV) foram encontradas com idade a partir de 264,7 dias, já os machos com seu saco espermatofórico vazio com 212,5 dias (Tabela 27).

Tabela 27 - Intervalo dos valores mínimo e máximo das idades por estádio de maturidade e por sexo.

\begin{tabular}{|c|c|c|c|}
\hline \multirow{2}{*}{ Maturação } & \multirow{2}{*}{ Sexo } & \multicolumn{2}{|c|}{$\begin{array}{c}\text { Idade (dias) } \\
\text { Intervalo }\end{array}$} \\
& & Média \\
\hline I & Juvenis & $2,7-198,5$ & 47,5 \\
\hline \multirow{2}{*}{ II } & F & $132,7-308,5$ & 203,8 \\
& M & $120,5-283,5$ & 174,1 \\
\hline \multirow{2}{*}{ III } & F & $152-355$ & 261,4 \\
& M & $200,7-355$ & 262,8 \\
\hline \multirow{2}{*}{ IV } & F & $264,7-286,7$ & 275,7 \\
\cline { 2 - 4 } & M & 212,5 & 212,5 \\
\hline
\end{tabular}




\subsubsection{Taxa instantânea de crescimento}

A taxa instantânea de crescimento (G) (Figura 29) evidenciou a variação do crescimento em diferentes intervalos de crescimento de Doryteuthis plei. Na Figura 29A (para todos os exemplares da amostra) é possível observar o decréscimo da taxa de crescimento conforme ocorre o crescimento. A taxa foi identificada com o valor de 1,15 $\mathrm{mm} /$ dia quando a lula tem $10 \mathrm{~mm}$ de ML, porém ocorre um decréscimo acelerando até atingir $60 \mathrm{~mm} \mathrm{ML}$, quando a taxa atinge valor de 0,65 mm/dia. Do intervalo de $\mathrm{ML}$ entre $60-160 \mathrm{~mm}$ a queda da taxa se torna gradual, porém quando atinge $180 \mathrm{~mm}$ ML o decréscimo se torna acentuado, e a taxa de crescimento pode resultar em $0,3 \mathrm{~mm} / \mathrm{dia}$. Quando comparado a taxa instantânea de crescimento por sexo (Figura 29B), observa-se que a queda da taxa de crescimento é igual entre os comprimentos de manto de 30 a 130, porém a taxa diminui de maneira mais acentuada quando ML $>150 \mathrm{~mm}$ para as fêmeas.
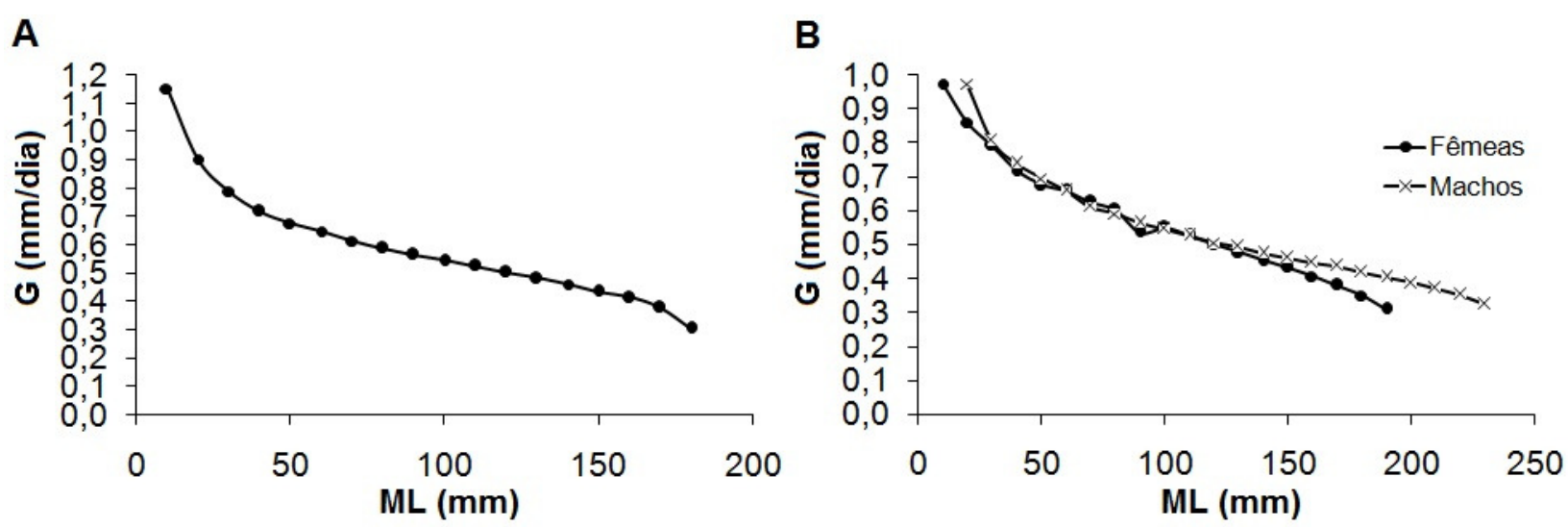

Figura 29 - Taxa instantânea de crescimento (G) estimada para a amostra total (A) e por sexo (B).

Quando G é estimado por estádio de maturidade (Figura 30), observa-se que a maior taxa de crescimento ocorre com os indivíduos de estádio de maturidade I e II. Há um decréscimo da taxa abrupto $(0,84 \mathrm{~mm} / \mathrm{dia})$ entre 10 e $20 \mathrm{~mm}$ de ML para os exemplares em estádio I. Ambos os estádios de maturidade apresentaram praticamente mesma queda na taxa de crescimento entre 50 e $70 \mathrm{~mm}$ de ML. A taxa G se comporta também em decréscimo para os exemplares maduros (III), quando os maiores valores atingidos entre 70 a $170 \mathrm{~mm}$ de ML, quando então a taxa G de lulas III fica menor do que a taxa dos exemplares em maturação (Figura 30). 
Machos em estádio II com $40 \mathrm{~mm}$ de ML apresentavam maior taxa de crescimento do que as fêmeas, porém quando atingiam $50 \mathrm{~mm}$, a taxa $\mathrm{G}$ se torna menor do que fêmeas, onde a taxa vai se igualar entre os sexos apenas quando atingem 150 mm de ML (Figura 31A). Quando analisado o decréscimo da taxa de crescimento entre os sexos, as fêmeas apresentam maiores valores de G quando comparados no mesmo intervalo de comprimento dos machos (Figura 31B).

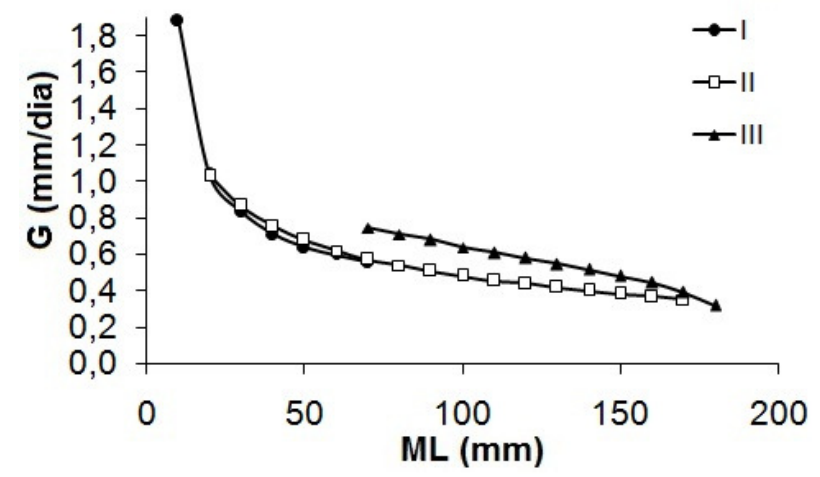

Figura 30 - Taxa instantânea de crescimento (G) para os estádios de maturidade I, II e III.

A

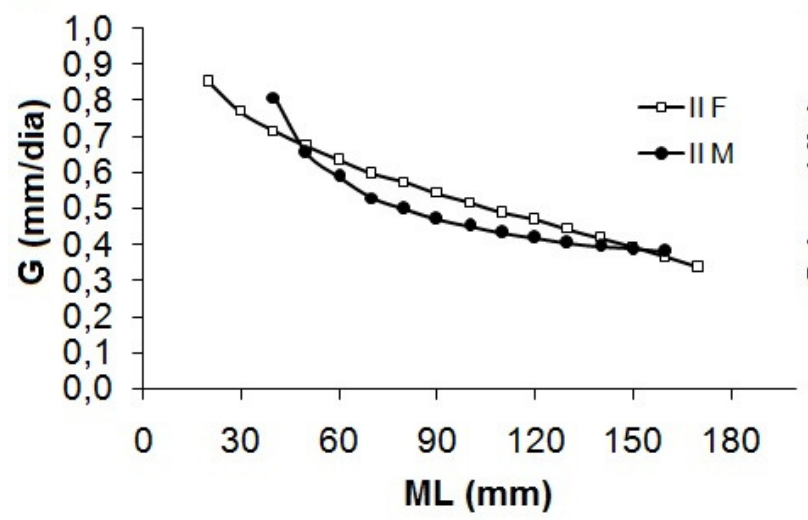

B

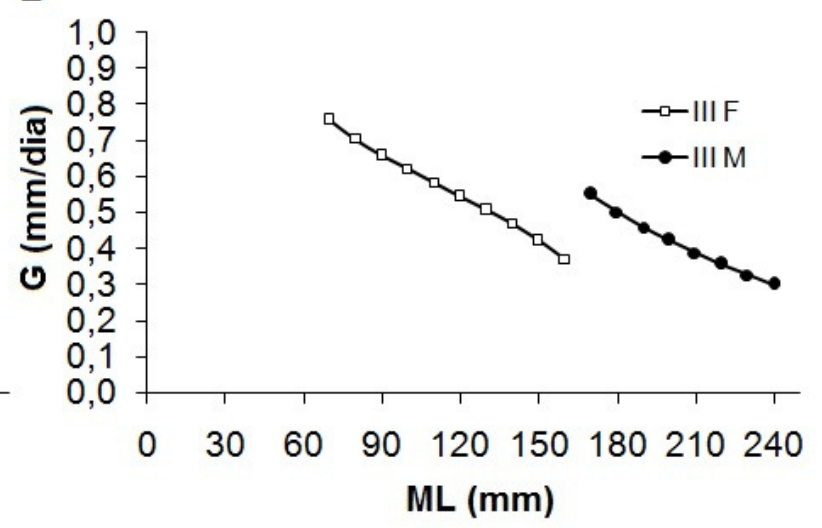

Figura 31 - Taxa instantânea de crescimento $(G)$ para fêmeas $(F)$ e machos $(M)$, em estádios de maturidade II (A) e III (B).

\subsubsection{Taxa instantânea de crescimento por estação do ano}

Com a plotagem da taxa instantânea de crescimento (G) em relação ao comprimento de manto (ML) das lulas nascidas nas diferentes estações do ano, observou-se que exemplares de Doryteuthis plei nascidos no outono e no inverno exibem praticamente o mesmo padrão de crescimento (Figura 32A). Porém quando se analisa os valores de $\mathrm{G}$ por sexo, verificou-se que o crescimento foi muito similar, com 
exceção das lulas fêmeas nascidas na primavera, as quais exibiram os maiores valores de taxa de crescimento (Figura 32B).

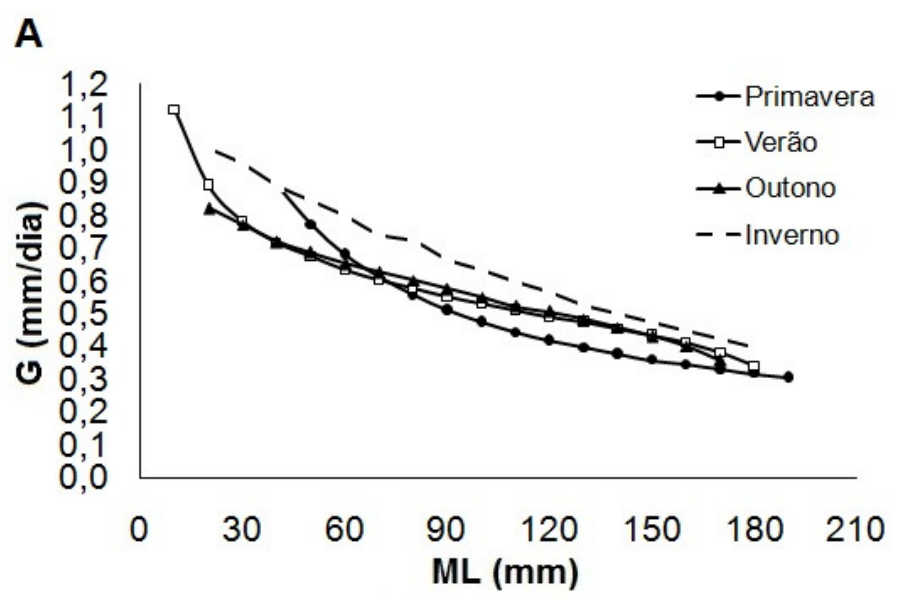

\section{B}

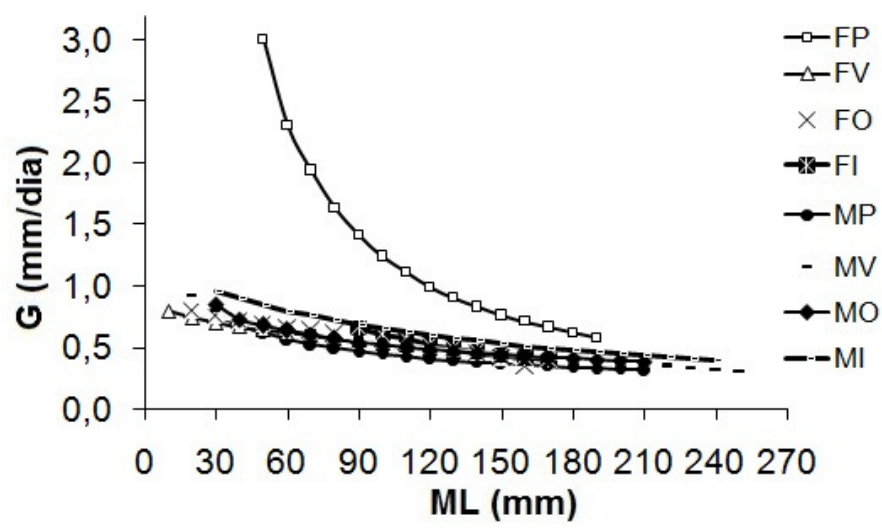

Figura 32 - Taxa instantânea de crescimento $(\mathrm{G})$ em mm/dia por comprimento do manto (ML) para indivíduos nascidos por estação do ano (A) e para fêmeas e machos (B), onde as legendas para fêmeas, as siglas representadas são: primavera $(\mathrm{FP})$, verão $(\mathrm{FV})$, outono $(\mathrm{FO})$ e inverno (FI); e para os machos: MP (primavera), MV (verão), MO (outono) e MI (inverno).

A Figura 33 exibe os valores de G para juvenis, fêmeas e machos nascidos nas quatro estações do ano. Observou-se que o crescimento das fêmeas nascidas na primavera é diferenciado em relação aos machos (Figura 33A). Os valores de G para as lulas juvenis são superiores em relação aos valores de outros espectros de ML (Figura 33B). Para as lulas nascidas no outono e inverno, não foi observado diferença no crescimento das lulas de ambos os sexos (Figura 33C-D). 


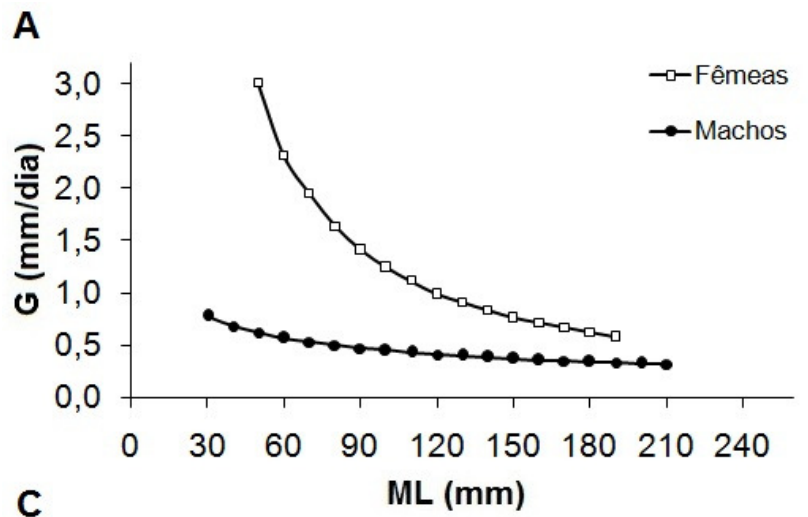

B
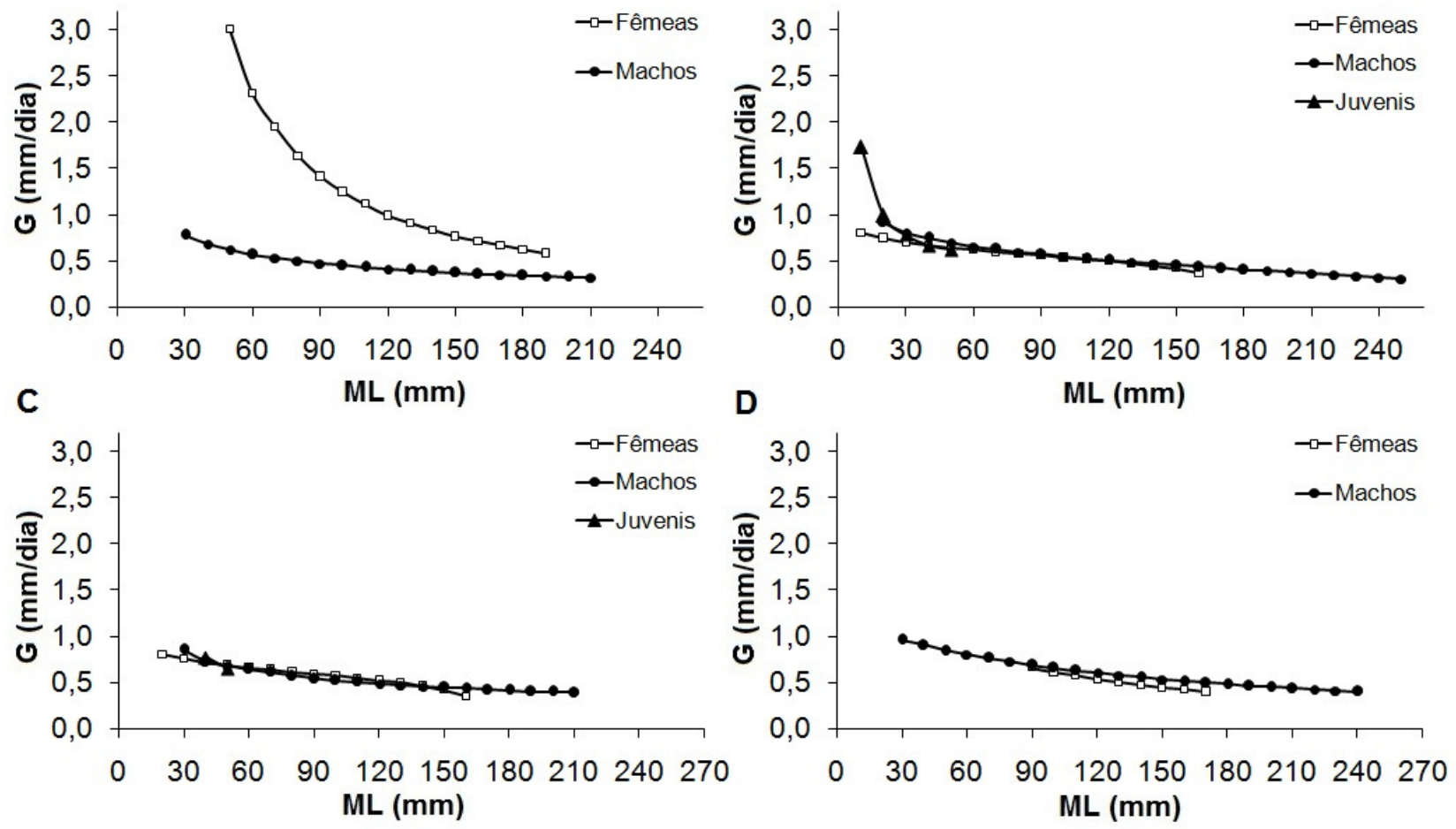

Figura 33 - Taxa instantânea de crescimento (G) em mm/dia por comprimento do manto (ML) para juvenis, fêmeas e machos, nascidos nas quatro estações do ano, onde: primavera (A), verão (B), outono (C) e inverno (D).

\subsection{Outras relações com a idade}

\subsubsection{Idade-comprimento dos estatólitos}

Para testar a relação entre a idade (em dias) das lulas com o comprimento dos estatólitos (SL), foram utilizados dados de 247 indivíduos, sendo destes 104 fêmeas (ML entre 36 a $191 \mathrm{~mm}$ ), 85 machos (variando o ML entre 30 a $267 \mathrm{~mm}$ ML) e 58 juvenis (espectro de ML entre 1,87 a $56 \mathrm{~mm}$ ).

Em geral, para todas as relações testadas (total, por sexo e juvenis), exibiram um coeficiente $\left(r^{2}\right)$ satisfatório (entre 0,67 e 0,99 ). A Tabela 28 exibe os modelos matemáticos testados, bem como os valores de $r^{2}$ e AICw. A Figura 34 expõe os ajustes graficamente. Sendo assim, para toda amostra, o melhor ajuste foi estabelecido pelo modelo exponencial (Figura 34A), para fêmeas e machos ajuste logarítmico e para juvenis, modelo exponencial (Figura 34B). 
Tabela 28 - Relação entre idade de $D$. plei com o comprimento dos estatólitos (SL) para a amostra total, fêmeas, machos e juvenis, com seus respectivos número amostral (n), parâmetros dos modelos ajustados: valor de $a$ e $b(a, b)$, coeficiente de determinação da equação $\left(r^{2}\right)$, índice Akaike (AIC) e peso de AIC (AICw).

\begin{tabular}{|c|l|c|c|c|c|c|}
\hline & Modelo & $\boldsymbol{A}$ & $\boldsymbol{b}$ & $\boldsymbol{r}^{\mathbf{2}}$ & AIC & AICw \\
\hline \multirow{4}{*}{ Total } & linear & 0,005 & 0,230 & 0,92 & $-265,089$ & 0 \\
$\mathbf{n = 2 4 7}$ & potencial & 0,052 & 0,605 & 0,94 & $-331,348$ & 0,500 \\
& exponencial & 0,052 & $-0,502$ & 0,94 & $-331,348$ & 0,500 \\
& logarítmico & 0,322 & $-0,364$ & 0,87 & $-135,492$ & 0 \\
\hline \multirow{4}{*}{ Fêmeas } & linear & 0,003 & 0,679 & 0,60 & $-122,808$ & 0 \\
$\mathbf{n = 1 0 4}$ & potencial & 0,087 & 0,513 & 0,64 & $-131,684$ & 0,009 \\
& exponencial & 0,087 & $-0,668$ & 0,64 & $-131,684$ & 0,009 \\
& logarítmico & 0,754 & $-2,683$ & 0,67 & $-140,970$ & 0,982 \\
\hline \multirow{3}{*}{ Machos } & linear & 0,004 & 0,366 & 0,76 & $-90,956$ & 0,114 \\
N= 85 & potencial & 0,028 & 0,718 & 0,77 & $-92,757$ & 0,280 \\
& exponencial & 0,028 & $-0,331$ & 0,77 & $-92,757$ & 0,280 \\
& logarítmico & 0,950 & $-3,739$ & 0,77 & $-93,055$ & 0,325 \\
\hline \multirow{3}{*}{ Juvenis } & linear & 0,005 & 0,149 & 0,99 & $-194,887$ & 0,002 \\
n= 58 & potencial & 0,080 & 0,503 & 0,99 & $-205,311$ & 0,499 \\
& exponencial & 0,080 & $-0,688$ & 0,99 & $-205,311$ & 0,499 \\
& logarítmico & 0,239 & $-0,187$ & 0,98 & $-166,533$ & 0 \\
\hline
\end{tabular}
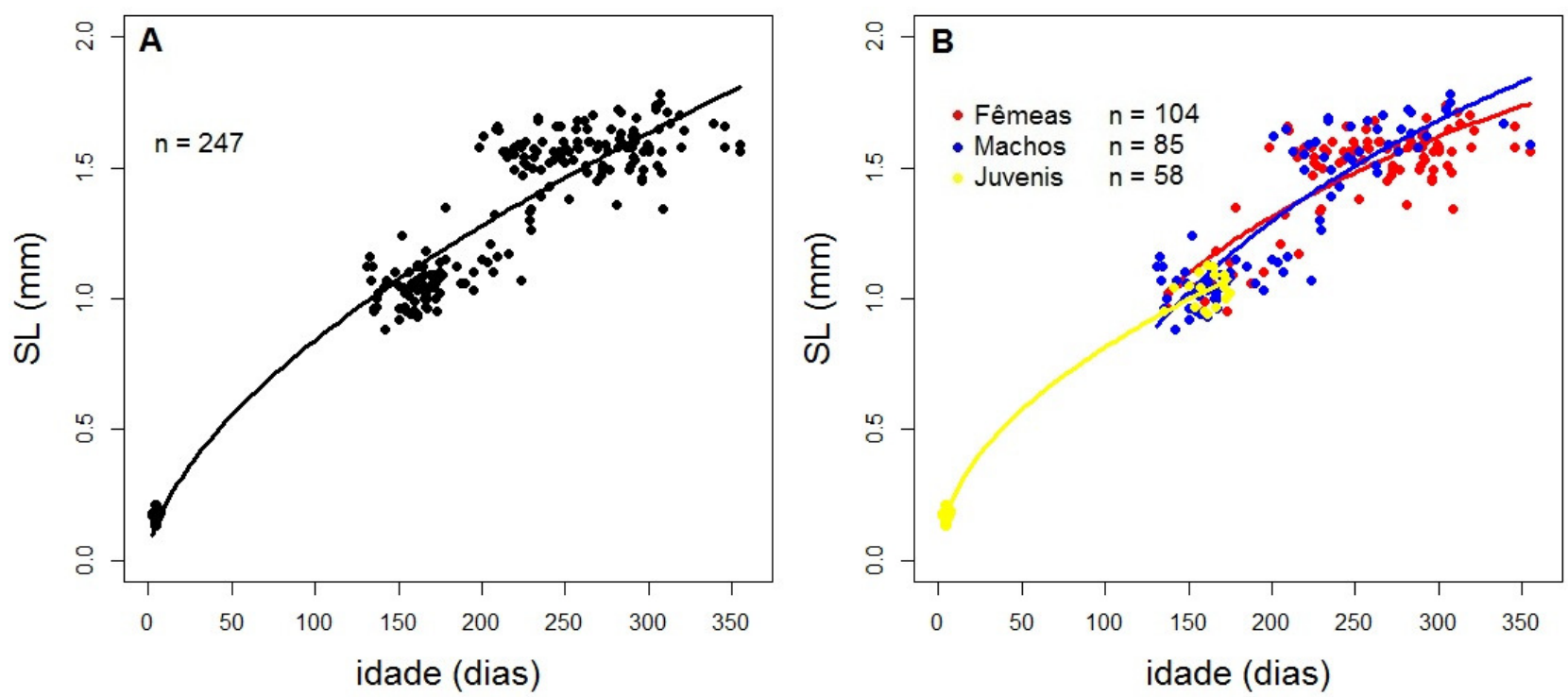

Figura 34- Relação entre idade e comprimento do estatólito (SL) para: Amostra total (A), ajuste exponencial; Fêmeas e machos (B), ajuste logarítmico; e juvenis (B), ajuste exponencial. Ver na Tabela 28 os parâmetros do ajuste obtido. 


\subsubsection{Idade-comprimento dos domos}

As mesmas lulas fêmeas e machos utilizados para a relação (idade vs. SL) foram utilizados para testar idade vs. DL, porém o número amostral de lulas juvenis utilizadas foi 17 , variando o comprimento de manto entre 30 a $56 \mathrm{~mm}$.

A Tabela 29 exibe os modelos matemáticos testados, bem como os valores de $r^{2}$ e AICw. A Figura 35 expõe os ajustes graficamente. Sendo assim, O melhor ajuste proposto para toda amostra, fêmeas e machos foi o ajuste logarítmico (variando o $r^{2}$ entre 0,57 a 0,76 ). Apenas para a relação dos juvenis os valores de $r^{2}$ não possuíam valores significativos $(0,05)$, sendo então ajustado o modelo linear.

Tabela 29 - Relação entre idade de D. plei com o comprimento dos domos (DL) para a amostra total, fêmeas, machos e juvenis, com seus respectivos número amostral (n), parâmetros dos modelos ajustados: valor de $a$ e $b(a, b)$, coeficiente de determinação da equação $\left(r^{2}\right)$, índice Akaike (AIC) e peso de AIC (AICw).

\begin{tabular}{|c|l|c|c|c|c|c|}
\hline & Modelo & $\boldsymbol{A}$ & $\boldsymbol{b}$ & $\boldsymbol{r}^{\mathbf{2}}$ & AIC & AICw \\
\hline \multirow{3}{*}{ Total } & linear & 0,002 & 0,276 & 0,70 & $-425,757$ & 0 \\
$\mathbf{n = 2 0 6}$ & potencial & 0,026 & 0,631 & 0,71 & $-434,980$ & 0,003 \\
& exponencial & 0,026 & $-0,461$ & 0,71 & $-434,980$ & 0,003 \\
& logarítmico & 0,492 & $-1,872$ & 0,73 & $-446,305$ & 0,994 \\
\hline \multirow{4}{*}{ Fêmeas } & linear & 0,002 & 0,372 & 0,53 & $-201,337$ & 0,004 \\
n= 104 & potencial & 0,045 & 0,529 & 0,55 & $-206,699$ & 0,054 \\
& exponencial & 0,045 & $-0,637$ & 0,55 & $-206,699$ & 0,054 \\
& logarítmico & 0,438 & $-1,578$ & 0,57 & $-212,294$ & 0,888 \\
\hline \multirow{3}{*}{ Machos } & linear & 0,003 & 0,222 & 0,75 & $-182,988$ & 0,082 \\
$\mathbf{n = ~ 8 5}$ & potencial & 0,018 & 0,701 & 0,75 & $-185,142$ & 0,240 \\
& exponencial & 0,018 & $-0,356$ & 0,75 & $-185,142$ & 0,240 \\
& logarítmico & 0,532 & $-2,078$ & 0,76 & $-186,346$ & 0,438 \\
\hline \multirow{3}{*}{ Juvenis } & linear & 0,001 & 0,466 & 0,05 & $-59,778$ & 0,250 \\
n= 17 & potencial & 0,206 & 0,209 & 0,05 & $-59,774$ & 0,250 \\
& exponencial & 0,206 & $-1,567$ & 0,05 & $-59,774$ & 0,250 \\
& logarítmico & 0,122 & $-0,030$ & 0,05 & $-59,773$ & 0,250 \\
\hline
\end{tabular}



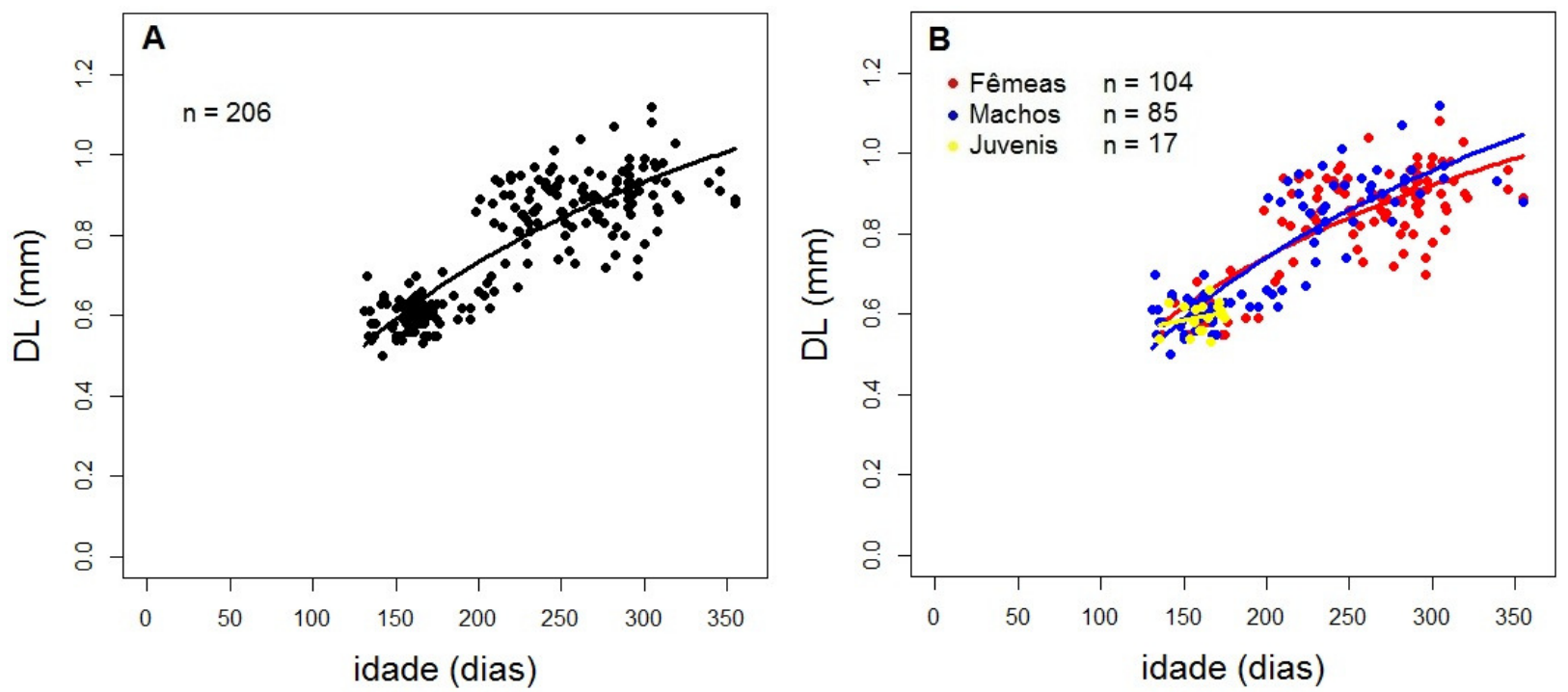

Figura 35 - Relação entre idade e comprimento dos domos do estatólito (DL) para: amostra total (A), ajuste logarítmico; Fêmeas e machos (B), ajuste logarítmico; e juvenis (B), ajuste linear. Ver na Tabela 29 os parâmetros do ajuste obtido. 


\section{DISCUSSÃO}

O conhecimento da composição etária, curva e taxas de crescimento populacional são essenciais para o estudo da dinâmica de populações marinhas, e fornece dados da estrutura dos estoques explotados pela pesca, útil para $\mathrm{o}$ monitoramento do desempenho pesqueiro (BOYLE \& RODHOUSE, 2005; SIFNER, 2008). Há mais de um século, investigações a respeito do crescimento de cefalópodes, em especial às lulas, têm sido realizado, onde se destaca o primeiro trabalho publicado por Verrill (1881 apud ARKHIPKIN \& ROA-URETA, 2005). De mesma maneira como há para peixes, ainda hoje não foi estabelecido um modelo de crescimento considerado padrão para todos os cefalópodes, pois cada espécie apresenta particularidades no comportamento etário da taxa de crescimento.

Estudos prévios de crescimento de Doryteuthis plei (AGUIAR, 2002; JACKSON \& FORSYTHE, 2002, AGUIAR et al., 2012), foram realizados também por meio dos estatólitos. Perez et al. (2006) destacaram que estas estruturas, além dos gládios, são indicadas para determinação da idade para essa espécie. No entanto, em nenhum dos estudos prévios foi dada ênfase na análise do crescimento nos estágios iniciais de vida, como também, nem todos os modelos de ajuste de crescimento foram testados.

Com os resultados obtidos no presente estudo, as equações que geram ajustes sigmóides como é o caso dos modelos de Gompertz, logístico e Schnute apresentam vantagem em relação aos demais modelos já testados para a relação idade e comprimento de manto da espécie. Os ajustes sigmoidais oferecem estimativas do comprimento ou idade na qual ocorrem as mudanças críticas no padrão de crescimento. Sendo assim, o presente estudo compensa os pontos não abordados nos estudos prévios, além do que, destaca outras características e relações entre mensurações dos estatólitos da espécie com a idade, as quais serão melhores discutidas adiante.

O número amostral utilizado no presente trabalho foi superior ao utilizado em estudos prévios de idade e crescimento (JACKSON \& FORSYTHE, 2002; AGUIAR, 2002; e PEREZ et al., 2006) para Doryteuthis plei, onde se pode comparar o número de exemplares capturado em cada estudo na Tabela 30. 
Tabela 30 - Comparação da variação de comprimento de manto (ML) e número amostral (n) de D. plei obtido no presente estudo em relação a outros trabalhos.

\begin{tabular}{|c|c|c|}
\hline Estudo & n & Variação em ML (mm) \\
\hline Este estudo & 424 & $1,58-267$ \\
Aguiar (2002) & 218 & $35-342$ \\
Jackson \& Forsythe (2002) & 50 & $71-214$ \\
Perez et al. (2002) & 1744 & $11-353$ \\
Perez et al. (2006) & 285 & $35-342$ \\
Martins \& Perez (2007) & 602 & $18-358$ \\
Rodrigues (2007) & 1665 & $30-307$ \\
Postuma (2010) & 1547 & $85-356$ \\
\hline
\end{tabular}

Vale destacar também o foco em indivíduos de pequeno porte corpóreo e o amplo espectro amostral atingindo pelo presente estudo, onde foram utilizadas lulas entre $1,58 \mathrm{~mm}$ a $267 \mathrm{~mm}$ de comprimento de manto, onde o espectro amostral foi mais amplo para fêmeas, machos e juvenis em relação aos estudos prévios de crescimento. $\mathrm{O}$ presente estudo se destaca também em relação aos demais, no sentido de ter amostrado paralarvas, estimando desta maneira a curva de crescimento do começo ao final do ciclo de vida.

\subsection{Um dia, um incremento de crescimento: validação da idade de $D$. plei}

Antes do estudo propriamente dito de crescimento ser efetuado para D. plei, foi preciso que fosse feito uma avaliação da viabilidade dos estatólitos, como estrutura para o estudo de idade e crescimento. Sendo assim, com observação de igual periodicidade de deposição de incrementos de crescimentos nos estatólitos, como também no gládius, Perez et al. (2006) verificaram que as estruturas em estudo podem ser utilizadas para o estudo de idade, restando confirmar apenas se a periodicidade de deposição coincide com os dias de vida da lula.

O primeiro estudo de idade e validação dos incrementos de crescimento diários depositados nos estatólitos de Doryeuthis plei do Noroeste do Golfo do México foi realizado por Jackson \& Forsythe (2002). Com número amostral de 19 indivíduos, foram confinados em tanques sob o acúmulo de solução de Tetraciclina, onde ao final do experimento os autores concluíram que os incrementos de crescimento são depositados nos estatólitos diariamente. Sakai et al. (2004) confirmaram em seu estudo que as marcas de crescimento no estatólito (deposição) ocorrem diariamente, em um 
ciclo sazonal. Sendo assim, o número total de marcas (incrementos de crescimento) corresponde ao total de idade da lula em estudo em dias.

Aguiar et al. (2012) também efetuaram a validação dos incrementos de crescimento de Doryteuthis plei capturados na costa sudeste do Brasil e obtiveram mesmo resultado obtido por Jackson \& Forsythe (2002). Sendo assim, a técnica de estimativa da idade e crescimento de Doryteuthis plei através da contagem dos incrementos de crescimento depositados nos estatólitos é plausível e fora testada em estudos anteriores, descartando assim a necessidade de uma terceira validação, a qual não foi realizada no presente estudo.

\subsection{Análise dos incrementos de crescimento}

Diferentemente de Aguiar (2002) e Aguiar et al. (2012) a idade da espécie em estudo foi estimada através da leitura dos incrementos de crescimento dos estatólitos, com análise direta dos incrementos nas lentes oculares do microscópio. De acordo com Arkhipkin \& Shcherbich (2012) os estatólitos e os incrementos de crescimento crescem em três dimensões. Em relação à análise de imagens de estatólitos para estimativa de idade, é praticamente impossível capturar em uma única fotografia a sequência dos incrementos de crescimento. O estabelecimento de um eixo para leitura (a partir da identificação do primeiro anel etário até o último, na borda do estatólito) fica prejudicado.

Além disto, exemplares amostrados e não consideradas para o estudo de idade e crescimento (42 indivíduos) apresentaram estatólitos ilegíveis para a leitura. Segundo Arkhipkin \& Shcherbich (2012) a microestrutura cristalina é propensa a danos em sua estrutura quando em contato em meio ácido. A melhor maneira de armazenar os estatólitos após sua extração é em tubos eppendorfs, submersos entre 70-90\% de etanol. Se os estatólitos forem armazenados de maneira correta, a aparência translúcida dos estatólitos e do rostro será mantida. Se após o armazenamento, os estatólitos apresentarem coloração esbranquiçada (opaca), a superfície dos estatólitos foram danificadas e as leituras dos incrementos próximos a borda poderão ser comprometidos (ARKHIPKIN \& SHCHERBICH, 2012).

Para a visualização dos incrementos de crescimento das paralarvas de Doryteuthis plei, foi preciso polir o estatólito colado em lâmina, porém de acordo com 
González et al. (2010), para a leitura dos anéis de crescimento das paralarvas de Doryteuthis vulgaris, não foi preciso de lixar e efetuar o polimento de nenhuma das porções dos estatólitos. Sendo assim, são destacadas as diferenças no preparo para a leitura dos anéis de crescimento dos estatólitos de paralarvas de D. plei em relação a outras espécies.

Os esforços e dificuldades executados no presente estudo para a leitura dos incrementos de crescimento dos estatólitos de paralarvas foram de menor proporção do que em relação a lulas adultas, fato que corrobora com González et al. (2000), onde é destacada as vantagens para a leitura de incrementos de crescimento de estatólitos de paralarvas, evidenciando a pouca quantidade de incrementos (menos do que um mês) e a não necessidade de lixar e polir (vale destacar que é em alguns casos) para a visualização dos incrementos e a rapidez para o preparo para a leitura dos estatólitos e a própria leitura.

A variabilidade entre as leituras $(\mathrm{CV})$ efetuadas no presente trabalho foi inferior a $5 \%$, atingindo valor de $4,85 \%$ e a precisão entre as contagens dos incrementos de crescimento (EMP) foi de $3,72 \%$. Sendo assim, a estimativa da idade dos indivíduos do presente estudo foi satisfatória, pois de acordo com Arkhipkin \& Shcherbich (2012) a sequência dos incrementos de crescimento deve ser contada com no mínimo duas leituras, para minimizar erros. Se a diferença entre as leituras for $<5 \%$, a média do número de incrementos identificados nas leituras é aceita e este valor representa a idade dos indivíduos. Se a diferença for $>5 \%$, outra contagem deve ser feita. Se mesmo após a terceira leitura for realizada e a diferença entre as leituras permanecer $>5 \%$, os estatólitos devem ser rejeitados para análise de idade do determinado indivíduo (ARKHIPKIN \& SHCHERBICH, 2012).

Os valores de CV e EMP obtidos no presente estudo foram de melhor precisão do que os valores obtidos por Aguiar et al. (2012), que trabalharam com o crescimento da mesma espécie, e obtiveram valores de CV e EMP de 9,6\% e 7,2\%. A maior precisão obtida no presente estudo deve-se ao fato da retirada da primeira e quinta leitura, onde foram considerados os valores médios entre a segunda, terceira e quarta. Vale ressaltar a importância das repetições (em valor acima de três vezes) entre as leituras dos incrementos de crescimento, como também de uma análise prévia das leituras obtidas, possibilitando selecionar as leituras com menores variações entre elas 
para se obter menores valores de EMP e CV, alcançando assim uma estimativa de idade mais próxima da idade real do indivíduo.

\subsection{Curva de crescimento}

Com os dados de idade e comprimento do manto de Doryteuthis plei, a curva de crescimento da população em estudo foi ajustada por modelos de ajustes sigmóides, diferentes dos utilizados por estudos prévios da mesma espécie, destacando-se os trabalhos de Aguiar (2002) e Jackson \& Forsythe (2002). Através da análise da curva de crescimento, os resultados obtidos para taxa de crescimento instantânea, analisada adiante, foram confirmados. Sendo assim, foi observado que o crescimento de fêmeas e machos é exatamente igual quando os exemplares estão entre 35-120 mm ML.

Apesar das fêmeas e machos possuírem $L_{\text {inf }}$ próximos, os machos apresentam maiores taxas de crescimento instantânea em relação as fêmeas quando apresentam ML> $120 \mathrm{~mm}$. Devido a isto, o ajuste da relação idade-ML (da curva de crescimento) dos machos (logístico) foi diferente do modelo obtido para as fêmeas (Gompertz). Estudos anteriores propuseram modelos tradicionais de ajuste para a espécie estudada, onde Jackson \& Forsythe (2002) estimaram que o modelo exponencial como o melhor ajuste $\left(\mathrm{y}=26,92 \mathrm{e}^{0,0131 \mathrm{x}}, r^{2}=0,74\right)$ para machos, porém não houve ajuste para as fêmeas devido a limitada variação de tamanho e idade das lulas amostradas. O modelo potencial foi o que melhor se ajustou para fêmeas e machos $\left(\mathrm{y}=0,38 \mathrm{x}^{1,081}, r^{2}=0,64\right.$ e $\mathrm{y}=$ $\left.0,024 \mathrm{x}^{1,611}, r^{2}=0,74\right)$, de acordo com os resultados obtidos por Aguiar (2002).

Os indivíduos em estádio de maturidade I, ou seja, os juvenis quando em ML entre 25-75 $\mathrm{mm}$ apresentam mesmas taxas de crescimento instantânea do que os exemplares em estádio II (fêmeas e machos), resultado este que não se confirmou no ajuste obtido, talvez devido a falta de dados de exemplares entre 10-19 mm ML. O $L_{\text {inf }}$ estimado para os exemplares juvenis (ML máximo estimado pelo modelo de crescimento em que os exemplares atingem em ML para efetuarem maior investimento energético no desenvolvimento das gônadas sexuais facilitando assim a identificação visual da diferenciação sexual, segundo a escala adotada) coincidiram com a média das mensurações de ML dos indivíduos em estádio de maturidade II, como também foi o mesmo valor de ML mínimo estimado para exemplares em estádio de maturidade III. Sendo assim, o $L_{i n f}$ estimado para os juvenis é o comprimento máximo de ML em que 
os exemplares atingem o estádio II, entre 136 e 229 dias de vida. De acordo com o intervalo de comprimento de ML dos exemplares em estádio II, estima-se que o comprimento mínimo da diferenciação sexual é $30 \mathrm{~mm}$ ML, entre 124 e 151 dias de idade, para população em estudo.

Quando comparada a curva de crescimento obtida com a de outras espécies, segundo Aguiar (2006) tanto para fêmeas, macho e imaturos de Doryteuthis sanpaulensis, o melhor ajuste para a curva de crescimento foi obtido pelo modelo potencial. Para Doryteuthis opalescens da Califórnia, o modelo linear foi o melhor ajuste para curva de crescimento para ambos os sexos (BUTLER et al., 1998). Já para Doryteuthis gahi, coletados ao redor das ilhas Falcon, o modelo exponencial para as fêmeas e o potencial para os machos foram os melhores ajuste para relação idade e crescimento (HATFIELD, 2000).

Os diferentes modelos ajustados para as espécies de cefalópodes confirmam que uma única curva de crescimento não demonstra as particularidades de crescimento da espécie. Sendo assim, não é possível estimar uma curva de crescimento padrão para os cefalópodes, assim como há um modelo estabelecido para o crescimento de peixes, como exemplo, von Bertalanffy.

\subsection{Taxa de crescimento}

Como visto anteriormente, diferentes ajustes de crescimento foram obtidos para as relações estabelecidas (como exemplo: por sexo e para juvenis) devido as diferenças entre as taxas de crescimento instantânea por estratos de comprimento de manto. Neste contexto, vale destacar alguns dos fatores que influenciam a taxa de crescimento dos cefalópodes.

A taxa de crescimento é influenciada pela temperatura como também altas taxas de conversão alimentar e disponibilidade de alimento fazem com que o organismo cresça mais rápido (BOYLE \& RODHOUSE, 2005). A demanda por alimento durante a fase de crescimento determina muitos aspectos como: impacto sobre populações de presas e de predadores; alta taxa de produção de biomassa pelas populações; disponibilidade desta produção para outros predadores marinhos e à pesca (BOYLE \& RODHOUSE, 2005). A alta taxa de crescimento é sustentada pela elevada taxa de alimentação e excepcional eficiência na conversão do alimento em tecido somático de 
crescimento (PACKARD, 1972; FORSYTHE \& VAN HEUKELEM, 1987; ZUEV \& NESIS, 2003; BOYLE \& RODHOUSE, 2005), como também há de se considerar, alto gasto energético causado pela captura de alimento pode causar uma queda na taxa de crescimento (SPRATT, 1979).

Foi observado nos resultados do presente estudo, onde em diferentes intervalos de crescimento de Doryteuthis plei, a taxa de crescimento foi identificada o seu valor mais alto valor quando o exemplar possui $10 \mathrm{~mm}$ de ML, porém há decréscimo acelerando da taxa ao atingir $60 \mathrm{~mm}$ ML. Do intervalo de ML entre 60-160 mm a queda da taxa se torna gradual, porém quando atinge $180 \mathrm{~mm}$ ML o decréscimo se torna acentuado e contínuo até o final da vida. Estes resultados confirmam as observações de Zuev \& Nesis (2003), os quais estimaram as variações da taxa de crescimento dos loliginídeos em diferentes intervalos de comprimento do manto.

Levando em consideração estes fatores levantados, as maiores taxas de crescimento identificadas no estudo, para os exemplares juvenis, principalmente para os exemplares com $\mathrm{ML}<30 \mathrm{~mm}$ talvez se deva ao consumo de vitelo e economia no gasto energético para a captura de alimento. Ou então há de se estimar que os indivíduos destes espectros de tamanho são oportunistas na predação, quando considerada também a capacidade ainda limitada de natação destes organismos para vencerem correntes ou então perseguir e encurralar as presas. Estas afirmações corroboram com Forsythe \& van Heukelem (1987) os quais apreciaram que o crescimento de um organismo representa o resultado líquido de uma série de processos fisiológicos e comportamentais. Estes incluem a busca do alimento, captura de presas, ingestão, digestão, absorção, assimilação, gasto metabólico e excreção.

Há de se discutir as diferenças entre o crescimento de fêmeas e machos, onde a intensidade da queda da taxa de crescimento por sexo foi observada no presente estudo. Pode-se considerar que o crescimento entre os sexos se diferencia quando os exemplares atingem ML> $120 \mathrm{~mm}$, quando os machos apresentam maiores taxas de crescimento em relação as fêmeas, quando analisados em mesmo intervalo de ML.

Ainda utilizando os argumentos apresentados anteriormente por Packard (1972), Spratt (1979), Forsythe \& van Heukelem (1987), Zuev \& Nesis (2003) e Boyle \& Rodhouse (2005), estima-se que as fêmeas com ML>120 mm, em geral, em estádio de maturação II, quase atingindo estádio III (o comprimento médio de primeira maturação 
e a idade será discutida adiante) efetuam maiores ganho em tecido somático do que os machos, ou seja, estima-se que a atividade de predação seja mais elevada do que os machos, isto resulta no consumo energético para crescimento.

O ganho em massa corpórea pode ser relacionado com a maturação das gônadas. De acordo com Postuma \& Gasalla (2014, no prelo) as gônadas das fêmeas quando maduras, possuem maior massa do que as gônadas em maturação. Sendo assim, há de se considerar que há gasto energético destinado para a maturação das gônadas das fêmeas, enquanto que os machos efetuam os mesmos gastos energéticos, porém em proporção menor.

Neste contexto, há relação de ganho em peso dos exemplares conforme ocorre o crescimento da lula, destacando maior ganho em massa corpórea (em maior taxa) quanto maior for o comprimento de manto do exemplar. Sendo assim, o melhor ajuste para a relação comprimento de manto-peso foi obtido pelo ajuste potencial, mesmo ajuste obtido pela maioria dos estudos prévios. Entretando, o presente estudo apresenta o coeficiente $\left(r^{2}\right)$ mais significativo do que os obtidos por Rodrigues (2007), Postuma (2010) e Postuma \& Gasalla (2014), ver Tabela 31.

Tabela 31 - Comparação da relação comprimento de manto-peso do presente estudo com estudos prévios. Os ajustes e os valores do coeficiente de correlação $\left(r^{2}\right)$ do presente estudo podem ser comparados por sexo em relação a estudos prévios de $D$. plei.

\begin{tabular}{|l|c|c|c|}
\hline \multicolumn{1}{|c|}{ Estudo } & Sexo & Ajuste & $\boldsymbol{r}^{2}$ \\
\hline Este estudo & & potencial & 0,98 \\
Rodrigues (2007) & fêmeas & $\begin{array}{c}\text { exponencial } \\
\text { potencial }\end{array}$ & 0,84 \\
Postuma (2010) & & 0,74 \\
Postuma \& Gasalla (2014) & & potencial & 0,87 \\
Este estudo & potencial & 0,98 \\
Rodrigues (2007) & machos & exponencial & 0,92 \\
Postuma (2010) & & potencial & 0,86 \\
Postuma \& Gasalla (2014) & & potencial & 0,86 \\
Este estudo & juvenis & potencial & 0,98 \\
\hline
\end{tabular}

Os resultados obtidos no presente estudo corroboram com os resultados de Jackson \& Forsythe (2002), que observaram que os machos de Doryteuthis plei do Golfo do México são maiores e taxas de crescimento mais acelerada do que as fêmeas. Como exemplo, as fêmeas, 150 dias de vida atingem em média $120 \mathrm{~mm}$ de comprimento de manto, enquanto que os machos atingem $200 \mathrm{~mm}$. 
Sendo assim, os comprimentos médios de maturação $\left(\mathrm{L}_{50}\right)$ estimados no presente estudo para fêmeas e machos foram muito próximos do comprimento de manto (ML) mínimo dos exemplares em estádio de maturação III. Ou seja, o $\mathrm{L}_{50}$ obtido no presente estudo foi observado nos dados amostrados, obtendo-se que a partir de 152 dias de idade as lulas fêmeas atingem a maturação (maduras), enquanto que os machos mais tardiamente com 201 dias.

Jackson \& Forsythe (2002) estimam para mesma espécie, porém do Noroeste do Golfo do México, as fêmeas ficam maduras com menos dias de vida em relação à população estudada, com 103 dias de vida e os machos com 80 dias de idade. Porém, para lulas de outras espécies, fêmeas de Illex argentinus do litoral sul do Brasil maturam com 143 dias de idade e os machos com 137 dias (SCHWARZ \& PEREZ, 2010). Para Jackson et al. (1997) o crescimento e maturação das gônadas de Lolliguncula brevis estão associados com o tamanho e não com a idade, o mesmo pode-se observar para Doryteuthis plei da região em estudo, para o qual as médias de idade e variação do comprimento do manto não coincidiram com o $\mathrm{L}_{50}$ estimado. A seguir são apresentados diferentes estimativas do comprimento médio da primeira maturação, destacando diferentes características particulares das populações de $D$. plei de diferentes regiões.

Para D. plei da região de Santa Catarina, costa Sudeste do Brasil, Perez et al. (2002) constatou também que os machos, em geral atingem o estádio de maturação com comprimento de manto superior do que as fêmeas, quando atingem 193,6 e as fêmeas com 141,1 mm ML, ou seja, estimativas que confirmam os valores obtidos no presente estudo. Para D. plei da mesma região de estudo de Perez et al. (2002), Martins \& Perez (2007) obtiveram que o comprimento médio de maturação das fêmeas é de 97 mm ML e os machos, 146,80 mm ML. Já para as lulas do entorno da ilha de São Sebastião, São Paulo, Postuma (2010) obteve valores de $\mathrm{L}_{50}$ inferiores ao estimado no presente estudo somente para as fêmeas, sendo então $140 \mathrm{~mm}$ e $215 \mathrm{~mm}$ para machos. Para Rodrigues (2007), fêmeas maturam quando atingem $125,3 \mathrm{~mm}$ de comprimento de manto e os machos, quando em $166 \mathrm{~mm}$. Baseados em dados de dez anos de desembarques pesqueiros, os valores estimados por Postuma \& Gasalla (2014, no prelo) do comprimento médio de maturação foram muito próximos dos avaliados no presente estudo, onde o $\mathrm{L}_{50}$ das fêmeas foi calculado em $143 \mathrm{~mm}$ e o dos machos, $210 \mathrm{~mm}$ ML. 
Assim como levantado por Aguiar (2006) para Doryteuthis sanpaulensis, as taxas instantâneas de crescimento também foram maiores para indivíduos imaturos em relação aos Doryteuthis plei maduros, destacando os indivíduos com comprimento de manto inferior a $35 \mathrm{~mm}$. A taxa de crescimento de Doryteuthis opalescens da Califórnia é menor do que de Doryteuthis plei (0,6 mmao dia). Não foi observada diferença significativa na taxa de crescimento entre machos e fêmeas e de indivíduos de sexo não identificado de Doryteuthis opalescens (BUTLER et al., 1998).

Para as lulas Galiteuthis phyllurae Belonella borealis, a taxa de crescimento foi identificada em 1,13 mm ao dia durante o oitavo ao décimo mês de vida (ARKHIPKIN, 1996a). Paralarvas de Loligo vulgaris do Oceano Mediterrâneo atingem $6 \mathrm{~mm}$ de comprimento em duas semanas após o nascimento, e em 2 a 2,5 meses atinge $40 \mathrm{~mm}$ (comprimento de manto) (ZUEV \& NESIS, 2003).

De acordo com Zuev \& Nesis (2003) loliginídeos apresentam taxa de crescimento acelerada, contínua e variável durante as estações do ano. No entanto, foram observadas poucas variações na taxa de crescimento durante as estações do ano para Doryteuthis plei. Lulas nascidas no outono e inverno exibiram praticamente mesmo padrão de crescimento e em mesma taxa de crescimento. Porém quando se observa os valores da taxa de crescimento por sexo, verificou-se que o crescimento foi muito similar, com exceção das lulas fêmeas nascidas na primavera, as quais exibiram os maiores valores de taxa de crescimento em relação aos machos e as outras estações do ano.

Já que foram observadas diferenças nas taxas de crescimento entre os indivíduos nascidos durante as diferentes estações do ano, as diferenças no crescimento é melhor visualizada através dos ajustes de crescimento obtidos para os exemplares nascidos conforme as estações do ano. Sendo assim, o mesmo ajuste obtido para a espécie se repetiu para os indivíduos nascidos no verão. Quando analisada as variações da taxa de crescimento de fêmeas, machos e juvenis conforme as estações do ano, estas variações são mais claras através dos diferentes ajustes da curva de crescimento obtidos durante as estações do ano. Aguiar (2002) obteve o ajuste do modelo potencial para todas as curvas de crescimento estimadas para ambos os sexos em ambas as estações do ano.

A hipótese de que as lulas nascidas no verão cresceriam mais rapidamente do que em outras épocas do ano não foi sustentada pelos resultados, devido ao destaque da 
taxa de crescimento (valores de $G$ entre 1,1 a $0,9 \mathrm{~mm} / \mathrm{dia}$ ) para lulas com até $25 \mathrm{~mm}$ ML, além do que espécimes nascidos no inverno apresentaram maiores taxas de crescimento em relação aos nascidos em outras estações do ano, talvez devido a maior disponibilidade de alimento em águas supostamente mais frias (enriquecidas).

Para outras espécies de loliginídeos foram identificados as variações de crescimento conforme as estações do ano, como para Loligo vulgaris do Mar do Norte, a média mensal de crescimento no inverno não excede $2,3-4,7 \mathrm{~mm} / \mathrm{dia}$, enquanto que no Mediterrâneo a média é de 4,5-9 $\mathrm{mm} /$ dia. Na primavera o crescimento de Loligo vulgaris é mais acelerado novamente e se mantém rápido até o final de outono (ZUEV \& NESIS, 2003). Para Jackson (1998) Doryteuthis opalescens que eclodiram durante estações mais quente apresentam taxa de crescimento mais alta e vida mais curta do que as que são eclodidas em estações do ano mais frias.

Os dados apresentados neste estudo corroboram parcialmente com os de Aguiar (2002), que observou que as fêmeas e machos de Doryteuthis plei nascidos em diferentes estações do ano não apresentaram diferença significativa no crescimento. Vale destacar a importância da análise da taxa de crescimento aliada com a curva de crescimento da espécie, onde neste caso a curva de crescimento apontou melhor as diferenças no comportamento de crescimento de uma mesma população, porém de diferentes estações do ano.

\subsection{Frequência de nascimento de $D$. plei ao ano}

Já que não foram identificadas diferenças significativas na taxa de crescimento de Doryteuthis plei durante as estações do ano, espera-se que a temperatura influencie então na desova das lulas da presente espécie, já que a freqüência de nascimento é variável conforme as estações do ano.

Através do retro-cálculo das idades das lulas, foi possível analisar a frequência relativa de nascimento de Doryteuthis plei durante todos os meses de 2011, sendo identificado nascimento durante todos os meses do ano, porém em maior frequência no primeiro semestre, resultado este que corrobora com Aguiar (2002) e Perez et al. (2002). A época do ano em que ocorreram as maiores porcentagens de eclosão é o verão seguido do outono. Aguiar (2006) também observou nascimento de Doryteuthis 
sanpaulensis durante todos os meses do ano, porém com maior freqüência durante a primavera e em menor proporção durante o inverno.

Neste contexto, é possível relacionar as maiores frequências de nascimento com a intrusão da ACAS sobre a plataforma continental. A ACAS promove o resfriamento da água de fundo, promovendo o fenômeno termoclina entre os meses outubro e abril (primavera-verão). Este fenômeno de grande escala promove o aumento da produtividade biológica, devido ao aumento das concentrações de nutrientes dissolvidos na zona eufótica, na costa sul do Brasil até aproximadamente os vinte metros de profundidade (MIRANDA, 1982; CASTRO-FILHO, 1987), profundidade na qual os exemplares foram coletados. Porém, o gradiente formado durante os meses de primavera e verão desaparece com a homogeneização da água ao longo do outono e inverno, quando diminui a produção biológica (MIRANDA, 1982; CASTRO-FILHO, 1987). Sendo assim, supõe-se que o fenômeno descrito anteriormente influencia na desova e nascimento de lulas, pois as lulas estudadas desovam em temporadas onde a produtividade biológica esta em queda. Relaciona-se também o desenvolvimento embrionário das paralarvas, ocorre durante a termoclina e quando as paralarvas eclodem, crescem com taxas de crescimento mais elevadas quando no início da formação da termoclina.

\subsection{Longevidade e influencias na duração do ciclo de vida}

O conhecimento do crescimento e longevidade é crucial para a gestão e monitoramento dos estoques pesqueiros. A longevidade estimada para a espécie em estudo foi de oito meses e sete dias, porém foram encontrados exemplares na amostra com até 355 dias de vida. Perez et al. (2002) estimou que o ciclo de vida de Doryteuthis plei era próximo a um ano; Jackson \& Forsythe (2002) obtiveram para exemplares do Noroeste do Golfo do México, que a longevidade da espécie era maior do que 6 meses de idade.

Perez et al. (2006) inferiram que Doryteuthis plei do sul do Brasil possa atingir até cerca de 9 meses de vida, estimativa que se aproximou do presente estudo. Vale destacar que a estimativa de longevidade calculada pelo método de Taylor (1958) não é adequada para a espécie em estudo ou então supostamente não é adequada para os parâmetros de crescimento de cefalópodes, por que a longevidade obtida foi muito inferior aos dados amostrados. 
Comparando os resultados obtidos no presente estudo com dados de outras espécies, para Doryteuthis sanpaulensis da plataforma Sudeste do Estado de São Paulo, a longevidade foi estimada também como menor de um ano, onde o comprimento de manto máximo estimado para a espécie (quando modelo ajustado para 365 dias de vida), $188 \mathrm{~mm}$ ML para as fêmeas e $195 \mathrm{~mm}$ ML para os machos (AGUIAR, 2006). Já Zaleski (2010) estimou que o ciclo de vida de Lolliguncula brevis é próxima a três meses.

O indivíduo mais jovem amostrado tinha três dias de vida e 2,23 mm de ML. Já o indivíduo mais velho capturado tinham 355 dias de idade, sendo uma fêmea com 185 mm de ML e um macho com 215 mm ML. Jackson \& Moltschaniwskyj (2002) capturaram outro loliginídeo, Sepioteuthis lessonianado no Indo Pacífico, sendo que o indivíduo mais jovem capturado tinha 7 dias de vida e $8,9 \mathrm{~mm}$ de ML. O macho mais velho tinha 224 dias de vida e $256 \mathrm{~mm}$ de ML.

Aguiar (2002) obteve amostras de Doryteuthis plei da região do litoral norte do Estado de São Paulo, sendo que a fêmea mais jovem tinha $61 \mathrm{~mm}$ de ML e 134 dias de idade e o macho, $35 \mathrm{~mm}$ ML e 95 dias de vida. Já as lulas mais velhas capturadas foi uma fêmea com 221 mm ML e 320 dias de vida e um macho com 342 mm ML e 362 dias de idade. Quando comparado os resultados do presente estudo com trabalhos prévios, observa-se que este estudo obteve dados de lulas juvenis para as quais antes não havia sido contemplado para a espécie e até então não atendida para outros loliginídeos.

No entanto, quando analisadas as idades mínimas e máximas obtidas para espécies de outras famílias, Arkhipkin \& Bjorke (2000) estimaram que Gonatus fabricii do Mar da Noruega, a menor paralarva amostrada apresentou 12 incrementos de crescimento. A idade máxima observada foi de um macho com $182 \mathrm{~mm}$ de ML e 654 dias de vida. O maior exemplar do sexo feminino (322 mm ML) apresentou 599 incrementos de crescimento. Ou seja, parece ocorrer um ciclo de vida muito diferente e de maior duração em relação as viventes em águas tropicais, ou quando comparada com o crescimento de Doryteuthis plei.

A temperatura influencia o crescimento das lulas. Segundo Boyle \& Rodhouse (2005) as taxas de crescimento variam de acordo com a elevada ingestão de alimento e na eficiência de conversão em crescimento somático, e temperatura, são os fatores mais 
prováveis que influenciam no crescimento dos cefalópodes (FORSYTHE \& VAN HEUKELEM, 1987; VILLANUEVA et al., 2003). Entretanto, fatores bióticos como: idade, tamanho, sexo, comida, atividade de interação interespecífica, intra-específica, efeitos geográficos; e fatores abióticos: temperatura (BOYLE \& RODHOUSE, 2005), luz, salinidade, e qualidade da água também influenciam na taxa de crescimento (FORSYTHE \& VAN HEUKELEM, 1987).

Considerando que a temperatura da água é um dos principais atuantes na taxa de crescimento dos cefalópodes, e que a temperatura influencia no metabolismo, estima-se que a longevidade e o ciclo de vida dos cefalópodes também dependem da temperatura do ambiente. Sendo assim, lulas com menores longevidades e ciclo de vida mais curto, vivem em águas mais quentes, e as que vivem em águas mais frias, apresentam longevidade e ciclo de vida maior. Para Jackson et al. (1997) e Jackson \& Moltschaniwskyj (2002), lulas que habitam águas quentes apresentam taxa de crescimento $9 \%$ superior do que as que vivem em águas frias.

Populações que habitam águas frias demoram mais para atingir a maturidade (PACKARD, 1972) sendo que, no inverno o crescimento das lulas é mais vagaroso e aquelas capturadas na primavera possuem pequena diferença em dimensão das capturadas no outono. Deste modo, tem sido observado que a redução da taxa de crescimento nos meses de inverno é característica entre as espécies que vivem em regiões boreais, subtropicais e tropicais (PACKARD, 1972; ZUEV \& NESIS, 2003). Considerando que a taxa de crescimento é influenciada pela temperatura ambiente (BOYLE \& RODHOUSE, 2005), as taxas variam conforme as épocas do ano, latitude e profundidade da água (FORSYTHE \& VAN HEUKELEM, 1987).

De acordo com Jackson (1994) lulas de mesma espécie, porém de regiões temperadas, podem completar seu ciclo de vida em menos de dois anos, enquanto que as de regiões tropicais podem viver menos de oito meses. Em geral, os loliginídeos apresentam crescimento rápido, sendo que a maioria das espécies apresentam ciclo de vida menor ou igual a um ano (VILLANUEVA, 2000), o que ocorre como exemplo para os loliginideos tropicais, Doryteuthis opalescens da Califórnia, onde a idade máxima obtida foi de uma fêmea de 238 dias e 243 dias para um macho (BUTLER et al., 1998). 
Outro exemplo, de acordo com Jackson et al. (1997) dependendo da temperatura em que vivem as lulas Lolliguncula brevis apresentam um período curto de vida entre 100 e 200 dias. Para Uroteuthis edulis do Sudeste do mar da China (ambiente subtropical), a longevidade foi estimada em 270 dias (9 meses), porém em águas temperadas a longevidade se aproximou de um ano (NATSUKARI et al., 1988; WANG et al., 2010; WANG et al., 2013).

Já que o crescimento em comprimento de Doryteuthis plei é variável conforme a temperatura ambiente, visto que há relação com efeitos biológicos de transformação de matéria orgânica em tecido somático, ganho em comprimento dos estatólitos e comprimento dos domos possuem relação com o crescimento das lulas. O crescimento tridimensional dos estatólitos é variável conforme a temperatura da água. Por este motivo Jackson (1995) sugere que a utilização da relação de comprimento do estatólito com comprimento do manto como um indicador de idade deve ser utilizado com cautela.

Para Thomas \& Moltschaniwskyj (1999) os estatólitos crescem conforme a idade da lula, porém o crescimento do estatólito pode responder de forma diferente a fatores ambientais do que para o crescimento do tecido somático. Sendo assim, fatores bióticos a abióticos influenciam no crescimento da estrutura calcária, pois ainda de acordo com Thomas \& Moltschaniwskyj (1999), variações nas condições ambientais influenciam na taxa de deposição de aragonita nos estatólitos, o que pode causar flutuações diárias nos incrementos diários, ocasionando a diferenças no comprimento total e peso de um estatólito com idade semelhante.

Sendo assim os tópicos seguintes descrevem o formato dos estatólitos da espécie estudada, e também relacionam os dados obtidos de idade com mensurações dos estatólitos.

\subsection{Os estatólitos da espécie}

O formato dos estatólitos de Doryteuthis plei foram descritos no presente estudo e resultaram similares aos descritos por Perez et al. (2006) para lulas capturadas na costa de Santa Catarina. Em ambos os estratos populacionais, a área do estatólito foi caracterizada por possuir um domo dorsal e lateral proeminente, mas em lulas juvenis, esta área se caracterizou por ser mais arredondada e de tamanho menor (BARCELLOS 
\& GASALLA, 2014). Contudo, o tamanho dos espécimes analisados no presente estudo (variação de ML entre 25-291 mm e média de 112,06 $\mathrm{mm}$ ) foi menor do que os amostrados por Perez et al. (2006) (lulas entre 35-342 mm ML).

Como observado por Aguiar (2002), diferenças morfológicas foram também observadas entre estatólitos de juvenis e adultos. Estatólitos de lulas juvenis tiveram tendência em ser pequenos em tamanho (em média 1,02 mm SL), com domo dorsal arredondado e rostro curto. Os estatólitos demonstraram tendência em mudança do formato com o crescimento das lulas. Sendo assim, a morfologia e a morfometria dessa estrutura foram bastante diferentes em lulas adultas e juvenis (BARCELLOS \& GASALLA, 2014). De acordo com Lombarte et al. (1997) isto ocorre devido à curta vida das lulas e rápido crescimento, ocasionando variação brusca em formato dos estatólitos conforme o crescimento. Aguiar (2006) também observou mudanças na morfologia dos estatólitos de D. sanpaulensis entre juvenis e adultos. Lulas adultas apresentam estatólitos mais arredondados e robustos quando comparados com lulas juvenis.

Em termos da relação entre ML e SL, o modelo logarítmico forneceu o melhor ajuste para $D$. plei e pode ser utilizado para estimar o comprimento de manto da lula tendo apenas a medida do comprimento de um dos estatólitos, e vice e versa (BARCELLOS \& GASALLA, 2014). Relações de ML e SL previamente estabelecidas para outras espécies foram também muito bem descritas pela função logarítmica, porém com ajustes inferiores aos apresentados no presente estudo (AGUIAR, 2002; PEREZ et al., 2006). Para Illex argentinus do Oceano Atlântico Sudoeste, a função potencial proveu o melhor ajuste para a relação em discussão (BRUNETTI \& IVANOVIC, 1991).

A função potencial é adequada para a descrição das diferenças entre estruturas corporais, apresenta o coeficiente alométrico (GOULD, 1966) muito utilizado para comparação do crescimento de uma dada estrutura com outras proporções do organismo. O coeficiente alométrico também é útil para a comparação da relação ML e SL entre as diferentes espécies de loliginídeos como D. sanpaulensis, D. gahi, Sepioteuthis lessoniana (PINEDA et al., 1998; THOMAS \& MOLTSCHANIWSKYJ, 1999; FLORES \& GARLAND, 2002). 


\subsection{Relação idade com a morfometria dos estatólitos}

De acordo com Morris \& Aldrich (1985) o comprimento do estatólito é um indicador mais preciso do que o número de incrementos de crescimento (idade a partir de leitura de anéis de crescimento depositados nos estatólitos). Sendo assim, foram testados os dados de idade obtidos com a leitura dos incrementos de crescimento nos estatólitos com os dados de: comprimento de estatólito (SL) e comprimento do domo dos estatólitos (DL). As relações de idade com mensurações dos estatólitos mostraram significância, gerando coeficientes de correlação dentro do intervalo de confiança.

Comprovada a utilização dos estatólitos de Doryteuthis plei para a estimativa de idade da espécie, destaca-se que além da contagem dos incrementos de crescimento, é possível estimar a idade dos exemplares com os valores de SL e DL através das equações de ajuste das relações, disponíveis no presente estudo, como também propor novos parâmetros a serem incorporados em uma análise estatística no estudo da biologia da espécie.

Devido a alta plasticidade na idade e à sensibilidade do crescimento das lulas às variáveis ambientais, em especial à temperatura, os ajustes de modelos de crescimento continuam sendo um desafio (FORSYTHE 2004). Diferenças ao longo das estações do ano tem sido identificadas nas taxas de crescimento de loliginídeos (JACKSON \& MOLTSCHANIWSKYJ, 2002; HATFIELD, 2000). Devem ser inclusos em modelos populacionais, trabalhos como o estudo de Jackson (1997) que considera a combinação do comportamento do crescimento de lulas e suas alterações em relação, como exemplo, a temperatura ambiente. Segundo Jackson (2004) o comportamento das taxas de crescimento e o habitat próximo a regiões costeiras colocam os loliginídeos em situação ideal para resposta as variações ambientais e as lulas, de maneira geral, tem sido consideradas eficientes indicadores ambientais. Sendo assim, o constante monitoramento das taxas de crescimento, tamanho do corpo e das condições somáticas dos loliginídeos pode fornecer informações importantes das condições ambientais (ZALESKI, 2010).

Neste contexto, os parâmetros de crescimento obtidos no presente estudo oferecem recursos para estudos como de mortalidade e conservação da espécie, pois compreender os diferentes processos que atuam na biologia da espécie em estudo, e poderá auxiliar também na compreensão da dinâmica dos ecossistemas costeiros. 


\section{CONCLUSÕES}

Os estatólitos de D. plei capturados na região de Ubatuba e São Sebastião são estruturas adequadas para estimar a idade através da leitura de microestruturas, o crescimento, e o tamanho dos exemplares;

A morfologia dos estatólitos mostrou semelhança à de outros loliginídeos, porém exibiu características particulares como o formato dos domos, rostro, e asa, suficientes para permitir a identificação da espécie;

Não foram encontradas diferenças na morfometria e morfologia dos estatólitos de machos e fêmeas, porém foi verificado que estatólitos dos jovens diferem dos adultos;

A relação entre o comprimento do manto e comprimento do estatólito foi melhor definida pelo modelo logarítmico, portanto, pode ser utilizado para estimar o comprimento de indivíduos de D. plei a partir de seus estatólitos;

D. plei da região em estudo nascem durante todo o ano, geralmente com maior frequência no primeiro semestre, nas estações do ano de verão e outono;

A curva de crescimento (relação idade e comprimento de manto) de D. plei da região de Ubatuba e São Sebastião foi melhor definida pelo modelo logístico $\left(L_{\text {inf }}=181,90 \mathrm{~mm}\right.$ ML e $k=0,03 \mathrm{~mm} / \mathrm{dia})$.

A longevidade para a espécie na região de estudo foi estimada em torno de oito meses, mas a espécie pode viver até 355 dias (indivíduo mais velho obtido na amostra);

A taxa instantânea de crescimento foi mais alta no estágio juvenil do que em adultos, com decréscimo acelerado após os $60 \mathrm{~mm}$ de comprimento de manto. A partir dos 120 mm de comprimento de manto, a taxa de crescimento se diferencia entre os sexos, sendo que os machos apresentam maiores taxas de crescimento em relação as fêmeas. Os maiores valores em taxa de crescimento dos exemplares imaturos foram também destacados quando em comparação com os exemplares de outros estádios de maturação;

Foram observadas variações sutis da taxa de crescimento durante as estações do ano;

Os diferentes ajustes de crescimento obtidos para os exemplares nascidos em diferentes épocas do ano auxiliam e evidenciam as variações do crescimento dos exemplares conforme as estação do ano; 
Valores das taxas de crescimento foram semelhantes para exemplares nascidos no verão e outono com comprimento de manto entre 30-160 mm. Maiores taxas de crescimento foram identificadas em exemplares nascidos no inverno. Fêmeas nascidas na primavera apresentaram maiores taxa de crescimento e queda acentuada nessa taxa em relação aos exemplares nascidos em outras estações do ano, os quais apresentaram praticamente mesmas taxas;

O estudo permite estimar a idade de Doryteuthis plei tendo apenas o comprimento dos estatólitos e o comprimento dos domos. O modelo logarítmico ofereceu o melhor ajuste aos dados de crescimento da espécie. 


\section{REFERENCIAS BIBLIOGRÁFICAS}

AGUIAR, D.C. 2002. Utilização da microestrutura do estatólito para a determinação da idade e estimativas de taxas de crescimento da lula Loligo plei. Trabalho de Conclusão de Curso, Universidade do Vale do Itajaí, Departamento de Oceanografia, 44 p.

AGUIAR, D.C. 2006. Idade e crescimento da lula Loligo sampaulensis Brakoniecki, 1984 (Cephalopoda: Myopsida) do sudeste - sul do Brasil. Dissertação de Mestrado, Universidade de São Paulo, Instituto Oceanográfico, 92 p.

AGUIAR, D.C.; ROSSI-WONGTSCHOWSKI, C. L.D.B.; PEREZ, J.A.A. 2012. Validation of daily growth increments of statoliths of brazilian squid Doryteuthis plei and D. sanpaulensis (Cephalopoda: Loliginidae). Bioikos, v. 26, n. 1, p. 13-21.

AKAIKE, H. 1973. Information theory and an extension of the maximum likelihood principle. In: PERTARAN, B. N; CSAAKI, F. (ed). Second International Symposium on Information Theory. Budapest: Acadeemiai Kiadi, p. 267-281.

AMARATUNGA, T. 1983. The role cephalopods in the marine ecosystems. In: Caddy, J.F., Advances in assessment of world cephalopod resources. FAO Fish. Tech. Pap., n. 231, p. 379-415.

ARKHIPKIN, A. I. 1995. Age, growth and maturation of the European squid Loligo vulgaris (Myopsida, Loliginidae) on the west Saharan shelf. J. Mar. Biol. Ass. U. K., v. 75 , p. 593-604.

ARKHIPKIN, A. I. 1996a. Statolith microstructure and age of early life stages of planktonic squids Galiteuthis phyllura and Belonella borealis (Oegopsida, Cranchiidae) from the northern North Pacific. J. Plankton Res., v. 18, n. 1, p. 123-132.

ARKHIPKIN, A. I. 1996b. Age and growth of the squid Abraliopsis pfefferi (Oegopsida: Enoploteuthidae) from the Central-East Atlantic based on statolith microstructure. Sci. Mar., v. 60, n. 2-3, p. 325-330.

ARKHIPKIN, A. I.; BJORKE, H. 2000. Statolith shape and microstructure as indicators of ontogenetic shifts in the squid Gonatus fabricii (Oegopsida, Gonatidae) from the Norwegian Sea. Polar Biol., v. 23, p. 1-10. 
ARKHIPKIN, A. I.; BIZIKOV, V. A. 2000. Role of the statolith in functioning of the acceleration receptor system in squids and sepioids. J. Zool., v. 250, p. 31-55.

ARKHIPKIN, A. I. 2005. Statoliths as "black boxes" (life recorders) in squid. Mar. Freshw. Res., v. 56, n. 5, p. 573-583.

ARKHIPKIN, A.I.; ROA-URETA, R. 2005. Identification of ontogenetic growth models for squid. Mar. Freshw. Res., v. 56, p. 371-386.

ARKHIPKIN, A. I.; SHCHERBICH, Z. N. 2012. Thirty years' in age determination of squid using statoliths. J. Mar. Biol. Ass. U. K., v. 92, p. 1389-1398.

BARCELLOS, R. L.; FURTADO, V. V. 1999. Processo sedimentar atual e a distribuição de carbono e nitrogênio orgânico no Canal de São Sebastião (SP) e plataforma continental interna adjacente. Rev. Bras. Oceanogr., v. 47, n. 2, p. 207-221.

BARCELLOS, D. D.; GASALLA, M. A. G. 2014. Morphology and Morphometry of Doryteuthis plei (Cephalopoda: Loliginidae) statoliths from the Northern shelf off São Paulo, Brazil. J. Nat. Hist., p.1-13, http://dx.doi.org./10.1080/00222933.2013.840937.

BEAMISH, R. J.; FOURNIER, D. A. 1981. A method for comparing the precision of a set of age determinations. Can. J. Fish. Aquat. Sci., v. 38, p. 982-983.

BETTENCOURT, V.; Guerra, A. 2000. Growth increments and biomineralization process in cephalopod statoliths. J. Exp. Mar. Biol. Ecol., v. 248, p. 191-205.

BLANK, A. G.; CARNEIRO, M. H.; SECKENDORFF, R. W. V.; OSTINI, S. 2009. A pesca de cerco-flutuante na Ilha Anchieta, Ubatuba, São Paulo: Instituto de Pesca, Série Relatórios Técnicos, n. 34. 20 p.

BOYLE, P. R.; RODHOUSE, P. G. 2005. Cephalopods: Ecology and Fisheries. Oxford: Blackwell Publishing. 464 p.

BRUNETTI, N. E.; IVANOVIC, M. L. 1991. Morfologia y morfometria de los estatolitos del calamar (Illex argentinus). Frente Marit., v. 9, p. 53-61.

BUTLER, J.; FULLER, D.; YAREMKO, M. 1999. Age and growth of market squid (Loligo opalescens) off California during 1998. Calif. Coop. Ocean. Fish. Invest. Rep., v. 40, p. 191-195. 
CASTRO FILHO, B. M.; MIRANDA, L. B.; MIYAO, S. Y. 1987. Condições hidrográficas na plataforma continental ao largo de Ubatuba: variações sazonais e em média escala. Bol. Inst. Oceanogr., Sao Paulo, v. 35, n. 2, p. 135-151.

CERIOLA, L.; MILONE, N. 2007. Cephalopods Age Determination by Statolith Reading: a Technical Manual. Scientific Cooperation to Support Responsible Fisheries in the Adriatic Sea. GCP/RER/010/ITA/TD-22. Rome: AdriaMed Technical Documents, v. 22.78 p.

CLARKE, M. R. 1966. A review of the systematics and ecology of oceanic squids. Adv. Mar. Biol., v.4, p. 91-300.

CLARKE, M. R.; FITCH, J. E. 1975. First fossil records of cephalopod statoliths. Nature, v. 257, p. 380-381.

CLARKE, M. R. 1978. The cephalopod statolith - An introduction to its form. . J. Mar. Biol. Ass. U. K., v. 58, p. 701-712.

DAWE, E. G.; O’DOR, R. K.; ODENSE, P. H; HURLEY, G. V. 1985. Validation and aplication of an ageing technique for short-finned squid (Illex illecebrosus). J. Northw. Atl. Fish. Sci., v.6, p. 107-116.

DAY, T.; TAYLOR, P. D. 1997. von Bertalanffy's growth equation should not be used to model age and size at maturity. Am. Nat., v. 149, n. 2, p. 381-393.

DURHOLTZ, M. D.; LIPINSKI, M. R. 2002. Field, J.D., Laboratory validation of periodicity of incrementation in statoliths of the South African chokka squid Loligo vulgaris reynaudii (d'Orbigny, 18450: a reevaluation. J. Exp. Mar. Biol. Ecol., v.279, n.1-2, p. 41-59.

FLORES, L. A.; GARLAND, D. E. 2002. Descripción de los estatolitos y relaciones morfométricas y gravimétricas em el calamar patagônico (Loligo gahi) (Cephalopoda: Loliginidae). Rev. Biol. Ter. Oceanogr., v.37, n. 1, p. 15-24.

FORSYTHE, J. W.; VAN HEUKELEM, W. F. 1987. Growth. In: BOYLE, P. R. Cephalopod Life Cycles, Comparative Reviews, $2^{\text {nd }}$ edition, London: Academic Press. p. $135-156$. 
FORSYTHE, J. W. 2004. Accounting for the effect of temperature on squid growth in nature: from hypothesis to practice. Mar. Fres. Res., v. 55, p. 331-339.

GASAlla, M. A; POStuMA, F. A.; TOMÁS, A. R. G. 2005. Captura de lulas (Mollusca: Cephalopoda) pela pesca industrial desembarcada em Santos: Comparação após 4 décadas. Braz. J. Aquat. Sci. Techn., v. 9, n. 2, p. 5-8.

GASAllA, M. A.; RODRIGUES, A. R.; POSTUMA, F. A. 2010. The trophic role of the squid Loligo plei as a keystone species in the South Brazil Bight ecosystem. ICES J. Mar. Sci., v. 67, p.1413-1424.

GONZÁlEZ, A. F.; DAWE, E. G.; BECK, P.; PEREZ, J. A. A. 2000. Bias associated with statolith-based methodologies for ageing squid: a comparative study on Illex illecebrosus (Cephalopoda: Ommastrephidae). J. Exp. Mar. Biol. Ecol., n. 244, p. 161180.

GONZÁleZ, A. F.; OTERO, J.; PIERCE, G. J.; GUERRA, Á. 2010. Age, growth, and mortality of Loligo vulgaris wild paralarvae: implications for understanding of the life cycle and longevity. ICES J. Mar. Sci., v. 67, p. 1119-1127.

GOULD, S. J. 1966. Allometry and size in ontogeny and phylogeny. Biol. Rev., v. 41, p. 587-640.

HATFIELD, E. M. C. 2000. Do some like ir hot? Temperature as a possible determinant of variability in the growth of the Patagonian squid, Loligo gahi (Cephalopoda: Loliginidae). Fish. Res., v. 47, p. 27-40.

HERMOSILlA, C. A.; ROCHA, F.; FIORITO, G.; GONZÁLEZ, A.F.; GUERRA, Á. 2010. Age validation in common octopus Octopus vulgaris using stylet increment analysis. ICES J. Mar. Sci., v. 67, p. 1458-1463.

HURLEY, G. V.; BECK, P.; DREW, J.; RADTKE, R. L. 1979. A preliminary report on validation age readings from statoliths of the short-finned squid (Illex ilecebrosus). ICANAF Res. Doc., v. 70, n. 26, p. 1-6.

HURLEY, G. V.; ODENSE, P. H.; O’DOR, R. K.; DAWE, E. G. 1985. Strontium labeling for verifying daily growth increments in the statolith of the short-finned squid (Illex illecebrosus). Can. J. Fish. Aquat. Sci., v. 42, p. 380-383. 
JACKSON, G. D. 1990a. Age and growth of the tropical nearshore Loliginid squid Sepioteuthis lessoniana determined from statolith growth-ring analysis. Fish. Bull., v. 88, n. 1, p.113-118.

JACKSON, G. D. 1990b. The use of tetracycline staining techniques to determine statolith growth ring periodicity in the tropical Loliginid squids Loliolus noctiluca and Loligo chinensis. Veliger, v. 33, p. 395-399.

JACKSON, G. D. 1994. Application and future potential of statolith increment analysis in squids and sepiods. Canadian Journal Aquatic Science, v. 51, p. 2612-2625.

JACKSON, G. D. 1995. Seasonal influences on statolith growth in the tropical nearshore loliginid Loligo chinensis (Cephalopoda: Loliginidae) off Townsville, North Queensland, Australia. Fish. Bull., v. 93, p. 749-752.

JACKSON, G. D.; FORSYTHE, J. W.; HIXON, R. F.; HANLON, R. T. 1997. Age, growth, and maturation of Lolliguncula brevis (Cephalopoda: Loliginidae) in the northwestern Gulf of Mexico with a comparison of length-frequency versus statolith age analysis. Can. J. Fish. Aquat. Sci., v. 54, p. 2907-2919.

JACKSON, G. D. 1998. Research into the life history of Loligo opalescens: where to from here? Calif. Coop. Ocean. Fish. Invest. Rep., v. 39, p. 101-107.

JACKSON, G.D.; FORSYTHE, J. W. 2002. Statolith age validation and growth of Loligo plei (Cephalopoda: Loliginidae) in the north-west gulf of Mexico during spring/summer. J. Mar. Biol. Ass. U. K., v. 82, p. 677-678.

JACKSON, G. D.; MOLTSCHANIWSKYJ, N. A. 2002. Spatial and temporal variation in growth rates and maturity in the Indo-Pacific squid Sepioteuthis lessoniana (Cephalopoda: Loliginidae). Mar. Biol., v. 140, p. 747-754.

JACKSON, G. D. 2004. Advances in defining the life histories of myopsid squid. Mar. Fres. Res., v. 55, p. 357-365.

JEREB, P.; ROPER, C. F. E. 2010. Cephalopods of the world. An Annotated and illustrated catalogue of cephalopod species known to date. Myopsid and Oegopsid Squids. Rome: FAO Species Catalogue for Fishery Purposes, v. 2, n. 4.605 p. 
JUANICÓ-RIVERO, M. 1979. Contribuição ao estudo da biologia dos Cephalopoda Loliginidae do Atlântico Sul Ocidental, entre Rio de Janeiro e Mar del Plata. Tese de Doutorado. Universidade de São Paulo, Instituto Oceanográfico, Universidade de São Paulo, 102p.

KRISTENSEN, T. K. 1980. Periodical growth rings in cephalopod statoliths. Dana, v. 1, p. 39-51.

LIPINSKI, M. R. 1986. Methods for the validation of squid age from statoliths. J. Mar. Biol. Ass. U.K., v. 66, n.2, p. 505-526.

LIPINSKI, M. R.; DURHOLTZ, M. D.; UNDERHILL, L. G. 1998. Field validation of age readings from the statoliths of chokka squid (Doryteuthis vulgaris reynauddi D’Orbigny, 1845) and an assessment of associated errors. ICES J. Mar. Sci., v. 55, p. 240-257.

LOMBARTE, A.; SANCHEZ, P.; MORALES-NIN, B. 1997. Intraspecific shape variability in statolith of three cephalopod species. Vie Milieu, v. 46, n. 2, p. 165-169.

MALHEIROS, H. Z. 2008. Avaliação da pesca de arrasto do Camarão-Sete-Barbas (Xiphopenaeus kroyeri) em comunidades do entorno do Parque Nacional do Superagui - Paraná. Dissertação de Mestrado, Universidade Federal do Paraná, Setor de Ciências da Terra, 123 p.

MARTINS, R.S.; PEREZ, J. A. A. 2006. Cephalopods and fish attracted by night lights in coastal shallow-waters, off southern Brazil, with the description of squid and fish behavior. J. Ethol., v. 8, n.1, p. 27-34.

MARTINS, R.S.; PEREZ, J. A. A. 2007. The ecology of loliginid squid in shallow Waters around Santa Catarina island, Southern Brazil. Bull. Mar. Sci., v. 80, n. 1, p. $125-146$

MIRANDA, L. B. 1982. Análise de massas de água da plataforma continental e da região oceânica adjacente: Cabo de São Tomé (RJ) à Ilha de São Sebastião (SP). Dissertação de Mestrado, Universidade de São Paulo, Instituto Oceanográfico, 123 p.

MUSSOLINI, G. 1980. Ensaios de Antropologia Indígena e Caiçara. Rio de Janeiro: Paz e Terra, Coleção Estudos Brasileiros, v. 38. 290 p. 
MORRIS, C. C.; ALDRICH, F. A. 1985. Statolith length and increment number for age determination in squid Illex illecebrosus (LeSueur, 1821) (Cephalopoda: Ommastrephidae). NAFO Sci. Coun. Studies, v. 9, p. 101-106.

NAKAMURA, Y.; SAKURAI, Y. 1991. Validation of daily growth increments in statoliths of Japanese common squid Todarodes pacificus. Nippon Suisan Gakk., v. 57, n. 11 , p. 2007-2011.

NATSUKARI, Y.; NAKANOSE, T.; ODA, K. 1988. Age and growth of loliginid squid Photololigo edulis (Hoyle, 1885). J. Exp. Mar. Biol. Ecol., v. 116, p. 177-190.

OGLE, D. H. 2012. FSA: Fisheries Stock Analysis. R package version 04-1.

PACKARD, A. 1972. Cephalopods and fish: the limits of convergence. Biol. Rev., v. 47, p. 241-307.

PEREZ, J. A. A.; AGUIAR, D. C.; OLIVEIRA, U. C. 2002. Biology and population dynamics of long-finned squid Loligo plei (Cephalopoda: Loliginidae) in southern Brazilian waters. Fish. Res., v. 58, p. 267-279.

PEREZ, J. A. A.; AGUIAR, D. C.; SANTOS, J. A. 2006. Gladius and statolith as tools for age and growth studies of the squid Loligo plei (Teuthida: Loliginidae) off southern Brazil. Braz. Arch. Biol. Techn., v. 49, n. 5, p. 747-755.

PINEDA, S. E.; HERNÁNDEZ, D. R.; BRUNETTI, N. E. 1998. Statolith comparison of two South-west Atlantic Loliginid squid: Loligo sanpaulensis and Loligo gahi. In: PAYNE, A. I. L.; LIPENSKI, M. R.; CLARKE, M. R.; ROELEVELD, M. A. C. Cephalopod Biodiversity, Ecology and Evolution. S. Afr. J. Mar. Sci., v. 20, p. 347-354.

PIRES-VANIN, A. M. S. 2008. Oceanografia de um ecossistema subtropical: plataforma de São Sebastião. São Paulo: Edusp. 462 p.

POSTUMA, F. A. 2010. Biologia pesqueira da lula Loligo plei capturada na Ilha de São Sebastião (SP) e dinâmica da atividade pesqueira associada. Dissertação de Mestrado, Instituto de Pesca, 107 p.

POSTUMA, F. A.; GASALLA, M. A. 2010. On the relationship between squid and the environment: artisanal jigging for Loligo plei at São Sebastião Island $\left(24^{\circ} \mathrm{S}\right)$, Southeastern Brazil. ICES J. Mar. Sci., v. 67, p. 1353-1362. 
POSTUMA, F. A.; GASALLA, M. A. 2014. Reproductive activity of the tropical Arrow squid Doryteuthis plei around São Sebastião Island (SE Brazil) based on a 10year fisheries monitoring. Fish. Res. http://dx.doi.org/10.1016/j.fishres.2013.12.011.

R Development Core Team. 2012, R: A language and environment for statistical computing. Vienna, Austria: R Foundation for Statistical Computing. ISBN 3-90005107-0. Available from: http://www.r-project.org/

RADTKE, R. L. 1983. Chemical and structural characteristics of statoliths from the short-finned squid Illex illecebrosus.Mar. Biol., v. 76, p. 47-54.

RODHOUSE, P. G.; BOYLE, P. R. 2010. Large aggregations of pelagic squid near the ocean surface at the Antarctic Polar Front, and their capture by grey-headed albatrosses. ICES J. Mar. Sci., v. 67, p. 1-4.

RODRIGUES, A. C. 2007. Caracterização da estrutura populacional e alimentação das lulas Loligo plei (Blainville, 1823) e Loligo sanpaulensis (Brakoniecki, 1984) (Cephalopoda: Loliginidade) capturadas pela pesca industrial do Estado de São Paulo, entre $23^{\circ} \mathrm{S}$ e $26^{\circ} 5^{\prime} \mathrm{S}$. Dissertação de Mestrado, Instituto de Pesca, 87 p.

ROPER, C. F. E; SWEENEY, M. J.; NAUEN, C. E. 1984. Cephalopods of The World. An Annotated and Illustrated Catalogue of Species of Interest to Fisheries. Rome: FAO Species Catalogue, v. 3, n.125. 227 p.

RUPPERT, E. E.; FOX, R. S.; BARNES, R. D. 2005. Mollusca. In: RUPPERT, E. E.; FOX, R. S.; BARNES, R. D. Zoologia dos Invertebrados, $7^{\text {th }}$ Ed., São Paulo: Editora Roca, p. 397-425.

ROSSI-WONGTSCHOWSKI, C. L. D. B.; SOARES, L. S. H.; MUTO, E. Y. 2008. Ictiofauna. In: PIRES-VANIN, A. M. S. (Org). Oceanografia de um ecossistema tropical. Plataforma de São Sebastião, SP. São Paulo: Edusp, p. 42-57.

SAKAI, M., BRUNETTI, N., IVANOVIC, M., ELENA, B., NAKAMURA, K. 2004. Interpretation of statolith microstruture in reared hatchling paralarvae of Illex argentines. Mar. Fresh.Res., v. 55, p. 403-413. 
SCHWARZ, R.; PEREZ, J.A. A. 2007. Diferenciação populacional do calamarargentino (Illex argentinus) (Cephalopoda: Teuthidea) no sul do Brasil através da morfologia e morfometria do estatólito. Braz. J. Aquat. Sci. Techn., v. 11, n. 1, p. 1-12.

SCHWARZ, R.; PEREZ, J. A. A. 2010. Growth model identification of short-finned squid Illex argentines (Cephalopoda: Ommastrephidae) off southern Brazil using statoliths. Fish. Res., v. 106, p. 177-184.

SCHWARZ, R.; PEREZ, J. A. A. 2013. Age structure and life cycles of the Argentine shortfin squid Illex argentinus (Cephalopoda: Ommastrephidae) in southern Brazil. J. Mar. Biol. Ass. U. K., v. 93, n. 2, p. 557-565.

SIFNER, S. K. 2008. Methods for age and growth determination in cephalopods. Ribarstvo, v. 66, n.1, p. 25-34.

SILVA, L. S.; MIRANDA, L.B.; CASTRO FILHO, B. M. 2004. Estudo numérico da circulação e da estrutura termohalina na região adjacente à Ilha de São Sebastião (SP). Rev. Bras. Geofis., v. 2, n.3, p. 197-221.

SPARRE, P.; VENEMA, S. C. 1992. Introduction to tropical fish stock assessment. Part 1. Manual. Rome: Fisheries Technical Paper, n. 206.1, v. 1. 376 p.

SPRATT, J. D. 1979. Age and growth of the market squid, Loligo opalescens Berry, from statoliths. Calif. Coop. Ocean. Fish. Invest. Rep., v. 20, p. 58-64.

STEPHENS, P.R.; YOUNG, J. Z. 1978. Semicircular canals in squids. Nature, v. 271, p. 444-445.

TOLL, R. B. 1998. The Gladius in Teuthoid Systematics. In: VOSS, N.A.; VECCHIONE, M.; SWEENEY, M. J. 1998. Systematics and Biogeography of Cephalopods. Washington DC: Smithsonian Institution Libraries,Smithsonian. Contributions to Zoology, n. 586, p. 55-68.

TAYLOR, C. C. 1958. Cod growth and temperature. J. Cons. Int. Explor. Mer., v. 23, n. 3, p. 365-370.

THOMAS, R.; MOLTSCHANIWSKYJ, N. A. 1999. Ontogenetic changes in size and shape of statoliths: implications for age and growth of the short-lived tropical squid Sepioteuthis lessoniana (Cephalopoda: Loliginidae). Fish. Bull., v. 97, n. 3, p. 636-645. 
VAZ, M. M. 2001. Problemas no ajuste da curva de crescimento do Pacu, Piaractus mesopotamicus (Holmberg, 1887) (Pisces: Characidae), e seu manejo no Pantanal Mato-Grossense. Tese de Doutorado. Universidade Estadual Paulista, Centro de Aquicultura, $149 \mathrm{p}$.

VEGA, M.R.; ROCHA, F.J.; OSORIO, C. 2001. Morfometría comparada de los estatolitos del calamar Loligo gahi d' Orbigny, 1835 (Cephalopoda: Loliginidae) del norte de Peru e islas Falkland. Invest. Mar., v. 29, p. 3-9.

VILLANUEVA, R.; ARKHIPKIN, A.I.; JEREB, P.; LEFKADITOU, E.; LIPINSKI, M.R.; RAYA, C.P.; RIBA, J. 2003. Embryonic life of the loliginid squid Loligo vulgaris: comparison between statoliths of Atlantic and Mediterranean populations. Mar. Ecol. Prog. Ser., v. 253, p. 197-208.

VILLANUEVA, R. 2000. Effect of temperature on statolith growth of the European squid Loligo vulgaris during early life. Mar. Biol., v. 136, p. 449-460.

WANG, K.Y.; LEE, K.T.; LIAO, C. H. 2010. Age, growth and maturation of swordtip squid (Photololigo edulis) in the southern East China Sea. J. Mar. Sci. Tech., v. 18, n. 1, p. $99-105$.

WANG, K.Y.; CHANG, K.Y; LIAO, C.H.; LEE, M.A.; LEE, K. T., 2013. Growth strategies of the swordtip squid, Uroteuthis edulis, in response to environmental changes in the southern East China Sea - a cohort analysis. Bull. Mar. Sci., v. 89, n. 3, p. 677-698.

ZAKARIA, M. Z. 2000. Age and growth of oceanic squid Sthenoteuthis oualaniensis using statolish in the South China Sea, area III, Western Philippines. In: Proceedings of the Third Technical Seminar on Marine Fishery Resources Survey in the South China Sea, area III: Western Philippines, p. 118-134.

ZALESKI, T. 2010. Ciclo de vida e ecologia da lula Lolliguncula brevis na Armação de Itapocoroy, Santa Catarina, Brasil. Tese de Doutorado, Universidade Federal do Paraná, Setor de Ciências Biológicas, 187 p.

ZAR, J. H. 1996. Biostatistical analysis, $3^{\circ}$ ed., New Jersey: Prentice-Hall International Editions. 662 p. 
ZUEV, G. V.; NESIS, K. N. 2003. Squid (biology and fishing). Washington DC: Smithsonian Institution Libraries, v. 2. 291 p. 
Apêndice 1 - Tabela 32: Leituras de idade de cada um dos exemplares com cálculo do erro médio porcentual (EMP) e do coeficiente de variação (CV)

Tabela 32 - Análise dos incrementos depositados nos estatólitos, onde: identificação do exemplar amostrado (n); leituras dos anéis de crescimento realizadas em cada estatólito, sendo que ocorreram com repetição entre três e cinco vezes; média entre as leituras (Média); desvio padrão (DP); erro médio porcentual (EMP); e coeficiente de variação (CV).

\begin{tabular}{|c|c|c|c|c|c|c|c|c|c|}
\hline \multirow{2}{*}{$\mathbf{n}$} & \multicolumn{5}{|c|}{ Leituras } & \multirow{2}{*}{ Média } & \multirow{2}{*}{ DP } & \multirow{2}{*}{ EMP } & \multirow{2}{*}{$\mathrm{CV}$} \\
\hline & 1 & 2 & 3 & 4 & 5 & & & & \\
\hline 1 & 119 & 131 & 138 & 134 & & 134,33 & 3,51 & 1,82 & 2,61 \\
\hline 2 & 161 & 172 & 174 & 178 & & 174,67 & 3,06 & 1,27 & 1,75 \\
\hline 3 & 172 & 179 & 172 & 174 & & 175,00 & 3,61 & 1,52 & 2,06 \\
\hline 4 & 210 & 208 & 214 & 209 & & 210,33 & 3,21 & 1,16 & 1,53 \\
\hline 5 & 226 & 276 & 238 & 243 & & 252,33 & 20,65 & 6,25 & 8,18 \\
\hline 6 & 227 & 242 & 256 & 241 & & 246,33 & 8,39 & 2,62 & 3,40 \\
\hline 7 & 285 & 279 & 299 & 288 & & 288,67 & 10,02 & 2,39 & 3,47 \\
\hline 8 & 226 & 209 & 215 & 220 & & 214,67 & 5,51 & 1,76 & 2,57 \\
\hline 9 & 219 & 219 & 225 & 221 & & 221,67 & 3,06 & 1,00 & 1,38 \\
\hline 10 & 275 & 270 & 282 & 276 & & 276,00 & 6,00 & 1,45 & 2,17 \\
\hline 11 & 244 & 229 & 234 & 231 & & 231,33 & 2,52 & 0,77 & 1,09 \\
\hline 12 & 181 & 205 & 243 & 209 & & 219,00 & 20,88 & 7,31 & 9,53 \\
\hline 13 & 239 & 258 & 228 & 236 & & 240,67 & 15,53 & 4,80 & 6,45 \\
\hline 14 & 282 & 296 & 298 & 293 & & 295,67 & 2,52 & 0,60 & 0,85 \\
\hline 15 & 281 & 243 & 257 & 248 & & 249,33 & 7,09 & 2,05 & 2,85 \\
\hline 16 & 220 & 223 & 227 & 220 & & 223,33 & 3,51 & 1,09 & 1,57 \\
\hline 17 & 236 & 233 & 238 & 236 & & 235,67 & 2,52 & 0,75 & 1,07 \\
\hline 18 & 212 & 204 & 210 & 212 & & 208,67 & 4,16 & 1,49 & 2,00 \\
\hline 19 & 266 & 288 & 287 & 296 & & 290,33 & 4,93 & 1,30 & 1,70 \\
\hline 20 & 221 & 230 & 228 & 231 & & 229,67 & 1,53 & 0,48 & 0,67 \\
\hline 21 & 210 & 216 & 233 & 236 & & 228,33 & 10,79 & 3,60 & 4,72 \\
\hline 22 & 153 & 150 & 151 & 154 & & 151,67 & 2,08 & 1,03 & 1,37 \\
\hline 23 & 157 & 178 & 181 & 175 & & 178,00 & 3,00 & 1,12 & 1,69 \\
\hline 24 & 209 & 217 & 219 & 211 & & 215,67 & 4,16 & 1,44 & 1,93 \\
\hline 25 & 208 & 205 & 211 & 206 & & 207,33 & 3,21 & 1,18 & 1,55 \\
\hline 26 & 252 & 263 & 266 & 262 & & 263,67 & 2,08 & 0,59 & 0,79 \\
\hline 27 & 139 & 155 & 149 & 161 & & 155,00 & 6,00 & 2,58 & 3,87 \\
\hline 28 & 136 & 134 & 132 & 133 & & 133,00 & 1,00 & 0,50 & 0,75 \\
\hline 29 & 158 & 162 & 163 & 162 & & 162,33 & 0,58 & 0,27 & 0,36 \\
\hline 30 & 164 & 165 & 166 & 169 & & 166,67 & 2,08 & 0,93 & 1,25 \\
\hline 31 & 161 & 157 & 162 & 161 & & 160,00 & 2,65 & 1,25 & 1,65 \\
\hline 32 & 142 & 154 & 153 & 154 & & 153,67 & 0,58 & 0,29 & 0,38 \\
\hline 33 & 149 & 148 & 150 & 146 & & 148,00 & 2,00 & 0,90 & 1,35 \\
\hline 34 & 187 & 169 & 182 & 184 & & 178,33 & 8,14 & 3,49 & 4,57 \\
\hline 35 & 200 & 180 & 188 & 186 & & 184,67 & 4,16 & 1,68 & 2,25 \\
\hline
\end{tabular}


Continuação Tabela 32.

\begin{tabular}{|c|c|c|c|c|c|c|c|c|c|}
\hline \multirow{2}{*}{ n } & \multicolumn{5}{|c|}{ Leituras } & \multirow{2}{*}{ Média } & \multirow{2}{*}{ DP } & \multirow{2}{*}{ EMP } & \multirow{2}{*}{ CV } \\
\hline & 1 & 2 & 3 & 4 & 5 & & & & \\
\hline 36 & 198 & 192 & 196 & 198 & & 195,33 & 3,06 & 1,14 & 1,56 \\
\hline 37 & 213 & 199 & 203 & 208 & & 203,33 & 4,51 & 1,53 & 2,22 \\
\hline 38 & 175 & 172 & 178 & 175 & & 175 & 3 & 1,14 & 1,71 \\
\hline 39 & 163 & 160 & 163 & 166 & & 163 & 3 & 1,23 & 1,84 \\
\hline 40 & 190 & 188 & 190 & 191 & & 189,67 & 1,53 & 0,59 & 0,81 \\
\hline 41 & 135 & 136 & 142 & 146 & & 141,33 & 5,03 & 2,52 & 3,56 \\
\hline 42 & 122 & 143 & 139 & 128 & & 136,67 & 7,77 & 4,23 & 5,68 \\
\hline 43 & 136 & 124 & 132 & 136 & & 130,67 & 6,11 & 38,04 & 4,68 \\
\hline 44 & 217 & 200 & 215 & 214 & & 209,67 & 8,39 & 3,07 & 4 \\
\hline 45 & 220 & 210 & 231 & 229 & & 223,33 & 11,59 & 3,98 & 5,19 \\
\hline 46 & 203 & 207 & 206 & 207 & & 206,67 & 0,58 & 0,22 & 0,28 \\
\hline 47 & 229 & 196 & 203 & 216 & & 205 & 10,15 & 3,58 & 4,95 \\
\hline 48 & 213 & 228 & 230 & 230 & & 229,33 & 1,15 & 0,39 & 0,5 \\
\hline 49 & 166 & 166 & 166 & 168 & & 166,67 & 1,15 & 0,53 & 0,69 \\
\hline 50 & 185 & 198 & 192 & 196 & & 195,33 & 3,06 & 1,14 & 1,56 \\
\hline 51 & 171 & 176 & 172 & 181 & & 176,33 & 4,51 & 1,76 & 2,56 \\
\hline 52 & 167 & 172 & 178 & 169 & & 173 & 4,58 & 1,93 & 2,65 \\
\hline 53 & 189 & 202 & 198 & 201 & & 200,33 & 2,08 & 0,78 & 1,04 \\
\hline 54 & 124 & 146 & 132 & 149 & & 142,33 & 9,07 & 4,84 & 6,38 \\
\hline 55 & 159 & 147 & 152 & 152 & & 150,33 & 2,89 & 1,48 & 1,92 \\
\hline 56 & 143 & 159 & 165 & & & 162 & 4,24 & 1,85 & 2,62 \\
\hline 57 & 143 & 156 & 161 & & & 158,5 & 3,54 & 1,58 & 2,23 \\
\hline 58 & 151 & 158 & 163 & & & 160,5 & 3,54 & 1,56 & 2,2 \\
\hline 59 & 169 & 174 & 170 & & & 172 & 2,83 & 1,16 & 1,64 \\
\hline 60 & 177 & 158 & 166 & & & 162 & 5,66 & 2,47 & 3,49 \\
\hline 61 & 162 & 158 & 174 & & & 166 & 11,31 & 4,82 & 6,82 \\
\hline 62 & 168 & 168 & 166 & & & 167 & 1,41 & 0,6 & 0,85 \\
\hline 63 & 134 & 154 & 147 & & & 150,5 & 4,95 & 2,33 & 3,29 \\
\hline 64 & 177 & 158 & 164 & & & 161 & 4,24 & 1,86 & 2,64 \\
\hline 65 & 149 & 152 & 158 & & & 155 & 4,24 & 1,94 & 2,74 \\
\hline 66 & 140 & 167 & 154 & & & 160,5 & 9,19 & 4,05 & 5,73 \\
\hline 67 & 168 & 165 & 166 & & & 165,5 & 0,71 & 0,3 & 0,43 \\
\hline 68 & 153 & 159 & 157 & & & 158 & 1,41 & 0,63 & 0,9 \\
\hline 69 & 175 & 165 & 172 & & & 168,5 & 4,95 & 2,08 & 2,94 \\
\hline 70 & 135 & 128 & 142 & 140 & & 136,67 & 7,57 & 4,23 & 5,54 \\
\hline 71 & 274 & 234 & 257 & & & 245,5 & 16,26 & 4,68 & 6,62 \\
\hline 72 & 205 & 228 & 211 & & & 219,5 & 12,02 & 3,87 & 5,48 \\
\hline 73 & 282 & 256 & 269 & & & 262,5 & 9,19 & 2,48 & 3,5 \\
\hline 74 & 275 & 273 & 275 & & & 274 & 1,41 & 0,36 & 0,52 \\
\hline 75 & 231 & 238 & 235 & & & 236,5 & 2,12 & 0,63 & 0,9 \\
\hline 76 & 217 & 252 & 238 & & & 245 & 9,9 & 2,86 & 4,04 \\
\hline
\end{tabular}


Continuação Tabela 32.

\begin{tabular}{|c|c|c|c|c|c|c|c|c|c|}
\hline \multirow{2}{*}{$\mathbf{n}$} & \multicolumn{5}{|c|}{ Leituras } & \multirow{2}{*}{ Média } & \multirow{2}{*}{ DP } & \multirow{2}{*}{ EMP } & \multirow{2}{*}{$\mathrm{CV}$} \\
\hline & 1 & 2 & 3 & 4 & 5 & & & & \\
\hline 77 & 296 & 302 & 299 & & & 300,5 & 2,12 & 0,5 & 0,71 \\
\hline 78 & 302 & 303 & 305 & & & 304 & 1,41 & 0,33 & 0,47 \\
\hline 79 & 228 & 234 & 236 & & & 235 & 1,41 & 0,43 & 0,6 \\
\hline 80 & 240 & 221 & 233 & & & 227 & 8,49 & 2,64 & 3,74 \\
\hline 81 & 212 & 217 & 222 & & & 219,5 & 3,54 & 1,14 & 1,61 \\
\hline 82 & 273 & 289 & 278 & & & 283,5 & 7,78 & 1,94 & 2,74 \\
\hline 83 & 231 & 249 & 237 & & & 243 & 8,49 & 2,47 & 3,49 \\
\hline 84 & 303 & 298 & 311 & & & 304,5 & 9,19 & 2,13 & 3,02 \\
\hline 85 & 250 & 255 & 257 & & & 256 & 1,41 & 0,39 & 0,55 \\
\hline 86 & 327 & 335 & 342 & & & 338,5 & 4,95 & 1,03 & 1,46 \\
\hline 87 & 245 & 231 & 237 & & & 234 & 4,24 & 1,28 & 1,81 \\
\hline 88 & 311 & 305 & 308 & & & 306,5 & 2,12 & 0,49 & 0,69 \\
\hline 89 & 269 & 288 & 276 & & & 282 & 8,49 & 2,13 & 3,01 \\
\hline 90 & 235 & 212 & 234 & 230 & & 225,33 & 11,72 & 3,94 & 5,2 \\
\hline 91 & 256 & 197 & 273 & 259 & & 243 & 40,45 & 12,62 & 16,65 \\
\hline 92 & 282 & 265 & 269 & 274 & & 269,33 & 4,51 & 1,16 & 1,67 \\
\hline 93 & 261 & 248 & 257 & 267 & & 257,33 & 9,5 & 2,5 & 3,69 \\
\hline 94 & 345 & 300 & 313 & 320 & & 311 & 10,15 & 2,36 & 3,26 \\
\hline 95 & 123 & 139 & 132 & & & 135,5 & 4,95 & 2,58 & 3,65 \\
\hline 96 & 174 & 157 & 166 & & & 161,5 & 6,36 & 2,79 & 3,94 \\
\hline 97 & 139 & 161 & 154 & & & 157,5 & 4,95 & 2,22 & 3,14 \\
\hline 98 & 153 & 154 & 166 & & & 160 & 8,49 & 3,75 & 5,3 \\
\hline 99 & 123 & 139 & 132 & & & 135,5 & 4,95 & 2,58 & 3,65 \\
\hline 100 & 150 & 135 & 141 & & & 138 & 4,24 & 2,17 & 3,07 \\
\hline 101 & 163 & 157 & 166 & & & 161,5 & 6,36 & 2,79 & 3,94 \\
\hline 102 & 158 & 152 & 163 & & & 157,5 & 7,78 & 3,49 & 4,94 \\
\hline 103 & 160 & 160 & 174 & & & 167 & 9,9 & 4,19 & 5,93 \\
\hline 104 & 157 & 170 & 164 & & & 167 & 4,24 & 1,8 & 2,54 \\
\hline 105 & 168 & 164 & 176 & & & 170 & 8,49 & 3,53 & 4,99 \\
\hline 106 & 165 & 164 & 163 & & & 163,5 & 0,71 & 0,31 & 0,43 \\
\hline 107 & 191 & 183 & 191 & & & 187 & 5,66 & 2,14 & 3,03 \\
\hline 108 & 177 & 166 & 170 & & & 168 & 2,83 & 1,19 & 1,68 \\
\hline 109 & 158 & 151 & 154 & & & 152,5 & 2,12 & 0,98 & 1,39 \\
\hline 110 & 162 & 159 & 166 & & & 162,5 & 4,95 & 2,15 & 3,05 \\
\hline 111 & 152 & 164 & 166 & & & 165 & 1,41 & 0,61 & 0,86 \\
\hline 112 & 150 & 125 & 142 & & & 133,5 & 12,02 & 6,37 & 9 \\
\hline 113 & 165 & 147 & 153 & & & 150 & 4,24 & 2 & 2,83 \\
\hline 114 & 173 & 178 & 172 & & & 175 & 4,24 & 1,71 & 2,42 \\
\hline 115 & 163 & 154 & 159 & & & 156,5 & 3,54 & 1,6 & 2,26 \\
\hline 116 & 175 & 176 & 168 & & & 172 & 5,66 & 2,33 & 3,29 \\
\hline 117 & 147 & 151 & 156 & & & 153,5 & 3,54 & 1,63 & 2,3 \\
\hline
\end{tabular}


Continuação Tabela 32.

\begin{tabular}{|c|c|c|c|c|c|c|c|c|c|}
\hline \multirow{2}{*}{ n } & \multicolumn{5}{|c|}{ Leituras } & \multirow{2}{*}{ Média } & \multirow{2}{*}{ DP } & \multirow{2}{*}{ EMP } & \multirow{2}{*}{$\mathrm{CV}$} \\
\hline & 1 & 2 & 3 & 4 & 5 & & & & \\
\hline 118 & 163 & 141 & 156 & & & 148,5 & 10,61 & 5,05 & 7,14 \\
\hline 119 & 161 & 154 & 166 & & & 160 & 8,49 & 3,75 & 5,3 \\
\hline 120 & 163 & 156 & 166 & & & 161 & 7,07 & 3,11 & 4,39 \\
\hline 121 & 149 & 159 & 163 & & & 161 & 2,83 & 1,24 & 1,76 \\
\hline 122 & 144 & 142 & 144 & & & 143 & 1,41 & 0,7 & 0,99 \\
\hline 123 & 169 & 169 & 174 & & & 171,5 & 3,54 & 1,46 & 2,06 \\
\hline 124 & 140 & 141 & 148 & & & 144,5 & 4,95 & 2,42 & 3,43 \\
\hline 125 & 170 & 170 & 172 & & & 171 & 1,41 & 0,58 & 0,83 \\
\hline 126 & 139 & 144 & 142 & & & 143 & 1,41 & 0,7 & 0,99 \\
\hline 127 & 160 & 168 & 163 & & & 165,5 & 3,54 & 1,51 & 2,14 \\
\hline 128 & 169 & 174 & 156 & & & 165 & 12,73 & 5,45 & 7,71 \\
\hline 129 & 173 & 164 & 177 & & & 170,5 & 9,19 & 3,81 & 5,39 \\
\hline 130 & 169 & 164 & 167 & & & 165,5 & 2,12 & 0,91 & 1,28 \\
\hline 131 & 167 & 153 & 159 & & & 156 & 4,24 & 1,92 & 2,72 \\
\hline 132 & 238 & 226 & 229 & 231 & & 228,67 & 2,52 & 0,78 & 1,1 \\
\hline 133 & 248 & 224 & 229 & 237 & & 230 & 6,56 & 2,03 & 2,85 \\
\hline 134 & 273 & 278 & 279 & 273 & & 276,67 & 3,21 & 0,88 & 1,16 \\
\hline 135 & 243 & 294 & 284 & 290 & & 289,33 & 5,03 & 1,23 & 1,74 \\
\hline 136 & 304 & 285 & 289 & 297 & & 290,33 & 6,11 & 1,53 & 2,1 \\
\hline 137 & 240 & 255 & 266 & 263 & & 261,33 & 5,69 & 1,62 & 2,18 \\
\hline 138 & 271 & 279 & 280 & 283 & & 280,67 & 2,08 & 0,55 & 0,74 \\
\hline 139 & 276 & 264 & 273 & 279 & & 272 & 7,55 & 1,96 & 2,78 \\
\hline 140 & 298 & 309 & 312 & 303 & & 308 & 4,58 & 1,08 & 1,49 \\
\hline 141 & 269 & 269 & 272 & 274 & & 271,67 & 2,52 & 0,65 & 0,93 \\
\hline 142 & 288 & 290 & 290 & 293 & & 291 & 1,73 & 0,46 & 0,6 \\
\hline 143 & 299 & 311 & 313 & 315 & & 313 & 2 & 0,43 & 0,64 \\
\hline 144 & 263 & 318 & 267 & 278 & & 287,67 & 26,84 & 7,03 & 9,33 \\
\hline 145 & 308 & 283 & 328 & 311 & & 307,33 & 22,72 & 5,28 & 7,39 \\
\hline 146 & 321 & 283 & 294 & 301 & & 292,67 & 9,07 & 2,2 & 3,1 \\
\hline 147 & 308 & 296 & 301 & 303 & & 300 & 3,61 & 0,89 & 1,2 \\
\hline 148 & 282 & 295 & 299 & 304 & & 299,33 & 4,51 & 1,04 & 1,51 \\
\hline 149 & 249 & 220 & 223 & 231 & & 224,67 & 5,69 & 1,88 & 2,53 \\
\hline 150 & 255 & 215 & 245 & & & 230 & 21,21 & 6,52 & 9,22 \\
\hline 151 & 282 & 278 & 283 & 288 & & 283 & 5 & 1,18 & 1,77 \\
\hline 152 & 264 & 294 & 289 & 292 & & 291,67 & 2,52 & 0,61 & 0,86 \\
\hline 153 & 282 & 294 & 288 & 297 & & 293 & 4,58 & 1,14 & 1,56 \\
\hline 154 & 308 & 291 & 300 & 300 & & 297 & 5,2 & 1,35 & 1,75 \\
\hline 155 & 317 & 341 & 343 & 328 & & 337,33 & 8,14 & 1,84 & 2,41 \\
\hline 156 & 194 & 178 & 240 & & & 209 & 43,84 & 14,83 & 20,98 \\
\hline 157 & 192 & 200 & 197 & & & 198,5 & 2,12 & 0,76 & 1,07 \\
\hline 158 & 382 & 349 & 357 & 359 & & 355 & 5,29 & 1,13 & 1,49 \\
\hline
\end{tabular}


Continuação Tabela 32.

\begin{tabular}{|c|c|c|c|c|c|c|c|c|c|}
\hline \multirow{2}{*}{$\mathbf{n}$} & \multicolumn{5}{|c|}{ Leituras } & \multirow{2}{*}{ Média } & \multirow{2}{*}{ DP } & \multirow{2}{*}{ EMP } & \multirow{2}{*}{ CV } \\
\hline & 1 & 2 & 3 & 4 & 5 & & & & \\
\hline 159 & 270 & 260 & 273 & 267 & & 266,67 & 6,51 & 1,67 & 2,44 \\
\hline 160 & 272 & 265 & 274 & 279 & & 272,67 & 7,09 & 1,87 & 2,6 \\
\hline 161 & 241 & 238 & 240 & 243 & & 240,33 & 2,52 & 0,74 & 1,05 \\
\hline 162 & 284 & 291 & 288 & 293 & & 290,67 & 2,52 & 0,61 & 0,87 \\
\hline 163 & 317 & 286 & 293 & 308 & & 295,67 & 11,24 & 2,78 & 3,8 \\
\hline 164 & 340 & 345 & 346 & 345 & & 345,33 & 0,58 & 0,13 & 0,17 \\
\hline 165 & 230 & 192 & 209 & 201 & 206 & 200,67 & 8,5 & 2,88 & 4,24 \\
\hline 166 & 365 & 351 & 368 & 346 & & 355 & 11,53 & 2,44 & 3,25 \\
\hline 167 & 254 & 270 & 267 & 272 & & 269,67 & 2,52 & 0,66 & 0,93 \\
\hline 168 & 244 & 289 & 294 & 286 & & 289,67 & 4,04 & 1 & 1,4 \\
\hline 169 & 187 & 192 & 192 & & & 192 & 0 & 0 & 0 \\
\hline 170 & 230 & 232 & 224 & & & 228 & 5,66 & 1,75 & 2,48 \\
\hline 171 & 260 & 250 & 244 & 248 & & 247,33 & 3,06 & 0,9 & 1,24 \\
\hline 172 & 246 & 231 & 236 & 236 & & 234,33 & 2,89 & 0,95 & 1,23 \\
\hline 173 & 191 & 199 & 202 & 202 & & 201 & 1,73 & 0,66 & 0,86 \\
\hline 174 & 228 & 235 & 253 & 239 & 223 & 242,33 & 9,45 & 2,93 & 3,9 \\
\hline 175 & 203 & 190 & 204 & 210 & & 201,33 & 10,26 & 3,75 & 5,1 \\
\hline 176 & 211 & 207 & 213 & 216 & & 212 & 4,58 & 1,57 & 2,16 \\
\hline 177 & 230 & 210 & 194 & 202 & & 202 & 8 & 2,64 & 3,96 \\
\hline 178 & 245 & 208 & 190 & & & 199 & 12,73 & 4,52 & 6,4 \\
\hline 179 & 189 & 163 & 177 & & & 170 & 9,9 & 4,12 & 5,82 \\
\hline 180 & 206 & 196 & 206 & 235 & 241 & 212,33 & 20,26 & 7,12 & 9,54 \\
\hline 181 & 301 & 277 & 278 & & & 277,5 & 0,71 & 0,18 & 0,25 \\
\hline 182 & 255 & 263 & 227 & 250 & & 246,67 & 18,23 & 5,32 & 7,39 \\
\hline 183 & 249 & 226 & 234 & 232 & & 230,67 & 4,16 & 1,35 & 1,8 \\
\hline 184 & 289 & 259 & 268 & & & 263,5 & 6,36 & 1,71 & 2,42 \\
\hline 185 & 264 & 249 & 261 & & & 255 & 8,49 & 2,35 & 3,33 \\
\hline 186 & 226 & 225 & 226 & & & 225,5 & 0,71 & 0,22 & 0,31 \\
\hline 187 & 255 & 230 & 236 & & & 233 & 4,24 & 1,29 & 1,82 \\
\hline 188 & 222 & 241 & 253 & & & 247 & 8,49 & 2,43 & 3,44 \\
\hline 189 & 285 & 218 & 234 & & & 226 & 11,31 & 3,54 & 5,01 \\
\hline 190 & 260 & 289 & 277 & & & 283 & 8,49 & 2,12 & 3 \\
\hline 191 & 247 & 244 & 250 & & & 247 & 4,24 & 1,21 & 1,72 \\
\hline 192 & 310 & 253 & 273 & & & 263 & 14,14 & 3,8 & 5,38 \\
\hline 193 & 319 & 317 & 319 & 321 & & 319 & 2 & 0,42 & 0,63 \\
\hline 194 & 317 & 319 & 320 & 319 & & 319,33 & 0,58 & 0,14 & 0,18 \\
\hline 195 & 338 & 290 & 309 & 325 & & 308 & 17,52 & 3,9 & 5,69 \\
\hline 196 & 347 & 344 & 346 & 348 & & 346 & 2 & 0,39 & 0,58 \\
\hline 197 & 277 & 299 & 286 & 288 & & 291 & 7 & 1,83 & 2,41 \\
\hline 198 & 263 & 268 & 270 & 270 & & 269,33 & 1,15 & 0,33 & 0,43 \\
\hline 199 & 344 & 309 & 321 & 313 & & 314,33 & 6,11 & 1,41 & 1,94 \\
\hline 200 & 211 & 202 & 208 & & & 205 & 4,24 & 1,46 & 2,07 \\
\hline
\end{tabular}


Continuação Tabela 32.

\begin{tabular}{|c|c|c|c|c|c|c|c|c|c|}
\hline \multirow{2}{*}{$\mathbf{n}$} & \multicolumn{5}{|c|}{ Leituras } & \multirow{2}{*}{ Média } & \multirow{2}{*}{ DP } & \multirow{2}{*}{ EMP } & \multirow{2}{*}{ CV } \\
\hline & 1 & 2 & 3 & 4 & 5 & & & & \\
\hline 201 & 241 & 222 & 228 & & & 225 & 4,24 & 1,33 & 1,89 \\
\hline 202 & 256 & 222 & 230 & & & 226 & 5,66 & 1,77 & 2,5 \\
\hline 203 & 249 & 232 & 236 & 234 & & 234 & 2 & 0,57 & 0,85 \\
\hline 204 & 249 & 264 & 252 & & & 258 & 8,49 & 2,33 & 3,29 \\
\hline 205 & 304 & 272 & 291 & & & 281,5 & 13,44 & 3,37 & 4,77 \\
\hline 206 & 220 & 223 & 207 & & & 215 & 11,31 & 3,72 & 5,26 \\
\hline 207 & 288 & 323 & 294 & & & 308,5 & 20,51 & 4,7 & 6,65 \\
\hline 208 & 267 & 259 & 266 & 269 & & 264,67 & 5,13 & 24,55 & 1,94 \\
\hline 209 & 241 & 258 & 247 & & & 252,5 & 7,78 & 2,18 & 3,08 \\
\hline 210 & 296 & 267 & 288 & & & 277,5 & 14,85 & 3,78 & 5,35 \\
\hline 211 & 246 & 247 & 247 & 249 & & 247,67 & 1,15 & 0,36 & 0,47 \\
\hline 212 & 301 & 326 & 317 & & & 321,5 & 6,36 & 1,4 & 1,98 \\
\hline 213 & 266 & 299 & 287 & 262 & 239 & 282,67 & 18,88 & 4,87 & 6,68 \\
\hline 214 & 322 & 258 & 280 & & & 269 & 15,56 & 4,09 & 5,78 \\
\hline 215 & 264 & 222 & 240 & & & 231 & 12,73 & 3,9 & 5,51 \\
\hline 216 & 248 & 261 & 236 & & & 248,5 & 17,68 & 5,03 & 7,11 \\
\hline 217 & 278 & 241 & 260 & & & 250,5 & 13,44 & 3,79 & 5,36 \\
\hline 218 & 315 & 302 & 308 & & & 305 & 4,24 & 0,98 & 1,39 \\
\hline 219 & 320 & 250 & 264 & & & 257 & 9,9 & 2,72 & 3,85 \\
\hline 220 & 272 & 250 & 264 & & & 257 & 9,9 & 2,72 & 3,85 \\
\hline 221 & 217 & 210 & 213 & & & 211,5 & 2,12 & 0,71 & 1 \\
\hline 222 & 236 & 231 & 233 & & & 232 & 1,41 & 0,43 & 0,61 \\
\hline 223 & 275 & 290 & 284 & 295 & & 289,67 & 5,51 & 1,3 & 1,9 \\
\hline 224 & 208 & 210 & 215 & & & 212,5 & 3,54 & 19,71 & 1,66 \\
\hline 225 & 259 & 283 & 283 & 285 & & 283,67 & 1,15 & 0,31 & 0,41 \\
\hline 226 & 281 & 300 & 293 & 298 & & 297 & 3,61 & 0,9 & 1,21 \\
\hline 227 & 280 & 293 & 289 & 294 & & 292 & 2,65 & 0,68 & 0,91 \\
\hline 228 & 285 & 287 & 286 & 287 & & 286,67 & 0,58 & 0,16 & 0,2 \\
\hline 229 & 307 & 301 & 306 & 311 & & 306 & 5 & 1,09 & 1,63 \\
\hline 230 & 270 & 271 & 273 & 272 & & 272 & 1 & 0,25 & 0,37 \\
\hline 231 & 234 & 249 & 252 & 236 & & 245,67 & 8,5 & 2,62 & 3,46 \\
\hline 232 & 241 & 223 & 253 & 249 & & 241,67 & 16,29 & 5,15 & 6,74 \\
\hline 233 & 243 & 251 & 269 & 253 & & 257,67 & 9,87 & 2,93 & 3,83 \\
\hline 234 & 249 & 293 & 281 & 286 & & 286,67 & 6,03 & 1,47 & 2,1 \\
\hline 235 & 233 & 232 & 234 & 233 & & 233 & 1 & 0,29 & 0,43 \\
\hline 236 & 306 & 307 & 309 & 307 & & 307,67 & 1,15 & 0,29 & 0,38 \\
\hline 237 & 197 & 191 & 205 & 204 & & 200 & 7,81 & 3 & 3,91 \\
\hline 238 & 218 & 191 & 194 & 194 & & 193 & 1,73 & 0,69 & 0,9 \\
\hline 239 & 257 & 219 & 220 & 220 & & 219,67 & 0,58 & 0,2 & 0,26 \\
\hline 240 & 153 & 156 & 150 & 150 & 153 & 152 & 3,46 & 1,75 & 2,28 \\
\hline 241 & 209 & 209 & 216 & 218 & 222 & 214,33 & 4,73 & 1,66 & 2,2 \\
\hline 242 & 211 & 224 & 193 & 212 & 199 & 209,67 & 15,63 & 5,3 & 7,46 \\
\hline
\end{tabular}


Continuação Tabela 32.

\begin{tabular}{|c|c|c|c|c|c|c|c|c|c|}
\hline \multirow{2}{*}{$\mathbf{n}$} & \multicolumn{5}{|c|}{ Leituras } & \multirow{2}{*}{ Média } & \multirow{2}{*}{ DP } & \multirow{2}{*}{ EMP } & \multirow{2}{*}{ CV } \\
\hline & 1 & 2 & 3 & 4 & 5 & & & & \\
\hline 243 & 261 & 225 & 239 & 233 & & 232,33 & 7,02 & 2,1 & 3,02 \\
\hline 244 & 263 & 299 & 241 & 237 & & 259 & 34,7 & 10,3 & 13,4 \\
\hline 245 & 293 & 254 & 261 & 260 & & 258,33 & 3,79 & 1,12 & 1,47 \\
\hline 246 & 229 & 280 & 269 & 276 & & 275 & 5,57 & 1,45 & 2,02 \\
\hline 247 & 258 & 245 & 249 & 252 & & 248,67 & 3,51 & 0,98 & 1,41 \\
\hline 248 & 268 & 238 & 264 & 272 & & 258 & 17,78 & 5,17 & 6,89 \\
\hline 249 & 256 & 271 & 276 & 278 & & 275 & 3,61 & 0,97 & 1,31 \\
\hline 250 & 269 & 275 & 278 & 282 & & 278,33 & 3,51 & 0,88 & 1,26 \\
\hline 251 & 261 & 225 & 250 & 253 & & 242,67 & 15,37 & 4,85 & 6,34 \\
\hline 252 & 288 & 273 & 286 & & & 279,5 & 9,19 & 2,33 & 3,29 \\
\hline 253 & 303 & 264 & 259 & 259 & & 260,67 & 2,89 & 0,85 & 1,11 \\
\hline 254 & 251 & 295 & 261 & 274 & & 276,67 & 17,16 & 4,42 & 6,2 \\
\hline 255 & 279 & 227 & 247 & 252 & & 242 & 13,23 & 4,13 & 5,47 \\
\hline 256 & 250 & 265 & 265 & 267 & & 265,67 & 1,15 & 0,33 & 0,43 \\
\hline 257 & 347 & 283 & 302 & 291 & & 292 & 9,54 & 2,28 & 3,27 \\
\hline 258 & 122 & 126 & 127 & 130 & & 127,67 & 2,08 & 1,22 & 1,63 \\
\hline 259 & 203 & 200 & 204 & 200 & & 201,33 & 2,31 & 0,88 & 1,15 \\
\hline 260 & 221 & 240 & 236 & 238 & & 238 & 2 & 0,56 & 0,84 \\
\hline 261 & 248 & 221 & 252 & 246 & & 239,67 & 16,44 & 5,19 & 6,86 \\
\hline 262 & 193 & 188 & 190 & & & 189 & 1,41 & 0,53 & 0,75 \\
\hline 263 & 172 & 152 & 168 & & & 160 & 11,31 & 5 & 7,07 \\
\hline 264 & 132 & 120 & 126 & & & 123 & 4,24 & 2,44 & 3,45 \\
\hline 265 & 169 & 164 & 166 & & & 165 & 1,41 & 0,61 & 0,86 \\
\hline 266 & 147 & 155 & 152 & & & 153,5 & 2,12 & 0,98 & 1,38 \\
\hline 267 & 155 & 149 & 152 & & & 150,5 & 2,12 & 1 & 1,41 \\
\hline 268 & 127 & 138 & 133 & & & 135,5 & 3,54 & 1,85 & 2,61 \\
\hline 269 & 167 & 165 & 167 & & & 166 & 1,41 & 0,6 & 0,85 \\
\hline 270 & 153 & 177 & 165 & & & 171 & 8,49 & 3,51 & 4,96 \\
\hline 271 & 206 & 204 & 205 & & & 204,5 & 0,71 & 0,24 & 0,35 \\
\hline 272 & 119 & 115 & 132 & & & 123,5 & 12,02 & 6,88 & 9,73 \\
\hline 273 & 164 & 155 & 159 & & & 157 & 2,83 & 1,27 & 1,8 \\
\hline 274 & 199 & 184 & 196 & & & 190 & 8,49 & 3,16 & 4,47 \\
\hline 275 & 170 & 164 & 172 & & & 168 & 5,66 & 2,38 & 3,37 \\
\hline 276 & 136 & 146 & 148 & & & 147 & 1,41 & 0,68 & 0,96 \\
\hline 277 & 170 & 202 & 184 & & & 193 & 12,73 & 4,66 & 6,59 \\
\hline 278 & 149 & 162 & 154 & & & 158 & 5,66 & 2,53 & 3,58 \\
\hline 279 & 158 & 154 & 156 & & & 155 & 1,41 & 0,65 & 0,91 \\
\hline 280 & 188 & 184 & 186 & & & 185 & 1,41 & 0,54 & 0,76 \\
\hline 281 & 160 & 177 & 171 & & & 174 & 4,24 & 1,72 & 2,44 \\
\hline 282 & 138 & 169 & 155 & & & 162 & 9,9 & 4,32 & 6,11 \\
\hline 283 & 179 & 178 & 173 & & & 175,5 & 3,54 & 1,42 & 2,01 \\
\hline 284 & 170 & 177 & 180 & & & 178,5 & 2,12 & 0,84 & 1,19 \\
\hline
\end{tabular}


Continuação Tabela 32.

\begin{tabular}{|c|c|c|c|c|c|c|c|c|c|}
\hline \multirow{2}{*}{$\mathbf{n}$} & \multicolumn{5}{|c|}{ Leituras } & \multirow{2}{*}{ Média } & \multirow{2}{*}{ DP } & \multirow{2}{*}{ EMP } & \multirow{2}{*}{ CV } \\
\hline & 1 & 2 & 3 & 4 & 5 & & & & \\
\hline 285 & 140 & 136 & 138 & & & 137 & 1,41 & 0,73 & 1,03 \\
\hline 286 & 257 & 220 & 226 & & & 223 & 4,24 & 1,35 & 1,9 \\
\hline 287 & 159 & 150 & 152 & & & 151 & 1,41 & 0,66 & 0,94 \\
\hline 288 & 163 & 153 & 152 & & & 152,5 & 0,71 & 0,33 & 0,46 \\
\hline 289 & 152 & 155 & 163 & & & 159 & 5,66 & 2,52 & 3,56 \\
\hline 290 & 176 & 194 & 185 & & & 189,5 & 6,36 & 2,37 & 3,36 \\
\hline 291 & 190 & 188 & 189 & & & 188,5 & 0,71 & 0,27 & 0,38 \\
\hline 292 & 125 & 144 & 156 & & & 150 & 8,49 & 4 & 5,66 \\
\hline 293 & 165 & 134 & 141 & & & 137,5 & 4,95 & 2,55 & 3,6 \\
\hline 294 & 186 & 167 & 174 & & & 170,5 & 4,95 & 2,05 & 2,9 \\
\hline 295 & 170 & 164 & 168 & & & 166 & 2,83 & 1,2 & 1,7 \\
\hline 296 & 167 & 173 & 172 & & & 172,5 & 0,71 & 0,29 & 0,41 \\
\hline 297 & 153 & 152 & 159 & & & 155,5 & 4,95 & 2,25 & 3,18 \\
\hline 298 & 180 & 182 & 178 & & & 180 & 2,83 & 1,11 & 1,57 \\
\hline 299 & 147 & 128 & 116 & & & 122 & 8,49 & 4,92 & 6,96 \\
\hline 300 & 170 & 177 & 169 & & & 173 & 5,66 & 2,31 & 3,27 \\
\hline 301 & 162 & 155 & 156 & & & 155,5 & 0,71 & 0,32 & 0,45 \\
\hline 302 & 176 & 170 & 179 & & & 174,5 & 6,36 & 2,58 & 3,65 \\
\hline 303 & 179 & 199 & 183 & & & 191 & 11,31 & 4,19 & 5,92 \\
\hline 304 & 181 & 201 & 196 & & & 198,5 & 3,54 & 1,26 & 1,78 \\
\hline 305 & 106 & 127 & 114 & & & 120,5 & 9,19 & 5,39 & 7,63 \\
\hline 306 & 118 & 129 & 134 & & & 131,5 & 3,54 & 1,9 & 2,69 \\
\hline 307 & 163 & 134 & 141 & & & 137,5 & 4,95 & 2,55 & 3,6 \\
\hline 308 & 142 & 154 & 164 & 126 & & 148 & 19,7 & 9,91 & 13,31 \\
\hline 309 & 139 & 171 & 173 & 178 & & 174 & 3,61 & 1,53 & 2,07 \\
\hline 310 & 145 & 158 & 157 & 152 & & 155,67 & 3,21 & 1,57 & 2,07 \\
\hline 311 & 181 & 187 & 192 & 189 & & 189,33 & 2,52 & 0,94 & 1,33 \\
\hline 312 & 213 & 218 & 220 & 219 & & 219 & 1 & 0,3 & 0,46 \\
\hline 313 & 151 & 178 & 187 & 182 & & 182,33 & 4,51 & 1,71 & 2,47 \\
\hline 314 & 179 & 170 & 174 & 171 & 175 & 171,67 & 2,08 & 0,91 & 1,21 \\
\hline 315 & 168 & 151 & 145 & 142 & & 146 & 4,58 & 2,28 & 3,14 \\
\hline 316 & 143 & 129 & 133 & 128 & & 130 & 2,65 & 1,54 & 2,04 \\
\hline 317 & 179 & 155 & 157 & 152 & & 154,67 & 2,52 & 1,15 & 1,63 \\
\hline 318 & 150 & 159 & 153 & 155 & & 155,67 & 3,06 & 1,43 & 1,96 \\
\hline 319 & 153 & 143 & 154 & 161 & & 152,67 & 9,07 & 4,22 & 5,94 \\
\hline 320 & 128 & 154 & 154 & 146 & & 151,33 & 4,62 & 2,35 & 3,05 \\
\hline 321 & 175 & 185 & 178 & 173 & & 178,67 & 6,03 & 2,36 & 3,37 \\
\hline 322 & 170 & 173 & 171 & 176 & & 173,33 & 2,52 & 1,03 & 1,45 \\
\hline 323 & 158 & 124 & 138 & 136 & & 132,67 & 7,57 & 4,36 & 5,71 \\
\hline 324 & 143 & 169 & 171 & 176 & & 172 & 3,61 & 1,55 & 2,1 \\
\hline 325 & 129 & 139 & 145 & 145 & & 143 & 3,46 & 1,86 & 2,42 \\
\hline 326 & 154 & 162 & 158 & 159 & & 159,67 & 2,08 & 0,97 & 1,3 \\
\hline
\end{tabular}


Continuação Tabela 32.

\begin{tabular}{|c|c|c|c|c|c|c|c|c|c|}
\hline \multirow{2}{*}{$\mathbf{n}$} & \multicolumn{5}{|c|}{ Leituras } & \multirow{2}{*}{ Média } & \multirow{2}{*}{ DP } & \multirow{2}{*}{ EMP } & \multirow{2}{*}{ CV } \\
\hline & 1 & 2 & 3 & 4 & 5 & & & & \\
\hline 327 & 172 & 160 & 160 & 162 & & 160,67 & 1,15 & 0,55 & 0,72 \\
\hline 328 & 173 & 180 & 178 & 175 & & 177,67 & 2,52 & 1 & 1,42 \\
\hline 329 & 160 & 171 & 174 & 178 & & 174,33 & 3,51 & 1,4 & 2,01 \\
\hline 330 & 178 & 170 & 176 & 179 & & 175 & 4,58 & 1,9 & 2,62 \\
\hline 331 & 175 & 164 & 173 & 174 & & 170,33 & 5,51 & 2,48 & 3,23 \\
\hline 332 & 175 & 185 & 190 & 193 & & 189,33 & 4,04 & 1,53 & 2,13 \\
\hline 333 & 177 & 164 & 169 & 172 & & 168,33 & 4,04 & 1,72 & 2,4 \\
\hline 334 & 4 & 5 & 4 & 4 & & 4,33 & 0,58 & 10,26 & 13,32 \\
\hline 335 & 5 & 4 & 4 & 7 & & 5 & 1,73 & 26,67 & 34,64 \\
\hline 336 & 3 & 3 & 4 & 5 & & 4 & 1 & 16,67 & 25 \\
\hline 337 & 6 & 4 & 5 & 5 & & 4,67 & 0,58 & 9,52 & 12,37 \\
\hline 338 & 3 & 3 & 4 & 4 & & 3,67 & 0,58 & 12,12 & 15,75 \\
\hline 339 & 4 & 4 & 5 & 4 & & 4,33 & 0,58 & 10,26 & 13,32 \\
\hline 340 & 4 & 5 & 5 & 5 & & 5 & 0 & 0 & 0 \\
\hline 341 & 3 & 4 & 4 & 4 & & 4 & 0 & 0 & 0 \\
\hline 342 & 3 & 3 & 5 & 4 & & 4 & 1 & 16,67 & 25 \\
\hline 343 & 4 & 4 & 5 & 5 & & 4,67 & 0,58 & 9,52 & 12,37 \\
\hline 344 & 3 & 4 & 4 & 4 & & 4 & 0 & 0 & 0 \\
\hline 345 & 4 & 3 & 5 & 5 & & 4,33 & 1,15 & 20,51 & 26,65 \\
\hline 346 & 2 & 3 & 1 & 4 & & 2,67 & 1,53 & 41,67 & 57,28 \\
\hline 347 & 3 & 4 & 4 & 4 & & 4 & 0 & 0 & 0 \\
\hline 348 & 2 & 3 & 3 & 5 & & 3,67 & 1,15 & 24,24 & 31,49 \\
\hline 349 & 3 & 2 & 5 & 5 & & 4 & 1,73 & 33,33 & 43,3 \\
\hline 350 & 3 & 4 & 5 & 5 & & 4,67 & 0,58 & 9,52 & 12,37 \\
\hline 351 & 3 & 4 & 3 & 4 & & 3,67 & 0,58 & 12,12 & 15,75 \\
\hline 352 & 3 & 2 & 4 & 5 & & 3,67 & 1,53 & 30,3 & 41,66 \\
\hline 353 & 3 & 4 & 3 & 4 & & 3,67 & 0,58 & 12,12 & 15,75 \\
\hline 354 & 3 & 4 & 6 & 5 & & 5 & 1 & 13,33 & 20 \\
\hline 355 & 4 & 5 & 5 & 5 & & 5 & 0 & 0 & 0 \\
\hline 356 & 3 & 2 & 3 & 3 & & 2,67 & 0,58 & 16,67 & 21,65 \\
\hline 357 & 4 & 4 & 3 & 3 & & 3,33 & 0,58 & 13,33 & 17,32 \\
\hline 358 & 6 & 5 & 5 & 5 & & 5 & 0 & 0 & 0 \\
\hline 359 & 4 & 4 & 4 & 4 & & 4 & 0 & 0 & 0 \\
\hline 360 & 6 & 7 & 5 & 7 & & 6,33 & 1,15 & 14,04 & 18,23 \\
\hline 361 & 4 & 6 & 7 & 7 & & 6,67 & 0,58 & 6,67 & 8,66 \\
\hline 362 & 6 & 6 & 6 & 5 & & 5,67 & 0,58 & 7,84 & 10,19 \\
\hline 363 & 6 & 7 & 7 & 7 & & 7 & 0 & 0 & 0 \\
\hline 364 & 5 & 6 & 5 & 5 & & 5,33 & 0,58 & 8,33 & 10,83 \\
\hline 365 & 5 & 5 & 6 & 5 & & 5,33 & 0,58 & 8,33 & 10,83 \\
\hline 366 & 5 & 6 & 7 & 8 & & 7 & 1 & 9,52 & 14,29 \\
\hline 367 & 5 & 5 & 5 & 5 & & 5 & 0 & 0 & 0 \\
\hline 368 & 5 & 5 & 5 & 5 & & 5 & 0 & 0 & 0 \\
\hline
\end{tabular}


Continuação Tabela 32.

\begin{tabular}{|c|c|c|c|c|c|c|c|c|c|}
\hline \multirow{2}{*}{$\mathbf{n}$} & \multicolumn{3}{|c|}{ Leituras } & Média & DP & EMP & CV \\
\cline { 1 - 7 } & $\mathbf{1}$ & $\mathbf{2}$ & $\mathbf{3}$ & $\mathbf{4}$ & $\mathbf{5}$ & & & & \\
\hline 369 & 7 & 7 & 6 & 7 & & 6,67 & 0,58 & 6,67 & 8,66 \\
370 & 5 & 5 & 4 & 5 & & 4,67 & 0,58 & 9,52 & 12,37 \\
371 & 4 & 5 & 7 & 5 & & 5,67 & 1,15 & 15,69 & 20,38 \\
372 & 4 & 5 & 5 & 5 & & 5 & 0 & 0 & 0 \\
373 & 6 & 5 & 6 & 6 & & 5,67 & 0,58 & 7,84 & 10,19 \\
374 & 5 & 5 & 5 & 5 & & 5 & 0 & 0 & 0 \\
375 & 6 & 6 & 6 & 5 & & 5,67 & 0,58 & 7,84 & 10,19 \\
376 & 7 & 6 & 6 & 6 & & 6 & 0 & 0 & 0 \\
377 & 4 & 4 & 5 & 4 & & 4,33 & 0,58 & 10,26 & 13,32 \\
378 & 5 & 5 & 5 & 5 & & 5 & 0 & 0 & 0 \\
379 & 6 & 6 & 6 & 6 & & 6 & 0 & 0 & 0 \\
380 & 6 & 5 & 5 & 5 & & 5 & 0 & 0 & 0 \\
381 & 6 & 6 & 6 & 6 & & 6 & 0 & 0 & 0 \\
382 & 6 & 5 & 5 & 5 & & 5 & 0 & 0 & 0 \\
383 & 5 & 5 & 6 & 6 & & 5,67 & 0,58 & 7,84 & 10,19 \\
384 & 6 & 6 & 6 & 6 & & 6 & 0 & 0 & 0 \\
385 & 5 & 6 & 5 & 6 & & 5,67 & 0,58 & 7,84 & 10,19 \\
386 & 6 & 6 & 7 & 7 & & 6,67 & 0,58 & 6,67 & 8,66 \\
387 & 7 & 5 & 6 & & & 5,5 & 0,71 & 9,09 & 12,86 \\
388 & 6 & 6 & 6 & 6 & & 6 & 0 & 0 & 0 \\
389 & 6 & 7 & 6 & 6 & & 6,33 & 0,58 & 7,02 & 9,12 \\
390 & 5 & 4 & 5 & 4 & & 4,33 & 0,58 & 10,26 & 13,32 \\
391 & 4 & 3 & 4 & 5 & & 4 & 1 & 16,67 & 25 \\
392 & 6 & 5 & 5 & 6 & 5,33 & 0,58 & 8,33 & 10,83 \\
393 & 3 & 5 & 7 & 6 & & 6 & 1 & 11,11 & 16,67 \\
394 & 5 & 4 & 4 & 5 & & 4,33 & 0,58 & 10,26 & 13,32 \\
395 & 5 & 5 & 4 & 5 & & 4,67 & 0,58 & 9,52 & 12,37 \\
396 & 5 & 6 & 6 & & & 6 & 0 & 0 & 0 \\
397 & 4 & 5 & 4 & & & 4,5 & 0,71 & 11,11 & 15,71 \\
398 & 5 & 8 & 5 & 8 & & 7 & 1,73 & 19,05 & 24,74 \\
399 & 4 & 4 & 6 & & & 5 & 1,41 & 20 & 28,28 \\
400 & 7 & 6 & 9 & 4 & & 6,33 & 2,52 & 28,07 & 39,74 \\
401 & 4 & 5 & 6 & 5 & & 5,33 & 0,58 & 8,33 & 10,83 \\
402 & 4 & 6 & 5 & 5 & & 5,33 & 0,58 & 8,33 & 10,83 \\
403 & 5 & 4 & 4 & & & 4 & 0 & 0 & 0 \\
404 & 4 & 4 & 4 & & & 4 & 0 & 0 & 0 \\
405 & 5 & 5 & 4 & & & 4,5 & 0,71 & 11,11 & 15,71 \\
406 & 5 & 5 & 6 & 4 & & 5 & 1 & 13,33 & 20 \\
407 & 3 & 5 & 6 & 4 & & 5 & 1 & 13,33 & 20 \\
408 & 8 & 7 & 9 & 9 & & 8,33 & 1,15 & 10,67 & 13,86 \\
409 & 8 & 7 & 7 & 7 & & 7 & 0 & 0 & 0 \\
410 & 6 & 9 & 7 & 8 & & 8 & 1 & 8,33 & 12,5 \\
\hline
\end{tabular}


Continuação Tabela 32.

\begin{tabular}{|c|c|c|c|c|c|c|c|c|c|}
\hline \multirow{2}{*}{$\mathbf{n}$} & \multicolumn{5}{|c|}{ Leituras } & \multirow{2}{*}{ Média } & DP & EMP & CV \\
\cline { 2 - 5 } & $\mathbf{1}$ & $\mathbf{2}$ & $\mathbf{3}$ & $\mathbf{4}$ & $\mathbf{5}$ & & & & \\
\hline 411 & 7 & 7 & 6 & 8 & & 7 & 1 & 9,52 & 14,29 \\
412 & 5 & 6 & 8 & 6 & & 6,67 & 1,15 & 13,33 & 17,32 \\
413 & 7 & 6 & 7 & 7 & & 6,67 & 0,58 & 6,67 & 8,66 \\
414 & 8 & 10 & 10 & 9 & & 9,67 & 0,58 & 4,6 & 5,97 \\
415 & 5 & 6 & 6 & 5 & 5,67 & 0,58 & 7,84 & 10,19 \\
416 & 6 & 7 & 5 & 6 & & 6 & 1 & 11,11 & 16,67 \\
417 & 6 & 5 & 5 & & 5 & 0 & 0 & 0 \\
418 & 6 & 7 & 6 & 6 & & 6,33 & 0,58 & 7,02 & 9,12 \\
419 & 7 & 7 & 7 & 7 & & 7 & 0 & 0 & 0 \\
420 & 5 & 6 & 6 & 6 & 6 & 0 & 0 & 0 \\
421 & 8 & 7 & 6 & 6 & & 6,33 & 0,58 & 7,02 & 9,12 \\
422 & 6 & 7 & 6 & 7 & 6,67 & 0,58 & 6,67 & 8,66 \\
423 & 5 & 6 & 8 & 7 & & 7 & 1 & 9,52 & 14,29 \\
424 & 10 & 10 & 9 & 8 & & 9 & 1 & 7,41 & 11,11 \\
\hline & & & & & \multicolumn{7}{|c|}{ Média } & & $\mathbf{3 , 7 2}$ & $\mathbf{4 , 8 5}$ \\
\hline
\end{tabular}

